Stille: the art of being silent a thesis presented by Emma Macann 


\section{Stille: The art of being silent;}

A study of the architectural implications of the search for collective stillness in the western urban city.

by

Emma Macann

A 120 point thesis submitted to the School of Architecture and Design, Victoria University of Wellington, in the fulfilment of the requirements for the degree of Masters of Architecture.

Victoria University of Wellington: 


\section{Abstract}

This thesis discusses the importance for people within the confines of high-density, metropolitan cities to find a collective moment of retreat through an architectural landscape of silence.

Silence is becoming a desired and yet difficult to obtain commodity in modern western society. Due to intensified work and home commitments combined with overwhelming sensory manipulation in the urban environment, stress and psychological overloading is common. Stress and psychological overloading is problematic with regards to a sense of connectivity to other people. With constant sensory onslaught it is becoming increasingly important to create moments of stillness, which in the course of controlling and manipulating external stimuli allows for mental and physical retreat through contemplation. Historically places of silence and contemplation in western urban settings were places of worship. These spaces are designed to encourage groups of people to congregate and experience internal reflection while establishing a sense of togetherness. As western society moves towards secularisation, finding moments of silence collectively becomes even more significant in harvesting and maintaining a sense of belonging.

Through referencing Juhani Pallasmaa and philosopher Max Picard an in-depth exploration into sensory design and what silence embodies is established. This, in combination with a critique of the detrimental current situation in modern society, asserts reasons for the need to revert to simplified sensory experiences in order to increase personal awareness of self and others.

Nature and its pivotal role in stimulating a sense of silence is investigated through current theory and personal design explorations. This research is reinforced by case studies into successful modern places of retreat, for example Dominique Perrault's Bibliothéque Nationale de France. Such schemes are used to understand notions of ritual and removal within a city setting. By incorporating silence (both visually and aurally) into an everyday city park in London, opportunities are created for the wider public to encounter and benefit from Stille. ${ }^{1}$ 


\section{Acknowledgements}

I would like to acknowledge my parents who have supported and encouraged me throughout my studies, with special mention to their unswerving belief in my capabilities. Also to my supervisor Philippe, who has inspired me and contributed to making this year of study the most enjoyable yet. And finally to all those who listened, read, and gave advice, you are appreciated beyond words. 


\section{Table of Contents}

Abstract

Acknowledgements

List of Figures

Preface

\section{Introduction}

Part A - Context

1 - Silence in Need

Introduction

Urban Stress

Notion of Overload

Environmental Sound, 'Urban Noise'

Environmental Imagery, 'Visual Overload'

The Need for Silence

Conclusion

2 - Silence in the Metropolitan City

Introduction

Silence in Different Cultures

Etymology

Silence in Society and Architecture

Conclusion

Part B - Religions

3 - Secularisation and Interpersonal Relationships in the City Introduction

Background 
Collectiveness within Religion

Return of Religion

Conclusion

4 - Manifestations of Silence in Religion

Introduction

Christian Worship

Prayer

Places of Worship

Buddhist Worship

Meditation

Zen Gardens

Conclusion Wabi-Sabi

\section{Part C - Manifestations}

5- Manifestations of Silence in Retreats

Introduction

Urban Architectural Retreats

Silence and Nature

Large City Parks

Pocket Parks

Conclusion

6 - Case Studies and Silence

Introduction

Tadao Ando: The Church of the Light

\section{Nature}

Religion

The Significance of the Wall

Dominique Perrault: Bibliothéque Nationale de France 
Architecture and Contextual Response

Contemplation

Gunnar Asplund and Sigurd Lewerentz: Woodland Cemetery

Conclusion

\section{Part D-Application}

7 - Process and Design

\section{Introduction}

Maquettes

Site and Program

Christ Church Greyfriars, London

Site Analysis

Historical Palimpsests

Acoustic Analysis and Wall Design

\section{Conclusion}

\section{Appendices}

Appendix A - Adaption to Urban Stress

Appendix B - Flotation REST (Isolation Tanks) 


\section{List of Figures}

1 -

Figure 1.1 - Overload Diagram

Figure 1.2 - WHO Recommended Guideline Values for Community Noise 10

In Specific Environments (Europe, 1999)

Figure 1.3 - Maquettes $1 \& 2$ : The City, Stress and Overload

$2-$

Figure 2.1 - Maquette 3: Stille through Simplicity and Materiality

3

Figure 3.1 - Belief in God, Great Britain, 1940's - 2000 (\%)

Figure 3.2 - Maquette 4: Secularisation and Interpersonal Relationships

\section{4 -}

Figure 4.1 - Main Hallway in a Carthusian Monastery

Figure 4.2 - Bottom Level, Church at La Tourette

Figure 4.3 - Second Level, Church at La Tourette 37

Figure 4.4 - Maquette 5: Repetition and Procession 38

Figure 4.5 - Maquettes $6 \& 7$ : Ritual and Perspective 39

Figure 4.6 - Plan and Section of Ryōanji Garden (orientation South) 42

Figure 4.7 - Rock Garden at Ryōanji, Kyoto, Japan, 2002

Figure 4.8 - Mystic 43

Figure 4.9- Maquette 8: Abstracting Ryōanji 45

Figure 5.1 - The Variable Evaluation and Distribution of Stillness in Contemporary Britain 48 Figure 5.2 - Exterior of Das Kunstmuseum Kolumba 49

Figure 5.3 - Commemorative Space 50

Figure 5.4 - Second Floor Gallery

Figure 5.5 - Holocaust Void of the Jewish Museum $\quad 52$

Figure 5.6 - Central Park: The Sheep Medow 55

Figure 5.7 - Post-War City of London

Figure 5.8 - Paley Park 58

Figure 5.9- Maquette 9: Enclosure and Nature $\quad 60$ 
Figure 5.10 - Maquette 10: Wabi-Sabi and Nature

$6-$

Figure 6.1 - Exterior Mass of the Church of the Light 63

Figure 6.2 - Interior Light $\quad 64$

Figure 6.3 - Entrance to Main Volume $\quad 65$

Figure 6.4- Bibliothéque Nationale de France $\quad 67$

$\begin{array}{ll}\text { Figure 6.5 - Mature Pines } & 68\end{array}$

Figure 6.6 - Entrance Steps $\quad 69$

Figure 6.7- Entrance Path to the Woodland Cemetery 71

Figure 6.8 - The Cross and Meditation Grove $\quad 71$

Figure 6.9-Meditation Grove $\quad 72$

Figure 6.10-Forest Graveyard $\quad 72$

Figure 6.11 - Maquettes 11 \& 12: Materiality and Filtering 74

7 -

$\begin{array}{lr}\text { Figure 7. } 1 \text { - Maquette } 1 & 78\end{array}$

$\begin{array}{ll}\text { Figure 7. 2- Maquette } 2 & 78\end{array}$

Figure 7. 3- Maquette $3 \quad 78$

Figure 7. 4- Maquette $4 \quad 79$

$\begin{array}{ll}\text { Figure 7. 5- Maquette 5 } & 79\end{array}$

Figure 7. 6- Maquette 6 79

$\begin{array}{lr}\text { Figure 7. 7- Maquette } 7 & 80\end{array}$

Figure 7. 8- Maquette $8 \quad 80$

Figure 7.9- Maquette 9 80

Figure 7. 10 - Maquette $10 \quad 81$

Figure 7. 11 - Maquette $11 \quad 81$

Figure 7. 12 - Maquette $12 \quad 81$

Figure 7.13 - London City and Green Space $\quad 82$

Figure 7.14 - Franciscan Complex $\quad 84$

Figure 7.15 - London City, Christ Church Greyfriars Historic Mapping 85

Figure 7.16 - Pictorial History of Christ Church Greyfriars 86

Figure 7.17 - Site Analysis Model $\quad 88$

Figure 7.18 - Site Analysis $\quad 89$ 
Figure 7.19- Summer Shadows $\quad 90$

Figure 7.20 - Winter Shadows $\quad 91$

Figure 7.21 - Site Situation Perspectives 92

Figure 7.22 - Tracing Foundation Plans 94

Figure 7.23 - 1704 Elevations 96

Figure 7.24-2010 Elevations

Figure 7.25 - Elevation Overlay 98

Figure 7.26 - Franciscan and Wren Foundation Elevation 99

$\begin{array}{lr}\text { Figure 7.27 - Ecotect Acoustic Analysis } & 101\end{array}$

Figure 7.28 - Geology of London City 102

Figure 7.29 - Wall Pattern Study 103

Figure 7.30 — Wall Pattern Scale Study 104

Figure 7.31 - Wall Perforation Study 106

Figure 7.32 - Acoustic Clay Wall Prototype 107

Figure 7.33 - Acoustic Clay Wall Prototype \#2 108

Figure 7.34 - Traffic Noise Diagram 109

Figure 7.35 - Acoustic Wall Detail 109

Figure 7.36 - Night Gate Diagram 112

Figure 7.37 - Aerial View Plan 113

Figure 7.38 - Ground Level Plan 114

$\begin{array}{ll}\text { Figure 7.39 - Underground Level Plan } & 115\end{array}$

Figure 7.40 - Underground Level Plan Detail 116

Figure 7.41 - Cross-Section AA 117

$\begin{array}{ll}\text { Figure 7.42 - Cross-Section BB } & 118\end{array}$

Figure 7.43 - Cross-Section BB Detail 119

Figure 7.44 - From Paternoster Square $\quad 120$

$\begin{array}{ll}\text { Figure 7.45 - From Newgate Street } & 121\end{array}$

Figure 7.46 - Filtering the External Environment 122

Figure 7.47 - Contemplative Stille 123

$\begin{array}{ll}\text { Figure 7.48 - Underground Waterfall } & 124\end{array}$

Figure 7.49- Contemplative Seat 125

Figure 7.50 - Tower Fragment Diagram 127 
Figure 7.51 - Fragment Behind Waterfall

Figure 7.52 - Fragment Underground

128

Figure 7.53 - Site Model: Greyfriars Silent-Scape 
Preface 
Stille

Stillness

\section{SILENCE}

The orchestra of sounds outside my window are nothing significant, common even, to an urban setting. At night instead of nocturnal birds chirping, car alarms screech. Drunks staggering between pavement and gutter simulate the rustling of tree leaves. Thumping, monotonous pop music, amplified in this cold, hard jungle, forces me to hum along as it penetrates my subconscious.

Sleeping can be a nightmare.

And its not just the night noise, it's the constant noise. Garbage trucks, buses and chattering taxi drivers form the soundtrack of my day. Escape to my place of work, to studio, is often no better. Construction workers ensure what little peace there is between students hassling, gossiping and stressing is thoroughly destroyed.

From the moment of awakening till sleep again there is relentless sound. I imagine it following me, a dark ominous cloud nipping at my heels, overtaking me from time to time, and suffocating me in its dense smoke.

Tonight I am fighting for breath.

Rolling out of bed I flip my lamp back to life as I drag my oversized and slightly tatty dressing gown across my shoulders. Resolutely I open my laptop, turn on some instrumental sound, and begin to type. 
Introduction

Still: the art of being silent

Introduction 
Silence is a desired and vastly receding quality in the $21^{\text {st }}$ century urban society. It has been suggested that the over-stimulated way the western urban dweller lives is detrimental to their wellbeing due to psychological stress. Such stress from the urban environment is predicted to worsen as issues pertaining to population and industrialisation continue to expand, intensifying the city experience. This research proposes that stillness is a possible solution to relieve the city dweller from over stress. As stillness in the urban environment becomes evasive it also becomes of intense interest. What is silence and how can it be achieved? This thesis investigates multidimensional qualities of silence and produces a contextual visualisation of these findings in the form of an architecturally built landscape in the City of London.

Silence offers the ultimate retreat, being referred to by architectural researcher Roger Connah as "respite from the world's excess." ${ }^{2}$ It has the ability to counter our hectic existence and provide inner balance. Places of worship were once the core to accessing silence within the confines of the city. Traditionally religion and religious architecture provided a means of connecting people and stimulating silence. However, due to western society moving towards secularisation, stillness is being experienced by less people. This insinuates an increase in the need for silence to be integrated into daily life to help restore a sense of the collective. Through an investigation into the ways stillness is manifested in religion I seek to demonstrate that it is possible to replicate dominant qualities in a secular setting for a greater expression of silence.

To cohesively frame my argument this thesis is structured into four parts, which are further segmented into chapters. Part A: Context contains Chapters 1 and 2. Chapter 1 focuses on environmental psychology and highlights the way the city acts as a stressor and the effect that has on people. Dominant stressors are urban noise and visual overload. These stressors suggest the need to create moments of silence to make city dwelling more bearable for the individual. Chapter 2 introduces the concept of silence and discusses differences between cultures. It also elaborates on current unsuccessful integration of stillness into society and architecture as philosophised by Max Picard and Juhani Pallasmaa. Overall this chapter seeks to explore the role of silence and its impact on interpersonal relationships.

2- Roger Connah, "Sometimes and Always, with Mixed Feelings: Untimely Notes on a Culture of Silence," The Culture of Silence: Architecture's Fifth Dimension, ed. Malcolm Quantrill and Bruce Webb (Texas: A\&M University Press, College Station, 1998) 6. 
Part B: Religions attempts to highlight the role of stillness in religion through Chapters 3 and 4. Chapter 3 elaborates on the lessening of interpersonal relationships through the advancing of secularisation, and with that the lessening of people coming into contact with silence. Qualities of silence through religion are analysed in Chapter 4 . A main focus is on Christianity due to its prevalence in London, and also Buddhism as one of the world's fastest growing religions in the West. Through this analysis an understanding of architectural techniques that inspire silence is sought after.

The next section, Part C: Manifestations, begins with Chapter 5 focussing on secular city retreats into silence. These institutions include galleries, museums and libraries. Two prominent examples are elaborated on to try and identify how they inspire stillness. Subsequently, a discussion by theorists such as Pierre Guéguen and Henry Thoreau aim to assert that silence is most readily observed in nature. There is an interesting tension in creating 'nature' for the city, as it becomes irrevocably un-natural by its integration, yet creates opportunities for architectural innovation. An investigation into city parks seeks to understand where they succeed and fail in providing silence.

As a demonstration of the research outlined, Chapter 6 highlights ways that silence has been successfully designed towards in the past. This manifestation is disclosed in an exploration of the Church of the Light, Bibliothéque Nationale de France and Woodland Cemetery. The research aims to identify the importance of ritual and filtering of the external environment through these three studies.

Part D: Application is entirely focused on the resulting design. As a prelude to this section, throughout the argument are maquettes that visually portray ideas discussed in each chapter. Their occurrence is intended to spark an understanding of the process of translating the chapters into an impetus for design. Through adhering to this process and taking an intense look into the condition of a site in London City, the outline for the intervention is established. The resulting proposal is an architectural landscape, designed to acoustically and visually screen the city while creating an atmosphere of silence. This design attempts to prove that it is possible and important to provide increased moments of collective stillness in the city for the benefit of the community. London is an appropriate site as its chaotic, vibrant and multicultural characteristics can often 
lead to issues pertaining to city stress. Due to this, London is used throughout the theoretical discussion as an illustration and to provide direction within the research. 
Part A - Context 


\section{Chapter 1 - Silence in Need}

\section{Introduction}

The creation of high-density ${ }^{3}$ cities is relatively recent, and as such its effects on people are still being understood. Although it is often acknowledged that city living can have detrimental effects, these are infrequently analysed for their individual and cumulative influence on a person. ${ }^{4}$ Analysis of the urban environment explains how it can act as a 'stressor', and identifies the ways that humans respond to the stress. It has been suggested that these responses involve a series of psychological cognitive approaches, which ultimately lead to an adaptive method in order to cope with the stimulus. Two main stressors are highlighted as of particular relevance, that of environmental noise and environmental visual stimulation. For the health and wellbeing of society it is not merely a matter of fixing these 'problems' that cities create, as cities are the reality of an increasing population with limited land resources. Instead the emphasis should be on finding ways of coping that make city living easier psychologically and ultimately more enjoyable for the individual by providing for moments of escape within the urban landscape. The main focus of this chapter is to highlight the effect which metropolitan living has on the individual, rather than the collective experience, which will be addressed in Chapter 2.

\section{Urban Stress}

"Life in the city is an endless round of obstacles, conflict, inconveniences, and bureaucratic routine. The urban dweller is confronted daily with noise, litter, air pollution and overcrowding. Some of these conditions are pervasive. Others occur only at home or at work or at transit. Their incidence is profoundly disturbing, and many commentators on modern urban life allege that such conditions produce behavioural and physiological consequences inimical to the health and well-being of man." 5

David C Glass and Jerome E Singer

3- Definition of 'high density' as outlined by Louis Wirth: Cities are defined by the relatively close concentration of people. While not being the only detrimental effect of cities, high density is certainly relevant to the cultural context and social dimensions of city life. Reference: Louis Wirth, "Urbanism as a Way of Life," The American Journal of Sociology 44 (1938): 6. 4- Edward Krupat, People in Cities: The Urban Environment and its Effects (Cambridge: University Press, 1985) 3. 5- David C Glass and Jerome E Singer, Urban Stress: Experiments on Noise and Social Stressors (New York: Academic Press, 1972) 5 . 
The urban environment is one of particular interest and concern in this modern age. People are migrating to cities in increasing numbers. In 1800 only 3\% of people lived in cities. By 1900 it grew to $14 \%$, with 12 cities containing over 1 million people. Today (2010) there are over 400 cities that top 1 million residents. ${ }^{6}$ With half the world's population residing in cities, this statistic is only expected to grow with predictions reaching $60 \%$ by $2030 .^{7}$ Due to this unprecedented growth, city living is becoming an increasingly diverse and important area for discussion.

With more people living in densely populated areas, aspects of the environment that have a negative influence on people become prominent. These aspects are termed urban 'stressors'. Stressors often affect people at a psychological level although they can cause physical damage as well. Stress is defined as the perception of a threat (not necessarily the eventuating of a dangerous or harmful situation) which impacts on a person's psychological being. Examples of urban stress include noise, physical and visual crowding and pollution. In addition, any situation that involves rapid stimulation reaching the uttermost limits of a person's toleration, and is uncontrollable by them, can be deemed to be an urban stressor. Therefore the city can be recognised for hosting many variables that are registered as threatening to people who live with them. ${ }^{8}$

"Urban Atmosphere" is an important aspect of urban stress. ${ }^{9}$ The atmosphere of a city is the culmination of aspects that endow it with a perceived character. Ironically the features of a city, which make it distinctive, are also often the aspects that we analyse when regarding excessive stimulation. Urban atmosphere is a dominant reason why people visit cities, or choose to live in them for short or long term. ${ }^{10}$ To be a part of the fast-pace life, that a metropolitan city such as London offers, can be exhilarating. The excitement, which these atmospheres create, is desirable for many. However, for others, city dwelling can be a negative rather than positive experience. This is why analysing a city's atmosphere is significant when looking into stressors as it acknowledges that they will never be exactly the same in different places, or to different people.

\footnotetext{
6- Population Reference Bureau, Human Population: Urbanization, 2010, 10 June 2010 <http://www.prb.org/Educators/ TeachersGuides/HumanPopulation/Urbanization.aspx>

7- United Nations Human Settlements Programme, State of the World's Cities 2008/2009 (London: Earthscan, 2008) x.

Norman W Heimstra and Leslie H McFarling, Environmental Psychology, ed. Edward L Walker (California: Brooks/Cole

Publishing Company, 1974) 152

9- Stanley Milgram, "The Experience of Living in Cities," Science 167 (1970): 1465.

10- Stanley Milgram, “The Experience of Living in Cities,” Science 167 (1970): 1465.
} 
People respond to cities in three ways, according to the social psychologist Stanley Milgram. The first is through comparison. For example someone who has lived in Wellington his or her whole life may find London intimidating, whereas a person from New York could be comfortable because of its relative smallness. The second influence is the status of the person, whether they are a tourist or a long time resident returning. And lastly, people harvest assumptions about a city prior to arriving. These assumptions may turn out to be correct but they still add to the conceived nature of the built environment. ${ }^{11}$ Stress induced from a city environment is perceived in a diverse way to differing people, and as such is a varied topic. Through generalisation the urban environment can be analysed for its negative effects, but it is important to recognise that it's variable.

As outlined by Lazarus in his 1966 book Psychological Stress and the Coping Process, a person's reaction to a stressful situation is dependent upon two things, the psychological structure of the individual and the level of cognitive features of the particular stimulus. ${ }^{12}$ Cognition is directly related to a person's perceived control over the stimulus, along with how close and abrasive it is in nature. In keeping with this model of cognition, the body is expected to instinctively assess whether the stressor is threatening or benign. Once assessed, the person subsequently enters into an appropriate coping or adaption strategy that is determined by the individual and cognitive process factors (for more on stress adaption refer to Appendix A). Thus, what may be threatening to one person, for example a tourist experiencing peak hour traffic in New York, may go unnoticed to a familiarized local. Therefore Lazarus establishes urban stress as an individual experience that is likely to be interpreted differently for everyone, consistent with Milgram's summary.

\section{Notion of Overload}

Milgram theorised a highly popular 'overload model' (Figure 1.1) to help explain people's reaction to environmental stimulus. Overload is defined as a "system's (person's) inability to process a set of inputs from an environment"13 due to simultaneously or consecutively presenting stimuli, 11 - Norman W Heimstra and Leslie H McFarling, Environmental Psychology, ed. Edward L Walker (California: Brooks/Cole Publishing Company, 1974) 95.

12 - David C Glass and Jerome E Singer, Urban Stress: Experiments on Noise and Social Stressors (New York: Academic Press,

1972) 6 .

13- Stanley Milgram, “The Experience of Living in Cities," Science 167 (1970): 1462. 


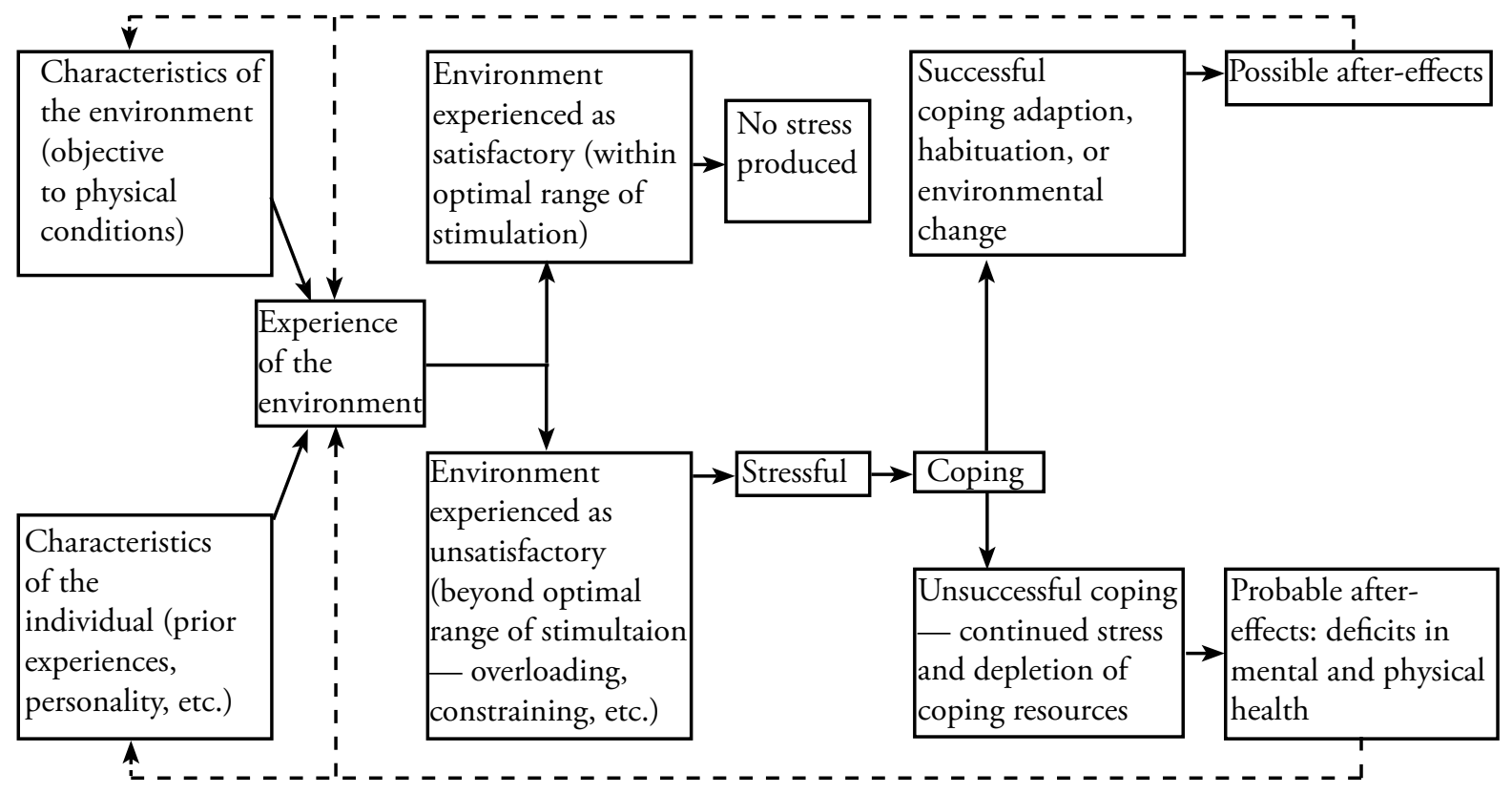

\section{Figure 1.1 - Overload Diagram}

Model of experience of the urban environment with stress as the central concept.

Source: qtd. in. Edward Krupat, People in Cities: The Urban Environment and its Effects (Cambridge: University Press, 1985$) 96$.

thereby being difficult to cope with. Milgram's model proposes an answer to why people in cities seem to have less 'time' for others. This coping method is referred to as the 'ultimate adaptation', and requires a prioritising of who is relevant (for example a friend) and who isn't, thereby disregarding or ignoring the needs of an irrelevant person to focus on yourself and those close to you. This severely affects interpersonal behaviour and contributes to the impersonal nature of cities. An impersonal nature can enhance environmental stressors, thereby perpetuating the cycle. In addition, Milgram proposed that the relationships people in cities form are more superficial than their rural counterparts, in order to conserve psychic energy for daily life functioning ${ }^{14}$ (more on interpersonal relationships in Chapters 2 and 3).

Critiques for Milgram's model include a need for a multi dimensional approach to people. Humans have proven to be more than just receptacles for receiving stimuli, and as such there is 14- Stanley Milgram, "The Experience of Living in Cities," Science 167 (1970): 1462. 
complexity to how we process excessive stimulation, more than can be recreated in a laboratory experiment. In many cases people go seeking stimulation, they are those who have perhaps grown up in an intense environment and feel comfortable there. ${ }^{15}$ However, the basic system of overload can be regarded as a serious problem in relation to city living, one that is detrimental to the well being of individuals as well as society.

Psychology professor Sheldon Cohen elaborates on Milgram's model, claiming that people have a limited amount of attention, and can only expend certain amounts of effort on that attention process at any one time. Cohen also stipulates that when the immediate environment exceeds capacity of attention a set of priorities are made, and attention focussed accordingly. The increased occurrence of environmental stimulus therefore results in a diminished attention capacity for the individual. The final response stage occurs during excess of a person's capability entirely, activating an adaptive process. An important aspect of Cohen's model is that recovery and capacity renewal is found at rest. ${ }^{16}$

This notion of stress coping is concerning when analysed for its effect on social behaviours. It makes people individually orientated, to the point where they may miss cues for help from others. Consequently one may argue that to lessen the stress that cities create through finding better ways of coping would result in an increased sensitivity towards other people. This has the potential for creating a more empathetic society, strengthening people's relations to each other and a sense of togetherness. ${ }^{17}$

Through experiments into this area of psychology further analysis of environmental stress has been undertaken. Observation of dual tasks completed in crowded and empty rooms, and in likewise quite and spontaneously noisy rooms, concluded that while primary tasks were unaffected secondary tasks suffered due to the environmental stress. Results proved that crowding (and within that 'visual overloading') and noise were significant urban stressors that drained a person's 'capacity'. The stressors became even more upsetting when they were intense, unpredictable, and

15- Andrew Baum, Jerome E Singer and Stuart Valins, Advances in Environmental Psychology: Volume 1, The Urban Environment (New Jersey: Lawrence Erlbaum Associates, 1978) 133.

16- Andrew Baum, Jerome E Singer and Stuart Valins, Advances in Environmental Psychology: Volume 1, The Urban Environment (New Jersey: Lawrence Erlbaum Associates, 1978) 3.

17- Andrew Baum, Jerome E Singer and Stuart Valins, Advances in Environmental Psychology: Volume 1, The Urban Environment (New Jersey: Lawrence Erlbaum Associates, 1978) 21. 


\begin{tabular}{|c|c|c|c|c|}
\hline $\begin{array}{l}\text { Specific } \\
\text { Environment }\end{array}$ & Critical Health Effect(s) & $\begin{array}{l}\text { Sound } \\
(\mathrm{dB})\end{array}$ & $\begin{array}{l}\text { Time-base } \\
\text { (hours) }\end{array}$ & $\begin{array}{l}\text { Sound } \\
\text { Max }(\mathrm{dB})\end{array}$ \\
\hline \multirow[t]{2}{*}{ Outdoor living area } & $\begin{array}{l}\text { Serious annoyance, } \\
\text { daytime and evening }\end{array}$ & 55 & 16 & - \\
\hline & $\begin{array}{l}\text { Moderate annoyance, } \\
\text { daytime and evening }\end{array}$ & 50 & 16 & - \\
\hline Dwelling, indoors & $\begin{array}{l}\text { Speech intelligibility and } \\
\text { moderate annoyance, } \\
\text { daytime and evening }\end{array}$ & 35 & 16 & - \\
\hline Inside bedrooms & $\begin{array}{l}\text { Sleep disturbance, } \\
\text { nighttime }\end{array}$ & 30 & 8 & 45 \\
\hline Outside bedrooms & $\begin{array}{l}\text { Sleep disturbance, } \\
\text { window open (outdoor } \\
\text { values) }\end{array}$ & 45 & 8 & 60 \\
\hline \multirow[t]{2}{*}{$\begin{array}{l}\text { Hospitals, } \\
\text { wardrooms, indoors }\end{array}$} & $\begin{array}{l}\text { Sleep disturbance } \\
\text { nighttime }\end{array}$ & 30 & 8 & 40 \\
\hline & $\begin{array}{l}\text { Sleep disturbance daytime } \\
\text { and evening }\end{array}$ & 30 & 16 & - \\
\hline $\begin{array}{l}\text { Industrial, } \\
\text { commercial, } \\
\text { shopping and traffic } \\
\text { areas, indoors and } \\
\text { outdoors }\end{array}$ & Hearing impairment & 70 & 24 & 110 \\
\hline $\begin{array}{l}\text { Ceremonies, } \\
\text { festivals and } \\
\text { entertainment } \\
\text { events }\end{array}$ & $\begin{array}{l}\text { Hearing impairment } \\
\text { (patrons: }<5 \text { times/year) }\end{array}$ & 100 & 4 & 110 \\
\hline
\end{tabular}

Figure 1.2 - WHO Recommended Guideline Values for Community Noise In Specific Environments (Europe, 1999)

Source: Jian King, Urban Sound Environment (Oxon: Taylor and Francis, 2007) 33. 
uncontrollable. ${ }^{18}$ Examples of harmful urban noise and visual overloading are discussed below to further illustrate how the city acts as a stressor, and to facilitate a search for an architectural solution.

\section{Environmental Sound, 'Urban Noise'}

Urban noise is being increasingly viewed as the most common and detrimental environmental stressor. Its increase in significance correlates to an increase in technology and transport that dates back to the beginning of the industrial revolution in the United Kingdom. Environmental noise is unwanted sound, usually produced by humans, and can interfere with activities and eventually become physiologically harmful. ${ }^{19}$ The helplessness, which an environment of extreme noise poses to an individual, is seen to be the real determent rather than the noise itself. People do not enjoy feeling 'at the mercy of the environment', which unavoidable noise presents. This relates back to previously discussed notions of cognition. ${ }^{20}$

In developed countries, regulations control the amount of noise exposed to the majority of people, meaning that the population is supposedly protected from over $70 \mathrm{dBA}$ (roughly). However, the moderate range of noise (55-65 dBA) continues to rise due to our modern technological lifestyle. ${ }^{21}$ Figure 1.2 highlights the optimum range for noise in different areas, and their 'critical health effects'.

Sound affects the human body physically. ${ }^{22}$ As demonstrated in the WHO Recommended table, extreme decibels are confined to public spaces which people spend little time comparatively to work and home. Although physical injury resulting in hearing loss (which occurs at $90 \mathrm{~dB}$ and

18- Andrew Baum, Jerome E Singer and Stuart Valins, Advances in Environmental Psychology: Volume 1, The Urban Environment (New Jersey: Lawrence Erlbaum Associates, 1978) 12

19- Gary W Evans, Environmental Stress (Cambridge: University Press, 1982) 27.

20- Edward Krupat, People in Cities: The Urban Environment and its Effects (Cambridge: University Press, 1985) 115.

21 - Jian Kang, Urban Sound Environment (Oxon: Taylor and Francis, 2007) 38.

22- Most of our bodily functions, including thirst, blood sugar levels and growth are regulated by the hypothalamus. The hypothalamus is a part of the brain which also regulates emotions, sleeping, walking and sexual arousal. When people hear noise it is sent straight to the hypothalamus and, in return, it is redirected to the entire body. This is one of the reasons why music can evoke such strong emotional reactions. It also helps explain why, when a noise is undesirable due to excessive

stimulation, it can likewise evoke feelings of frustration. Negative sound is therefore scientifically proven to be draining on the body. Reference: Balwant Saini, Fengshui Seminars with Roger Green, May 2000, 2 May 2010 <http://www.fengshuiseminars. com/articles/healingarchmusic.html>. 
over) is unlikely to transpire, sensitivity to sound varies greatly between people and has a lasting effect on coping abilities. A recent European Environment Agency report outlined the shocking statistic that around 67 million people in Europe are exposed to daily road noise levels that exceed $55 \mathrm{~dB}$. In this report transport was highlighted as the most detrimental noise modern society is exposed to, affecting negatively the cardiovascular system, mental health of people and school performance in children. ${ }^{23}$

The Noise Sensitivity Scale was created by psychologist Neil Weinstein in the late 1970's to try to understand why some people respond to sound differently than others. People were divided into two groups, screeners and non-screeners. Screeners were defined as those who were able to overcome stimulation that caused distraction for the non-screeners. The ultimate goal of the investigation was to gauge people's emotional response to noise, and how it influences relationships. Results concluded that both the two groups had places they disliked due to noise. The difference between them was that non-screeners made an effort not to enter these spaces, and if forced to, socialised and worked less than the screeners did. Another revelation was that non-screening students generally held a lower academic performance than their counterparts. Although unsurprising, these results highlight the importance of noise sensitivity in the urban environment due to non-screeners being unable to adapt, even over time. The stress - which an urban environment of inescapable noise holds for these individuals - impacts on their work, life and study, and proves to be severely detrimental. ${ }^{24}$

The detrimental effects of noise have undergone many experiments in order to prove prevailing theories. Cohen conducted an effective study in 1973 that looked at the long-term effects of noise on individuals. This study analysed fifty-four elementary students (twenty-nine boys and twenty-five girls) who lived in a 34-storey aluminium building near the expressway. Their living environments differed between noise disturbances of $55 \mathrm{dBA}$ to $66 \mathrm{dBA}$, being quieter at the higher levels. The study analysed the student's examination results in the Metropolitan Achievement test in reading and the Wepman test in auditory discrimination compared to the

23- European Environment Agency, Transport at a Crossroads: Term 2008: Indicators Tracking Transport and Environment in the European Union, EEA Report (Copenhagen, 2009) 22-23.

24- Robert Gifford, Environmental Psychology: Principles and Practice 2ed (Boston: Allyn and Bacon, 1997) 91. 
floor they lived on. ${ }^{25}$ The results showed a strong correlation between the noise the students were exposed to in the apartments and the score in the Wepman test, especially when the results were narrowed to those who had been living there for four years or more $(+.48$, as opposed to .06 for three years and less). Therefore it was concluded that prolonged exposure to noise in an immediate environment created lasting effects. The children may have adapted to the noise and even felt comfortable in the setting, but that adaption has been quantitatively proven to be at a personal cost, the loss of auditory and verbal capacity. ${ }^{26}$

\section{Environmental Imagery, 'Visual Overload'}

While auditory noise in cities has been widely researched as detrimental, one area that I argue is equally prominent but less well identified is the notion of visual noise. In essence it contains the underlying detriments of uncontrollable noise applied visually to the urban setting. This phenomenon is termed 'visual overload' and refers to the immediate environment being visually stimulating to the point of damage to the individual. Visual overload highlights the paradox that "the more you see, the less you see." ${ }^{27}$ Dr Glen Johnson calls this problem the "Meijers Effect". 28 Dr Johnson has had many complaints from head injury patients claiming that they cant stay in a Meijers store for more than 10-15mins before the information becomes too much to process. The stress, which they suffer in that particular environment, is a physical reaction of anxiety and feeling overwhelmed. Although an extreme case, this notion of visual overload is constantly occurring within urban society, the only difference being that for the majority of people the effects aren't great enough to mean a proactive removal from the visual stress is needed. Instead

25- The Metropolitan Achievement Test analyses the student's level of reading ability by testing them upon word knowledge and reading comprehension. The Wepman Test is an Auditory Discrimination test. It examines students on 40 pairs of words, 30 of which differ in sound. It is up to the student to recognise which words have similar sounds, and those that are different (such as gear-bear). Reference: Seldon Cohen, David C Glass and Jerome E Singer, "Apartment Noise, Auditory Discrimination, and Reading Ability in Children," Journal of Experimental Social Psychology (1973): 411.

26- Claude Levy-Leboyer, Psychology and Environment, trans. David Canter and Ian Griffiths (California: Sage Publications, Inc, 1982) 106

27- Fernette Eide and Eide Brock, "Visual Overload and Visual Crowding - When More Means Less," 7 September 2009, Eide Neurolearning Blog , 4 June 2010 <http://eideneurolearningblog.blogspot.com>.

28 - Meijers is a large department store in America which houses a hardware store, grocery, clothes shop and photo department all in the same space. Reference: Glen Johnson, "Getting Overloaded," 1998, Traumatic Brain Injury Survival Guide, 1 June $2010<$ http://www.tbiguide.com/index.html> 
the constant bombardment of visual information eats away at a person's capacity, as outlined previously in the example of Milgram's and Cohen's overload model. ${ }^{29}$

The visual climate that we live in is referred to by Michel de Certeau as the "cancerous growth of vision". ${ }^{30}$ He believes commercial exploitation is centred on vision and as such we have become a reading and writing culture. Through translating everything into a "visual journey"31 society is perpetuating visual overstimulation without offering equal amounts of release. This flow of information cuts us off emotionally from our setting, increasing segmentalised relationships between people. Relationship segmentalisation through the visual urban environment is discussed in further detail in Chapter 2.

\section{The Need for Silence}

It is clear through the amount of data collected that the city can be an overwhelming place to visit and especially live. A summarisation would suggest that humans are not designed to sustain long exposure to intense, or even moderate noise and that visual complexity can often have stressful effects. It may be centuries before we learn to survive in cities successfully, readjusting our behaviours to ensure our mental and physical health. Robert Gifford (Professor of Psychology and Environmental Studies at the University of Victoria, British Columbia, Canada) suggests some strategies for dealing with the urban environment, including allowing for "more times and places for escape." ${ }^{32}$

This idea of escaping is elaborated by psychologist Peter Suedfeld through describing desirable levels of environmental stimulus as "less is more." 33 His experiments into sensory deprivation that lead him to coin the term REST (Restricted Environmental Stimulation Technique) help assert his position advocating for moments of understimulation (further information on REST in

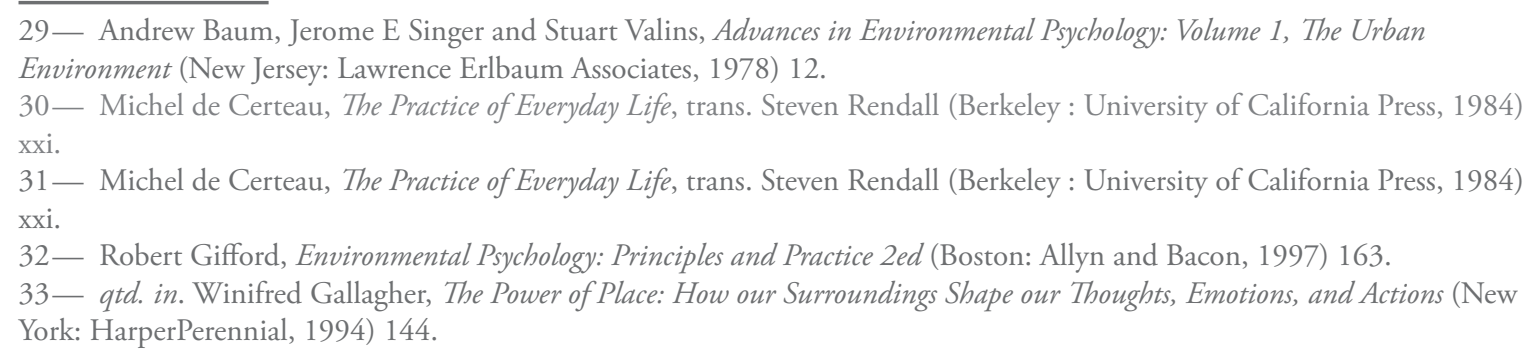


Appendix B). ${ }^{34}$ People who undertake his study are put in a soundproof darkened chamber for 24 hours. Despite this sounding arduous, many people are reluctant to leave by the end, and wonder at how quickly the time has gone. It usually becomes a therapeutic reawakening for the individual by being forced to disregard external stimulation - for perhaps the first time ever. ${ }^{35}$

Isolation in order to achieve personal peace is an old concept, dating back to early Christian hermits and anchorites creating retreat experiences into their culture for the same reason ${ }^{36}$ (this notion of religious retreat will be further developed in Chapter 4). Suedfeld believes with the extreme spectrum of stimulation a city offers it is "important psychologically and probably neurologically to reduce the load periodically and restore the balance." ${ }^{37}$ This requires creating opportunities within city limits for obtaining inner silence in order to ensure the well being of an individual.

\section{Conclusion}

As highlighted throughout this chapter, the city can be a stressful place to live. Environmental psychology studies have analysed ways which humans respond to urban stress through psychological cognitive approaches. Lack of control over stressful stimuli is the true detriment to urban dwelling. Two prominent forms of city stress are environmental noise and visual overstimulation. Facilitating for release from these two forms of stress would go a long way towards rectifying the imbalance currently observed in cities. It is imperative that individuals are able to experience a moment of stillness in order for them to regain psychological peace, particularly in a hectic modern city such as London. Stillness is elaborated in the following chapter in relation to silence and its place in the current urban environment.

34- Dirk Van Dierendonck and Jan Te Nijenhuis, "Flotation Restricted Environmental Stimulation Therapy (REST) as a Stress-management Tool: a meta-analysis," Psychology and Health June 2005: 406.

35- Winifred Gallagher, The Power of Place: How our Surroundings Shape our Thoughts, Emotions, and Actions (New York: HarperPerennial, 1994) 145.

36- Winifred Gallagher, The Power of Place: How our Surroundings Shape our Thoughts, Emotions, and Actions (New York: HarperPerennial, 1994) 145-146.

37 - qtd. in. Winifred Gallagher, The Power of Place: How our Surroundings Shape our Thoughts, Emotions, and Actions (New York: HarperPerennial, 1994) 148. 

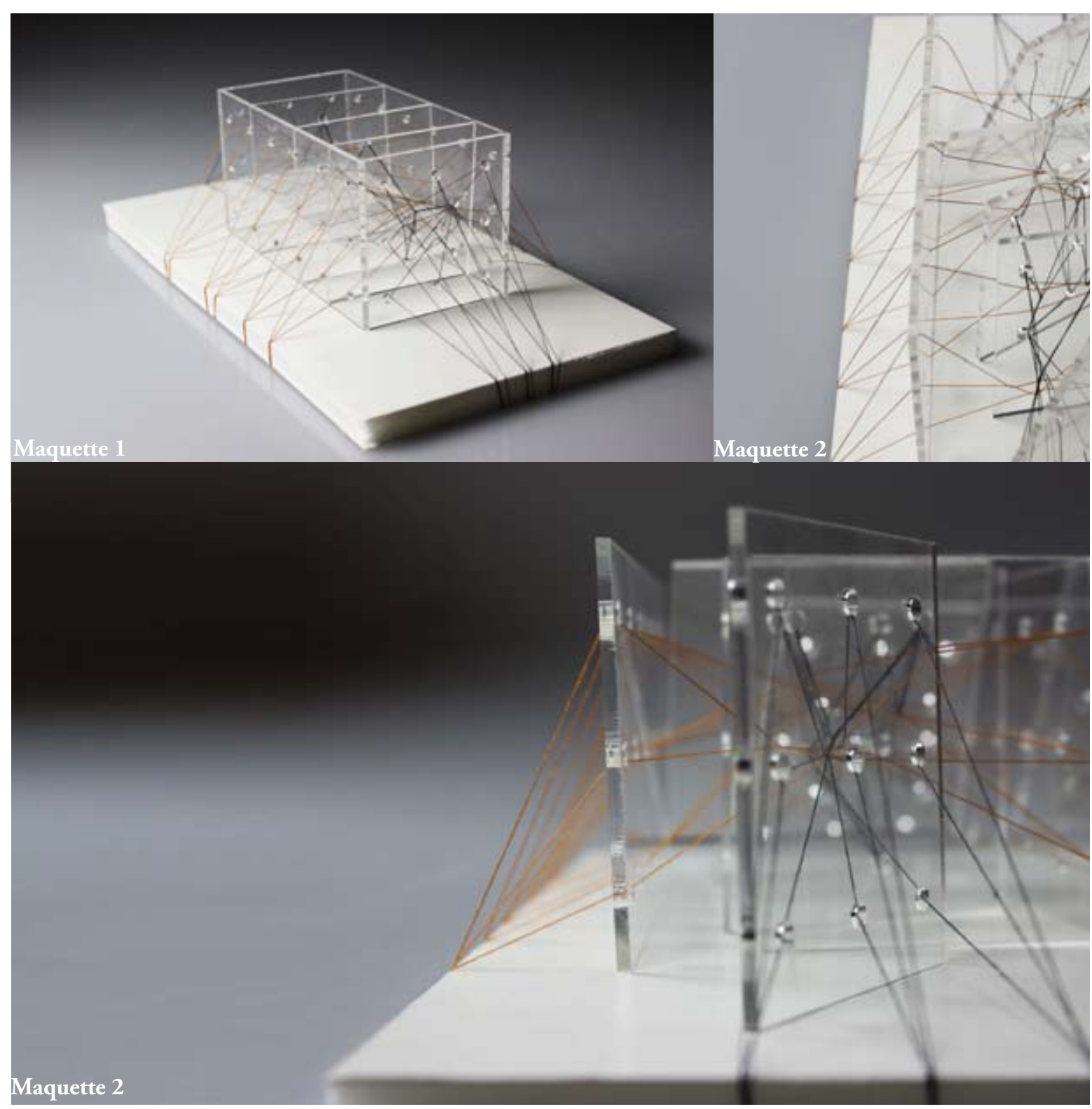

Figure 1.3-Maquettes 1 \& 2 The City, Stress and Overload 


\section{Chapter 2 - Silence in the Metropolitan City}

\section{Introduction}

"Silence is the rarest condition of modern life, an unexpected puncture in the incessant chattering of consciousness." 38

Malcolm Quantrill and Bruce Webb

With world technology progressing at an overwhelming speed people are constantly in noisy close connection, whether physically through compact city living or through electronic means. There is little time for moments of personal space in this world that relies on quick communication to continue its vastly expanding business and social networking. The stress of such a setting is damaging for the individual, as highlighted in the previous chapter. As silence becomes a rare quality, it also becomes one of intense interest. What is silence and how can it be achieved? This chapter's aim is to establish the importance of silence in contemporary society. The basis for this search is initialised by the tracing of examples of silence in different cultures and studying its etymology. This chapter also analyses the need for silence by examining two main theorists, philosopher Max Picard and architectural theorist Juhani Pallasmaa. In addition comments about the lack of silence and how this affects interpersonal relationships in the city are made, further advocating its integration into daily life.

\section{Silence in Different Cultures}

Throughout this thesis examples of silence from theorists and architects around the world will be used to give a holistic understanding, with London as the principal example. Research from Europe, America and Asia is used to demonstrate cross-cultural aspects of society, and to highlight discrepancies. It is my aim to demonstrate how western society is increasingly adopting the principles of the East, especially in relation to meditative silence through Buddhism being a 
widely spreading religion. ${ }^{39} \mathrm{With}$ the modern world in constant close connection it is imperative to recognise different cultures when trying to define the qualities of silence.

The Finnish culture offers its own unique approach to silence. Silence is a fundamental element according to architect Kaisa Broner-Bauer. For the Finnish it is not merely quietness but a way of being. After living in Japan for many years Broner-Bauer summarises the similarities with Japanese appreciation of silence with that of his culture, but makes some notable differences. For the Japanese silence is a concept of nothingness, a metaphysical way of connecting with one's self, as explored through Buddhism (expanded on in Chapter 4). For the Finns silence is a way of life, of being close to nature. Everything that is important to Finns is "appreciated... in silence." ${ }^{40}$ It is seen as a natural way of being and as such is not speculated upon as it is in other cultures. Nor is it sought in the same way that it is in many western cultures, as it is a quality that exists fundamentally in daily life. This is one example of how silence can change from culture to culture.

\section{Etymology}

Etymologically silence in German recognises how a culture has acknowledged the existence of several definitions of the word. In German there are two words that translate to the English term silence, only with significantly different implications. The first is Schweigen and means literal silence. It is used in reference to vocal quietness, waiting for the moment of breaking through the utterance of a word. It can often have negative connotations associated to it, such as withholding of information or a subject of taboo. Predominantly this is how English-speaking cultures understand its meaning, that of vocal muteness ("will you please be silent"). However, silence can mean more than mere quietness. Stille, the second German word for silence, means a 'silence of peace,' as found in a beautiful landscape. This second notion of silence is a way of being, and considered an active rather than passive word. ${ }^{41}$ Silence as a verb is what this thesis aims to identify and explore.

\footnotetext{
39- Janaka Perera, "Buddhism fastest growing religion in West," 7 April 2008, Asian Tribune, 20 March 2010 <http://www. asiantribune.com/?q=node/10418>

40- Kaisa Broner-Bauer, "Aarno Ruusuvuori and the Continuity of Finnish Modernism," The Culture of Silence: Architecture's Fifth Dimension, ed. Malcolm Quantrill and Bruce Webb (Texas: A \& M University Press, College Station, 1998) 195. 41 - Celeste Williams, "Recent Austrian Architecture: A Dynamic Silence," The Culture of Silence: Architectures Fifth Dimension, ed. Malcolm Quantrill and Bruce Webb (Texas: A\&M University Press, College Station, 1998) 174.
} 
Stille has roots in the English language as well. In the Oxford Dictionary silence as a verb is defined as becoming "silent or still." ${ }^{22}$ When one looks up the meaning for the verb still we find its Old English origin as the word stillian, and as an adjective stille. ${ }^{43}$ Therefore the notion of Stille is linked with the idea of stillness, which in turn is an aspect of silence. For silence is more than soft acoustics, it incorporates visual calm, beauty and inner quiet. When these four qualities combine we begin to understand Stille, and through conception we can seek it more readily to enhance and stabilise our hectic modern lives. It is for this reason that Stille was selected as the title for this thesis.

\section{Silence in Society and Architecture}

Max Picard, through his book The World of Silence (Die Weld des Schweigens) 1948, investigates the meaning of silence and its relationship to people through language and culture. During this time period Picard was a strong activist against the pollution of 'noise' in society, believing silence to be an essential state of being for man, one that is often undermined.

"In the modern world the individual no longer faces silence, no longer faces the community, but faces only universal noise. The individual stands between noise and silence. He is isolated from noise and isolated from silence. He is forlorn. "'44

Max Picard

Picard believed that silence is the one phenomenon which urban society cannot exploit, having no materialistic value. Despite having no value it is more precious than all the worlds "useful things." ${ }^{5}$ However, as society has progressed and with it consumerism rising to new extreme heights, even silence has managed to have a price tag attached. Being such a rare commodity, this invaluable experience has been manufactured to the ever-eager market. With modern installations such as sensory deprivation tanks you can buy 'silence' for as little as $\$ 80$ per hour. ${ }^{46}$ This in

42- Oxford University Press Inc, Shorter Oxford English Dictionary, On Historical Principles: Sixth Edition, Vol. 2 (New York: Oxford University Press, 2007) 2835.

43- Oxford University Press Inc, Shorter Oxford English Dictionary, On Historical Principles: Sixth Edition, Vol. 2 (New York: Oxford University Press, 2007) 3028.

44- Max Picard, The World of Silence, trans. Stanley Godman (London: Harvill Press, 1964) 65

45- Max Picard, The World of Silence, trans. Stanley Godman (London: Harvill Press, 1964) 19.

46- The Floatation Sanctuary, 2008, 12 May 2010 <http://www.floatationtank.co.nz/Home.html>. 
itself directly defies Picard's notion of silence 'simply being'. It brings to question whether this marketable product is indeed the Stille that we, as society, desire and raises issues concerning how accessible it is to the wider community. For further information on sensory deprivation tanks refer to Appendix B.

A benefit of incorporating silence into your life, according to Picard, is the ability of man to deal with the myriad of objects that are constantly presenting themselves. Silence is the means of sifting through stimulation and finding an appropriate emotional response. ${ }^{47}$ This idea supports recent neuroscience fMRI (Functional Magnetic Resonance Imaging) studies proving that those who practice silence in the form of regular meditation are more able to deal with excessive stimulation. Meditation enables a person to discriminate between important and unimportant information by quietening the mind and relaxing the body. This has the beneficial individual effect of creating the ability to command a calculated rather than impulsive response to stimuli. ${ }^{48}$ In this example Picard's own beliefs correspond with scientific findings, but do not originate from them.

Although thought provoking, Picard's tendency to make prophetic statements without scientific grounding may be concerning. Widely recognised as the 'guru of silence', his written works are far removed from scientific thought, and often states 'facts' "implicitly rather than explicitly." 49 His writing style is engagingly poetic, which has helped his theorising become of international importance. More than anything his work reflects his own religious morals regarding silence as a neo-Platonist and the dilemma which modern man has in maintaining a connection to the invisible, the Mysterium. ${ }^{50}$ So while Picard is referred to throughout this thesis as a person who has devoted his life towards a search for silence, it is acknowledged that such a silence for him has heavy religious overtones. I propose that secularisation, and thereby the lessening of religion

47- Max Picard, The World of Silence, trans. Stanley Godman (London: Harvill Press, 1964) 69.

48 - When a person is learning a new activity the brain responds accordingly, stimulating neurons, glutamate receptors and eventual enzyme activation as calcium is released into the cells. This whole process becomes more refined as the activity becomes familiar. The eventual drop in brain activity demonstrates adaption to the new stimulation. Meditators on the other hand have been recorded as having lower reactions to initial stimulation that does not require their full attention. This means a reduction in brain activity can be achieved when the individual wishes to ignore a particular stressor. Results include likelihood for a less-stressed individual, as they do not constantly have to be intimate with the immediate environment at every moment. Reference: George Prochnik, In Pursuit of Silence: Listening for Meaning in a World of Noise (New York: Random House, 2010) 35-36.

49- Siegfried B Puknat, "Max Picard,” Books Abroad 25.4 (1951): 340.

50— Siegfried B Puknat, "Max Picard,” Books Abroad 25.4 (1951): 343. 
in the West, is a strong motivation for Picard's search for silence. Secularisation will be discussed further in the following chapter.

Similar to Max Picard's theorising for silence within culture is Juhani Pallasmaa's belief in silence within architecture. In his recent works, Pallasmaa makes a strong argument expressing his ideals about architecture and its role in protecting us from an "excessive existence." Pallasmaa is primarily interested in bringing peoples experiences of buildings back to the tactile:

"Instead of further speeding up the experience of the world, architecture has to slow down experience, halt time, and defend the natural slowness and diversity of experience. Architecture must defend us against excessive exposure, noise and communication. Finally the task of architecture is to maintain and defend silence." $"$ 1

Juhani Pallasmaa

Through connecting with architecture it is possible to engage the whole body, rather than staying locked in the cold and distant realm of the eye. ${ }^{52}$ Traditionally man used vision to supplement hearing. For the hunter, waiting in silence and listening for movement was a means of survival. Human ears are able to pickup sound at far greater distances than the reach of sight, and as such it was natural to rely upon them. However, according to Walter J Ong, the shift from oral to written (and therefore visual) was a milestone in the civilisation of man, and began the transition of reliance upon sight rather than hearing. ${ }^{53}$

It could be argued that the transition from an oral culture to a written one is the reason for excess noise currently observed in society. As we let our eyes dominate our world, our ears have become of little consequence. In addition, the transition to the dominance of the eyes has lead to excess in that region, relating back to notions of visual overload discussed in the first chapter. With an increase in iconic images/reading and noise simultaneously it is rare to find moments of quiet and peace. Peaceful and moving architecture is what Pallasmaa advocates reverently. As every experience - which is deeply moving for a person - relies on all the body's senses, we must

51 - Juhani Pallasmaa, The Thinking Hand: Existential and Embodied Wisdom in Architecture (Chichester: Wiley, 2009) 150.

52 - Juhani Pallasmaa, "An Architecture of the Seven Senses," Questions of Perception: Phenomenology of Architecture. ed. S.

Holl, J. Pallasmaa, \& A. Pérez-Gómez (San Francisco: William Stout Publishers: 2006) 29.

53- Walter J Ong, Orality and Literacy: The Technologizing of the World (New York: Methuen \& Co Ltd, 1982) 2. 
therefore embrace architecture that aims at addressing similarly these qualities. With an equal emphasis on sight as with sound, touch, smell and even taste, ${ }^{54}$ Pallasmaa demands architecture that exudes silence internally, creating peace and serenity in a world of chaos.

Pallasmaa argues that superficial architecture has a community consequence of too much noise. This consequence is defined as a "growing experience of alienation, detachment and solitude" within cities. ${ }^{55}$ Through the dominance of the eye, other sensory elements have been either ignored or exploited. Lack of phenomenological design means an imprisonment within the experience of the eye, creating a sense of exteriority within society. This sense of exteriority is reflected through interpersonal relationships becoming strained and superficial. Sensory design, in the opinion of Pallasmaa, could go a long way to re-connecting relationships within cities.

This consequence reflects the summarisation of modern cities by American sociologist Louis Wirth. Wirth explains that the result of having people live close together is the "segmentalization of human relationships." ${ }^{56}$ By this he is referring to the density of people in the city being so great that it is impossible to know everyone as a whole person. Relationships can become superficial in order to cope with the vast demand. This is referred to as too many 'secondary contacts.' While a rural dweller may have fewer contacts than an urbanite, they are more likely to consist of 'primary contacts' of which they have a deeper connection with. ${ }^{57}$ Experiencing close proximity yet impersonal relationships can induce feelings of "loneliness, nervous tension and mutual irritation. ${ }^{58}$ Therefore the city amplifies stress, alienation and anonymity, while offering little benefits in return.

An analysis of relationships within a community reflects the field of interest of the chosen theorist. This is demonstrated through Pallasmaa analysing architectures reasons leading towards alienation while Wirth studies environmental sociologies contribution. Although both these theories differ in their assessment of the city they point towards the same conclusion, that the city creates

\footnotetext{
54- Juhani Pallasmaa, "An Architecture of the Seven Senses," Questions of Perception: Phenomenology of Architecture. ed. S

Holl, J. Pallasmaa, \& A. Pérez-Gómez (San Francisco: William Stout Publishers: 2006) 30

55- Juhani Pallasmaa, The Eyes of the Skin: Architecture and the Senses (London: Academy Editions, 1996) 9-10.

56 - Louis Wirth, "Urbanism as a Way of Life," The American Journal of Sociology 44 (1938): 12.

57 - Louis Wirth, "Urbanism as a Way of Life," The American Journal of Sociology 44 (1938): 12.

58- Edward Krupat, People in Cities: The Urban Environment and its Effects (Cambridge: University Press, 1985) 51.
} 
segmentalised relationships and can be a lonely place to live. As a response this research explores the idea that through establishing a collective place of silence, the need for people to reside in physical and psychological calm can be addressed to re-create a sense of community.

\section{Conclusion}

In summary the phenomenon of Stille could go a long way towards creating meaningful architecture and re-establishing interpersonal relationships. Silence is an elusive but important quality in the $21^{\text {st }}$ century as discussed by Picard and Pallasmaa. For people to have meaningful spiritual and architectural connections it is imperative that Stille be embodied. This need can be translated onto the role of the designer. Through manipulating a setting one can manufacture an experience of silence within the metropolitan western city. An experience of silence could help lessen the rise in superficial relationships due to too much 'noise' within the community. This phenomenon is further discussed in the following chapter in relation to secularisation, as through its rise not only have community relationships suffered but also the silence observed in religion has become less prevalent. 


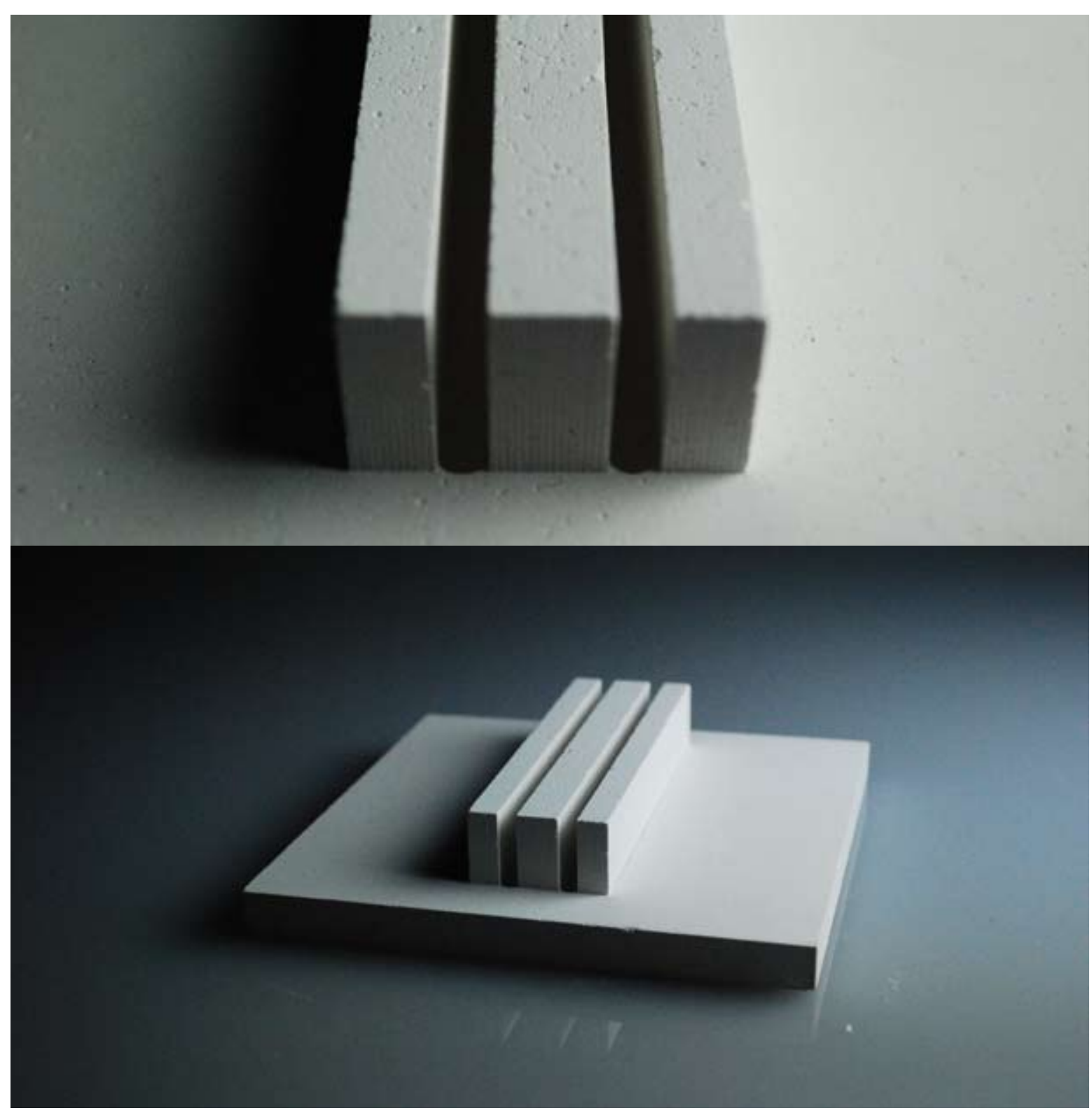

Figure 2.1 - Maquette 3 :

Stille through Simplicity and Materiality 


\section{Part B - Religions}




\section{Chapter 3 - Secularisation and Interpersonal Relationships in the City}

\section{Introduction}

Another reality of the western modern city, which severely affects relationships of people within a community, is secularisation. Religion has historically been a means of uniting people. This role has been progressively diminished since Modernism. Religious practice allows people to congregate and feel a sense of connectivity from believing in a shared spirituality. Often this congregation takes place in silence, becoming a respite from the world's worries as one can reside within the protective walls of a place of worship. Silence is experienced overwhelmingly through religion, as the next chapter will discuss. However, the focus of this chapter is to demonstrate that with secularisation comes the decreasing number of people who partake in religious ritual, and therefore encounter stillness. As this is an increasing trend it highlights society's need to create alternative ways of establishing a sense of community through a shared experience. This thesis proposes one such way is through silence.

\section{Background}

"With the progress of science and technology, man has stopped believing in magic powers, in spirits and demons; he has lost his sense of prophecy and, above all, his sense of the sacred. Reality has become dreary, flat and utilitarian, leaving a great void in the souls of men which they seek to fill by furious activity and through various devices and substitutes." 59

Julien Freund on Max Weber

There have been differing ideas about the meaning of secularisation between sociologists. According to Marcel Gauchet (in a forward by Charles Taylor) secularisation can be separated into two different categories, the personal which entails an increase in those who profess to not believe in religion or attend services, and the decline of its prominence in the public sphere with institutions preferring neutrality. It can be argued either way which one influenced the 
others existence, but the important note is that they now both exist, fundamentally, in western culture. $^{60}$

The word secularisation originated through the official separation of the church from political life. This separation echoed the growing trend of modernity, a trend that was established (according to sociologist Daniel Bell) through these three factors:

- Increase in the notion of the individual in culture,

- The turning from religion to the arts (poetry, art, literature, music),

- And the removal of the belief in the existence of heaven and hell to the fear of the unknown void. ${ }^{61}$

\begin{tabular}{|l|l|l|l|l|l|}
\hline Beliefs & 1940 's & 1947 & 1981 & 1990 & 2000 \\
\hline There is a Personal God & 43 & 45 & 41 & 32 & 26 \\
\hline $\begin{array}{l}\text { There is some sort of higher } \\
\text { power, spirit or life force }\end{array}$ & 38 & 39 & 37 & 41 & 21 \\
\hline There is something there & & n.a. & n.a. & n.a. & 23 \\
\hline $\begin{array}{l}\text { I don't really know what to } \\
\text { think }\end{array}$ & 16 & 16 & 15 & 12 \\
\hline $\begin{array}{l}\text { I don't really think there is any } \\
\text { sort of God, spirit or life force }\end{array}$ & & n.a. & 6 & 10 & 15 \\
\hline None of these & & n.a. & n.a. & 1 & 3 \\
\hline
\end{tabular}

Note: n.a. = not asked

\section{Figure 3.1 - Belief in God, Great Britain, 1940’s - 2000 (\%)}

Source: Steve Bruce, God is Dead: Secularization in the West (Oxford: Blackwell Publishers, 2002) 138.

60- Charles Taylor, "Forward," The disenchantment of the world: a political history of religion, Marcel Gauchet, trans. Oscar Burge (New Jersey: Princeton University Press, 1997) ix.

61 - Daniel Bell, "The Return of the Sacred? The Argument on the Future of Religion," The British Journal of Sociology 28.4 (1977): 431. 
Through modernity and the increasing inability of man to believe in 'magic,' secularisation became a dominant aspect of social life in the West. Max Weber refers to this as the "de-magification (Entzauberung) of the world." 22 Disbelief in the 'mystery' of the world was brought about on two fronts for the two different forms. For the personal experience it was a change in beliefs and culture, whereas the institutional effect steamed from the process of rationalization. ${ }^{63}$ Today the effect is continuing, with statistics supporting the slow movement of mass society away from religion and religious thought (Figure 3.1). These figures suggest that this drift will continue in the years to come.

\section{Collectiveness within Religion}

"The moral prescriptions of Christianity were relevant for interpersonal relations, for face-to-face contacts, for the intimacies of the family, courtship, friendship, and neighbourliness. But (today) they have much less immediate application to the mass society, with its impersonal and anonymous interaction of roleperformers... in short... whose sense of themselves is merely that of a 'class.' "64

Bryan Wilson

The unity established from religion gave society an overwhelming sense of collectiveness and a continuous retreat into silence. With the decline of the social importance of religion came the lessening of a sense of community within cities and access to religious silence. People once relied on religion to create neighbourly bonds. Bryan Wilson argues that now interpersonal relationships are gone and replaced by daily 'anonymous interaction' consisting of work and consumerism. The time has gone when one could know their neighbour and their spiritual values. Instead we work alongside near strangers who we share little with aside from depending "for a livelihood on the export or the import of the same commodities." ${ }^{5}$

62- Daniel Bell, “The Return of the Sacred? The Argument on the Future of Religion," The British Journal of Sociology 28.4 (1977): 428.

63- Daniel Bell, "The Return of the Sacred? The Argument on the Future of Religion," The British Journal of Sociology 28.4 (1977): 428.

64 - Bryan Wilson, Contemporary Transformations of Religion (Oxford: University Press, 1976) 6.

65- Bryan Wilson, Contemporary Transformations of Religion (Oxford: University Press, 1976) 6. 
This is a concerning aspect of secularisation and modernity in the West. Without religion to unite people, cities have become fragmented. This has resulted in an increase of internally focussed citizens, some of whom still seek a form of spirituality and internal silence. The fragmented search for spirituality is the impetus for the rise in sectarianism. It is appropriate that while the social value of old religions is lessened people look towards other sources of spirituality (such as Buddhism) and disciplines (such as yoga) to fulfil spiritual needs. ${ }^{66}$ Wilson sees this as "confirmation of the process of secularization." ${ }^{67}$ With every religious experience available to the modern person, how can society unite the secular people?

According to renowned sociologist Steve Bruce, the majority of secular people (specifically in Britain) are not spiritual seekers. ${ }^{68}$ Bruce believes that although a self proclaimed secular country may have devout religious people living within, the overall lessening of the social significance of religion decreases the number of people who worship, and the degree to which they worship. Therefore religion and religious people are a vastly receding phenomenon in the $21^{\text {st }}$ century. ${ }^{69}$ With an increasing number of people becoming secular, finding ways of incorporating a sense of community and silence away from religion and spirituality becomes increasingly important in addressing the underlying needs of society.

\section{Return of Religion}

Weber saw two options for the future society, man returning to the 'tranquillity' of the churches, or accepting the present technology-focussed culture and facing it with courage. ${ }^{70}$ This view differs from Bell who believes that the future lies in new religions. He believes that to be successful they will uphold the rituals of the past and become a means of tying the person within the continuum of time through acting as a "resurrection of Memory." While both these opinions are different they have a similar thread of identifying the importance of the past within society today.

\footnotetext{
66- Bryan Wilson, Contemporary Transformations of Religion (Oxford: University Press, 1976) 42-43.

67- Bryan Wilson, Contemporary Transformations of Religion (Oxford: University Press, 1976) 96.

68 - Steve Bruce, God is Dead: Secularization in the West (Oxford: Blackwell Publishers, 2002) 237.

69- Steve Bruce, God is Dead: Secularization in the West (Oxford: Blackwell Publishers, 2002) 3.

70 - Julien Freund, The Sociology of Max Weber, trans. Mary Ilford (New York: Random House, 1968) 24

71 - Daniel Bell, "The Return of the Sacred? The Argument on the Future of Religion," The British Journal of Sociology 28.4

(1977): 444.
} 
When considering the future of religion there are many complexities to acknowledge, and research would suggest there is no one way forward. Despite Bell's proposition, there seems to be little place at present for returning to a past institution in such a forward focussed society. ${ }^{72}$ While my design objective is secular in nature, it is intended to provide a spiritual setting. By recreating the silence (or tranquillity) found in religious practice I offer an overreaching alternative for the religious, spiritual, and the atheist alike. Silence is therefore rendered as spiritual for those who wish to perceive it.

\section{Conclusion}

The effect of secularisation in the West is far reaching. Religious disintegration from public and private life has left the community less connected. As such interpersonal relationships are strained. People who used to have constant access to the silence which religion contains now either search for it through different spiritualities or reside without it. If a connection through silence could be manifested then this could create the means for re-establishing relationships while imparting calm and serenity into the lives of people. A place of retreat for secular society could establish this opportunity. The ways which religion manifests silence is analysed in the following chapter to fully understand its historical and modern religious integration into society. 

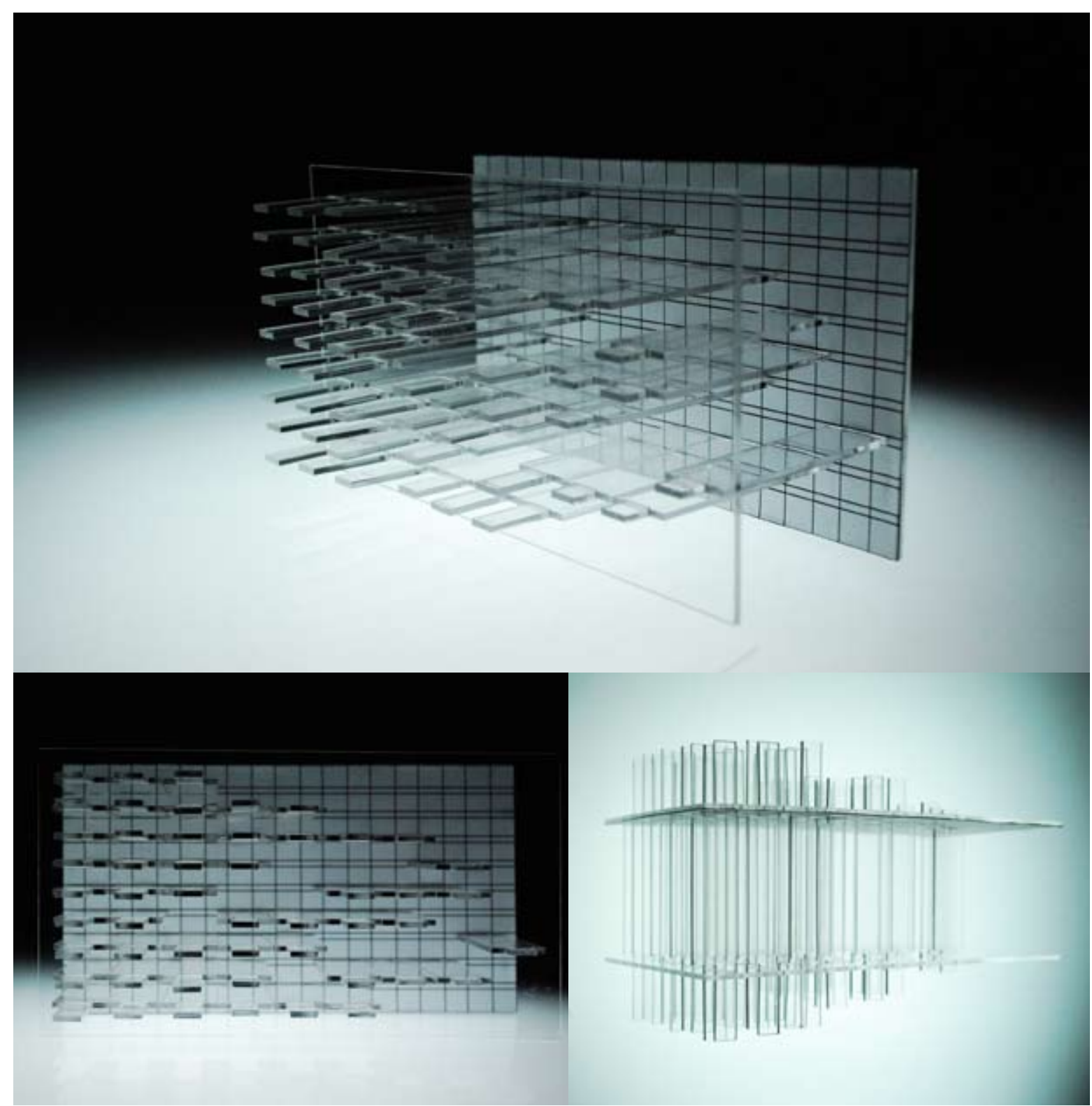

Figure 3.2 - Maquette 4:

Secularisation and Interpersonal Relationships 


\section{Chapter 4 - Manifestations of Silence in Religion}

\section{Introduction}

"Indeed if we were to look for a shared theological (as opposed to ethical) ground between religions, a good starting point would be silence." $" 3$

George Prochnik

Around the world religions have many significant differences but one main similarity, silence. The ways which silence has been adopted affects each religion independently and in multiple ways, ranging from methods of worship to the architecture which it takes place in. The secularisation of society has seen a decline in experiencing silence through religion. With Stille being such an important aspect to a person's wellbeing (as established in Chapters 1 and 2) it becomes imperative that we recognise the ways which religion establishes silence to enable its application in a secular setting. With the prominent example for this thesis as central London, Christianity is appropriately selected for its manipulation of silence due to its extensive historical importance there. To contrast Christianity and acknowledge the spreading influence of Eastern religions (particularly in London through the process of re-sacralisation, or what Steve Bruce refers to as the "Easternization of the West"74), Japanese Buddhism will also be studied. Buddhism is an increasingly practised form of spirituality that pays particular attention to silence through contemplation, meditation and nature, making it a pertinent case study. ${ }^{75}$ 


\section{Christian Worship}

\section{Prayer}

"Silence is God's first language and all other languages are but poor translations."

Thomas Keating: Trappist Monk

Silence can be quickly understood in relationship to prayer in the most basic of terms. Prayer is conducted in personal silence. The silence which prayer instigates is a means for communicating with God. However, the original reason behind silent prayer was more rational than mystical. During the Antiquity prayers were spoken out loud, and silent prayers were regarded as suspicious as it was assumed that one did not wish to be overheard professing their sins. ${ }^{77}$ It was only later, after the (Neo)Platonists and their influence from values of transcendentalisation, that silence became the "purest form" of worship. ${ }^{78}$

Porphy, a third century student of neoplatonism, wrote in his text De Abstinentia (On Abstinence) II 34,2:

"Let us sacrifice in such a manner as is fit... For there is nothing material which is not immediately impure to an immaterial nature.. Hence neither is vocal language nor internal speech adapted to the highest God... but we should venerate him in profound silence. ""99

This was the beginning of the silent prayer. In order to reach a transcendent being you had to venerate God in an appropriate way. Stillness was seen as reaching out beyond the world's senses towards the divine, therefore putting you in closer contact with God. Worshipping Him through silence maintained purity. Therefore silence is seen as the means for communicating and truly understanding the word of God.

\footnotetext{
76- Thomas Keating, Intimacy with God (New York: Crossroad Publishing Company, 1996) 55.

77 - Pieter W van der Horst, "Silent Prayer in Antiquity," Numen 41 (1994): 1

78 - Pieter W van der Horst, "Silent Prayer in Antiquity," Numen 41 (1994): 1

79- qtd. in. Pieter W van der Horst, "Silent Prayer in Antiquity," Numen 41 (1994): 10-11.
} 


\section{Places of Worship}

"The cathedrals are deserted today, just as silence is deserted. They have become museums of silence, but they are still inter-related, cathedral with cathedral, silence with silence... It was inevitable that they should be bombarded in the war: absolute noise shooting at absolute silence." 80

Max Picard

Monasteries are the epitome of silence within Christian worship. They abide by it both internally and externally in their devotion to God. In the example of Cistercian monks, they adhere to the Rule of Benedict, which clearly states in the Prologue; "The disciple's part is to be silent and to listen." ${ }^{11}$ By listening instead of talking they gain a shift in attention and concentration. By being silent they exist in a contemplative state for the majority of the day. It is believed that through silence new understandings can occur, and through listening one learns more about the world and self.

In the documentary Into Great Silence (Die Große Stille) the way which silence is adhered to in Carthusian monastic life is reverently explored..$^{82}$ By following a cloister of Carthusian monks residing in the remote French Alps for six months, director Philip Gröning captivates an audience through all consuming silence. ${ }^{83}$ No soundtrack or commentary breaks through the footage, which relies on natural lighting for all of its frames. The very method of minimal editing reflects that raw nature of the silence as we watch the monk's daily routines. The idea of repetition and the extending of perspective (towards infinity) supporting silence is presented in many different ways. Chores, which occur diligently like clockwork, mirror the dominant architecture of the hallway (Figure 4.1), which is a common scene within the film. Punctured with regular windows and minimally decorated arches, the hallway extends into the distant darkness, seemingly embodying

80- Max Picard, The World of Silence, trans. Stanley Godman (London: Harvill Press, 1964) 169

81- qtd. in. Terryl N Kinder, Architecture of Silence: Cistercian Abbeys of France (New York: Harry N. Abrams, Inc, 2000) 19.

82 - The Carthusian Order is a Roman Catholic religious order that includes both nuns and monks.

83- Into Great Silence (Die Große Stille), dir. Philip Gröning, Carthusian Monastery, Philip-Gröning-Filmproduktion (2005) Film.

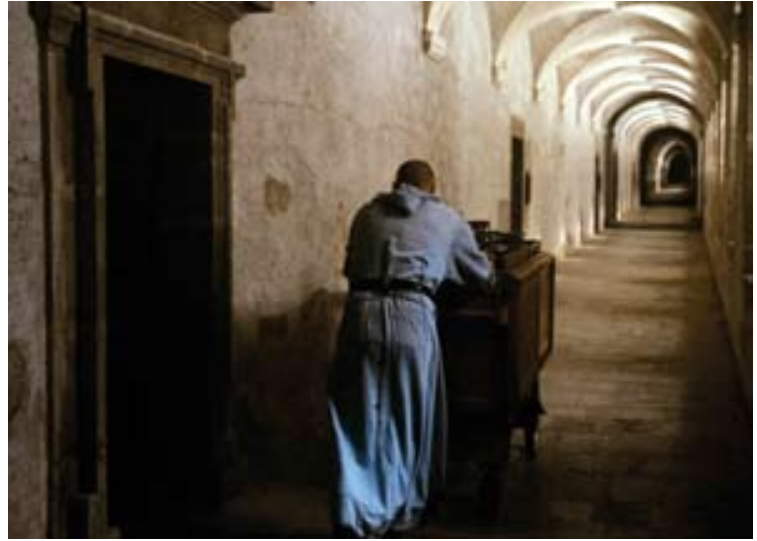

Figure 4.1 - Main Hallway in a Carthusian Monastery

The Monks sleeping quarters are located to the side of this long hall. The Monk depicted is wheeling food to each cell. Source: Kevin, "Into Great Silence," 26 January 2007 Codex, 10 July 2010, <http://vanderleek.com/codex/ archive/2007_01_01_archive.html>. 


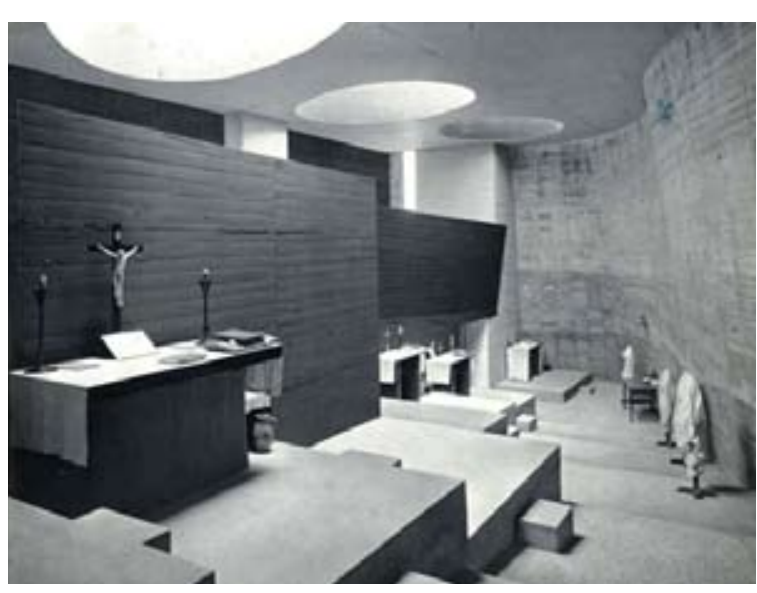

Figure 4.2 - Bottom Level, Church at La Tourette by Bernhard Moosbrugger

Source: Anton Henze, La Tourette: The Le Corbusier Monastery, trans. Janet Seligman (London: Percy Lund, Humphries \& Co. Ltd, 1966) 49. silence with its thick stone walls and muffled echoes as the monks move slowly from task to task. $^{84}$

As illustrated in Figure 4.1, the architecture within monasteries reflects the rituals they are designed for. While varied greatly depending on landscape and available materials, there are some universal aspects that emphasise their adherence to silence, the most predominant feature being simplicity. Through lack of ornamentation, monastic abodes allow the individual to be focused internally. Bernard of Clairvaux (a Cistercian monk) is recorded as blatantly rallying against images that might lead to distraction. "There must be no decoration, only proportion." ${ }^{55}$ Having pictures carved or painted into the stone, or fitting stained glass windows (as was prevalent in Christian architecture) would have disturbed the monk's internal silence. This links back to notions of images creating 'noise' discussed in the first chapter.

A prominent example of this is Le Corbusier's La Tourette. La Tourette is simple to the point of poverty. Based upon a traditional layout of an internal courtyard, the spaces ring the open area and contain church, oratory, chapter room, refectory, cloister, library, lecture rooms and cells. ${ }^{86}$ Heavy concrete defines the spaces, which are strictly separated into a hierarchical layout. Portraying this predominantly is the church, which is separated into two levels. ${ }^{87}$ The bottom consists of a series of altars subtly separated through descending steps for the monks to complete silent morning worship at (Figure 4.2). In contrast the upper level is dedicated to communal mass with the front altar raised above the even communion space that is open and symmetrical

84- Prior to the closing credits of the documentary a poignant quote is played across the screen, summarising the monks affiliation with God and silence. It is played against a black background in white text, which fits the simplicity of the film and subject matter. It reads:

"The Lord passed by. Then a great wind tore the mountains apart and shattered the rocks before the Lord, but he was not in the wind. After that there was an earthquake, but the Lord was not in the earthquake. After that came a fire, but the Lord was not in the fire. After the fire came a gentle whisper." 1 Kings 19, 11-13.

As God is a silent presence it is appropriate to honour him likewise in silence. For monks silence is more than refusing to speak, it is a reaching of the soul towards the divine and a coming into contact with pure being. Reference: Into Great Silence (Die Große Stille), dir. Philip Gröning, Carthusian Monastery, Philip-Gröning-Filmproduktion (2005) Film.

85 - qtd. in. Thomas Barrie, Spiritual Path, Sacred Place: Myth, Ritual and Meaning in Architecture (Boston: Shambhala Publications, Inc, 1996) 70.

86- Anton Henze, La Tourette: The Le Corbusier Monastery, trans. Janet Seligman (London: Percy Lund, Humphries \& Co. Ltd, 1966) 8.

87- Anton Henze, La Tourette: The Le Corbusier Monastery, trans. Janet Seligman (London: Percy Lund, Humphries \& Co. Ltd, 1966) 8. 
(Figure 4.3). Utilising basic principles of proportion, the church is the perfect shoebox shape to amplify internal sound, while external sound is subdued.

Consistent with the notion of a connection to a higher being is the manipulation of the concrete. With a rough finish inspiring a connection to nature and the essence of the material, its unswerving use in varying modules throughout the complex as a whole - and in the church in particular livens the spaces without interrupting a basic sense of repetition, uniformity, simplicity and procession. This highlights the architectural decree of Bernard of Clairvaux and is appropriate in simulating the austere silence associated with monastic architecture. Church architecture is further analysed through a discussion of The Church of the Light in Chapter 6, Case Studies and Silence.

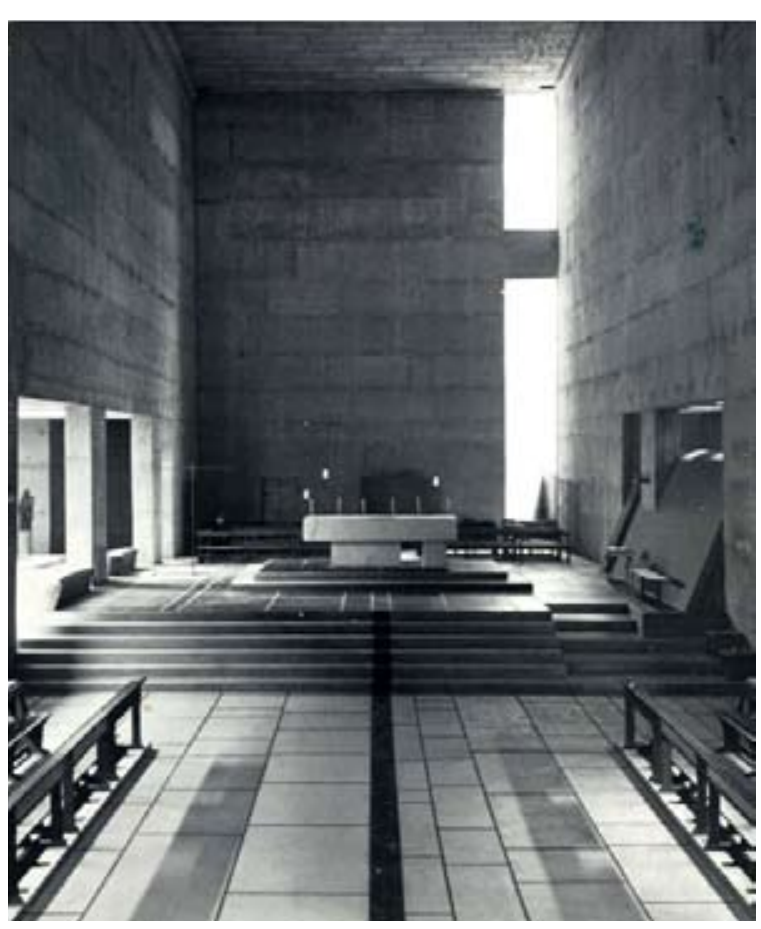

Figure 4.3 - Second Level, Church at La Tourette by Bernhard Moosbrugger

Source: Anton Henze, La Tourette: The Le Corbusier Monastery trans. Janet Seligman (London: Percy Lund, Humphries \& Co. Ltd, 1966) 53. 


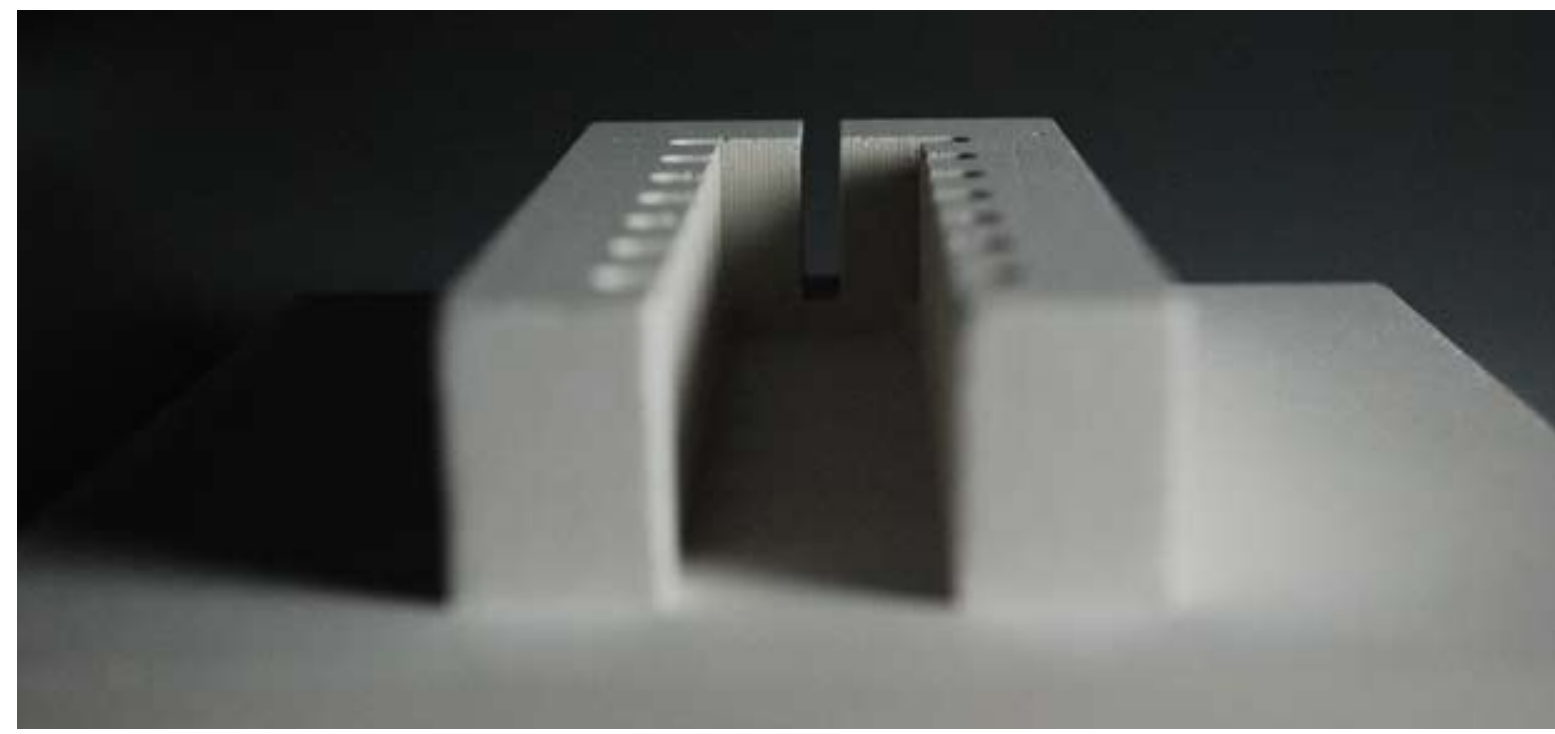

Figure 4.4- Maquette 5:

Repetition and Procession 


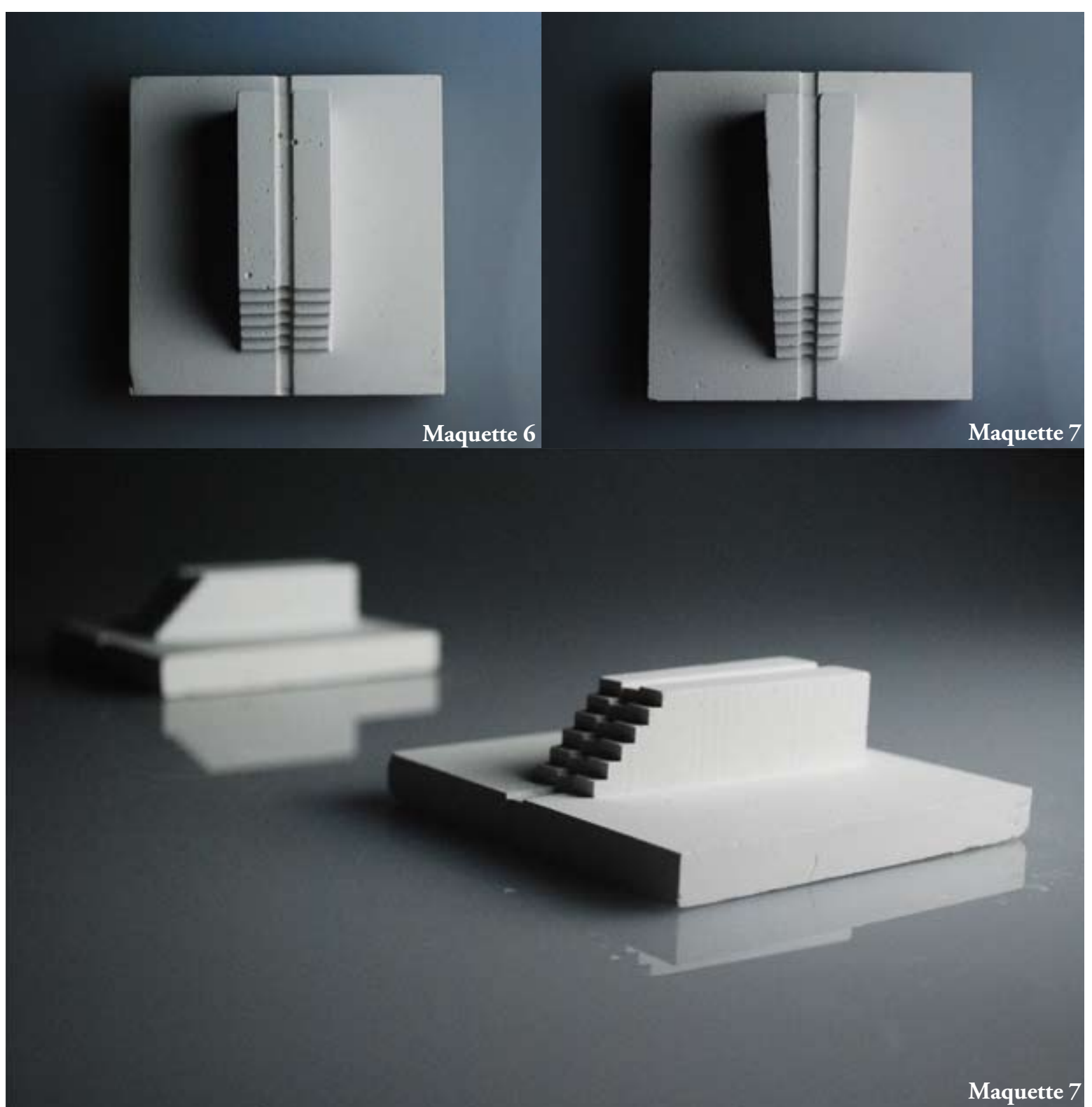

Figure 4.5-Maquettes $6 \& 7$ :

Ritual and Perspective 


\section{Buddhist Worship}

\section{Meditation}

"No dependence on letters or words,

Pointing directly at the Mind in every one of us,

And seeing into ones Nature, whereby one attains Buddhahood." 88

Daisetz Suzuki

Silence within Buddhism is most intently experienced through meditation. Meditation is one of the three main features to the practice of Buddhism, which also includes philosophy and the teachings of Gautama (Three-Body or Three-Aspect Doctrine of the Buddha). ${ }^{89}$ The silence which meditation instils affects the whole body. It's the silencing of the mind as well as physical silence that makes it such a powerful experience. By breaking down the way our active minds impose meanings on the world's objects, we can begin to understand the essence of an entity without language and thought distorting it. For additional information on meditation refer to Appendix C.

Meditation is used to appreciate the "true beauty of Nature." 90 Through silence beauty can be made known to us and we can benefit from the knowledge of having come into contact with it. In essence, meditation is a tool in overcoming ignorance through silently realising the world for what it really is, beyond the hindering shackles of words. ${ }^{91}$

Not all meditations take place while sitting quietly. Samu (manual labour) in Zen Buddhism gives people the chance to deepen their meditative state through repetition, thereby energising and quietening the mind. Roshi Philip Kapleau wrote that manual labour has been an essential ingredient of Zen discipline for thousands of years. Occupants of Zen monasteries spend their mornings sweeping, scrubbing and gardening, all within a silent and meditative state, similar to the way Christian monks perform their tasks in a mode of contemplation. ${ }^{92}$ The role of using 88- Daisetz Suzuki, Zen and Japanese Buddhism (Tokyo: Japan Travel Bureau, 1970) 19.

89- Ninian Smart, Background to the Long Search (London: British Broadcasting Corporation, 1977) 91.

90 - Ninian Smart, Background to the Long Search (London: British Broadcasting Corporation, 1977) 276.

91- Andrew Juniper, Wabi Sabi: The Japanese Art of Impermanence (Boston: Tuttle Publishing, 2003) 22.

92- Philip Kapleau, The Three Pillars of Zen (New York: Anchor Books, 1980) 210. 
work to attain silence is particularly interesting, as performing a task seems at odds with silence at a surface level. However, it is clearly an important aspect of meditation and contemplation that is employed in both Christianity and Buddhism, and demonstrates the ability for silence to be embodied in a myriad of ways. ${ }^{93}$

\section{Zen Gardens}

\section{'Prevailing silence — / and penetrating the rock / the cicada's cry.'}

"I am nothing but blocks of stone on pieces of gravel, I am nothing but weight and silence, inertia and density. Nothing will ever learn my secret, or even whether I contain one. The only thing that can penetrate me is the strident cry of the cicada that pierces the heart of summer. Be content to taste the raw beauty of my opaque flesh; look at me without saying a word and ask me nothing; be silent and try, through my hermetic body, to find yourself. 'x4

Matsuo Bashō: Poet

For a simpler road to transcendence, Zen Gardens provide an appropriate background for practising meditation. The silence that is practiced in Zen Buddhism is reflected in Zen Gardens through the use of long horizontal planes and multiple points of focus, which draw the mind inwards rather than upward (as opposed to Christian cathedrals). As Muso Soseki, a Zen Buddhist Monk, once said, "He who distinguishes between the garden and practice cannot be said to have found the true way." ${ }^{55}$ It is fitting, with Buddhism's belief in the beauty of nature, that a prominent place for meditation should be designed outdoors. Although ultimately reaching a meditative state is an individual achievement, there is little doubt that a supportive setting is helpful in attaining the calm and silence required.

One type of Zen garden used for meditation is the Karesansui (dry landscape): a garden without water. Rocks and gravel are designed to stimulate contemplation. The white gravel represents 93- Robyn Griggs Lawrence, The Wabi-Sabi House (New York: Clarkson Potter/Publishers, 2004) 132.

94- qtd. in. Francios Berthier, Reading Zen in the Rocks: The Japanese Dry Landscape Garden, trans and preface. Graham Parkes (Chicago: University Press, 2000) 42.

95- qtd. in. Francios Berthier, Reading Zen in the Rocks: The Japanese Dry Landscape Garden, trans and preface. Graham Parkes (Chicago: University Press, 2000) 3. 


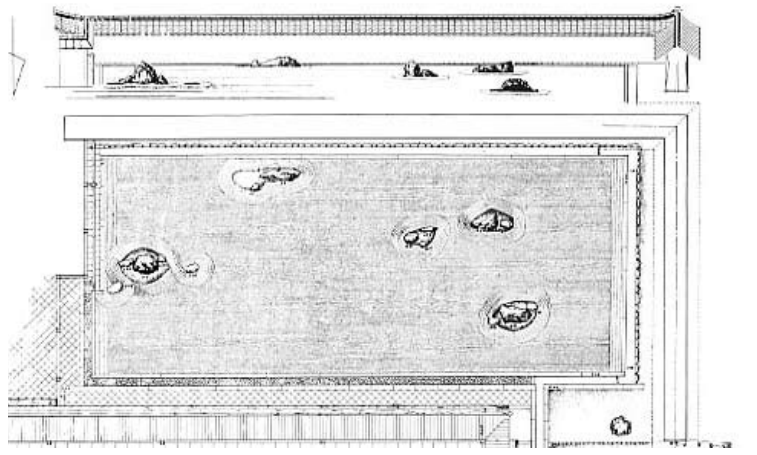

Figure 4.6 - Plan and Section of Ryōanji Garden (orientation South)

Source: Colby, "Week 6 Muromachi Period" Colby, 12 July 2010, <http://www.colby.edu/art/AR274/Week_6/Week_6. htm>.

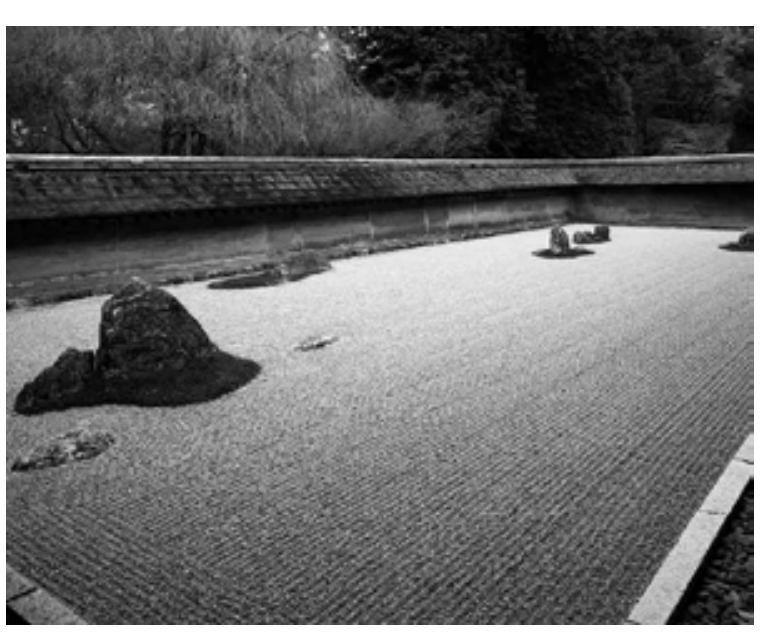

Figure 4.7 - Rock Garden at Ryōanji, Kyoto, Japan, 2002

Source: Bruce R. Watson, "Rock Garden at Ryoan-Ji, Kyoto, Japan," 2002, Achromatic Arts: Japan, 10 July $2010<$ http:// www.achromaticarts.com/japan/02.html> $m a$, that of nothingness, the ultimate silence. The act of raking patterns into the gravel begins the meditative state towards that nothingness, rendering it a less intimidating journey (the act of samu). ${ }^{96}$ Through stripping nature back to its bare elements one can abstract its essence and expose your own "original nature". ${ }^{97}$

One prominent example of Karesansui is the highly documented Ryōanji Garden (Figure 4.6). Established around the late fifteenth to early sixteenth century, it is a relatively small garden measuring 336.6 square meters. ${ }^{98}$ It's second name mutei, or in English the "garden of emptiness," gives people a better understanding of its aesthetic properties. ${ }^{99}$ Attached to the Temple of Ryōanji, the Garden was used predominantly by Zen monks who are said to have inspired the design through their minimalist landscape painting styles. This coupled with inspiration from Chinese and Japanese tray gardens, and the pebbles covering sacred Shinto precincts, resulted in the unique garden of Ryōanji (Figure 4.7). ${ }^{100}$

Unlike Zen gardens previous to it, Ryōanji's orientation does not represent natural phenomenon such as a waterfall or landscape. Due to this abstraction of nature a subtle elegance is rendered. There are an odd number of rocks, with 5 groups of 2-5 rocks. Within Chinese and Japanese culture an odd number is the dominant yang, with 5 being superior as it is the centre of the first 9 . Re-emphasising this point is the total number of rocks, which are $15 .{ }^{101}$ Therefore this is a fitting symbolic element of power within the design.

The actual meaning of the garden is ambiguous, much like its exact time of creation and creator. The undefined symbolism in the rocks is said to help people reach a contemplative state as it gives the individual something to ponder. This high level of abstraction and simple honesty in

96- George Prochnik, In Pursuit of Silence: Listening for Meaning in a World of Noise (New York: Random House, 2010) 238. 97- Francios Berthier, Reading Zen in the Rocks: The Japanese Dry Landscape Garden, trans. Graham Parkes (Chicago: University Press, 2000) 6.

98- Mitchell Bring and Josse Wayembergh, Japanese Gardens: Design and Meaning (New York: Von Hoffman Press, Inc, 1981) 58.

99- Francios Berthier, Reading Zen in the Rocks: The Japanese Dry Landscape Garden, trans. Graham Parkes (Chicago: University Press, 2000) 30

100 - Mitchell Bring and Josse Wayembergh, Japanese Gardens: Design and Meaning (New York: Von Hoffman Press, Inc, 1981) 56.

101 - Mitchell Bring and Josse Wayembergh, Japanese Gardens: Design and Meaning (New York: Von Hoffman Press, Inc, 1981) 58. 
materials reflects the aesthetic of wabi-sabi found in Zen and Zen art. With the stones seeming to flow from East to West your gaze is taken in an optical circle, allowing contemplation towards the mysteries of the garden. ${ }^{102}$ Compelling and yet mystifying, Ryōanji epitomises the culmination of silence of the landscape inspiring silence within the mind, ultimately Stille.

\section{Wabi-Sabi}

"From a Mountain Temple

the sound of a bell struck fumblingly

vanishes in the mist"103

Yosano Buson,

Eighteenth-century Japanese poet

The notion of wabi-sabi relates to a Zen aesthetic of "imperfect, impermanent and incomplete." 104 Displayed predominantly in the private domain, wabi-sabi is the aesthetic refuge from the noise and clutter of modern life. Emulating the phenomenon of silence, wabi-sabi is a quality of beauty and being.

Wabi-sabi reflects the qualities of silence visually. This can be portrayed through tracing its underlying principles. It originated through the ideas of "simplicity, naturalness, and acceptance of reality" which are reflected in Zen Buddhism. ${ }^{105}$ Zen monks were among the first to advocate the wabi-sabi aesthetic through their loosely defined brushwork and love of the unconventional (as in the example of Ryōanji) for the way it stimulates the mind and challenges perception. Mostly they were inspired by nature, and the beauty found in details of imperfection such as changes in colour, rust and even rotting and cracking patterns. Since then wabi-sabi has become an integral part of Japanese culture, being a main element within the traditional tea ceremony

102- Mitchell Bring and Josse Wayembergh, Japanese Gardens: Design and Meaning (New York: Von Hoffman Press, Inc, 1981) 168.

103- qtd. in. Akiko Hirano and Tim Wong, Wabi Sabi-Learning to See the Invisible, September 2007, 29 June $2010<$ http:// www.touchingstone.com/Wabi_Sabi.html>.

104- Leonard Koren, Wabi-Sabi for Artists, Designers, Poets and Philosophers (California: Stone Bridge Press, 1994) 7. 105- Leonard Koren, Wabi-Sabi for Artists, Designers, Poets and Philosophers (California: Stone Bridge Press, 1994) 31

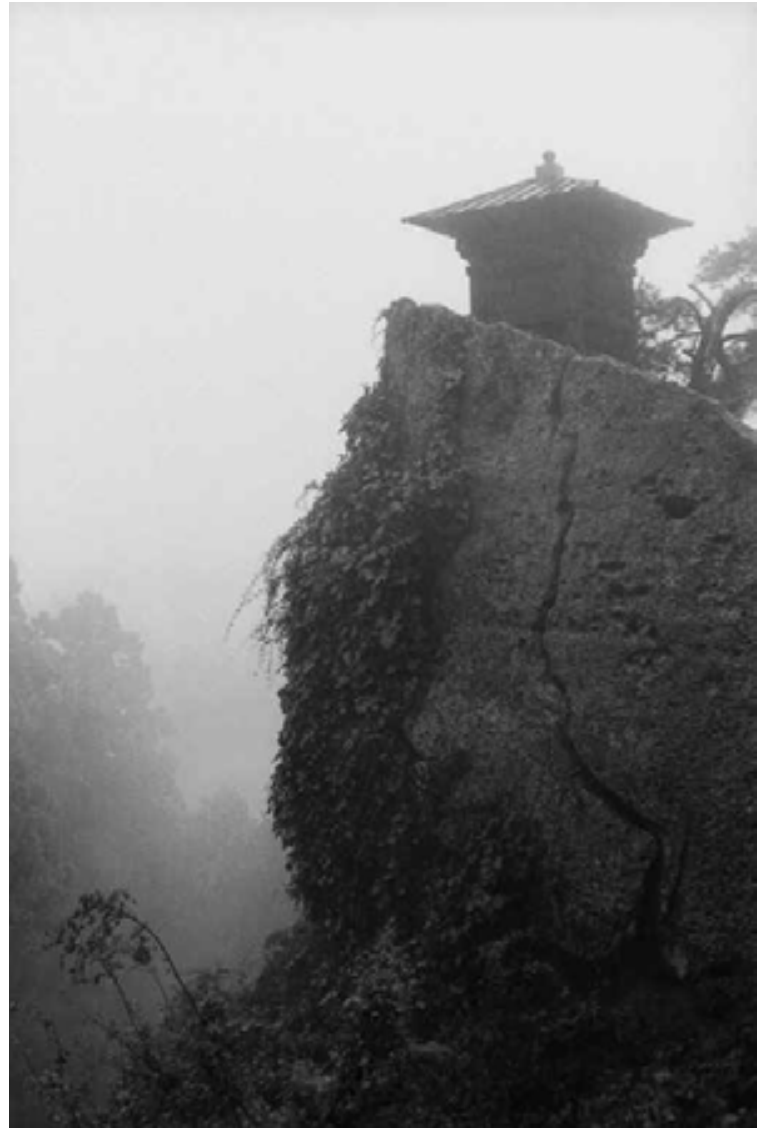

Figure 4.8 - Mystic

by Tim Wong

Source: Akiko Hirano and Tim Wong,

"Wabi Sabi-Learning to See the Invisible,"

September 2007, Touching Stone Gallery, 29 June 2010

<http://www.touchingstone.com/Wabi_Sabi.html>. 
and a stimulus for architecture. ${ }^{106}$ Despite its universal use today, its roots remain intertwined with Zen Buddhism and is an important aspect to consider when analysing Buddhism's culture of silence.

\section{Conclusion}

Religion and religious buildings create and encourage silence in many ways, as examined above. Christianity, with its long history in British culture, uses effective architectural ways of stimulating silence as discussed in the architecture of monasteries and churches. Certain activities, which are performed within these spaces, encourage such a mindset as in the example of prayer and repetitive daily tasks. Similarly Buddhism uses mediation and samu to attain silence, while landscapes like the Karesansui support such an endeavour. All of these modes of silence are available to the religious person. However, through secularisation religious experiences are being exposed to less people in the West. Through understanding what visual and aural elements stimulate meaningful silence, I aim to embody these in a secular urban retreat for the benefit of the community. Urban retreats into Stille are currently inadequate to address the needs of the modern city dweller. The next chapter will discuss how they are currently being used and what opportunities there are for future development 


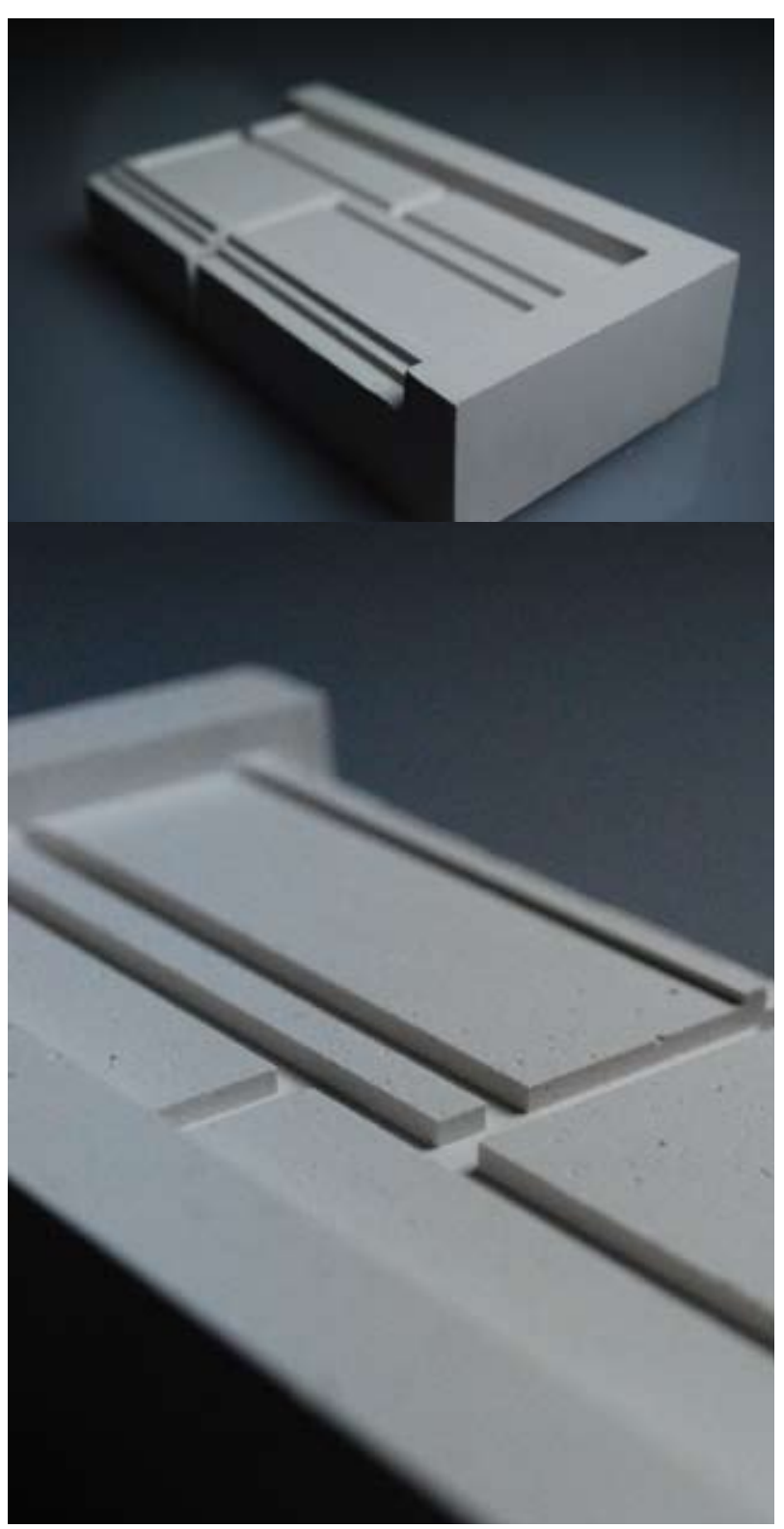

Figure 4.9-Maquette 8:

Abstracting Ryōanji 


\section{Part C - Manifestations}




\section{Chapter 5 - Manifestations of Silence in Retreats}

\section{Introduction}

As the world becomes increasingly hectic there is a trend within western countries to seek Stille. This trend is described as desiring 'slow time' and can be witnessed through an increasing number of holidays to remote places where the fast rhythm of everyday life is interrupted and stilled. ${ }^{107}$ This "valorisation of stillness in western society" 108 is a direct response to our immediate environment and the inaccessibility for many the silence found through religion (as discussed in Chapter 3). Unfortunately the option of escaping on a holiday is not viable for everyone due to reasons including commitments and lack of finance. This becomes problematic for individual wellbeing as it is difficult to obtain moments of silence at the work or home-space, as expressed in Figure 5.1.

Without the constant option of escaping the pressures of city life by travelling to an idyllic setting, several techniques are employed to assist Stille. Some personal religious techniques include meditation and prayer, which allow for internal silence, as discussed in the previous chapter. There are also built and secular solutions, such as the silence found within public buildings like libraries and museums. All of these retreats into silence are relevant as they are considered 'elsewhere settings,' dwell within the confines of the city, and as previously outlined by Daniel Bell, contain objects which were subject to the re-orientation of the sacred for secular people. Another prominent form of communal escape from the pressure of city life is large city parks and, more intimately, the installation of pocket parks. Pocket parks are designed to assimilate the silence of being within nature while unable to physically remove the person from the urban setting. Parks are important when assessing an experience of silence, as stillness is associated with an engagement of nature (Figure 5.1). While pocket parks do not physically remove the individual from the city they are possibly even more important an institution than libraries or museums due to their ready availability and multi functional integration into the urban community as a secular retreat.

107- Adrian Franklin, Tourism: an Introduction (London: SAGE Publications Inc, 2003) 57

108 - David Conradson, “The Experiential Economy of Stillness: Places of Retreat in Contemporary Britain,” Allison Williams, Therapeutic Landscapes (Aldershot: Ashgate Publishing, 2007) 35. 


\begin{tabular}{|l|l|l|l|}
\hline Activity Sphere & Workspace & Homespace & 'Elsewhere Settings' \\
\hline $\begin{array}{l}\text { Key influences upon the } \\
\text { experiential texture of spaces } \\
\text { within these activity spheres }\end{array}$ & $\begin{array}{l}\text { Employers and management } \\
\text { Regulatory authorities } \\
\text { Legislation (e.g labour law, } \\
\text { health and safety directives) }\end{array}$ & $\begin{array}{l}\text { Household members } \\
\text { Those financially responsible } \\
\text { for property, such as tenant(s) } \\
\text { or owner(s) } \\
\text { Government initiatives (e.g. } \\
\text { work-life balance policies) }\end{array}$ & $\begin{array}{l}\text { Private companies (e.g. slow } \\
\text { tourism and wilderness holiday } \\
\text { firms; gym offering yoga } \\
\text { classes) } \\
\text { Government bodies (e.g. } \\
\text { National Park committees) } \\
\text { Community, religious and } \\
\text { spirituality groups (e.g. walking } \\
\text { collectives, monasteries, retreat } \\
\text { centres) }\end{array}$ \\
\hline $\begin{array}{l}\text { Dominant evaluation of } \\
\text { stillness as a psychosocial } \\
\text { state }\end{array}$ & 'Unproductive Activity' & $\begin{array}{l}\text { Typically Valued But Under } \\
\text { Pressure }\end{array}$ & Productive non-activity \\
\hline $\begin{array}{l}\text { Social practices that facilitate } \\
\text { or marginalise stillness }\end{array}$ & $\begin{array}{l}\text { Techniques to minimise } \\
\text { stillness may be evident in } \\
\text { highly structured work } \\
\text { environments, such as time- } \\
\text { sheeting and clocking in/out } \\
\text { procedures }\end{array}$ & $\begin{array}{l}\text { Some evidence of efforts to } \\
\text { reduce activity, such as the } \\
\text { 'slow food' movement and } \\
\text { personal meditation. But such } \\
\text { practices are highly variable by } \\
\text { income and class status }\end{array}$ & $\begin{array}{l}\text { Techniques to cultivate stillness } \\
\text { include: engagement with } \\
\text { nature such as walking in } \\
\text { scenic settings; lowering levels } \\
\text { of activity; and therapeutic } \\
\text { mind-body techniques (e.g. } \\
\text { yoga and pilates) }\end{array}$ \\
\hline Distribution of stillness & $\begin{array}{l}\text { Stillness is a relatively scarce } \\
\text { psychosocial state within many } \\
\text { contemporary workplaces }\end{array}$ & $\begin{array}{l}\text { Stillness is unevenly present in } \\
\text { contemporary home-spaces, } \\
\text { with significant variation by } \\
\text { household composition, } \\
\text { education, income, and } \\
\text { position in life course }\end{array}$ & $\begin{array}{l}\text { Stillness is often perceived to be } \\
\text { more easily achieved in } \\
\text { 'elsewhere settings' than in } \\
\text { work or home space }\end{array}$ \\
\hline
\end{tabular}

Figure 5.1 - The Variable Evaluation and Distribution of Stillness in Contemporary Britain 


\section{Urban Architectural Retreats}

"A powerful architectural experience silences all external noise; it focuses our attention on our very existence, and as with all art, it makes us aware of fundamental solitude." 109

Juhani Pallasmaa

"To me, buildings can have a beautiful silence that I associate with attributes such as composure, selfevidence, durability, presence and integrity, and with warmth and sensuousness as well; a building that is being itself, being a building, not representing anything, just being. "110

Peter Zumthor

Architectural techniques that the city employs to offer retreats of silence include art galleries, commemorative spaces, museums and libraries. These spaces, through their interior focussed design and clearly defined modes of behaviour, provide collective release from the noisy city for the secular person. They are effective as they offer a protected place for contemplation. Contemplation is aided in each case by the objects they possess, whether that be art, artefacts or books. Through almost complete removal from the city one can experience a form of retreat and, in the case of 'powerful architecture,'111 a sense of Stille.

Art galleries in particular adhere to the theory that 'true art' can instil silence through contemplation. In the internationally acclaimed book The Eyes of the Skin, Pallasmaa calls on art (and within that, architecture) to install a sense of 'tranquillity.'112 Pallasmaa views art as being capable of capturing the essence of silence, and embodying it responsively for those who choose to listen. ${ }^{13}$ Similarly

109_ Juhani Pallasmaa, The Eyes of the Skin: Architecture and the Senses (London: Academy Editions, 1996) 36.

110 - Peter Zumthor, Thinking Architecture: Second Expanded Version, trans. Maureen Oberli-Turner and Catherine

Schelbert (Basel: Birkhäuser: Publishers for Architecture, 2006) 34.

111 - Juhani Pallasmaa, The Eyes of the Skin: Architecture and the Senses (London: Academy Editions, 1996) 36.

112- Juhani Pallasmaa, The Eyes of the Skin: Architecture and the Senses (London: Academy Editions, 1996) 36.

113 - Kaisa Broner-Bauer supports the notion that not only does art instil silence, but also to create art requires silence. "True art is born in the silence of contemplation." Although he recognises that materialism and commercialism has invaded art and polluted it to some degree, there still remains a quality within "true art" which cannot be exploited. As the world progresses towards never before seen heights of materialism, relief can be found in the beauty and silence of creating and experiencing true art and architecture. Reference: Kaisa Broner-Bauer, "Aarno Ruusuvuori and the Continuity of Finnish Modernism," The Culture of Silence: Architecture's Fifth Dimension, ed. Malcolm Quantrill and Bruce Webb (Texas: A\&M University Press, College Station, 1998)196-197.

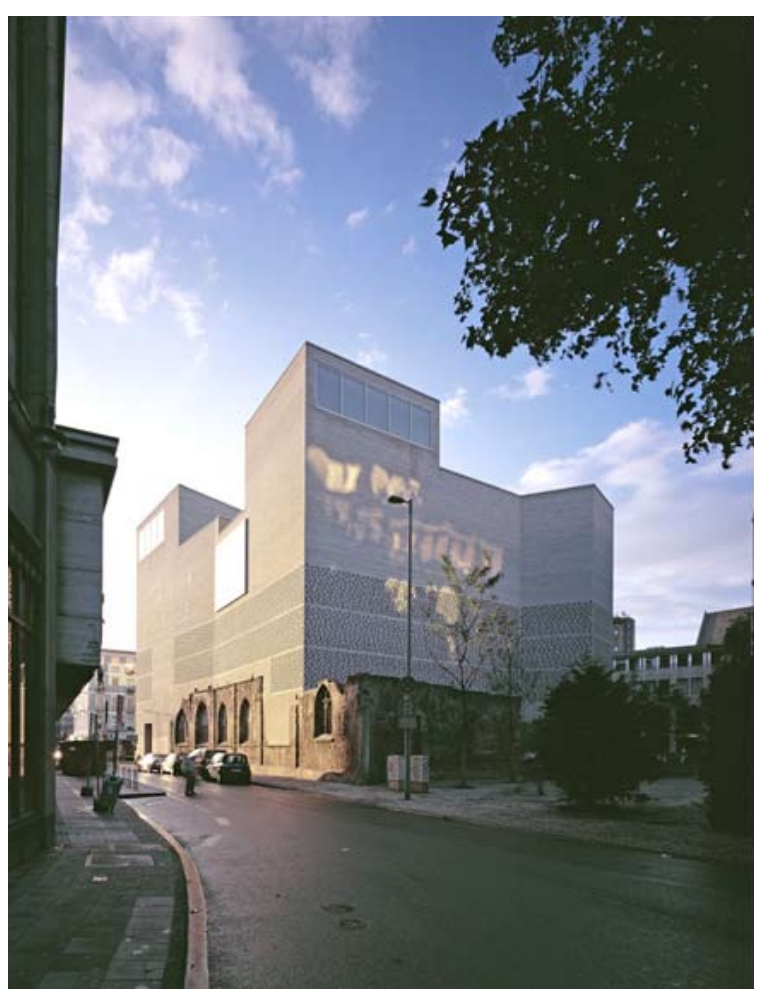

Figure 5.2 - Exterior of Das Kunstmuseum Kolumba

by Hélène Binet

Source: Ellis Woodman, "Zumthor's Cologne modern art museum is beyond time," 21 September 2007, bd.online. co.uk, 2 July $2010<$ http://www.bdonline.co.uk/buildings/ zumthor\%E2\%80\%99s-cologne-modern-art-museum-isbeyond-time/3095607.articles. 


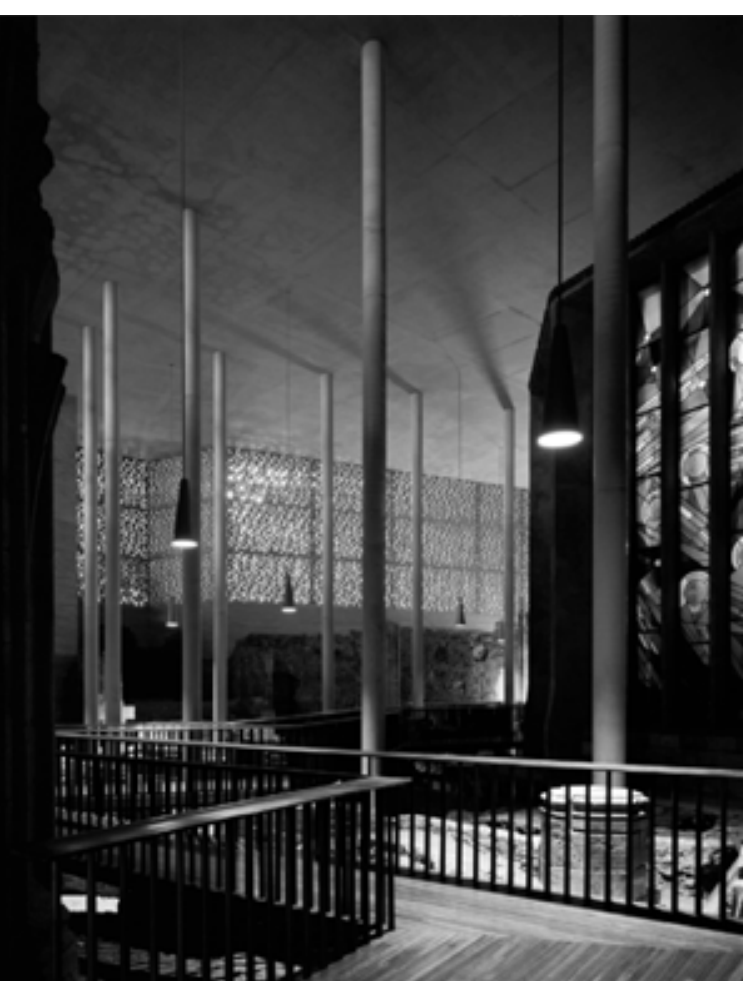

Figure 5.3 - Commemorative Space

by Hélène Binet,

Source: Peter Cachola Schmal, "Explorations: German Architecture Museum," March 2009, European Architectural History Network, 18 August $2010<$ http://www.eahn.org> 19. to Pallasmaa's argument, Picard displays his belief of art "offering" silence to man. Both of these philosophers understand the capacity for art and architecture to effulge a person in a moment of silence. ${ }^{114}$

One successful example of an art museum as a place of contemplation is that by Peter Zumthor: Das Kunstmuseum Kolumba (The Art Museum of Kolumba) built in 2007 Cologne, Germany. The silence that this particular building exudes is one of contemplation through commemoration. Commemoration is reflected through the layers of visible religious ruin. Built on top of the foundations of the Gothic church of St Kolumba, the site had previously housed buildings from Early Christian to Medieval, Carolingian, Romanesque, Gothic and late Gothic. ${ }^{115}$ The past plans were adopted and re-developed for modern use. In addition heavy grey brick walls separate the outside profane from the sacred art on the interior, once again similar to the churches gone before (Figure 5.2).

Arguably the most provocative room in relation to Stille is the Commemorative Space that does not involve art as an exhibition, rather allowing the architecture and architectural remains to facilitate the experience (Figure 5.3). The perforated walls act as a light and air filter. Through articulating the external façade they reconnect the immersed person with the outside environment, a sensation that is treated more generically through large windows in subsequent exhibition spaces. ${ }^{116}$ This renders the room unique. People are able to engage and contemplate through their raw exposure to the religious archaeological ruin. The naturalness of this space speaks of ideas relating to wabisabi and Karesansui as a dry, rough and unsystematic landscape. It is a contrast to the upstairs

114- In contrast to the notion of 'true art', the French Enlightenment philosopher Denis Diderot explored the notion of visual noise. In response to a painting by artist Francois Boucher, Diderot proclaimed in Salon de 1765 that he had created "an unbearable racket for the eye". He went on to write that such style (that of louche frivolity) is "the deadliest enemy of silence." Reference: qtd. in. Michael Fried, Absorption and Theatricality (California: University Press, 1980) 41. The idea that a visually unpleasant image can be 'loud' brings us back once again to understanding the experience of Stille. I propose that one cannot alienate the ears from the eyes when assessing silence, to do so would undermine its revered qualities, that of stillness, calm, and beauty.

115- Lesa Mason, Teresa Norton and David C. Overholt, "At St Kolumba: The Drowned and the Saved: Transmitting the Spirit of Place-Interpretation/Meaning," 28 May $2010<$ http://74.125.155.132/scholar?q=cache:z-OPdbKGS2oJ:scholar. google.com/+st+kolumba+peter+zumthor\&hl=en\&lr=lang_en\&as_sdt=2000>3.

116- Ellis Woodman, “Zumthor's Cologne modern art museum is beyond time," 21 September 2007, bd.online.co.uk, 2 July 2010 <http://www.bdonline.co.uk/buildings/zumthor\%E2\%80\%99s-cologne-modern-art-museum-is-beyond-time/3095607. article>. 
gallery rooms that rely on the art to stimulate contemplation while the walls, floors and ceilings themselves are visually quiet to the point of invisibility (Figure 5.4). By heavily controlling the external stimulation through tiny apertures the space becomes subtly integrated with the city setting, an architectural landscape of a kind.

Similarly to the way the Commemorative Space functions in the Kunstmuseum is the Holocaust Void in Daniel Libeskinds Jewish Museum in Berlin. The tower, which was completed in 2001, is accessible only from underground and consists of a concrete 'void' with one light source from a narrow slit in a top corner (Figure 5.5). A staff member who opens the heavy door at roughly 5-minute intervals manages access to the room. ${ }^{117}$ The austere space is directly linked to the external environment. In summer it is cool and moist, in winter it is cold and brisk. Libeskind states that the voids (of which there are several in the building) are "not really a museum space." 118 Perhaps due to them not having a prescribed function besides silence they become debatably more evocative than any of the exhibition areas. Linked with feelings of immense tragedy, the room is almost oppressive in its silence as you stare up at the one point of release, the sliver of daylight. The silence in this space is all consuming and a poignant example of how commemoration can create Stille.

The silence that Zumthor's art museum and Libeskind's Jewish museum embodies is evocative. It demonstrates how art galleries, museums and libraries, while having silence in relation to their functional requirements, could also create potentially more interesting experiences of Stille through utilising contemplative silence devoid of programmatic incentive. Their design can effectively quieten the exterior metropolis and create a sense of tranquillity if executed appropriately. Another example of a contemplative space integrated with a library is the Bibliotheque Nationale de France, discussed in Chapter 6, Case Studies and Silence.

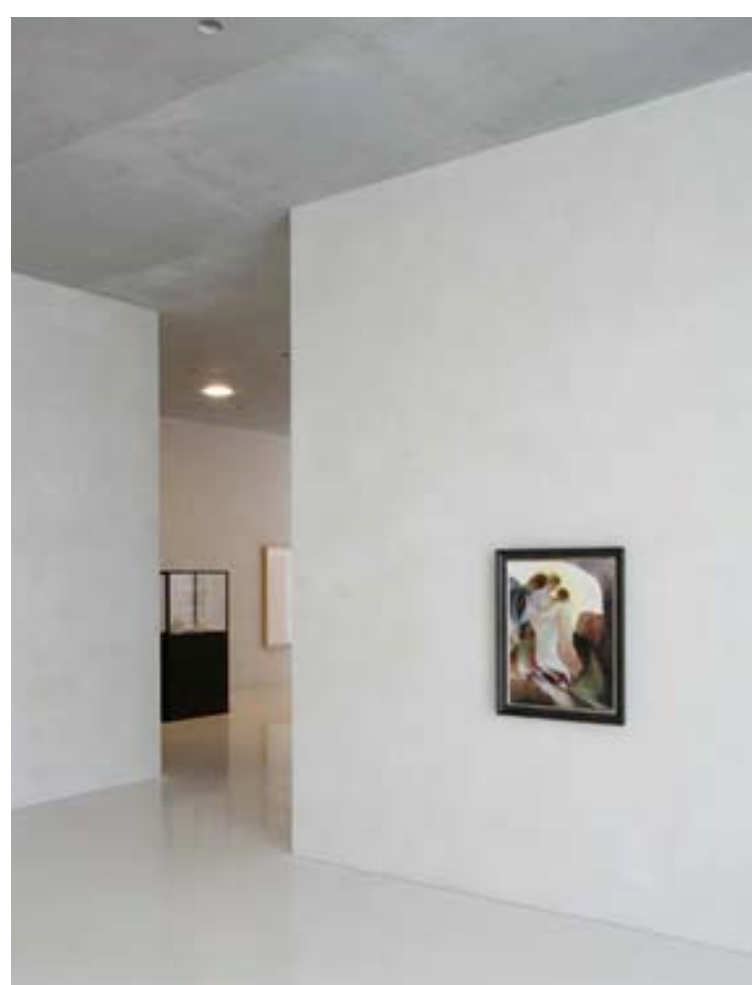

\section{Figure 5.4 - Second Floor Gallery}

by Hélène Binet

Source: Ellis Woodman, "Zumthor's Cologne modern art museum is beyond time," 21 September 2007, bd.online. co.uk, 2 July $2010<$ http://www.bdonline.co.uk/buildings/ zumthor\%E2\%80\%99s-cologne-modern-art-museum-isbeyond-time/3095607.articles. 


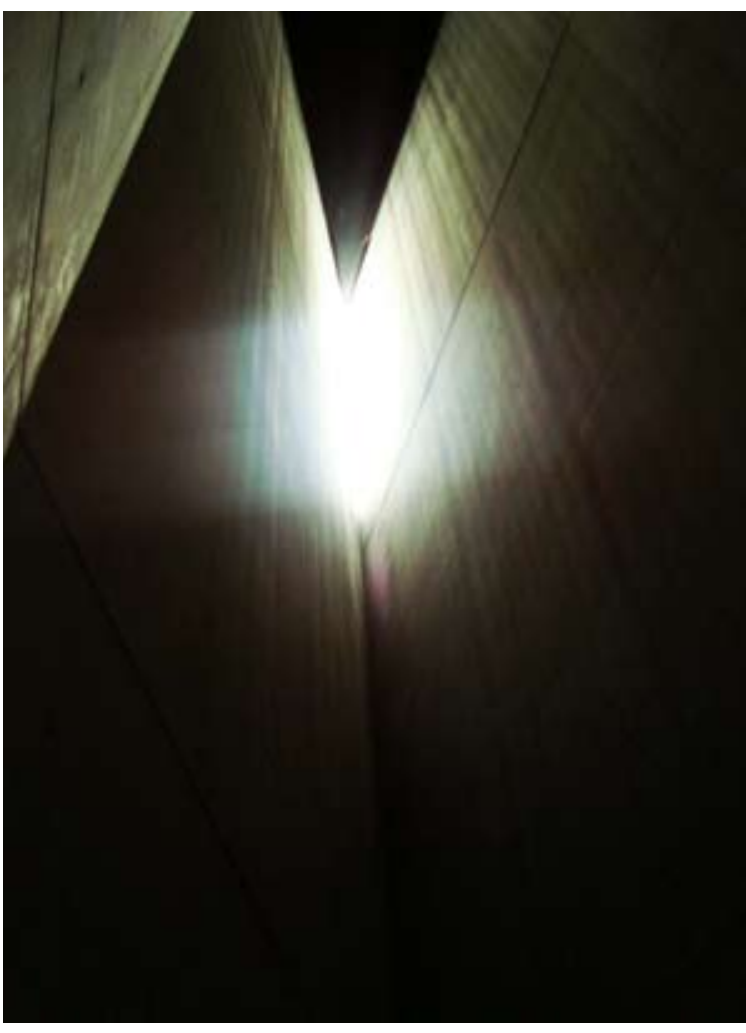

Figure 5.5 - Holocaust Void of the Jewish Museum by Emma Macann

Source by Author: Emma Macann, Jewsih Museum, 2009 Photography, Berlin.

\section{Silence and Nature}

"Sometimes... I sat in my sunny doorway from sunrise to noon, rapt in a reverie, amidst the pines and hickories and sumachs, in undisturbed solitude and stillness, while the birds sang around or flitted noiseless through the house, until by the sun falling in at my west window, or the noise of some travellers wagon on the distant highway, I was reminded of the lapse of time." 119

Henry David Thoreau

Although there are effective forms of architectural secular retreats through silence as previously disclosed, for many people silence is observed most readily in nature. ${ }^{120}$ In addition, figures from 2009 demonstrate that in England around 90\% of people visited parks and green spaces, where only $29 \%$ visited galleries. ${ }^{121}$ Green space within cities is a desired and highly sought after commodity that lessens the intensity of high-rise buildings lining the cityscape. It highlights an ironic ideal, that of experiencing nature within urban confines. The availability of a park to the public endows it with potential to become that 'elsewhere' setting for which a transition into Stille can take place. Ways which nature creates silence is discussed below, followed by a critique of the integration of nature into the city at present.

There is a common trend amongst theorists to compare silence to the qualities of nature. This analogy emphasises how it is a commodity that extends beyond mere acoustics to that of a fullembodied experience. It also highlights the paradoxes that we come across when discussing silence and our appreciation of it. Sometimes it is only through noise that we can value and come into contact with meaningful silence, as a bustling forest is testimony towards.

Gaston Bachelard quotes theorist Pierre Guéguen from his book La Bretagne when describing aspects of silence. Guéguen believes that silence is found in a deep forest. ${ }^{122}$ For him silence goes beyond that of acoustic muteness and translates into a way of being, an "inner state" found

119- Henry David Thoreau, Walden: or, Life in the Woods (London: David Campbell Publishers Ltd, 1992) 99. 120 - David Conradson, "The Experiential Economy of Stillness: Places of Retreat in Contemporary Britain," Allison Williams, Therapeutic Landscapes (Aldershot: Ashgate Publishing, 2007) 37.

121 - "More than 90 per cent of the population use parks and green spaces: more green flag awards given this year," 2010, rudi.net, 12 October $2010<$ http://www.rudi.net/node/22142>

122 — qtd. in. Gaston Bachelard, The Poetics of Space, trans. Maria Jolas (Boston: Beacon Press, 1969) 187. 
through contemplation. ${ }^{123}$ Although a forest hums with the sounds of life, the rustling of leaves and movement of creatures serve to enhance the forests quiet, rather than detract. The calm that such an environment inspires is one of deep psychological peace.

Charles Darwin noticed a similar phenomenon of noise emphasising silence within nature. During his explorations of the coast of Brazil the sound of insects within the forest were extremely loud, enough to be heard at a great distance from the trees. However, once the universe within the greenery had you fully submerged, within that deafening racket of insects were pockets of silence. ${ }^{124}$ Enclosure is therefore an important aspect of Stille. In this case as with the one prior, paradoxes between noise and silence are more poignant when found in nature.

A more extreme example is the tale of Walden by Henry Thoreau. Walden is testimony towards the idealised silence of nature. Thoreau was a lone man in the wilderness for two years. Although he was a part of a small community he kept to himself mostly, choosing to live simply and in that way become closer to nature, to Walden. His experience was a deep and personal exploration. He did little more than read, write and labour for those years, and found it profoundly rewarding. Through his escape into nature he discovered the quiet inside himself and by later publishing his book - which was written in part during his escape to Walden - he shared his experiences with the world. By connecting with nature and himself he found that the universe became simpler, and the solitude comforting. ${ }^{125}$

An interesting aspect, which is dominant throughout the literature accounts of nature, is the assumption of solitude whilst immersed in a forest. This suggests that it is the notion of solitude alongside nature itself that stimulates silence. Certainly an idyllic setting is helpful in creating silent moments through unstructured beauty and activity stimulating the bodily senses. However, I propose that the experience which Guéguen, Darwin and Thoreau all refer to would be significantly different had it been with a group of people. Thoreau's experience in particular is based upon notions of solitude. Solitude for him is as pivotal in obtaining silence as being immersed in nature. So while it has been acknowledged in Chapters 2 and 3 that establishing a

123 - qtd. in. Gaston Bachelard, The Poetics of Space, trans. Maria Jolas (Boston: Beacon Press, 1969) 187.

124- Charles Darwin, The Voyage of the Beagle (New York: Cosimo, Inc, 2008) 21.

125- Henry David Thoreau, Walden: or, Life in the Woods (London: David Campbell Publishers Ltd, 1992) 286. 
sense of connectivity is important for society, this chapter has highlighted that it is also critical to allow for individual contemplation in establishing moments of meaningful silence.

\section{Large City Parks}

A form of nature that is accessible for urban residents are large city parks. City parks are derived from a country setting of nature where the phenomenon of the silence is readily experienced. Inspiration for them came from economic and social reforms connected to industrialisation within the $19^{\text {th }}$ century. During this time in Europe and America the country park was seen as a respite from the grime of the city. Those who were able proceeded to flee to the countryside for a break, particularly in London. Inner city town and royal parks were either too small to accommodate the severe increase in population or non-existent. The creation of the $19^{\text {th }}$ century city park was to benefit the greater community by allowing the working class to gain fresh air, relax in a pleasant setting and experience mental retreat. ${ }^{126}$ Seen to embody "purity, simplicity, harmony and morality," 127 the city park brought nature to the machine driven town and offered an effective contrast to city life.

Among the first to contrive towards the city park was London. At this time London was comparing unfavourably to its Europeans counterparts in providing green space. To rectify this was the opening of private parks for the public. St James Park was one of the first, opening its doors in 1823. Similarly Regent Park opened 88 acres to the public in 1834 after proactive rallying against its use as a wealthy mans park. Within the same theme was the conversion of Hyde Park's perimeter walls that were large and imposing to smaller painted iron railings, effectively making the 750 acres of land visually more accessible. Due to this proactive action large parks in London City were made available to the wider public by the mid 1800 's. ${ }^{128}$

Amongst this fervour for the city park was the initiation of Central Park in New York City. Central Park is unique because it is the first purpose built large park for the enjoyment of the

126 - Karen R Jones and John Wills, The Invention of the Park: From the Garden of Eden to Disney's Magic Kingdom (Cambridge: Polity Press, 2005) 44

127 - Karen R Jones and John Wills, The Invention of the Park: From the Garden of Eden to Disney's Magic Kingdom (Cambridge: Polity Press, 2005) 45

128 - Karen R Jones and John Wills, The Invention of the Park: From the Garden of Eden to Disney's Magic Kingdom (Cambridge: Polity Press, 2005) 46. 
public, rather than the aristocracy (as in the case of London). ${ }^{129}$ Built largely during the 1860 's, the 843-acre park may seem naturalistic but is in fact severely engineered. ${ }^{130}$ Despite its deceiving demeanour it has had a significant impact on New York and subsequent parks in America. Historian and photographer Sara Miller goes as far as to say that:

"Central Park is the most important work of American art of the nineteenth century. In the visual arts no single painting, sculpture, or structure can compare with this unique and long-recognized masterpiece of landscape architecture. "'131

Therefore Central Park offers silence through an experience of beauty and articulated nature to the inhabitants and tourists alike of New York City (Figure 5.6).

Despite the international success of the city park, a summarisation would suggest that they "failed to offer urbanites a perfect Eden." 132 Too often crime and volatile activities are associated with the spaces. Poor management and design has meant that they are not always places of respite. Today city parks are a mixture of a healthy leisure resort and a space for derelict behaviour. ${ }^{133}$ Regardless they are still a significant aspect within the city that can provide for an experience of Stille if managed appropriately. Unlike their silent architectural counterparts (art galleries, museum and libraries), their containment of silence is related to their size. A sense of removal is achieved through sheer volume rather than a reliance on containment. This is one way which natural landscapes contrast with built environments. To further the quest of the city park is a modern day challenge for designers. How can nature and its qualities of Stille be integrated more frequently into the city fabric and daily life?

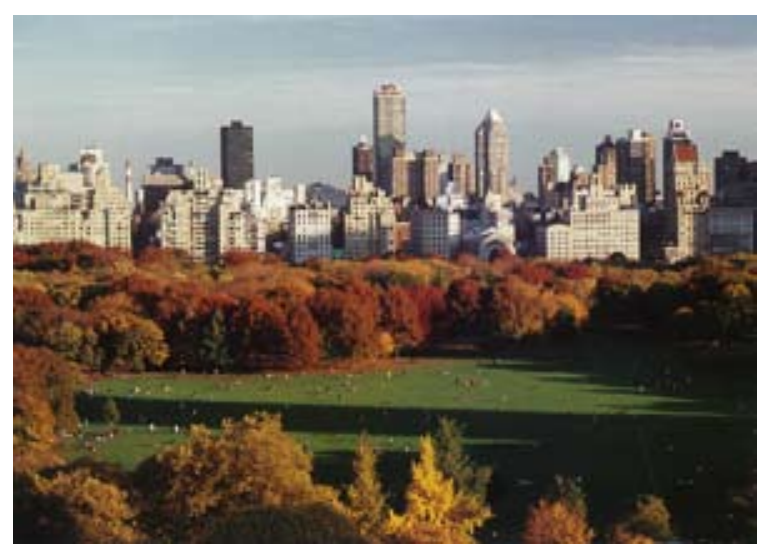

Figure 5.6 - Central Park: The Sheep Medow by Sara Cedar Miller Source: Sara Cedar Miller, Central Park, An American Masterpiece (New York: Harry N. Abrams, Inc, 2003) 112.

129- Kenneth T. Jackson, "Preface," Central Park, An American Masterpiece, Sara Cedar Miller, (New York: Harry N. Abrams, Inc, 2003) 7.

130 - Sara Cedar Miller, Central Park, An American Masterpiece (New York: Harry N. Abrams, Inc, 2003) 13.

131 - Sara Cedar Miller, Central Park, An American Masterpiece (New York: Harry N. Abrams, Inc, 2003) 8.

132 - Karen R Jones and John Wills, The Invention of the Park: From the Garden of Eden to Disney's Magic Kingdom

(Cambridge: Polity Press, 2005) 61.

133 - Karen R Jones and John Wills, The Invention of the Park: From the Garden of Eden to Disney's Magic Kingdom

(Cambridge: Polity Press, 2005) 63 


\section{Pocket Parks}

Experiencing nature within the tight confines of the city is a different experience from that in the wilderness or a large city park. There is limited space for individual experience as they are designed to be congregating places within a small amount of space. Predominantly without the use of architectural elements to effectively separate the noise from the silence they have less means to eliminate unwanted noise both visually and aurally. Despite this they remain a relative respite from the hectic motions of the cityscape. Successful city planning endeavours to include frequent green spaces for the qualities of peace they provide. Churchyard cemeteries were a traditional means of the city creating these moments. Prolific in London in particular, they embody a sombre silence and were surprisingly often subject to secular activities. ${ }^{134}$ However, through increasing confines in city space they are no longer an expanding institution. ${ }^{135}$ Due to this, and the confines of this thesis, they will not be elaborated upon. Instead the focus is on pocket parks and how they can act as intimate moments of retreat.

The pocket park was a term coined in America in 1897 by Jacob Riis, then secretary of New York City's Committee on Small Parks. Despite being a $19^{\text {th }}$ century development they did not take notable effect until post-war Europe (in particular London) where the shear volume of bombed out buildings made it uneconomical to restore (Figure 5.7). Therefore, by chance, sites within the city were transformed into green space. ${ }^{136}$ Historian and philosopher Lewis Mumford described the effect of pocket parks "as a place of refuge, whose main values derived from the contrast with the noisy, crowded, dusty, urban hive."137 These so-called 'intimate open spaces"138 act to bring people together through creating social opportunities which are generally missing in busy urban settings. Small in size, the frequency of their positioning means the hectic urban environment is subtly broken up by green 'utopias'. In addition, it has been discovered that people's appreciation of vastness within nature is not directly related to size. Instead the main

134- Vanessa Harding, The Dead and the Living in Paris and London, 1500-1670 (Cambridge: University Press, 2002) 52. 135 - Vanessa Harding, The Dead and the Living in Paris and London, 1500-1670 (Cambridge: University Press, 2002) 48. 136 - Thomas P. F Hoving, "Think Big about Small Parks," 10 April 1966, The New York Times, 4 June 2010 <http://www. nytimes.com>.

137- Lewis Mumford, "The Philosophy of Urban Open Space," Small Urban Spaces: The Philosophy, Design, Sociology and Politics of Vest-Pocket Parks and other Small Urban Spaces, ed. Whitney North Seymor, (New York: University Press, 1969) 14. 138 - Lewis Mumford, "The Philosophy of Urban Open Space," Small Urban Spaces: The Philosophy, Design, Sociology and Politics of Vest-Pocket Parks and other Small Urban Spaces, ed. Whitney North Seymor, (New York: University Press, 1969) 14 \& 


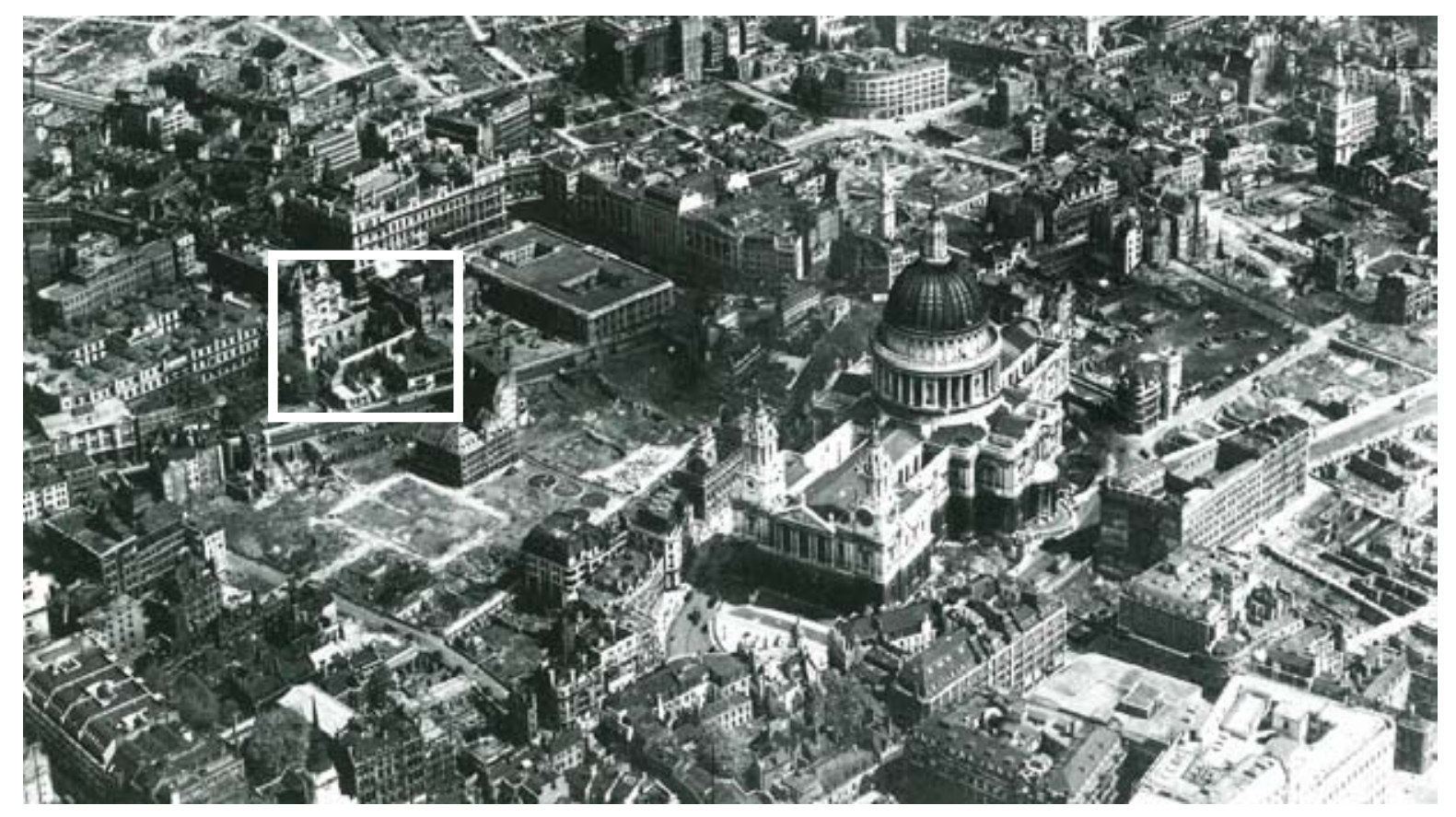

Figure 5.7 - Post-War City of London

Highlighted Christ Church Greyfriars — pocket park and proposed site for the design

Source: Andreas Papakadis and Kenneth Powell, "The Urban Form of Paternoster Square," Architectural Design Profile No 97: Paternoster Square and the New Classical Tradition 62 (1992): 12. 


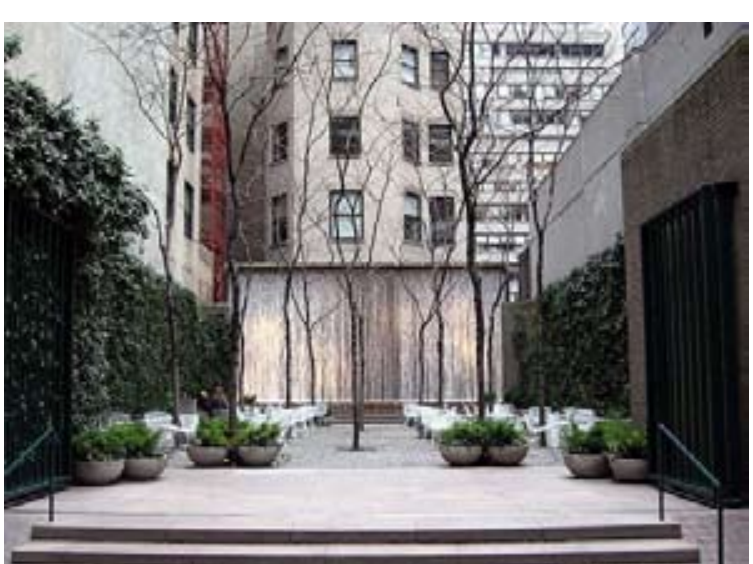

Figure 5.8 - Paley Park

Source: Jim Henderson, "Paley Park, New York City," Earth Documentary: World Budget Travel Guides, 17 August 2010 $<$ http://www.earthdocumentary.com/paley-park_new-yorkcity.htm >. requirements are open spaces, large and numerous trees, and pathways and trails. ${ }^{139}$ This means that through manipulating these elements people can feel satisfied with a minimal experience of nature.

Through creating these moments of release pocket parks have a significant impact on the city. But they are by no means perfect. The greenery, while being visually inviting, rarely creates any physical silence. Instead it harvests an appearance through nature. This relates back to previously discussed notions of visual overload, with the controlled nature acting to quiet the image saturated urban life. Although an inner city park may be no more silent than the road beside, it feels as though it is. So while being unsuccessful in creating auditory silence, through emulating a relative tranquillity a form of silence is available to the public. ${ }^{140}$

In the US, Paley Park is one of the most well known pocket parks and is located in Manhattan, New York. Built in 1967 and rebuilt to the same design in 1999 it is an example of a new trend of park design in America (Figure 5.8). In a 1963 exhibition 'New York Parks for New York' the idea of creating many small areas of green space was proposed as inspired by the European movement. The proposal was met with controversy. Robert Moses, Park Commissioner from 1930-1960, stated that anything less than 1.2 hectares would be too expensive and an administrative nightmare. ${ }^{141}$ In response William S. Paley, a wealthy businessman, saw merit in creating numerous spaces for individual release and decided to take matters into his own hands. The result is the privately owned Paley Park available free to the public. Being a mere 12.8 meters by 30.5 meters deep, the park makes the most of its small size. ${ }^{142}$ The design concept was to enclose the space, thereby removing it from traffic and pedestrian noise while creating a place for adults to rest. ${ }^{143} \mathrm{~A}$ few stairs at its entrance act to physically remove the park from the cityscape. Inserted walls on three sides have vines growing over them while a large water fountain is placed at the back to drown out city noise. Movable seating allows people to articulate the space as they 139- Rachel Kaplan and Stephen Kaplan, The Experience of Nature: A Psychological Perspective (Cambridge: University Press, 1989) 152 .

140 - Through my research I have found that there has been extensive analysis into the psychological benefits of nature.

Unfortunately due to the confines of this thesis they will not be further elaborated upon, except to say that the benefits are

diverse and restorative in a cognitive sense, regardless of the size of the nature accessed. Reference: Rachel Kaplan and Stephen

Kaplan, The Experience of Nature: A Psycholooical Perspective (Cambridge: University Press, 1989) 189.

141 - qtd. in. Alan Tate, Great City Parks (London: Spon Press, 2001) 6.

142- Alan Tate, Great City Parks (London: Spon Press, 2001) 6.

143- Alan Tate, Great City Parks (London: Spon Press, 2001) 7. 
wish, and large gates at the entrance mean the space can be locked up at night for safety. Alan Tate claims "its impact has been as potent in its own way as the impact of Central Park." 144 This is one example of how a pocket park can be articulated to give relative respite from city life. Success is evident through its use and preservation, but it is not a silent landscape. Visually it does not veil the city and there is no device put in place to lessen noise but rather mask it with the sound of water. As demonstrated in this example, the design of pocket parks needs to be re-evaluated in terms of the phenomenon of Stille for a new and profound park experience.

\section{Conclusion}

Stille is integrated into the city through secular means in many ways. The architecturally built solutions are effective in creating silence though their internally focused design. Interestingly, opportunity for poignant experiences of silence often lie outside of the dominant programmatic scope of these retreats, as displayed in the case of the archaeological Commemorative Space in Das Kunstmuseum and the Holocaust Void in the Jewish Museum.

A prominent realisation throughout this chapter was that silence is prevalent in nature. I suggest that through the disclosed personal accounts with nature it has been demonstrated as significant an element in attaining a state of Stille as places of worship are for religious people. Although institutions such as pocket parks are designed to create an oasis of silence in the city they often fall short of this desire. This could be remedied by implementing architectural strategies similar to built urban retreats, and therefore adapting the park to its cityscape location more thoroughly. Due to the public nature of a pocket park this could result in silence being accessed more readily. Through establishing a landscape architecture of retreat and internal reflection, the pocket park has the opportunity to become enriched with Stille and an effective secular retreat for the urban city dweller. Further investigations into places of retreat that highlight dominant aspects of silence are explored in the next chapter. 

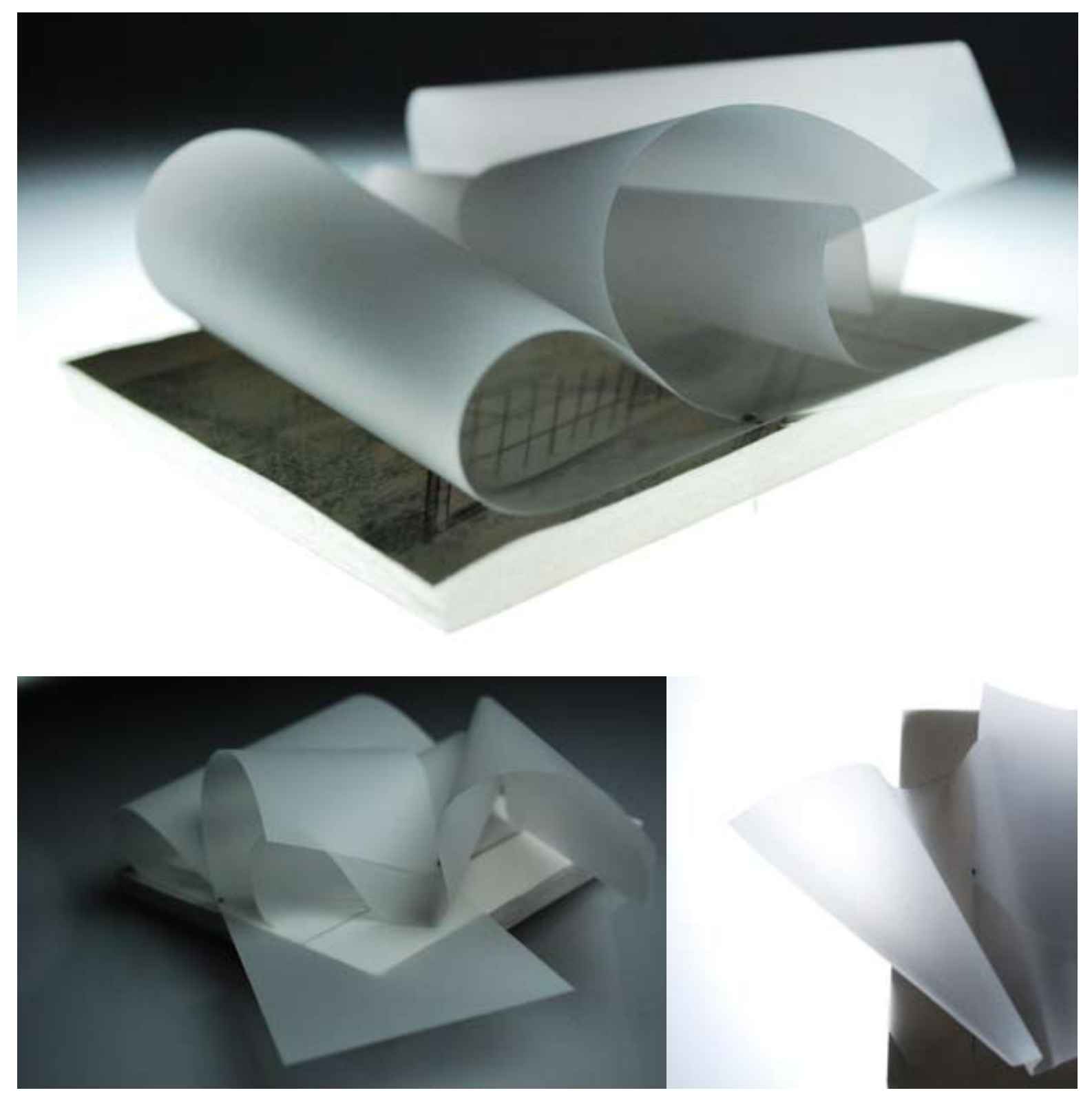

Figure 5.9- Maquette 9:

Enclosure and Nature 

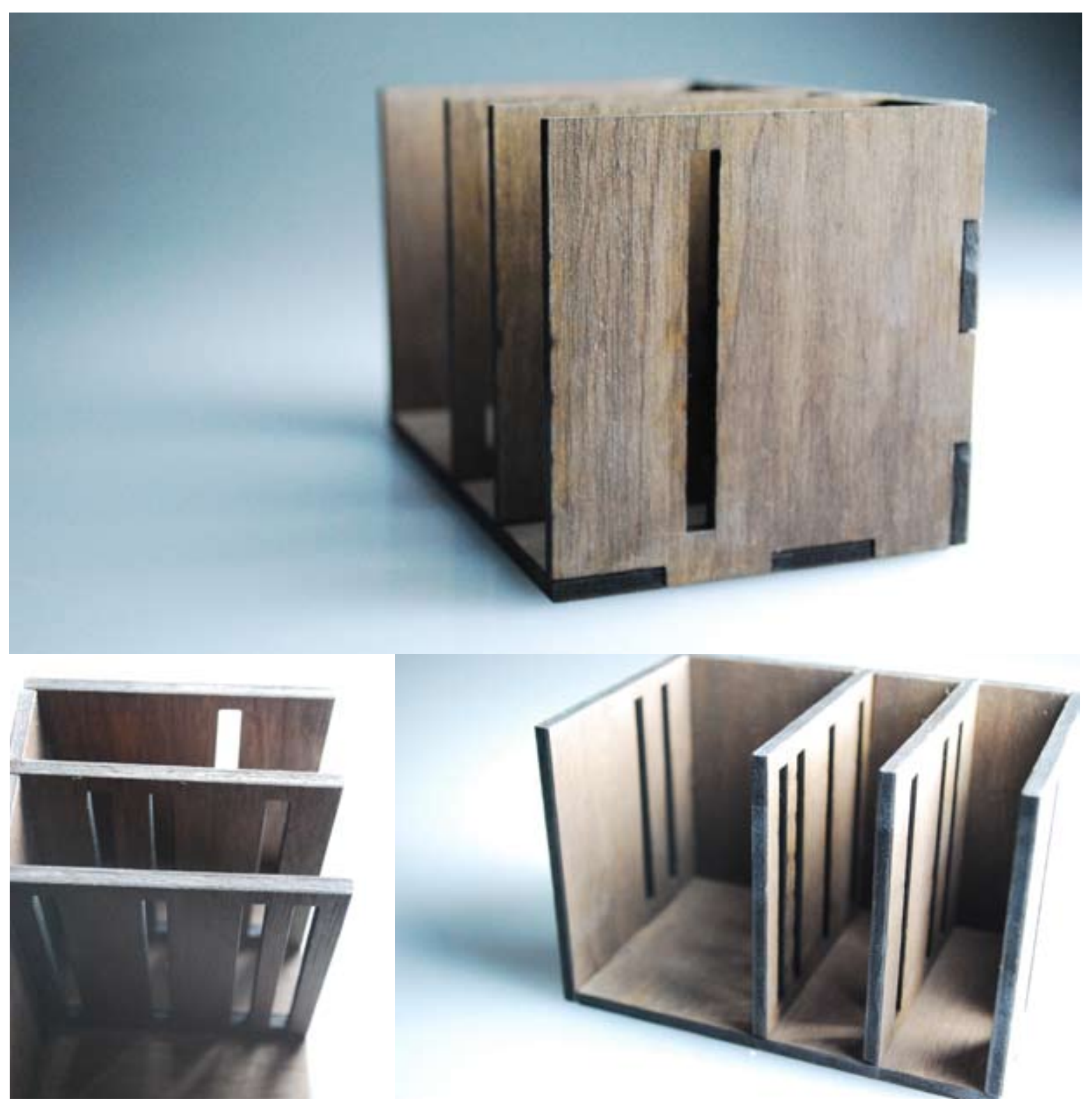

Figure 5.10-Maquette 10:

Wabi-Sabi and Nature 


\section{Chapter 6 - Case Studies and Silence}

\section{Introduction}

In this chapter there are three pertinent case studies highlighted due to their unique and provocative design in relation to Stille and subsequently their use as collective places of retreat. These case studies are the Church of the Light, Bibliothéque Nationale de France, and the Woodland Cemetery. In the example of the Church of the Light, a religious building is discussed in relation to the ways it treats religious silence and responds to its setting through a process of removal. Following, the Bibliothéque Nationale de France examines integration of nature with a public building. In this example it is the silence instilled through the articulation of the nature that creates a contemplative atmosphere rather than the programme of the building itself. Lastly the Woodland Cemetery is discussed as a landscape for contemplation and silence. This case study is unique as it is the only one that resides outside of a city setting, yet its articulation of nature is tightly controlled to create a ritualistic landscape. Through progressing from a completely internalised building to a landscape, these case studies highlight the significance of silence experienced through ritual and nature for the religious and secular alike.

\section{Tadao Ando: The Church of the Light}

1989 Osaka, Japan

\section{Nature}

"This profound identity of silence has a unique charm, stimulating our senses through the choice of natural materials. Andos dedication to closeness to nature is truly exceptional. To the passer-by, his buildings are never monumental or ostentatious. This work is all about refining and perpetuating an "architecture of silence. ${ }^{3145}$

Werner Baser

In the Church of the Light Tadao Ando uses a minimal and basic palette of materials: concrete, glass, wood and steel. These materials are expressed truthfully, each representing inherent qualities 145 - Werner Blaser, Tadao Ando: Architektur der Stille: Architecture of Silence, trans. Elizabeth Schwaiger (Basel: Birkhäuser Publishers for Architecture, 2001) 13 
without masking. Material simplicity echoes the simplicity of the building, which is constructed around a rectangle box with an angled (15-degree) intersecting wall (Figure 6.1). The stripping of unnecessary elements reflects Protestant beliefs in visual minimalism to further honour God. In conjunction it portrays ideas about visually symbolic silence. By removing unnecessary adornment the church becomes one of visual as well as mental retreat.

This truthfulness of materiality and form makes the church appear closer to nature. Closeness to nature is a phenomenon that Ando celebrates in many of his buildings. He once said:

"I want to give nature's power a presence in contemporary society and provide thereby the kind of stimulating places that speak directly to man's every sense as a living, corporal being. "146

By stimulating a connection with nature, Ando's buildings display notions of Stille. This is especially witnessed with the Church of the Light. Deep silence resonates throughout the church. With a glimpse of trees through the focal point of the space, the $0.2 \mathrm{~m}$ wide crucifix aperture, the connection to nature and silence is subtly enforced (Figure 6.2). Being the dominant source of light, the cross once again reconnects the individual with nature through its ephemeral spatial lighting. The overall impact is simple and yet powerful.

\section{Religion}

The church of the light demonstrates notions of cross-cultural silence both visually and intuitively through a Japanese Buddhist architect designing a Protestant church. The simplicity of the church, which clearly references ideas relating to Zen such as ma (emptiness), contrasts strongly against the incorporation of the Christian crucifix. Architectural author Philip Drew calls this "the sign of the West against the non-sign of the East." ${ }^{147}$ Although contrasting, there remains a harmony between the two elements. Through the simplicity of the Buddhist inspired 'nothingness' the decoration of the western symbolic cross is more apparent and therefore more powerful. By reconnecting the concrete box with the outside world the cross articulates the silence and avoids it becoming overwhelming.

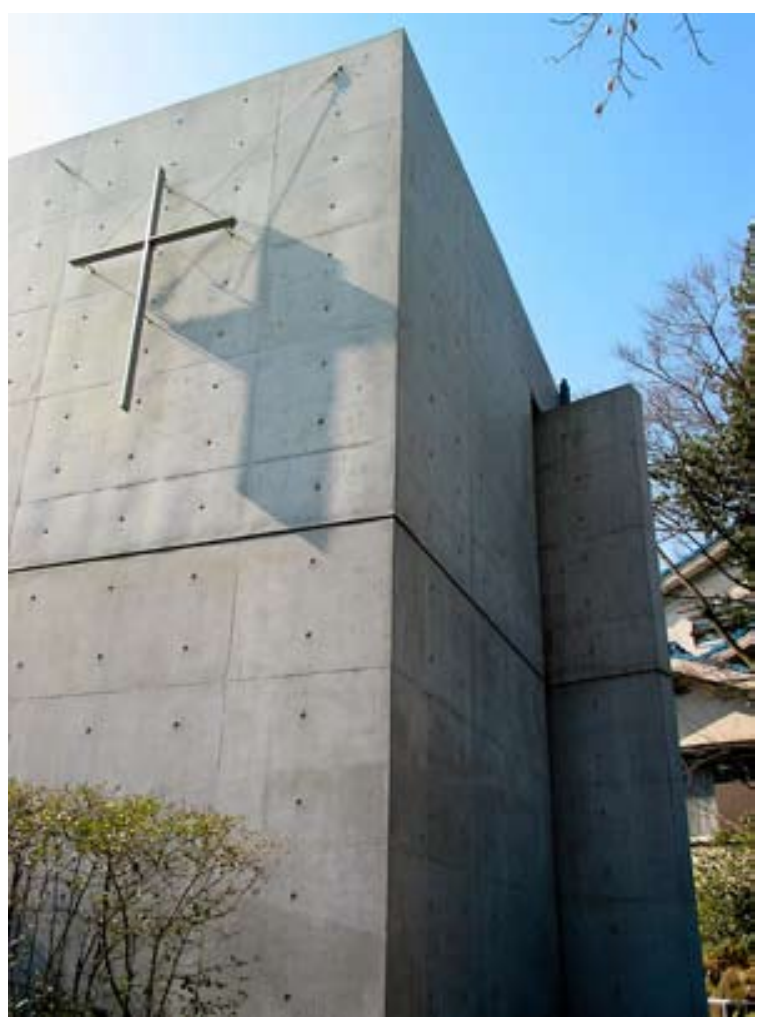

Figure 6.1 - Exterior Mass of the Church of the Light

by Liao Yusheng

Source: Liao Yusheng, "Church of the Light (1989) - Tadao Ando," February 2002, Figure/Ground, 1 July $2010<$ http:// figure-ground.com/church_light/>. 


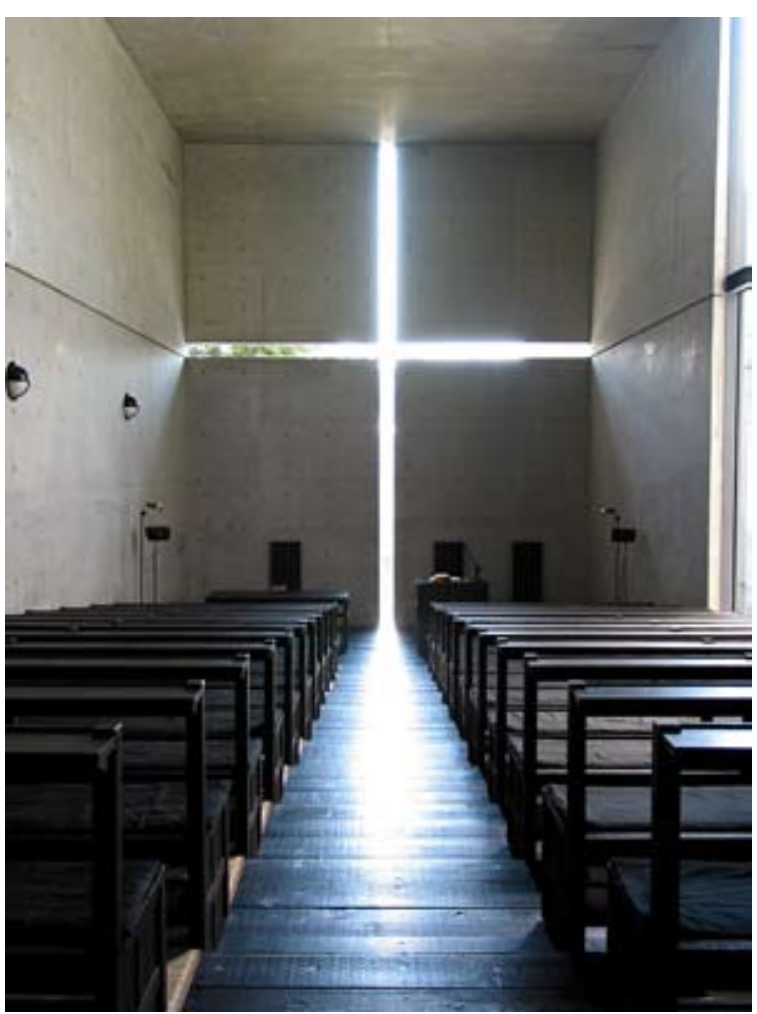

Figure 6.2 - Interior Light

by Liao Yusheng

Source: Liao Yusheng, "Church of the Light (1989) - Tadao Ando," February 2002, Figure/Ground, 1 July $2010<$ http:// figure-ground.com/church_light/>.
The use of human scale is another technique that references Buddhist ideals instead of the verticality found in Christianity. This is displayed within the concrete panels used throughout the building (and in most of Ando's work) measuring $1.8 \mathrm{~m} \times 0.9 \mathrm{~m}$. This is roughly the height of a person. By being a recognisable scale they break up the space and put people in personal connection with the heavy material.

Within Zen and Zen art (wabi-sabi) the function of beauty is to spark a connection with nothingness, and in doing so become relieved from the materialism of the world to be in closer connection with 'God'. Within this belief emptiness equals zero, and zero equals infinity. The idea of infinity is expressed in the church of light through the symmetrical central cross disappearing into the distance visually as we look through it into the light. By drawing our gaze into the undefined infinity of light the church evokes a stillness of mind. This is referred to by Drew as the moment of 'nothing' becoming 'everything.' ${ }^{148}$

\section{The Significance of the Wall}

"Today, the architect's major task is building walls that cut the interior off entirely from the exterior. In this process, the ambiguity of the wall, which is simultaneously interior and exterior, is of great significance." "149

Tadao Ando

Ando is well documented as re-establishing the use of the wall in society. His belief that buildings should be internalised sanctuaries is akin to his desire to create a moment silence within architecture. In the Church of the Light the main shell walls are $0.38 \mathrm{~m} .{ }^{150}$ This is a re-occurring theme throughout his architecture. By excluding the urban setting he believes we can redefine our sense of place and connection to nature. Through building large walls that eliminate the cityscape humans can re-connect themselves with the last remaining piece of nature within a city, that of

148 - Philip Drew, Church on the Water, Church of the Light (London: Phaidon Press Limited, 1996) 8.

149- qtd. in. Marc Treib, "Silence may be the most Significant Gift an Architect can give a Noisy Society," Metropolis 10.6 (1991): 58 .

150 - Philip Drew, Church on the Water, Church of the Light (London: Phaidon Press Limited, 1996) 11 
the sky. By incorporating the fluctuations in natural daylight, wind, and rain, we are reminded of the natural order that we are a part of. ${ }^{151}$

In the Church of the Light the delineation between the sacred/silent and profane/noise is important with the location of a prominent road so close. Being separated physically by the dense concrete walls, the difficult entrance serves to further separate inside from outside. This ritualistic entrance is achieved by making the visitor twist to access the opening in the rectangle volume just prior to the second threshold within the angled wall (Figure 6.3). By having two clearly defined thresholds the silence on the interior is effectively protected from the noise and profanity of exterior both physically and symbolically.

Through clearly defining inside and outside, Ando creates 'pure space' within his buildings. ${ }^{152}$ This pure space references the silence of 'true art' by remaining uncontaminated by the exterior. By rendering the space spiritual and peaceful he avoids a feeling of containment and desolation. Through careful articulation and attention to details I suggest that the Church of the Light successfully emulates an architecture of silence.

151 - Marc Treib, "Silence may be the most Significant Gift an Architect can give a Noisy Society," Metropolis 10.6 (1991): 58-59.

152 - Werner Blaser, Tadao Ando: Architektur der Stille: Architecture of Silence, trans. Elizabeth Schwaiger (Basel: Birkhäuser Publishers for Architecture, 2001)17.

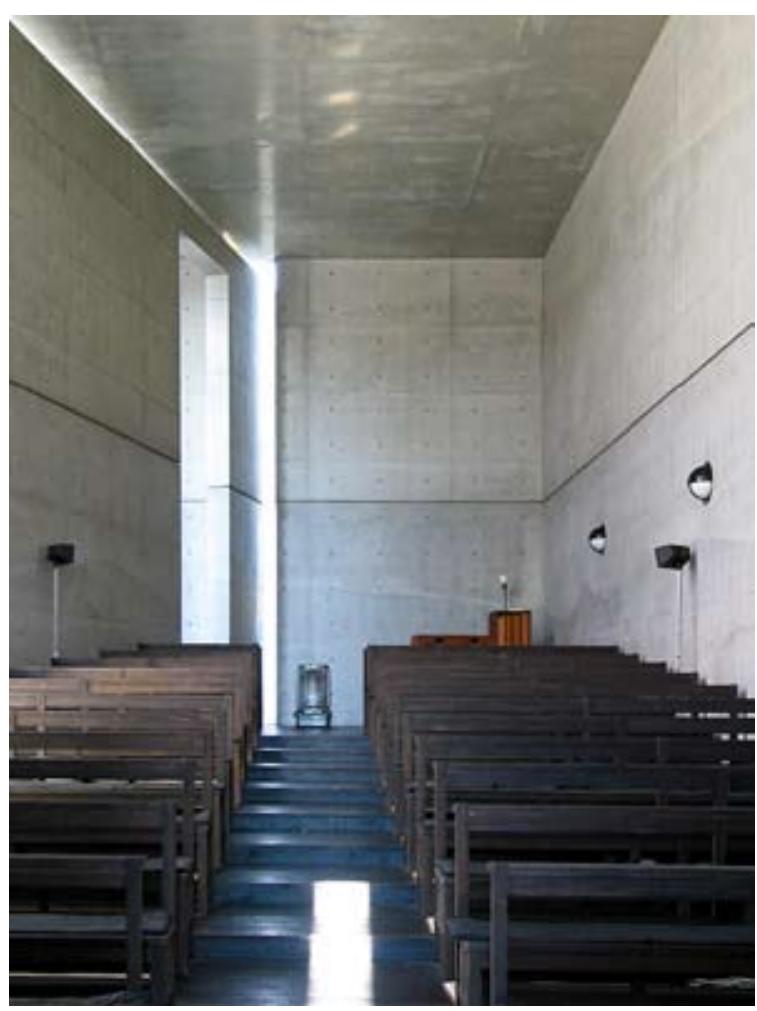

Figure 6.3 - Entrance to Main Volume by Liao Yusheng

Source: Liao Yusheng, "Church of the Light (1989) - Tadao Ando," February 2002, Figure/Ground, 1 July $2010<$ http:// figure-ground.com/church_light/>. 


\section{Dominique Perrault: Bibliothéque Nationale de France (National Library of France) 1989-1995 Paris, France}

\section{Architecture and Contextual Response}

"A square for Paris, a Library for France." 153

Dominique Perrault

Another building which references silence in a contrasting way to the Church of the Light is the secular project of Bibliothéque Nationale de France. The bibliothéque was a relocation project for the original National Library of France. The selected site was a large piece of land in an industrial waste area on the bank of the Seine River, East end of Paris. The aim of the project was to create open space within Paris, a respite from the close quarters of the city general and a moment of urban silence. ${ }^{154}$ To achieve this sense of emptiness and space, sheer volume was utilised. The Library had to be designed to house twenty million books on 4 kilometres of shelving. ${ }^{155}$ With the addition of an inaccessible courtyard garden of approximately $205 \mathrm{~m}$ by $50 \mathrm{~m},{ }^{156}$ the overall result is an immensity that is part architectural and part urban space. ${ }^{157}$

Although immense, the building remains visually quiet through the use of "simple bodies in geometrical terms" ("Corps simples en terme de géométrie"). ${ }^{158}$ This is displayed in a basic rectangle building with its centre removed to house the courtyard garden. Four 'corner' towers continue the Library and delineate the space from a distance (Figure 6.4). Aside from the towers the

153- Dominique Perrault, Bibliotheque nationale de France, 1989-1995, ed. Michel Jaques and Gaëlle Lauriot (Artemis, 1995) 74.

154- Dominique Perrault, Bibliotheque nationale de France, 1989-1995, ed. Michel Jaques and Gaëlle Lauriot (Artemis, 1995) 74.

155- Dominique Perrault, Dominique Perrault, Projects and Architecture: with an essay by Laurent Stalder, trans. Christopher Evans (Milano: Electa Architecture, c2002) 36.

156 - Rebecca Krinke, "Contemplative Landscapes, Restorative Landscapes," Contemporary Landscapes of Contemplation, ed. Rebecca Krinke (New York: Routledge, 2005) 115.

157- Laurent Stalder, "Architecture, Projection of the Mind and Projection of the Body", Dominique Perrault, Dominique Perrault, Projects and Architecture, trans. Christopher Evans (Milano: Electa Architecture, c2002) 36.

158 - Laurent Stalder, "Architecture, Projection of the Mind and Projection of the Body," Dominique Perrault, Dominique Perrault, Projects and Architecture, trans. Christopher Evans (Milano: Electa Architecture, c2002) 14. 
building is horizontally aligned with long steps surrounding three sides, leading the public up towards the main entrance and an urban square with a view down to the wild park contained by the library walls.

Material simplicity echoes geometry simplicity. The dominating entrance steps are wooden, a contrasting and calming material to use in the industrial setting (Figure 6.6). The use of wood is a prelude to the mature forest courtyard, which is even more pronounced in its contrast to the setting than the steps. Other materials used include steel, concrete and glass, with a double skin of glass on the towers to allow views outwards while shielding and diffracting direct light. ${ }^{159}$

An interesting aspect to the project is how Perrault considered the opportunity of creating a Library consistent with creating an urban square. He felt that by incorporating the two he could encourage further architectural development in that quarter of Paris. In addition, Perrault believed that by linking the two programs the Library would become of national importance, on par with Champ de Mars or Place de la Concorde. ${ }^{160}$ This objective is an urban response to the issue of connectivity addressed in Chapters 2 and 3. By creating a place for people to come together in like-minded silence (that of reading) and creating space for wider social interaction, Perrault is architecturally uniting Parisian society for that moment in time. However, it is noted that the mode of contemplative silence is created through the containment of the wild forest rather than the library itself. I suggest that the library in this example has become secondary to the role of the forest and the square, a situational strategy for exposing the community to the silence experienced through nature.

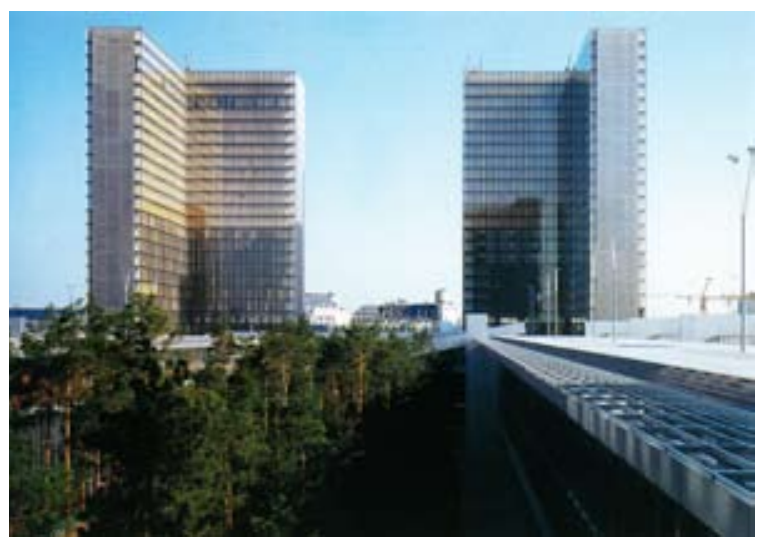

Figure 6.4-Bibliothéque Nationale de France Source: Dominique Perrault, Bibliotheque nationale de France. 1989-1995, ed. Michel Jaques and Gaëlle Lauriot (Artemis 1995) 155. 


\section{Contemplation}

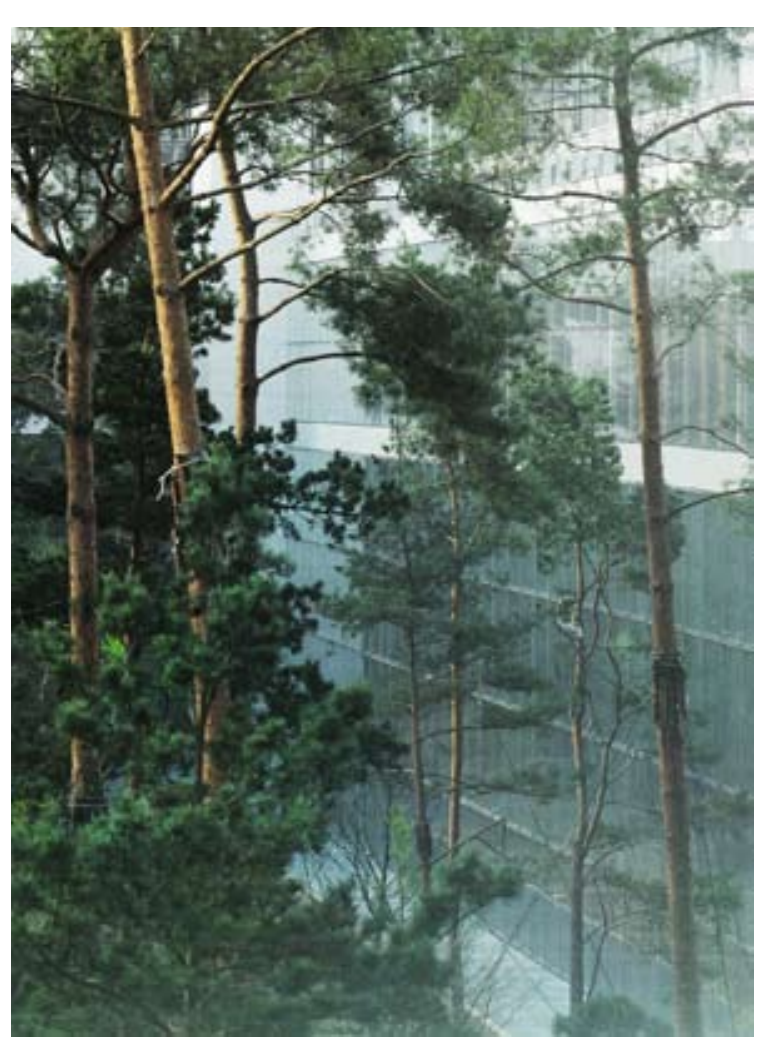

Figure 6.5 - Mature Pines

Source: Dominique Perrault, Bibliotheque nationale de France, 1989-1995, ed. Michel Jaques and Gaëlle Lauriot (Artemis, 1995) 157
"The inclusion of an 'inlaid', sunken garden rounds off the symbolic siting of the project, offering a quiet spot away from the fuss and bother of the city. Like a cloister, this tranquil unruffled space will invite contemplation and a flowering of intellectual endeavor." 161

Dominique Perrault

The sunken garden of mature pines at the Bibliothéque de France were sourced and relocated from a forest at Forêt de Bord. Perrault was specific in his desire to have grown trees that were rough and natural looking as opposed to ones sourced from a nursery and pruned. ${ }^{162}$ Through this desire Perrault was displaying a design sensibility of wabi-sabi. To further similarities with Japanese culture the garden acts as a stimulus for contemplation that one can only visually inhabit, in effect working as Zen Buddhist gardens do (such as Ryōanji). The unstructured layout and growth of the trees stimulates the mind, aiding in meditation and inner silence. Instead of being Zen inspired, Perrault refers to the courtyard as like a medieval cloister garden. Similar characteristics include converting the traditional covered circulating walkway to internal glass corridors inside the Library, a modern appropriation of a religious method of walking to obtain silence. ${ }^{163}$ While the references to a cloister are apparent, I suggest that the layout of the garden is too unstructured to expressively reflect a cloister garden. One familiar with Zen principles cannot help but see those underlying connections in the design and notice how it strengthens the overall quality of the space (Figure 6.5).

To emphasise a contemplative state, ritual is heavily used to effectively separate the urban context from the library, or as Perrault calls it, "away from hubbub towards hush". ${ }^{164}$ The steps leading towards the library entrance are particularly steep and as previously mentioned, visually separate from the context due to their materiality (Figure 6.6). Nearing the top of the staircase you gain

161 - Dominique Perrault, Bibliotheque nationale de France, 1989-1995, ed. Michel Jaques and Gaëlle Lauriot (Artemis, 1995) 75.

162 - Rebecca Krinke, "Contemplative Landscapes, Restorative Landscapes," Contemporary Landscapes of Contemplation, ed. Rebecca Krinke (New York: Routledge, 2005) 120.

163 - Rebecca Krinke, "Contemplative Landscapes, Restorative Landscapes," Contemporary Landscapes of Contemplation, ed. Rebecca Krinke (New York: Routledge, 2005) 112

164- Dominique Perrault, Bibliotheque nationale de France, 1989-1995, ed. Michel Jaques and Gaëlle Lauriot (Artemis, 1995) 76. 
glimpses of treetops, an intriguing and bemusing element at first glance. In order to access the Bibliothéque you must walk towards the courtyard and descend through elevators at the gardens perimeter, another surprising element after having laboured up the staircase. Once inside and the obligatory metal detector and bag searches have been completed, you find yourself in the general library area. Connecting this space are corridors fully exposed to the view of the garden, with couches placed in designated nooks along the way for reflection. The final stage of removal is within the reading rooms, which are located off the corridors. These rooms are completely internalised and designed for individual reflection; one must return to the corridor to reconnect with the forest. In these spaces it is the books themselves that instil silence; there is no other visual trigger. ${ }^{165}$ Therefore the process of removal in the Bibliothéque Nationale de France is pivotal in experiencing individual and collective silence.

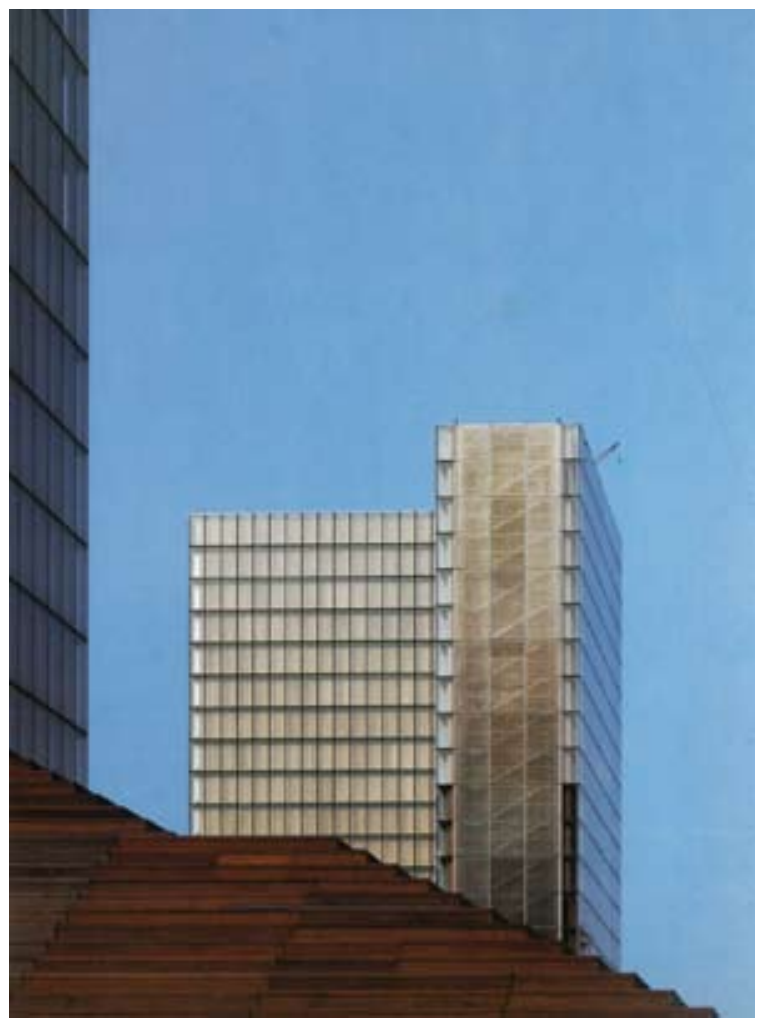

Figure 6.6 - Entrance Steps

Source: Dominique Perrault, Bibliotheque nationale de France 1989-1995, ed. Michel Jaques and Gaëlle Lauriot (Artemis, 1995) 147. 


\section{Gunnar Asplund and Sigurd Lewerentz: Woodland Cemetery \\ 1915-1940, Stockholm, Sweden}

\section{Landscaping}

The Woodland Cemetery is a beautifully poignant landscape located in Stockholm. Similar to the Bibliothéque Nationale de France it utilises nature and specifically wild trees in aiding collective and individual silence. Incorporating both architecture through numerous chapels and carefully articulated landscaping, the space holds spiritual importance. In this analysis of the Woodland Cemetery I will focus on the landscape and how it has been manipulated to create a sense of Stille. This is because of my belief that the most powerful moments of silence are contained within the articulation of nature at Woodland Cemetery rather than in the buildings.

The landscape design in this scheme was pivotal in Asplund and Lewerentz winning the design competition. Asplund in particular had made it his life work to "revitalize the landscape," 166 something that is clearly displayed in the Woodland Cemetery's aesthetic. Overall the design displays secular notions through burial being located amongst nature instead of connected to the church. Echoing the secular notion of separation is the layout, which has a naturalistic asymmetry. In this example the scheme works on two scales. On a large scale it is asymmetrical, but in contrast each element's individual articulation is strictly symmetrical. The symmetry re-aligns the design with a religious context, adding complexity. Despite this complexity through symmetry, the actual intervention into the nature at Woodland Cemetery is minimal. The sparse design is provocative and inspires a connection to nature, silence and death. Through this discussion the ways which death has been handled will not be elaborated on, due to the confines of this thesis. However they are acknowledged as imparting a sombre silence upon the site.

\section{Ritual}

The first space you encounter as a pedestrian is the Central Clearing (Figure 6.7). Approaching the cemetery from north you pass through the entry threshold and are aligned to the Way of the Cross. This is marked by a low wall, a path of rough flagstones set into the grass and symbolic granite cross in the distance. As you walk forward you begin to notice the vastness of the space 166 - Stuart Wrede, "The Work of Erik Gunnar Asplund," Perspecta 20 (1983): 196. 
you currently reside. In the distance to the West are steps up to Meditation Grove, its weeping elms juxtaposed against the sky and dissecting the infinite space. ${ }^{167}$ The lack of vegetation gives it a strictly controlled demeanour emphasized by the foliage evident being treated as geometrical, architectural forms. ${ }^{168}$ The overall intention of the space is to act as a place of orientation to begin the ritualistic process of experiencing the notion of death in different forms. As you progress 'inner silence' is obtained, rendering an appropriate reflective mood for the subsequent journey. Referred to as a "haven of silence", ${ }^{169}$ this central area is key in evoking the richness of the subsequent spaces through its long procession.

The Way of the Cross is the pathway towards the Columbarium, Cremation Chapels and Monument Hall; the dominant built interventions within the site. The cross works well as a symbolic landmark to an important path for people attending a funeral service. On the surface it portrays Christian ideals. However, after further inspection it can also be abstracted to signify a connection between the earth and sky, with its main body physically connecting the two while its large arms stretch East towards the earthbound crematorium and West to the sky focussed Meditation Grove (Figure 6.8).${ }^{170} \mathrm{~A}$ contrast to the central vastness, the area the Way of the Cross leads to is narrow and intimate. To heighten this experience, from the Columbarium you can glimpse the vastness of the Central Clearing over the low wall separating the two, putting the intimate setting into a wider context.

A space with particular importance relating to silence is Meditation Grove (Figure 6.9). Located in the centre of the clearing it is at the top of a gently rising knoll. Ritual is a key component in Meditation Grove's design. The access steps are unique as they respond to the person travelling towards the grove. They do this by extending in depth and decreasing in height as you move up them, supporting the weary walker as they ascend towards their goal. ${ }^{171}$ The grove itself consists

167- Caroline Constant, The Woodland Cemetery; Towards a Spiritual Landscape (Stockholm: Byggforlaget, 1994) 8. 168 - Heinrich Hermann, "On the Transcendent in Landscapes of Contemplation," Contemporary Landscapes of Contemplation, ed. Rebecca Krinke (New York: Routledge, 2005) 62.

169- Heinrich Hermann, "On the Transcendent in Landscapes of Contemplation," Contemporary Landscapes of Contemplation, ed. Rebecca Krinke (New York: Routledge, 2005) 59.

170 - Heinrich Hermann, "On the Transcendent in Landscapes of Contemplation," Contemporary Landscapes of Contemplation, ed. Rebecca Krinke (New York: Routledge, 2005) 53.

171 - Heinrich Hermann, "On the Transcendent in Landscapes of Contemplation," Contemporary Landscapes of Contemplation, ed. Rebecca Krinke (New York: Routledge, 2005) 55.

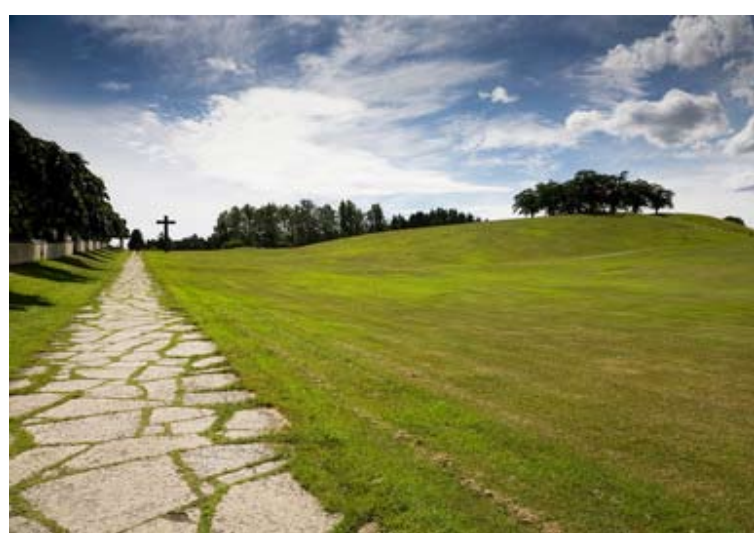

Figure 6.7- Entrance Path to the Woodland Cemetery

by Peter Guthrie

Source: Peter Guthrie, "Skogskyrkogarden Woodland Crematorium," Gardenvisit.com: The Garden and Landscape Guide, 10 November 2010, <http://www.gardenvisit.com/ garden/skogskyrkogarden_woodland_crematorium>.

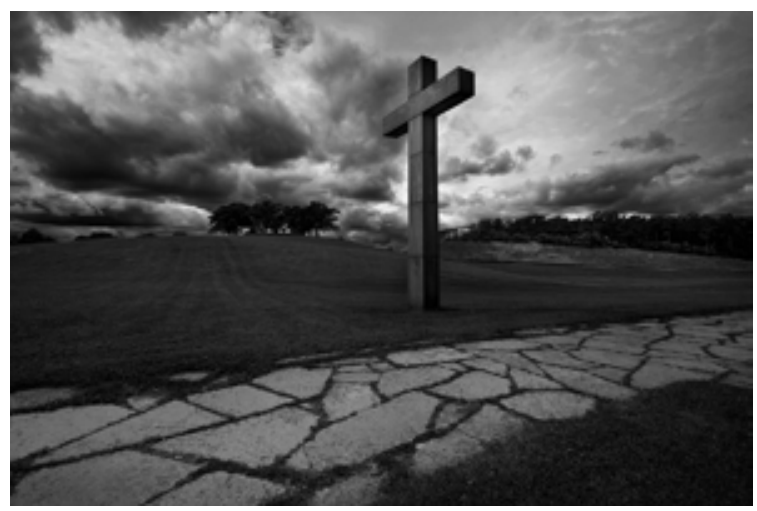

Figure 6.8 - The Cross and Meditation Grove

by Calle Hoglund

Source: Calle Hoglund, "Skogskyrkogården," 6 July 2009, Flickr, 8 November 2010, <http://www.flickr.com/photos/ hocal/3694044849/sizes/o/in/photostream/> 


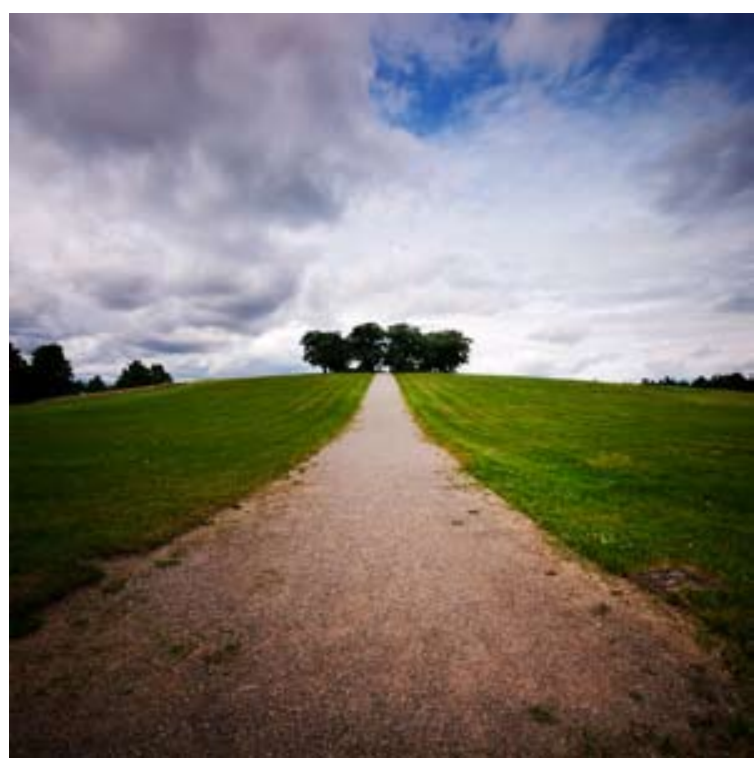

Figure 6.9- Meditation Grove

by Calle Hoglund

Source: Calle Hoglund, "Skogskyrkogården II" 6 July 2009, Flickr, 8 November 2010, <http://www.flickr.com/photos/ hocal/3694596521/>.

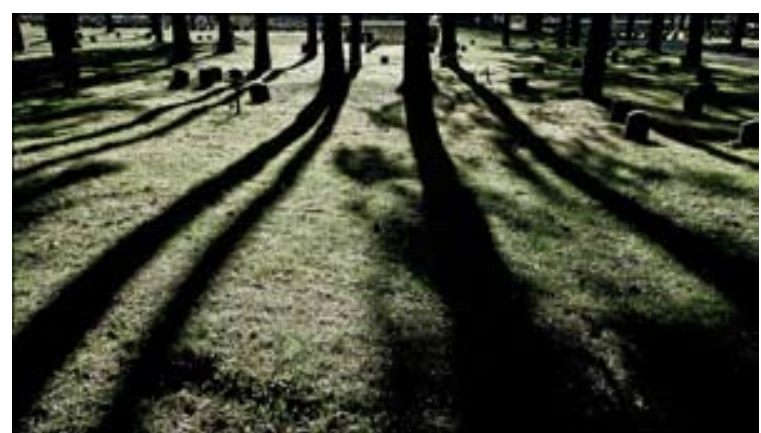

Figure 6.10 - Forest Graveyard

by Stefan $\mathrm{H}$.

Source: Stefan H., "L1080021," 18 September 2010 Flickr, 5 November 2010, <http://www.flickr.com/photos/ pareder/5001386778/sizes/o/in/pool-46411833@N00/>. of a square waist high ashlar wall with a north and south opening. Surrounding this walled space is another square formed by 12 weeping elms. This concentric square pattern continues into the space, as the steps merge into a gravel floor with wooden benches faced inward at intervals. This then surrounds a square patch of lawn that has a contemplative pond at its centre. Not quite open and yet designed for more than one person, this space feels intimate by contrast with its setting. Being removed from the cemetery itself "it turns one's mind inward to silence, and up towards the sky." ${ }^{772}$ This is similar to Tadao Ando's belief in stimulating a connection to the sky through the use of courtyards. The sky is one of the pure elements left in our world and opening out to it can inspire reflection within a silent moment. ${ }^{173}$ In this space there is nothing to do other than meditate/contemplate as you gaze upon the wild beauty of the weeping elm trees adjacent to the tightly controlled spatial layout. Through rigorous control a sense of calm is obtained; through the incorporation of the rough aesthetic of nature Stille is obtained.

Following to the South of Meditation Grove is the Way of the Seven Wells. This space is the first place that feels like you are in a 'natural' setting. Weeping birches form an enclosing forest, the complete opposite to the clearing adjacent. A narrow path cuts the space in a straight line, propelling you forward. As the birches give way to mature pines, tombs begin to appear amongst the nature. This is a place for friends and family to visit their loved ones. To visit a tomb you must break from the path and walk across the lawn (Figure 6.10). The path pulls you into the earth and releases you at the Chapel of Resurrection. ${ }^{174}$ This place feels intimate through its density and the unsystematic layout. One can contemplate nature and death in such a setting, instilling a sense of silence as you move while linked closely to both phenomenon.

Nature at Stockholm's Woodland Cemetery inspires a sense of silence in varying degrees. By contrasting containment with vastness, strongly articulated with wild and natural, a dialogue of architectural moments exists. I suggest the success of this landscape is partly due to the size of the land. Asplund and Lewerentz's design completely encases the person within the setting, becoming an all-encompassing experience. A challenge for a designer would be to create a similar

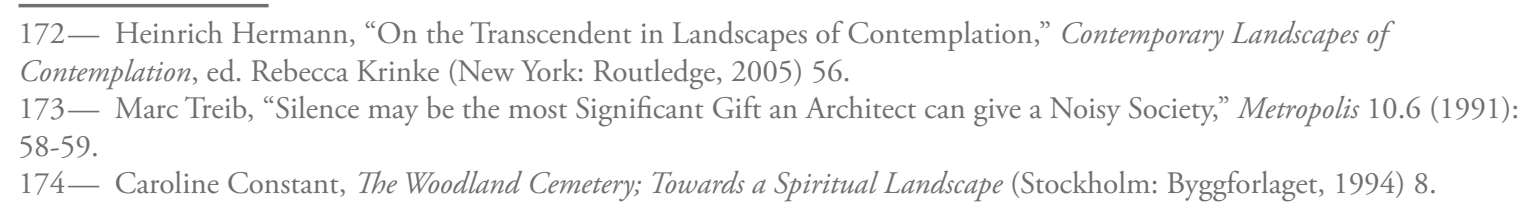


feeling within a more confined and urban space. By designing moments of enclosure versus exposure within a city 'nature' setting can there be as great a sense of Stille?

\section{Conclusion}

The above case studies have highlighted ways which silence has been manifested into an architectural form. In the example of the Church of the Light, silence has been articulated in a small-scale building, using religious (both Christian and Buddhist) incentives to enhance the experience. In addition the shoebox design inspires a connection to nature through materiality and natural daylight. In contrast, both the Bibliothéque National de France and the Woodland Cemetery have the advantage of using a greater area to create silence, meaning a wider spacing of thresholds can take place to facilitate the experience. They both successfully use landscaping to create Stille, and in doing so exhibit the importance of nature in the designs. Comparing the three demonstrates the challenge in creating a sense of removal into silence, a challenge that is easier to meet within a large space. In addition it has been demonstrated that in order to have a place of Stille within the tight confines of a city it is necessary to incorporate both nature and architecturally built elements. Nature is needed to emulate silence and built space to create thresholds so the city can be physically filtered. I propose that through a mixture of both of these elements a unique and responsive design for the urban dweller can be created, a space of nature, community and silence. The following design chapter discusses how this has been designed towards. 


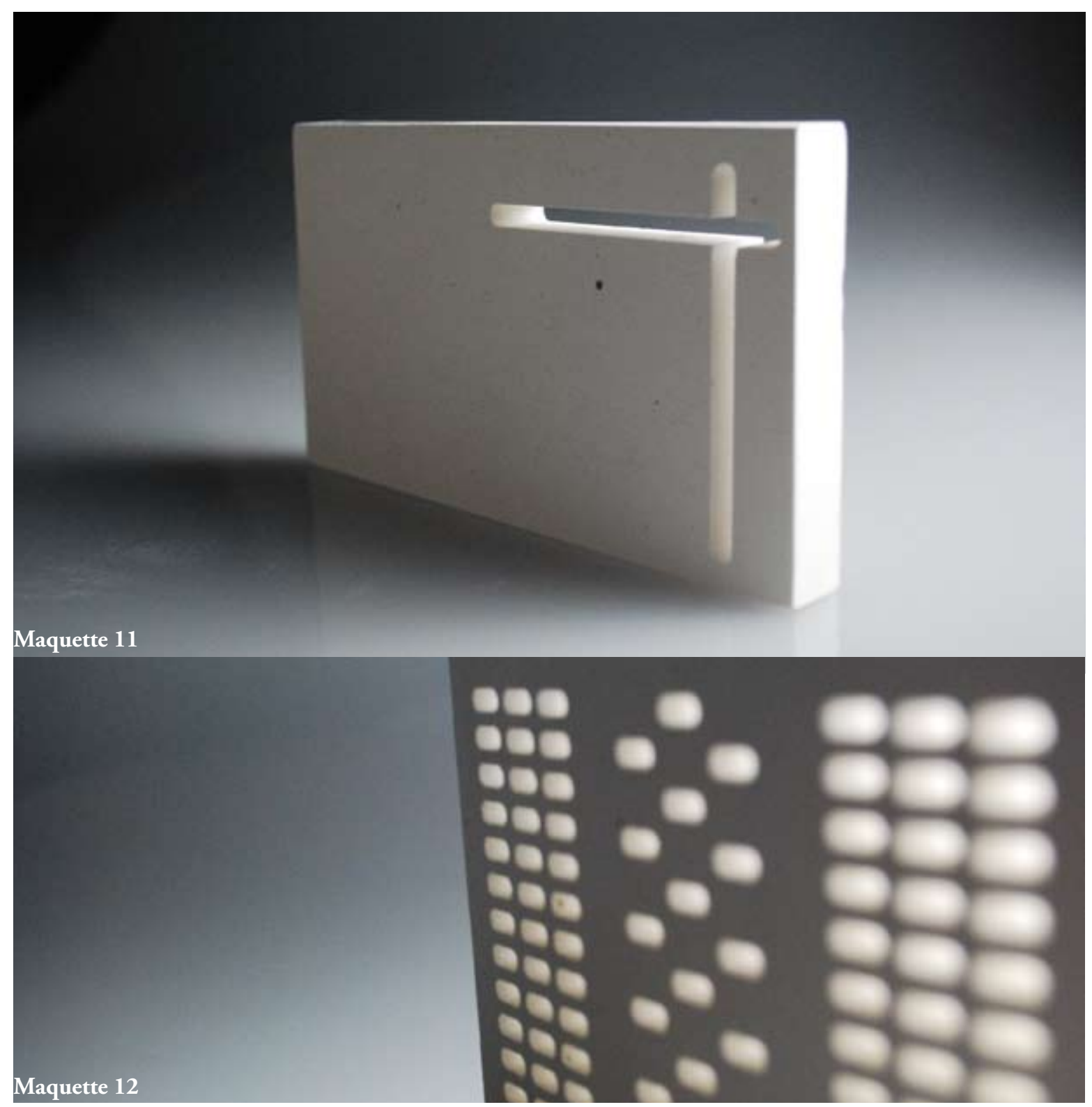

Figure 6.11 - Maquettes 11 \& 12:

Materiality and Filtering 


\section{Part D - Application}




\section{Chapter 7 - Process and Design}

\section{Introduction}

A silent urban landscape is the most challenging and provocative program for the full exploration of the ideas highlighted in this thesis. Designed as a mixture between landscape architecture and architecture, this hybrid design solution is most aptly termed a silent-scape. The silent-scape intervention contains pathways, sitting and relaxing areas, and moves underground to secluded contemplative spaces. All of these areas are placed amongst highly controlled vegetation, which is used sparingly to heighten specific moments within the program. The result, a retreat into silence through a nature inspired design.

A site in London, England has been selected to sharply contrast busy city life with the calm enclosure that the silent-scape provides. The site is the pocket park Christ Church Greyfriars and contains church ruins that reference the destruction wrought during World War II. There is intended irony in the selection of the site and the notion of Stille. As only through the destruction of the church by German bombing is the opportunity for a responsive silent retreat manifested. By designing modern spaces for silence on a historical site I am creating a secular yet spiritual retreat, and re-appropriating the traditionally religious site for its successful use today.

Through adhering to a process of maquettes I began the visualisation of this design (as demonstrated intermittently throughout this thesis). I then moved into site analysis, historical palimpsest tracing and acoustic design. In turn this design has become irrevocably site-specific and is a demonstration of how silence can be incorporated into the modern city, rather than a strict process by which to attain it.

This design demonstrates the subtle beauties found from incorporating silence into the city fabric. It addresses issues within the text such as overstimulation and connectivity, and concludes that the city has the potential to create greater moments of Stille to benefit the individual and society in general. 


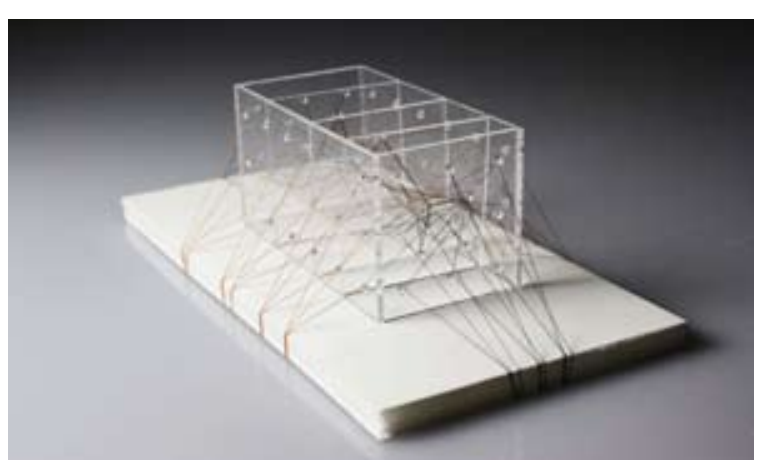

Figure 7. 1 - Maquette 1

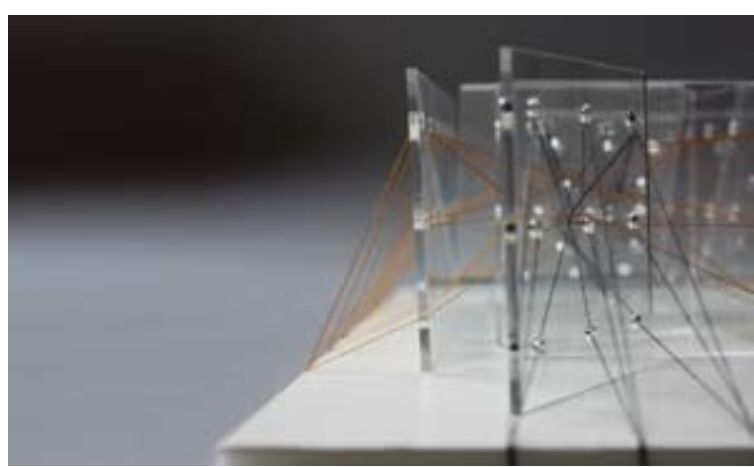

Figure 7. 2 - Maquette 2

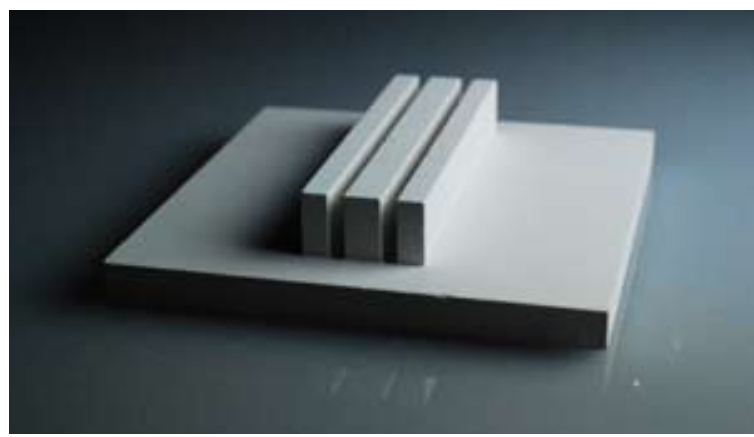

Figure 7. 3 - Maquette 3

\section{Maquettes}

To begin the designing process maquettes were produced to visually portray and critique some of the prominent ideas discussed throughout each chapter. The outcome of this investigation was an understanding of the design aesthetic, and ways to best approach aspects such as materiality, proportion, ritual, perspective, and filtering as pertaining to notions of silence. While the investigation began with maquettes, the site was soon after chosen. Therefore maquettes and site analysis were produced simultaneously in some cases, but for simplification they are presented in this thesis as a linear progression.

\section{Chapter 1 -}

\section{Maquettes 1 \& 2: The City, Stress and Overload}

Maquettes 1 and 2 explored the notion of city stress as outlined in Chapter 1. Originally designed as a rectangle box, a series of grids were used to control and manipulate the string that passes through in a semi-random manner. The grid references a city, with the clear Perspex as the infrastructure. By the same notion the string denotes movement within a city, and the beautiful chaos that this can create as the string negotiates the Perspex holes. After an analysis of this first maquette it was observed that it appeared too controlled. In its perfect rectangle form it seemed too manipulated to fully represent the atmosphere of a metropolis. Although it's a person's perceived lack of control over stimuli that is the real detriment, ${ }^{175}$ this model felt contrived and over manipulated. In an attempt to rectify a second maquette was fashioned. Designed along the same notions of the first, this time the model used the string to derive form. The string acts in tension to control the angles of the Perspex, creating an interesting relationship between that being controlled and the controller. The overall outcome is even more chaotic than the original. There is a beauty within the chaos, as many beholders to a vibrant city would assert. This thesis does not aim to detract from that vibrancy, but rather offer an alternative for those who wish to regain a sense of peace and silence.

\section{Chapter 2-}

\section{Maquette 3: Stille through Simplicity and Materiality}

This maquette was the first exploration into the concept of Stille. White with subtle imperfections due to its materiality, it embodies a beautiful honesty. By using basic proportions the eye is 175 - Andrew Baum, Jerome E Singer and Stuart Valins, Advances in Environmental Psychology: Volume 1, The Urban Environment (New Jersey: Lawrence Erlbaum Associates, 1978) 12 
drawn to the centre of the plaster form where it extends along, quietening the mind. The gaps in-between each extrusion extends down past the ground plane, enforcing the void in contrast to the solid. While not directly related to the theory outlined in this chapter, this was one of the first maquettes produced and denotes the beginning of visualising silence, in the same manner as this chapter introduced Stille as a topic for discussion.

Chapter 3 -

Maquette 4: Secularisation and Interpersonal Relationships

Secularisation and the subsequent lessening of relationships within the community is communicated in Maquette 4. Set into a grid, movement travels from collective and organised within that collectiveness to dispersed and random. This is a visualisation of society's movement throughout the past century. The weakening of religious ties has weakened interpersonal relationships. The silence experienced within the controlled conformity of religion weakens as people move away from the institution, and silence within daily life becomes a rarity.

\section{Chapter 4 -}

\section{Maquette 5: Repetition and Procession}

Maquette 5 was designed to begin the process of abstracting visual codes within religion that support an environment of silence. Less successful than subsequent designs it still speaks of important ideas, including repetition and procession (and within that the use of perspective). Similar to the way in which monks stand in a line before the altar (as they would in La Tourette, Figure 4.3), this design demonstrates a basic Christian worshipping space. These elements are further abstracted in the following maquettes. Through the process of abstraction there is the result of separating the exploration visually from a church-space into a silent-space. This is an important step towards the visualising of an appropriate aesthetic for the manifestation of secular silence in modern western society.

\section{Maquettes 6 \& 7: Ritual and Perspective}

Designed in accordance with religious silence, these two maquettes are significant within this series of explorations. Maquette 6 focuses on notions of ritual, materiality and procession. The stark object in its extruded form is intended to stimulate ideas pertaining to silence through

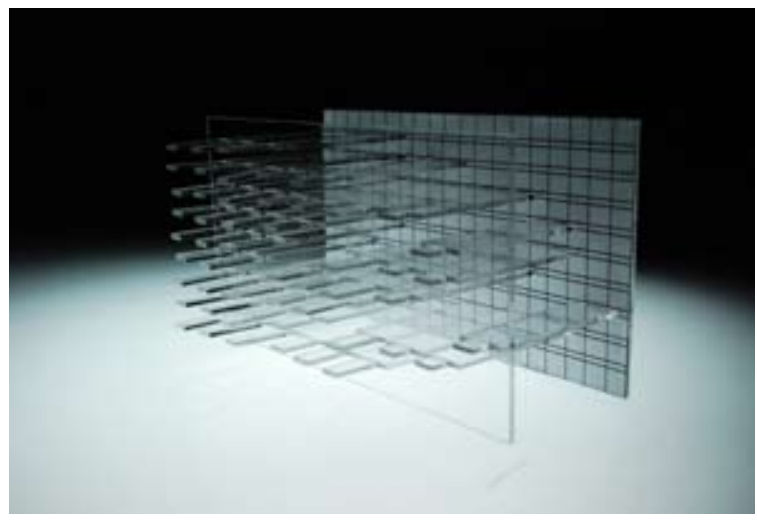

Figure 7.4- Maquette 4

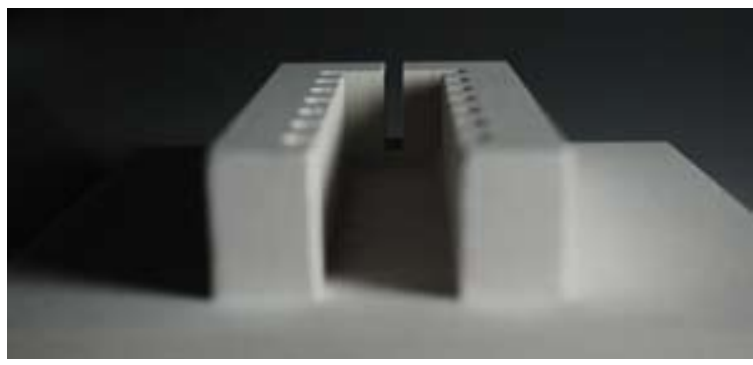

Figure 7.5 - Maquette 5

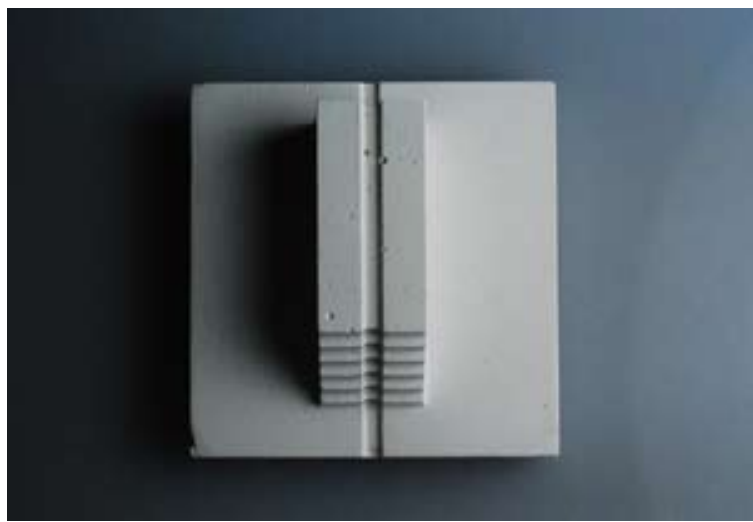

Figure 7.6 - Maquette 6 


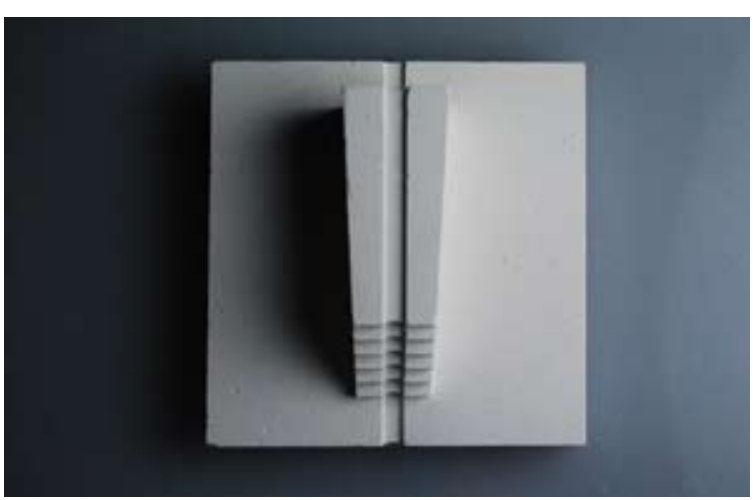

Figure 7.7-Maquette 7

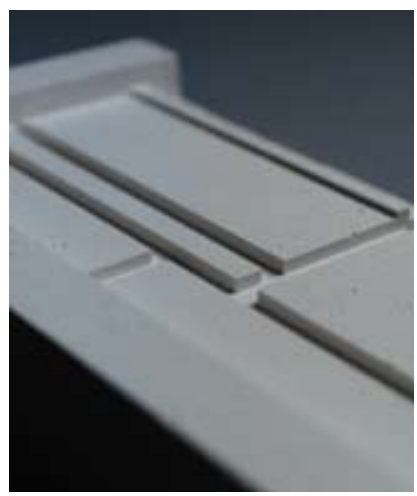

Figure 7.8 - Maquette 8

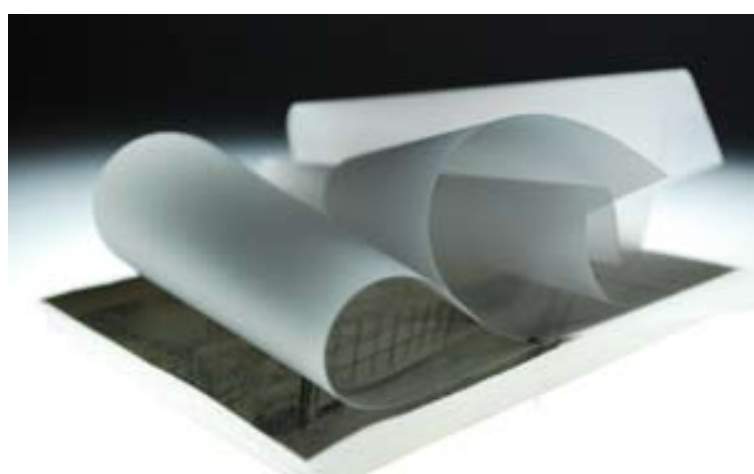

Figure 7.9 - Maquette 9 ritual. The idea of perspective and procession found within religion is enforced by the central groove that extends up the stairs, along the pathway, and disappears into the distance.

After the manifestation of this maquette, the idea of forced perspective and ritual was critiqued. Religious architecture, and thereby ritual, controls the experience of the beholder. A prime example of this is the previously disclosed hallway image in the Carthusian monastery (Figure 4.1). Therefore in a second iteration of the first maquette the pathway was altered. The form was angled inwards to enforce more stringently a sense of movement, perspective, and the religious notion of extending towards infinity. All of these elements support silence as found in religion. Through a lengthening of the mind past the immediate to the undefined infinity, these elements help create stillness internally as well as externally.

Unrelated to religion, Maquette 6 in its shoebox shape would amplify sound as a building. By angling the walls in Maquette 7 the sound is diffracted around the 'space', playing with ideas of visual versus aural noise.

\section{Maquette 8: Abstracting Ryōanji}

Designed as an abstraction of Ryōanji, this maquette employs the same proportions but in a simplified manner. To try and understand the aesthetic of Stille Ryōanji inherently holds the layout of the rocks were simplified into segments within the design, and the process of arrival and enclosure symbolised through steps and a barrier. An element, which arose from this exploration, was the notion of treating junction points of connecting planes with a shallow indent in the same material. Through recessing merging points the planes became more prominent. This is a subtle way of detailing a space, which is subsequently used in greater depth throughout the final design.

\section{Chapter 5 -}

\section{Maquette 9: Enclosure and Nature}

The most unstructured in the series of maquettes, this particular one aimed to inspire a connection to nature. Through its soft folds of semi transparent paper, the model encases each space delicately. This maquette speaks of an atmosphere of silence. Underneath the folding paper lies a detail to a window. This window is part of the ruin attached to the site at Christ Church Greyfriars. 
Through revealing and concealing moments of it I aimed to inspire complexity and layering as one would find in a forest. Further investigation proved this maquette to be successful regarding atmospheric qualities, but ultimately unsuccessful in articulating architectural elements in the final design.

\section{Maquette 10: Wabi-Sabi and Nature}

Maquette 10 was an exploration into the stillness which nature inspires through a man-made object, or the aesthetic of wabi-sabi. Wood was used with a textured grain to add subtle complexity to the simple design. The slits within the panels allow light to filter through as it would in a forest, while still creating enclosure. The detailing of the form was designed to operate without any adhesive. Through using finger joints the form stays pure. Although finger joint detailing is fitting for this particular materiality, for the final design the use of clay as the dominant material made it redundant. However, this maquette begins to discuss ideas of walls acting as filtering elements, which is explored in greater detail in the following maquettes, and even more so through the Acoustic Analysis and Wall Design.

\section{Chapter 6}

\section{Maquettes $11 \& 12$ : Materiality and Filtering}

These two models analysed materiality and voids. Filtering the external environment is extremely important in creating spaces of silence, as case studies throughout Chapter 6 have highlighted. In response apertures were manipulated to give different results. The first example with its linear and rigid void is solid and brute in its filtering. Maquette 12 by contrast is subtler. Its perforations allow for greater visibility while still creating a barrier against the external environment. This later condition is deemed the most relevant and interesting, and is explored in further detail throughout the designing process.

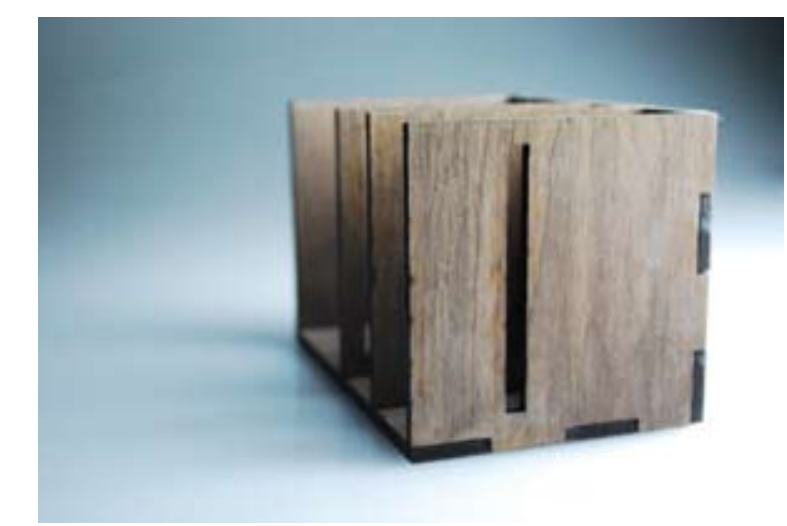

Figure 7.10- Maquette 10

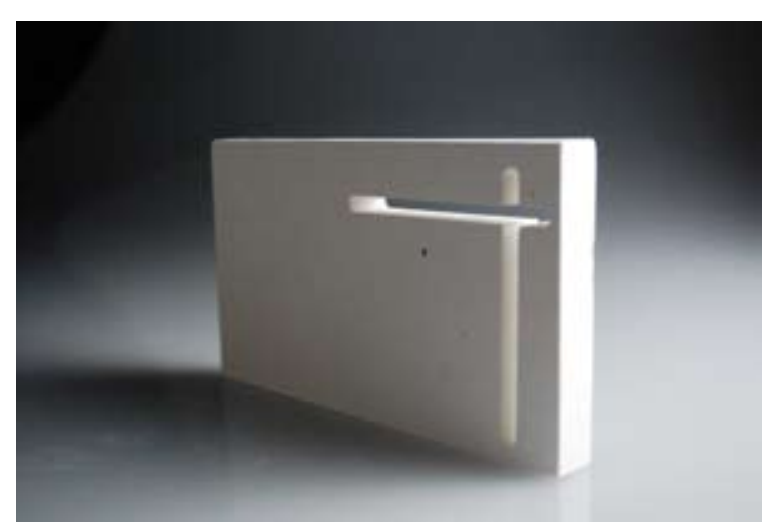

Figure 7.11 - Maquette 11

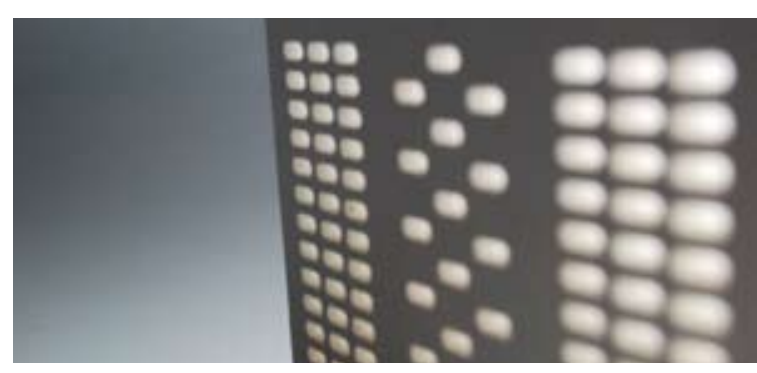

Figure 7.12 - Maquette 12 


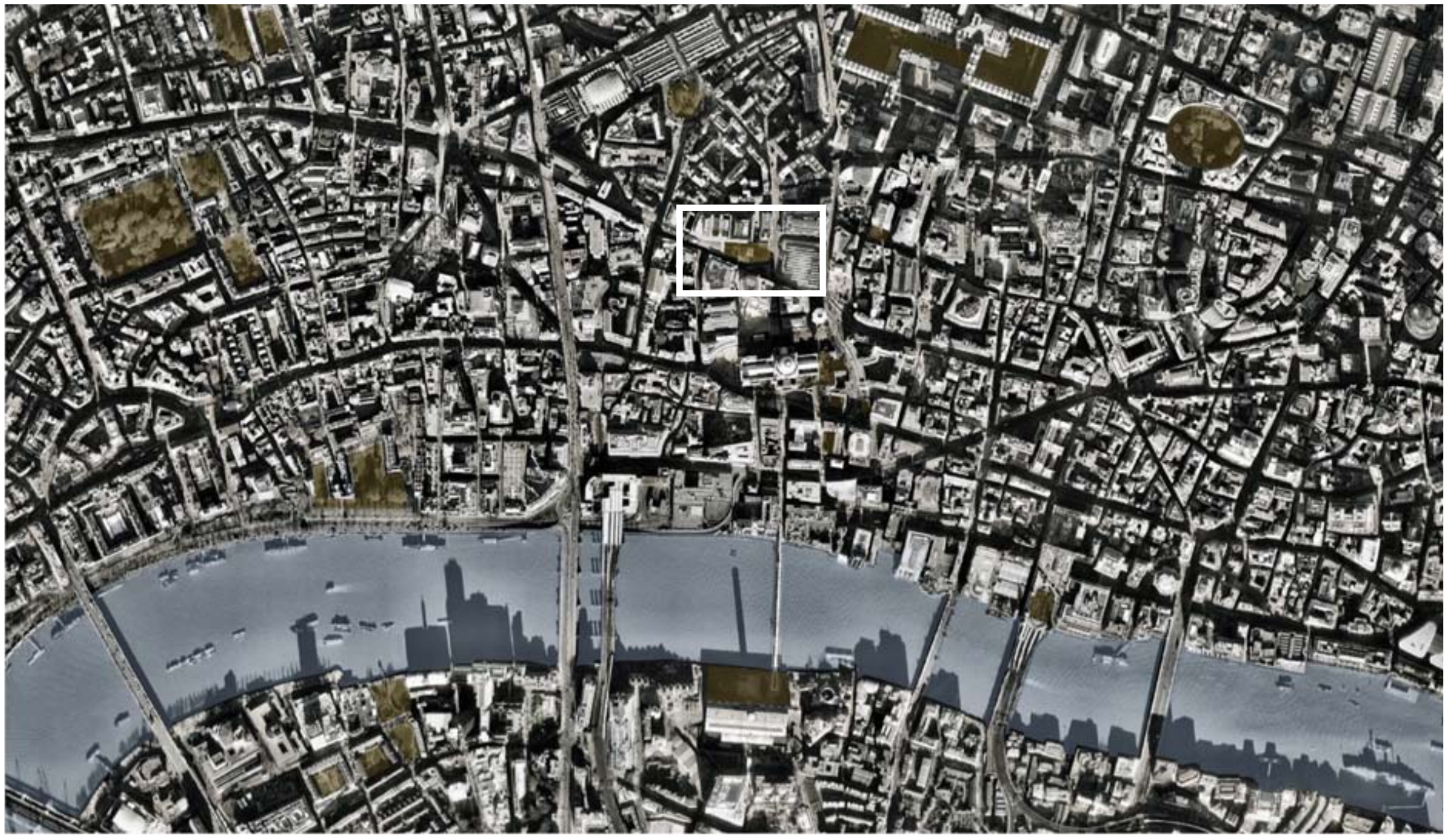

Figure 7.13 - London City and Green Space

Source: "City of London," 5 March 2009, Google Earth, 10 June
2010. 


\section{Site and Program}

\section{Christ Church Greyfriars, London, England}

Christ Church Greyfriars was the site chosen to best exemplify previously outlined ideas of urban stress. It is located in the business district of the City of London, which is a high-density space that is used prevalently during day hours. Currently serving as an unarticulated pocket park, Greyfriars has a rich history of religious architecture and use as a place for silent retreat within the dense confines of the city.

The history of the site began with the Franciscan monks from Assisi. After arriving in England in 1224 they were gifted land on what was then called Stinking Lane (now King Edward Street). Shortly after, in 1229, they built their church. Over the next hundred years they gained ownership to the majority of the land in-between the City Wall and Newgate Street (Figure 7.14). ${ }^{176}$ Unfortunately there are no existing accurate drawings of the Franciscan's compound as it stood firm before being destroyed in the 1666 Great Fire of London. However, foundation excavations on the site give an indication to the nature of the buildings that once were there. ${ }^{177}$

Following the devastating fire, Christopher Wren rebuilt another church on top of the medieval foundations by $1704 .{ }^{178}$ Only half the size of the previous church Wren made another distinction, he designed a tower with which he broke away from the strict layout of the pre-existing foundations and created his own architectural gesture. Unfortunately during World War II incendiary attacks on London ensured that Wren's church was left in ruin (as previously illustrated in Figure 5.7). The one element that did survive was the tower. Left severely weakened after the raids, London City deemed to dissemble then reassemble it using modern technology. ${ }^{179}$ The rest of the site was to become an inner city green space, with further demolition occurring to the remains of the eastern wall during the widening of the adjacent road. ${ }^{180}$

\footnotetext{
176 - Paul Herbert, "Excavations at Christ Church Greyfriars, 1976," London Archaeologist 3-12 (1979): 327.

177- J. H Birch, "The Franciscan Monastery of the Greyfriars, Newgate," Newbery House Magazine 10 or 11 (1894): 209.

178 - Paul Herbert, "Excavations at Christ Church Greyfriars, 1976," London Archaeologist 3-12 (1979): 330.

179- Paul Jeffery, The City Churches of Sir Christopher Wren (London: The Hambledon Press, 1996) 192.

180 - Paul Jeffery, The City Churches of Sir Christopher Wren (London: The Hambledon Press, 1996) 192.
} 
Today Christ Church Greyfriars contains ruinous walls which surround the tower that has since been converted into an apartment. The footprint of the destroyed Franciscan and Wren church is barren, except for some rose bushes denoting where Wren's pillars once stood (Figure 7.16). The site is a prime location and currently being underutilised. Through manipulating the history of silence held within this site, my design program aims to create a responsive and secular retreat for the modern city dweller.

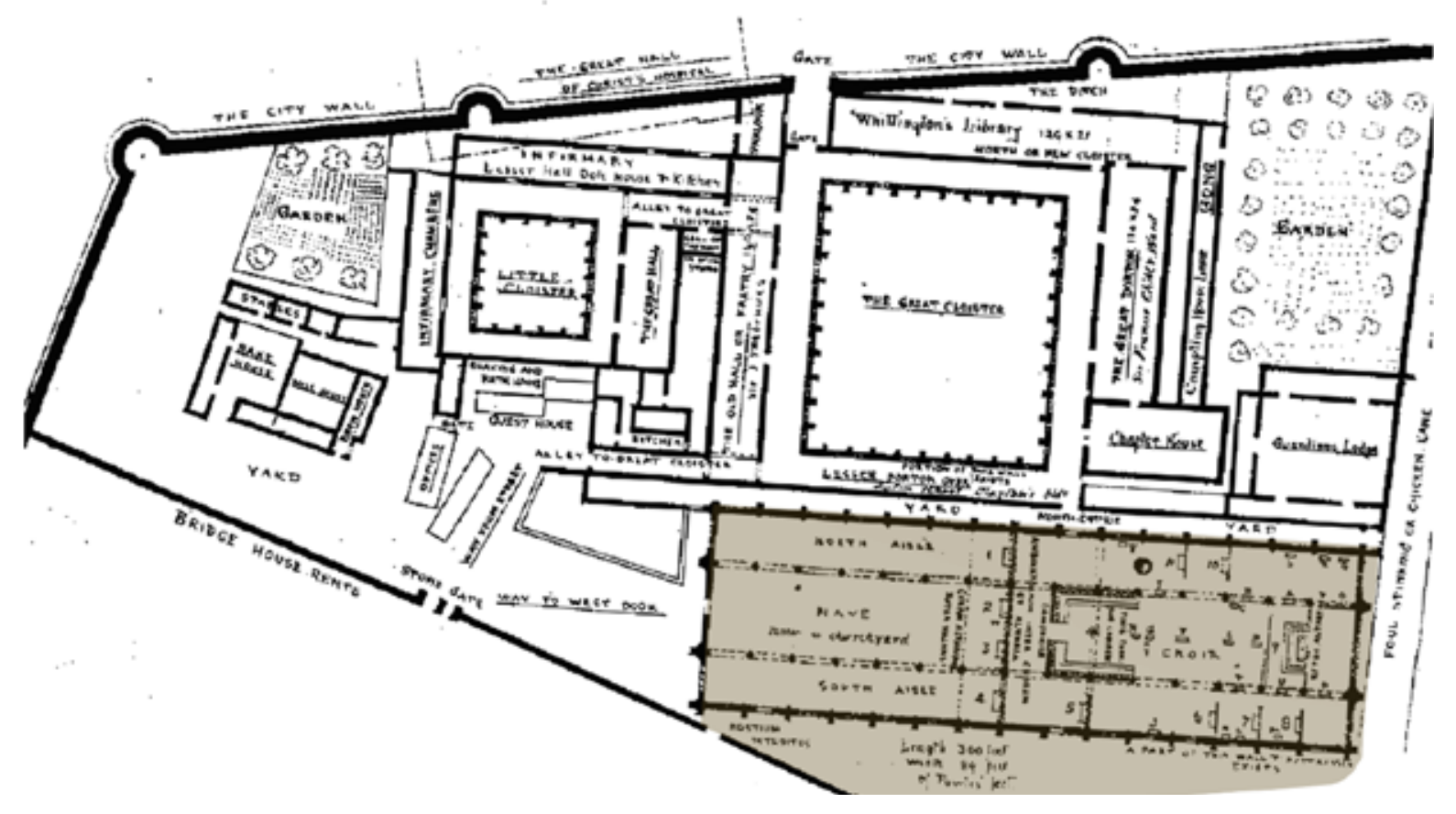

Figure 7.14- Franciscan Complex

Source: J. H Birch, "The Franciscan Monstery of the Greyfriars,

Newgate," Newbery House Magazine 10 or 11 (1894): 210. 

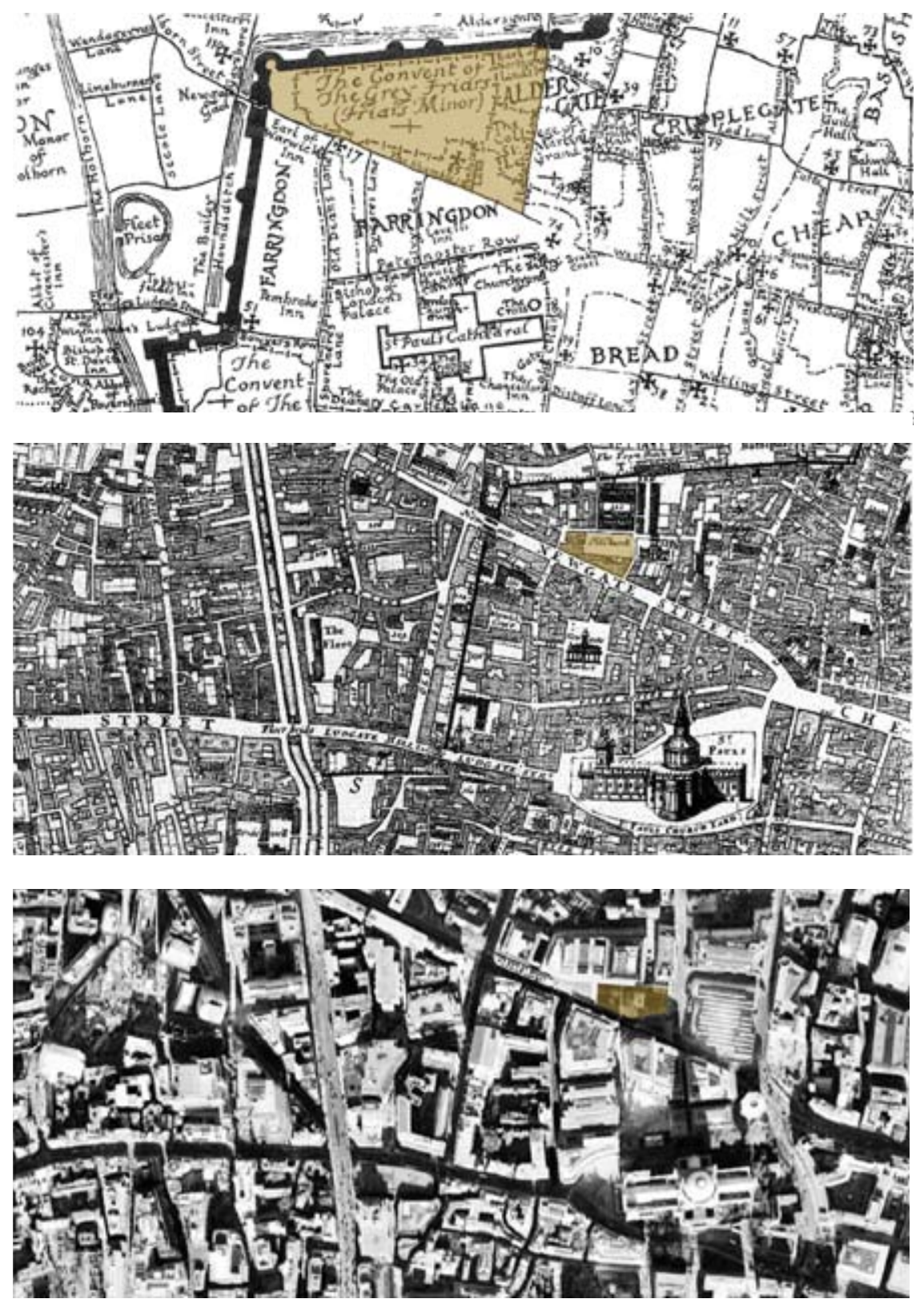

Figure 7.15 - London City, Christ Church Greyfriars Historic Mapping
City of London, 1377

Source: Andreas Papakadis and Kenneth Powell, "The History of St Paul's Cathedral and Paternoster Square" Architectural

Design Profile No 97: Paternoster Square and the New Classical Tradition 62 (1992): 10

\section{City of London, 1682}

Source: Andreas Papakadis and Kenneth Powell, "The History of St Paul's Cathedral and Paternoster Square" Architectural Design Profile No 97: Paternoster Square and the New Classical Tradition 62 (1992): 10

City of London, 2006

Source: "City of London," 5 March 2009, Google Earth 10 June 2010. 


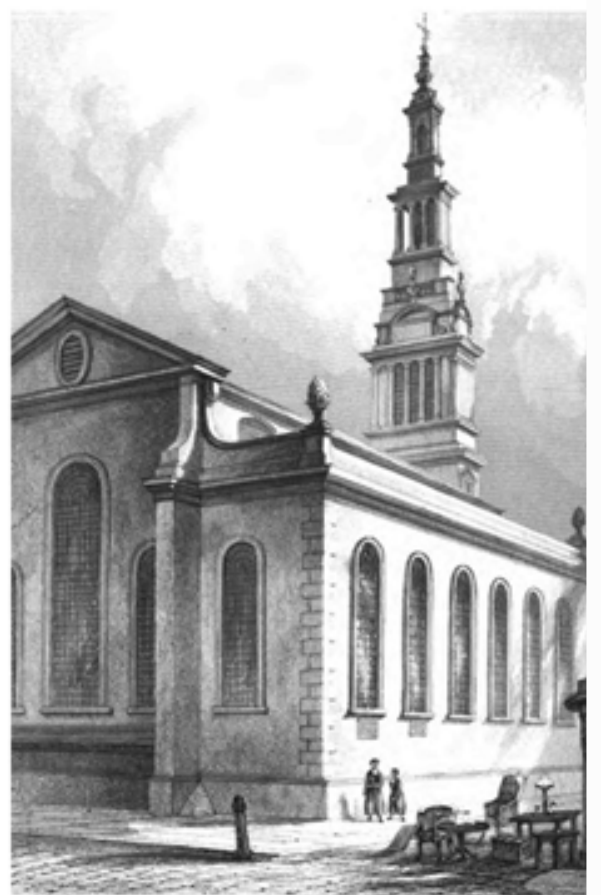

Christopher Wren’s Church

by Frederick Mackenzie

Source: George Godwin, John Britton, Frederick Mackenzie and Robert William Billings, "St. Clements, Eastcheap," The Churches of London; Vol II, (London: C. Tilt, 1935) 8.

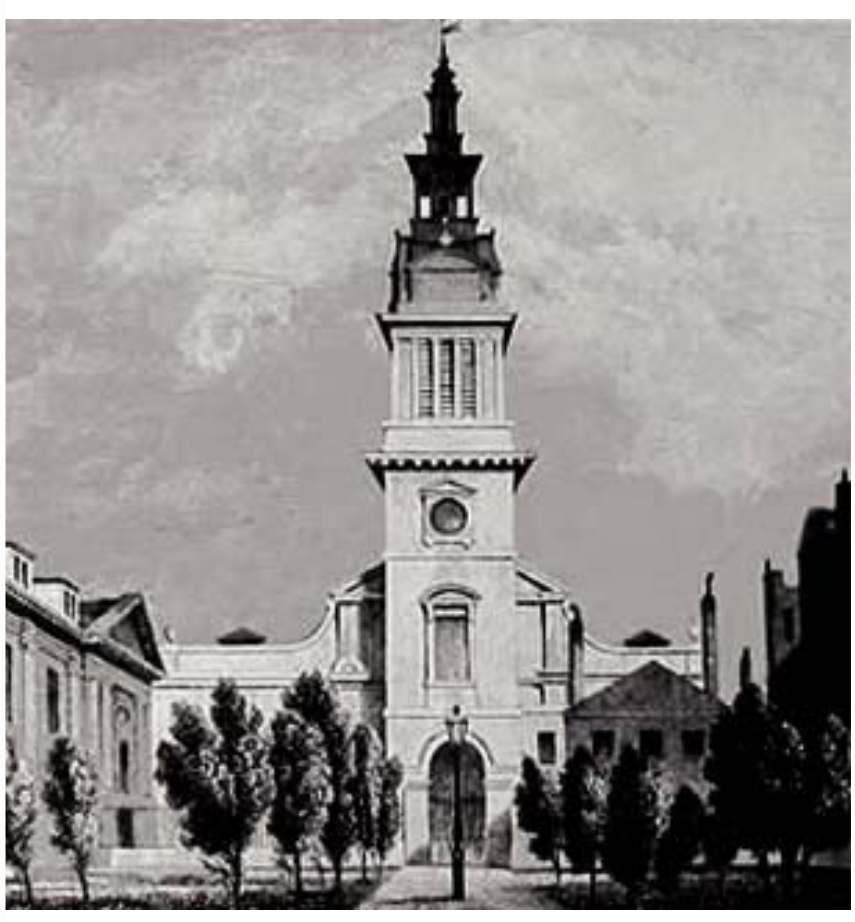

Christopher Wren's Church

Source: "Christ Church Greyfriars, Newgate,

London Old Maps, 18 May 2010 <http://www.

oldlondonmaps.com/viewspages/0337.html>.

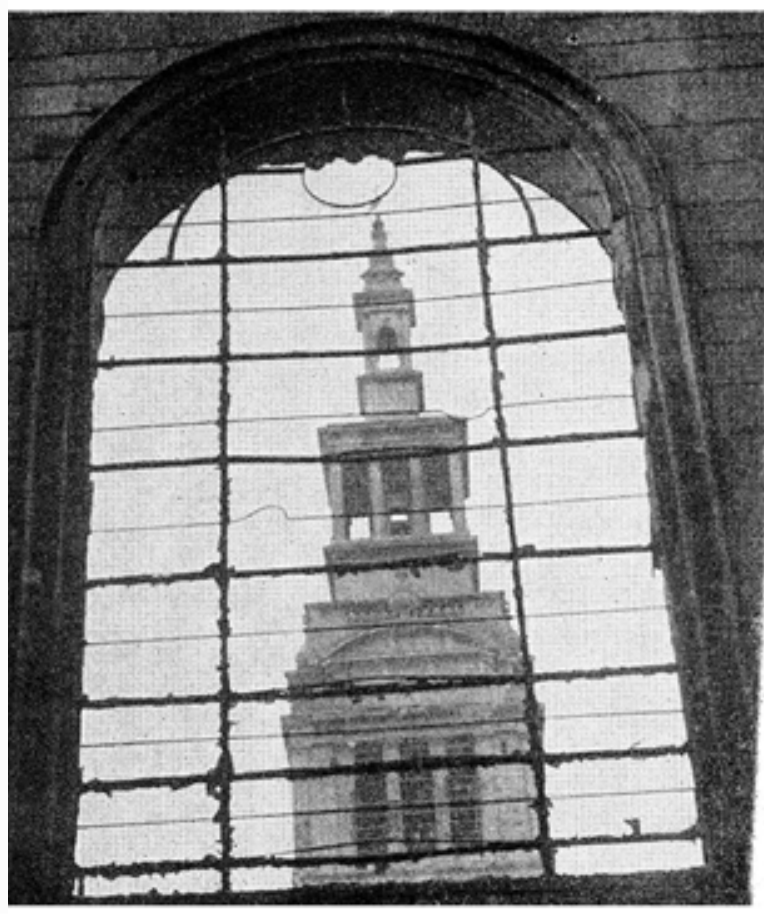

Post WWII Bombing

Source: Richards, J. M, ed, The Bombed Buildings of Britain: Second Edition, (London: The Architectural Press, 1947) 30.

Figure 7.16 - Pictorial History of Christ Church Greyfriars 


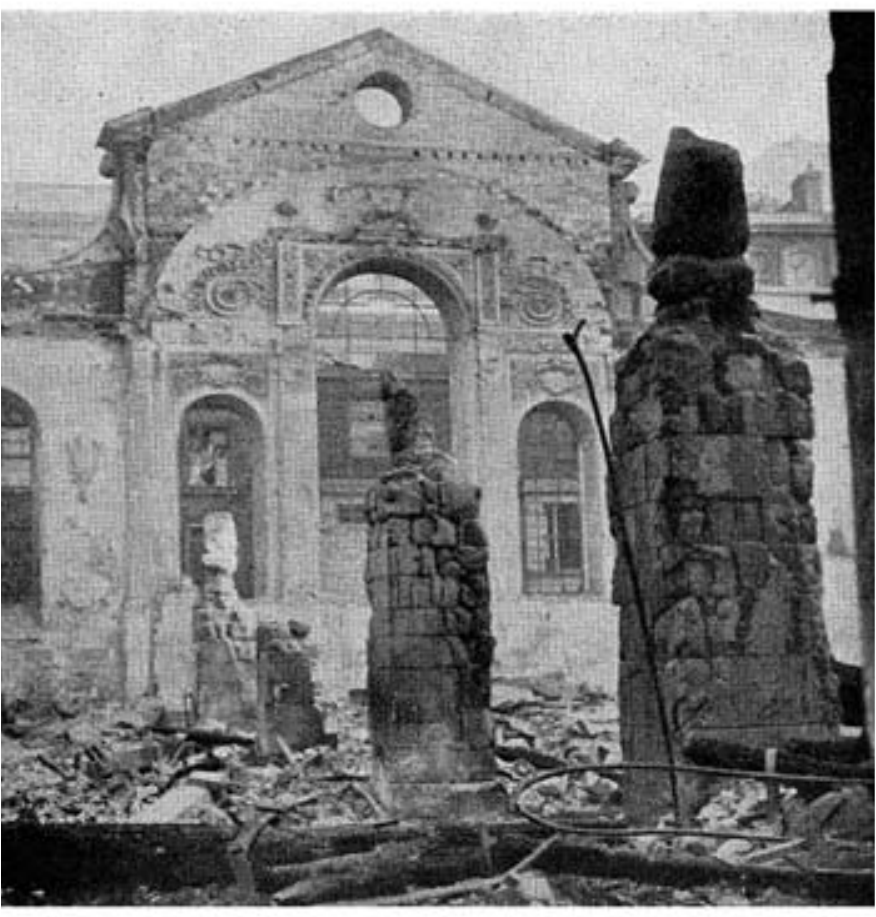

Post WWII Bombing

Source: Richards, J. M, ed, The Bombed

Buildings of Britain: Second Edition, (London:

The Architectural Press, 1947) 30.

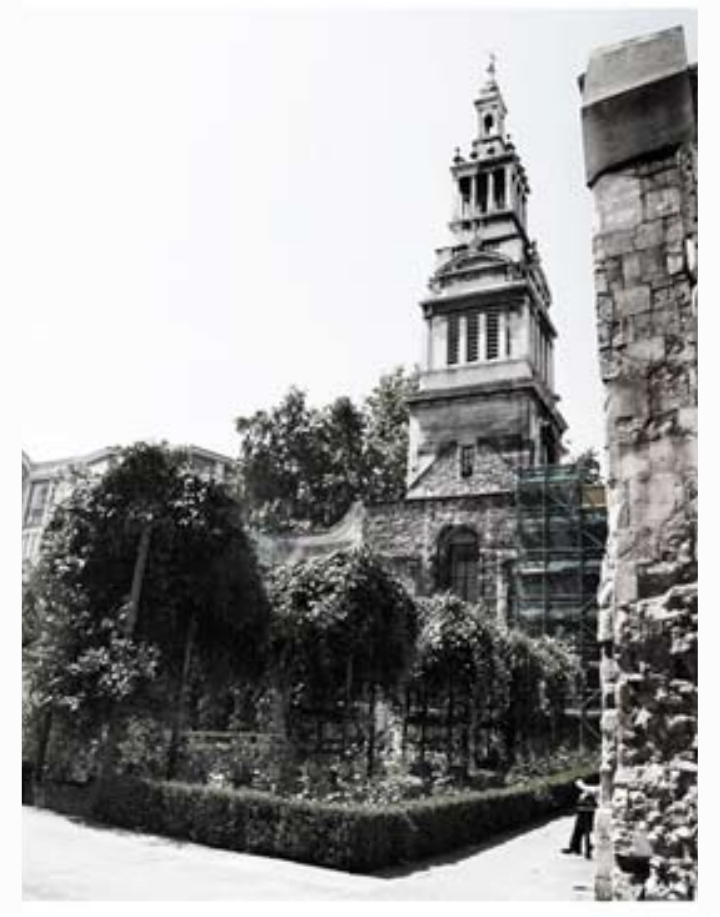

London City Park 2010

by Ella Sutherland

Source: Ella Sutherland, Christ Church Greyfriars, 2010, Photography, City of London.

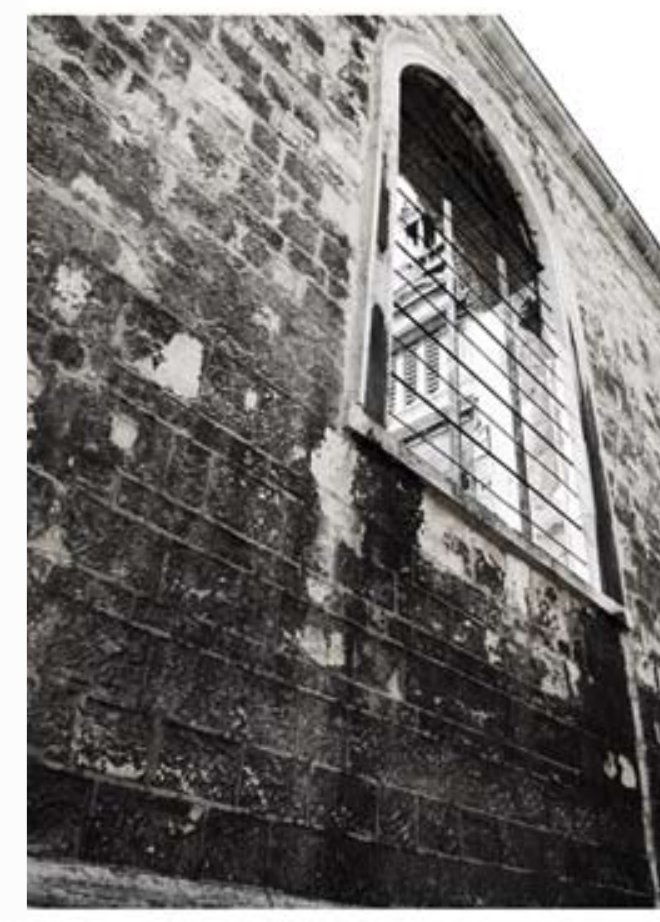

London City Park 2010

by Ella Sutherland

Source: Ella Sutherland, Christ Church Greyfriars, 2010, Photography, City of London. 


\section{Site Analysis}

Utilised predominantly at lunchtimes, this site currently acts as a pocket park for business people to congregate, sit on the grass, and enjoy the sunshine. Its high pedestrian flow means it's exposed to a variety of people. As a consequence it's a loud site with heavy traffic noise pollution and insufficient seating and space articulation. In addition there is little distinction between the park and the footpath, save for a small wrought iron fence. Aspects that would make this space more successful include screening from the noise pollution adjacent and creating further spaces for people to sit, eat and move around, making the park a varied and intricate experience. By creating a series of spaces that effectively remove you from the city environment one can transition into a personal moment of Stille.

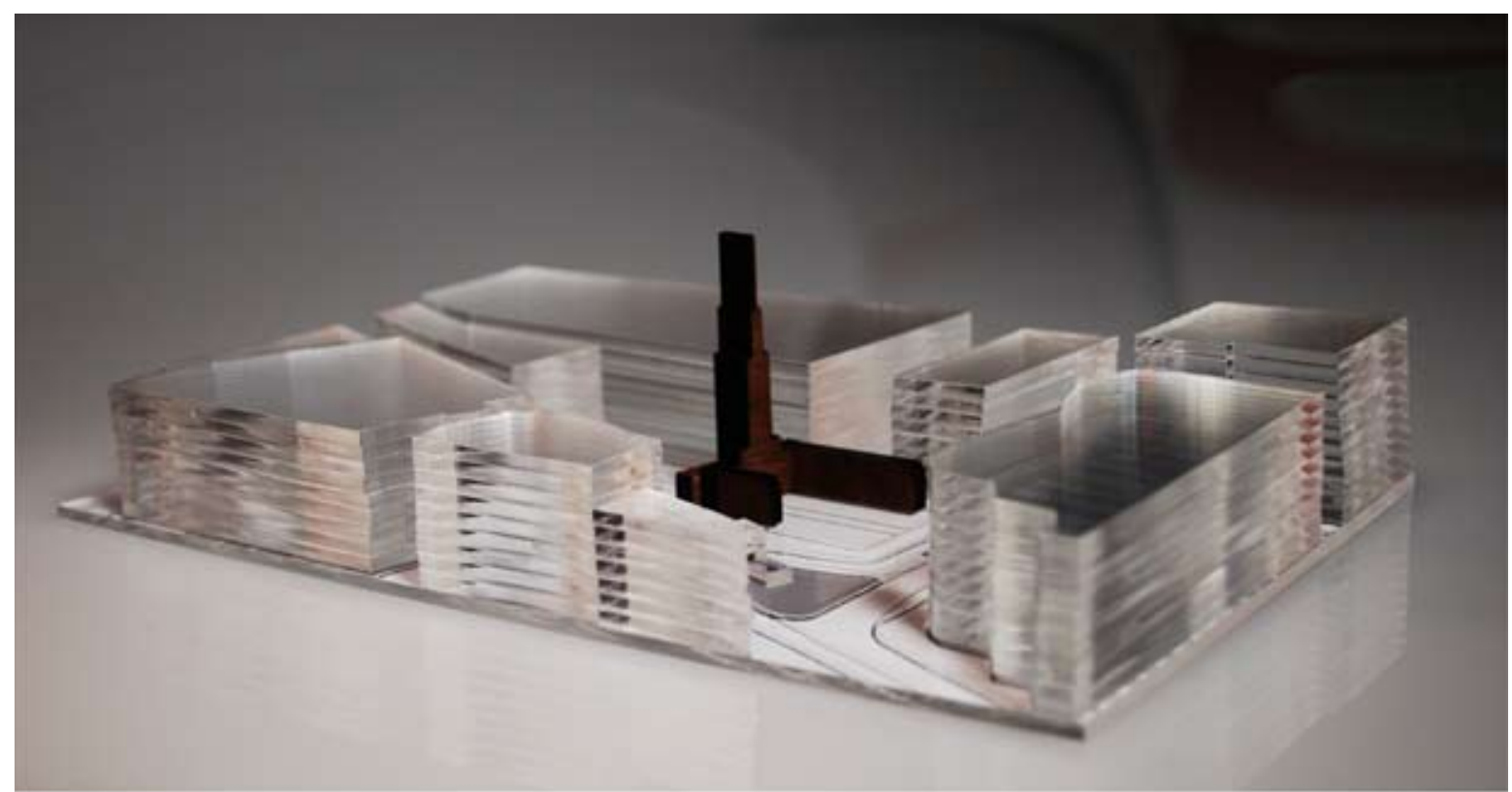

Figure 7.17- Site Analysis Model

built at 1:1000 
$\widehat{\mathrm{N}}$
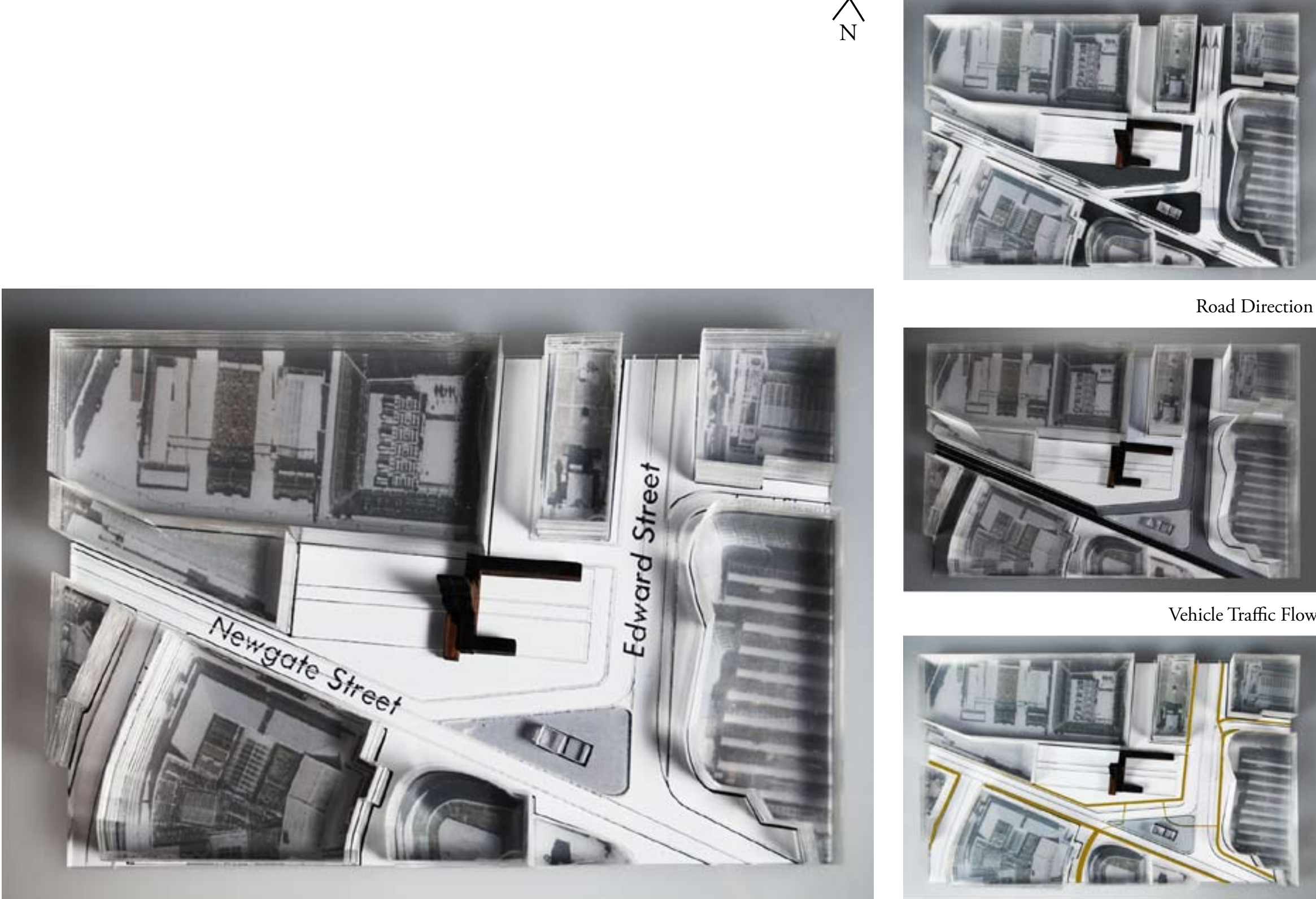

Road Direction

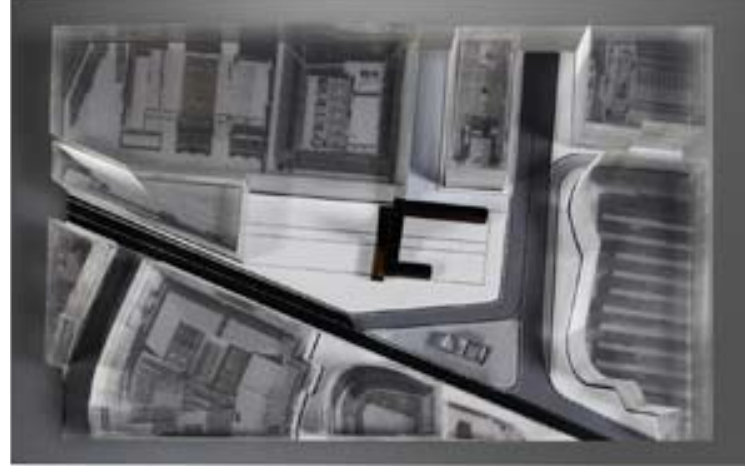

Vehicle Traffic Flow

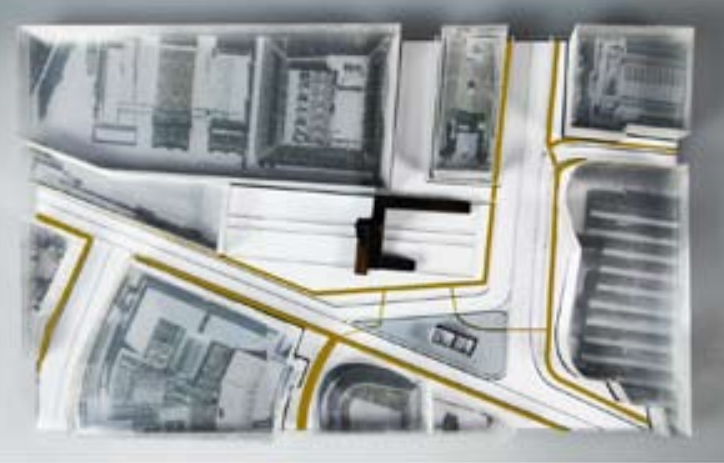




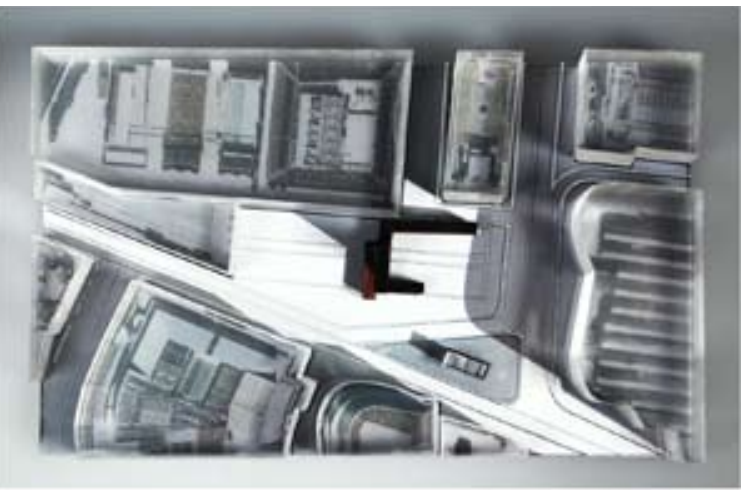

9am

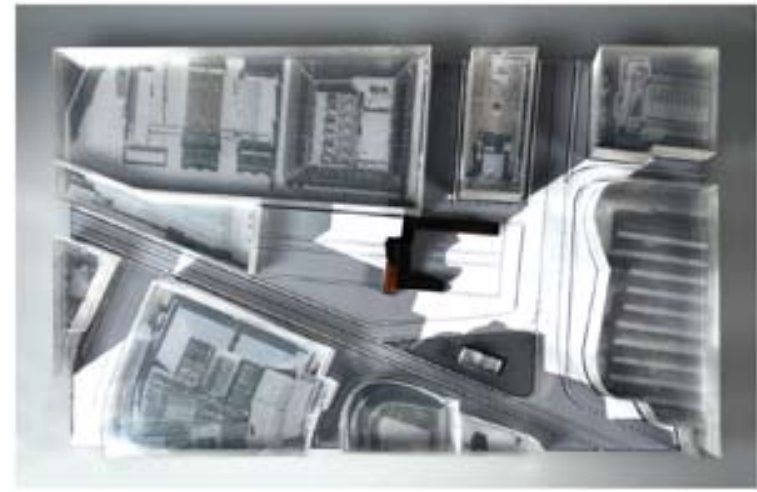

Figure 7.19- Summer Shadows

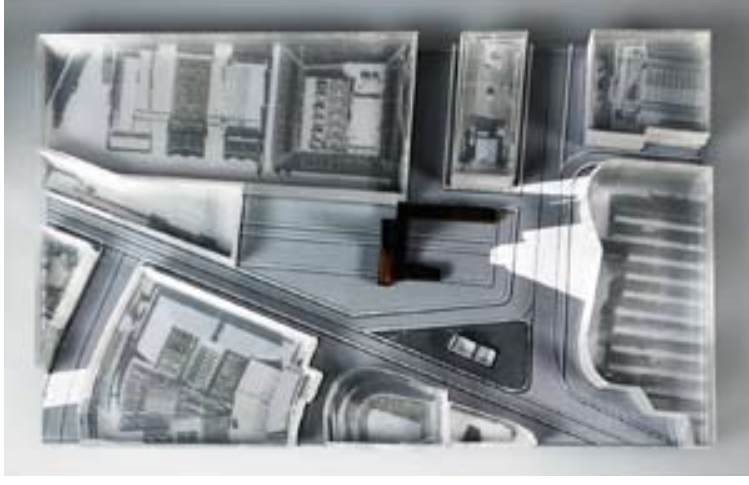



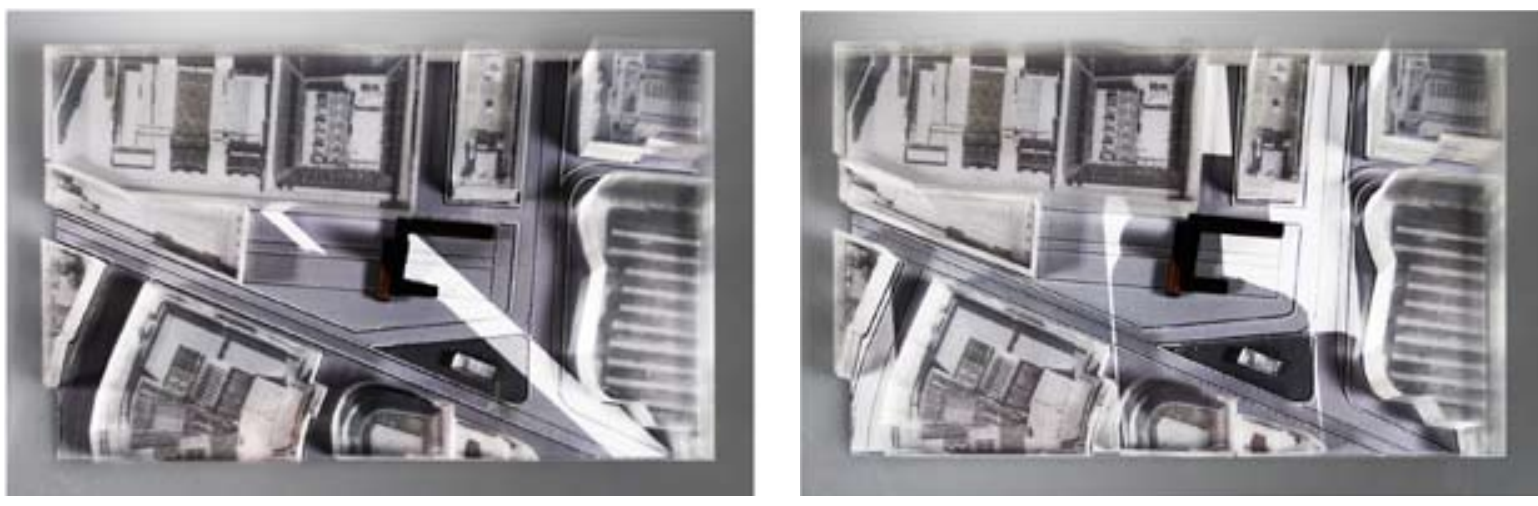

$9 \mathrm{am}$
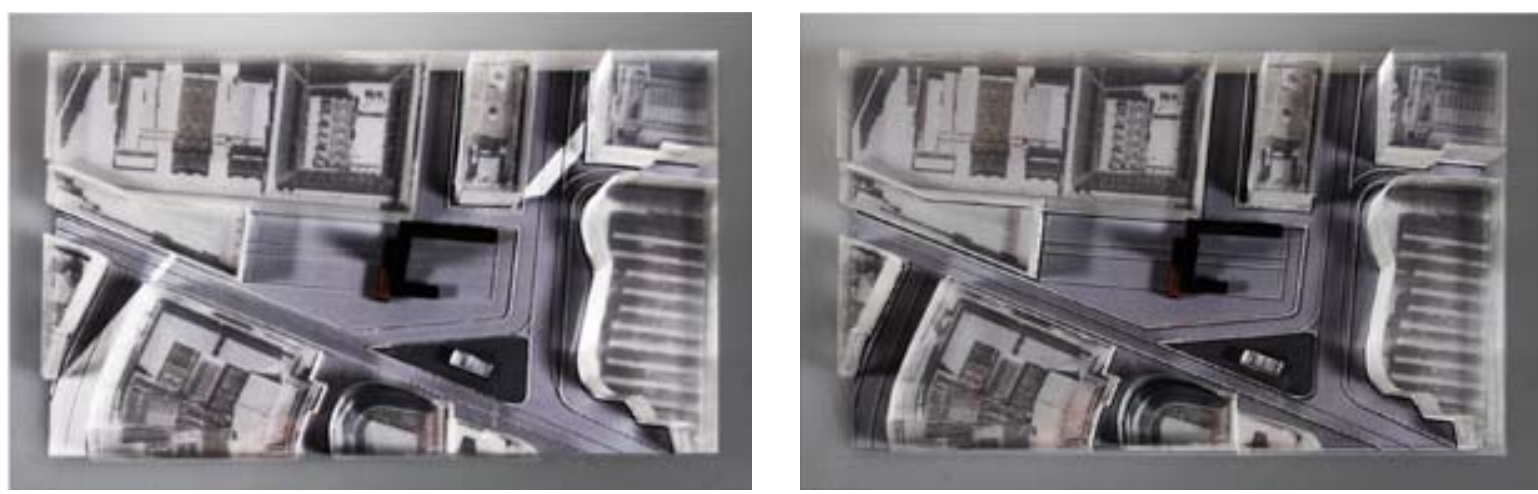

Figure 7.20 - Winter Shadows 


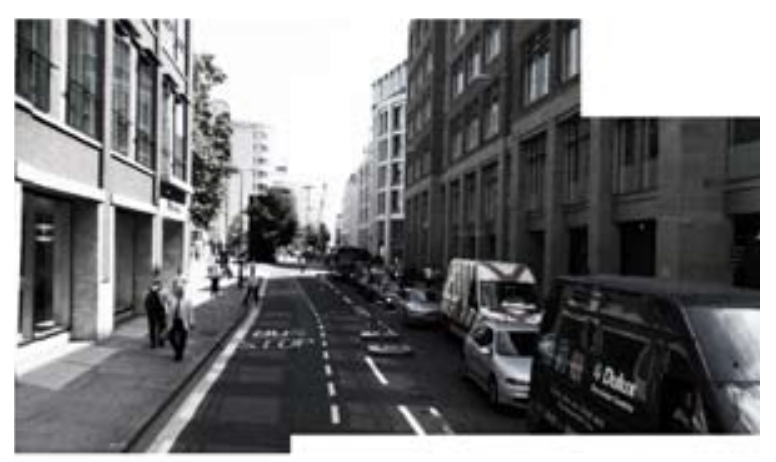

Newgate Street

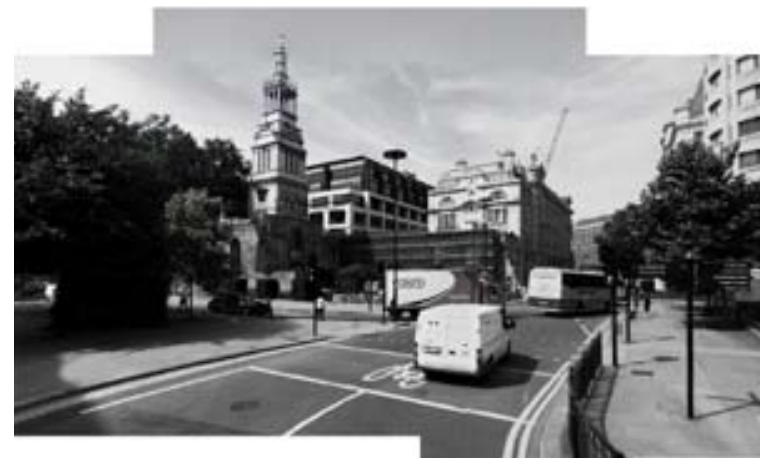

Edward Street

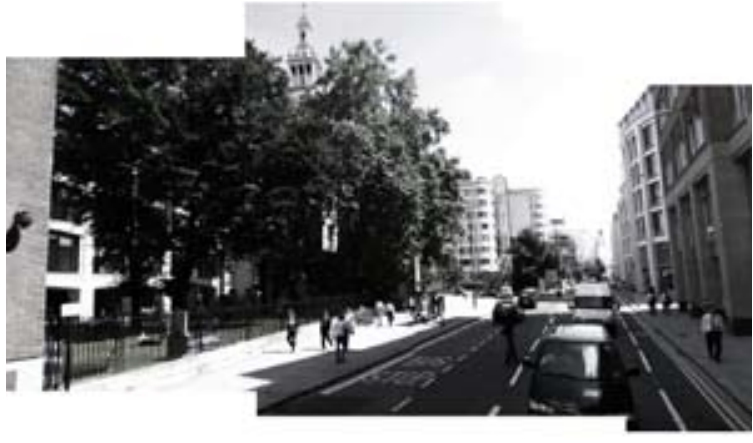

Newgate Stree

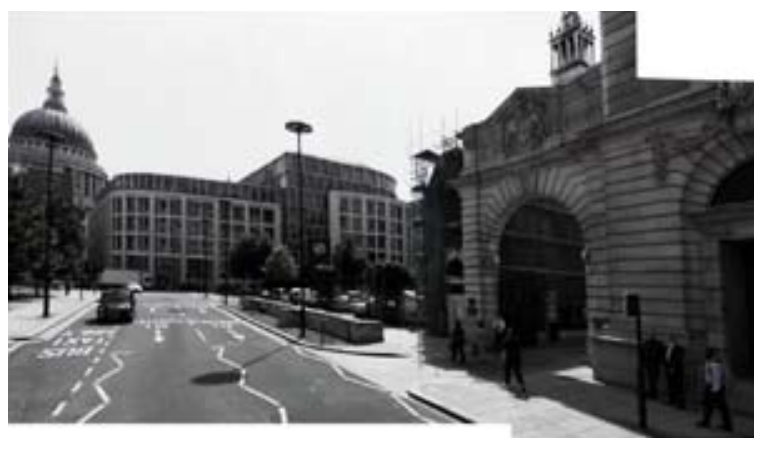

Edward Street

Figure 7.21 - Site Situation Perspectives

Source: "Newgate Street - Edward Street," Google Earth

Street View, 10 June 2010. 


\section{Historical Palimpsests}

Before a successful intervention into the site could be created, an understanding of the previous historical buildings and their architectural rhythms needed to be established. To do this I traced the foundations of the Franciscan Monastery and Christopher Wren Church (Figure 7.22). In addition I studied the elevations of Wren's church in comparison to how it is viewed today in its ruinous garden form (Figures 7.23, 7.24 and 7.25 $)^{181}$. The combination of this information set useful parameters within the architecture. The foundation trace in particular became a heavy impetus for creating circulation and significant moments within the design. Part of this intervention is focussed on re-orientating the role of Christ Church Greyfriars in its modern setting. Therefore the stringent axis the foundations have created since 1229 are adhered to for the most part but broken away from at significant moments to re-emphasize its shift in use. In doing so the foundations are both celebrated and subverted, making its new use as a silent-scape even more apparent. 

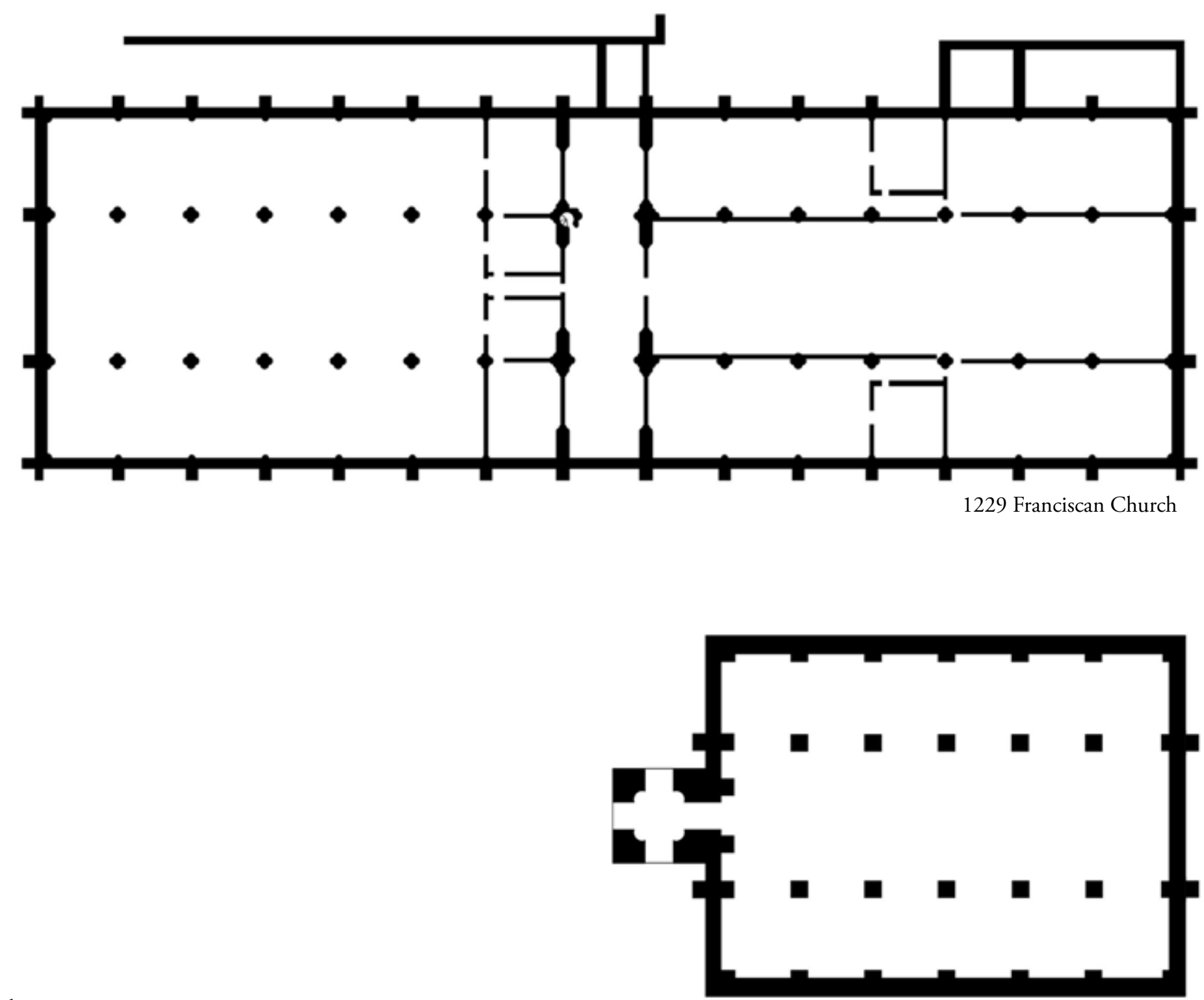


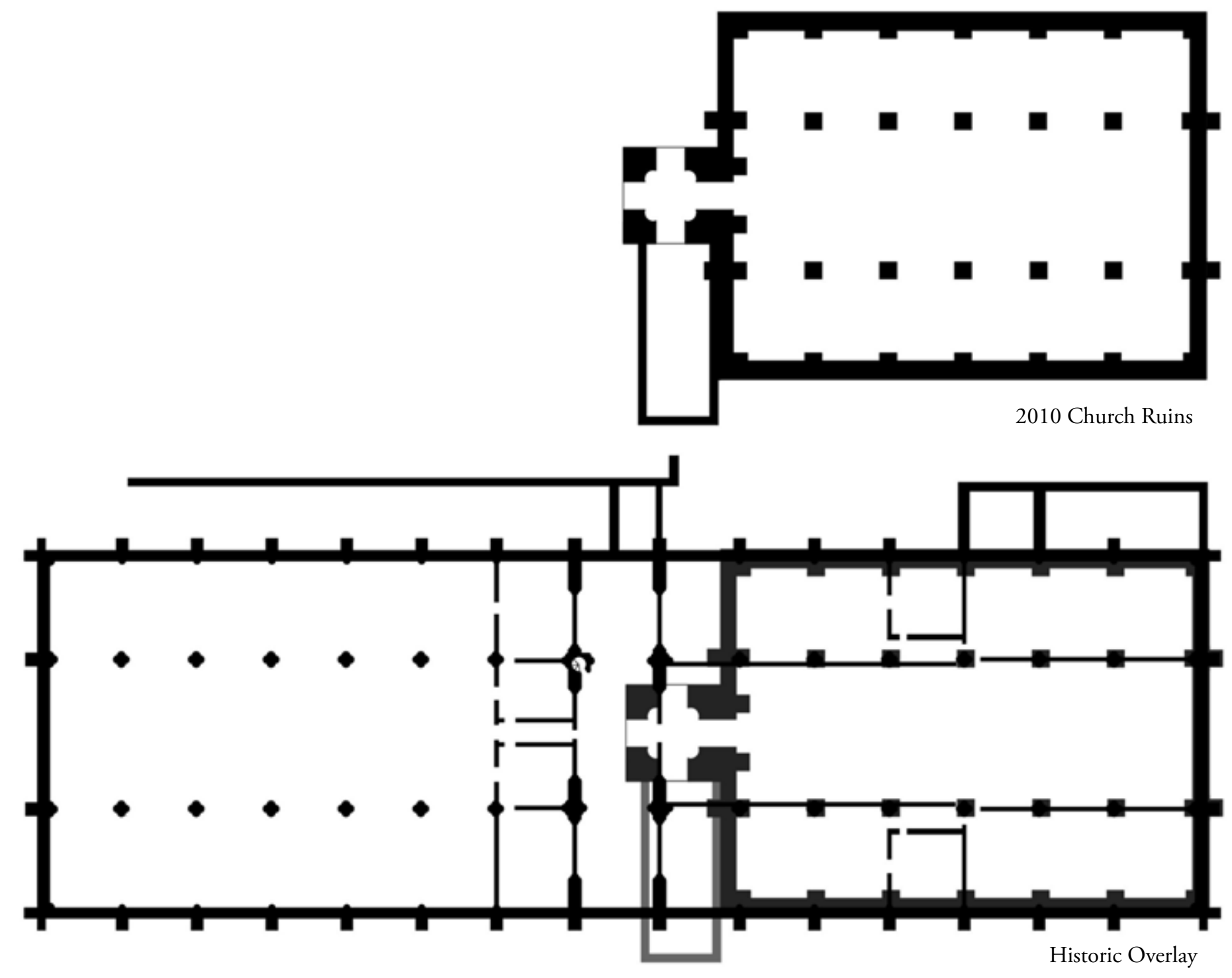



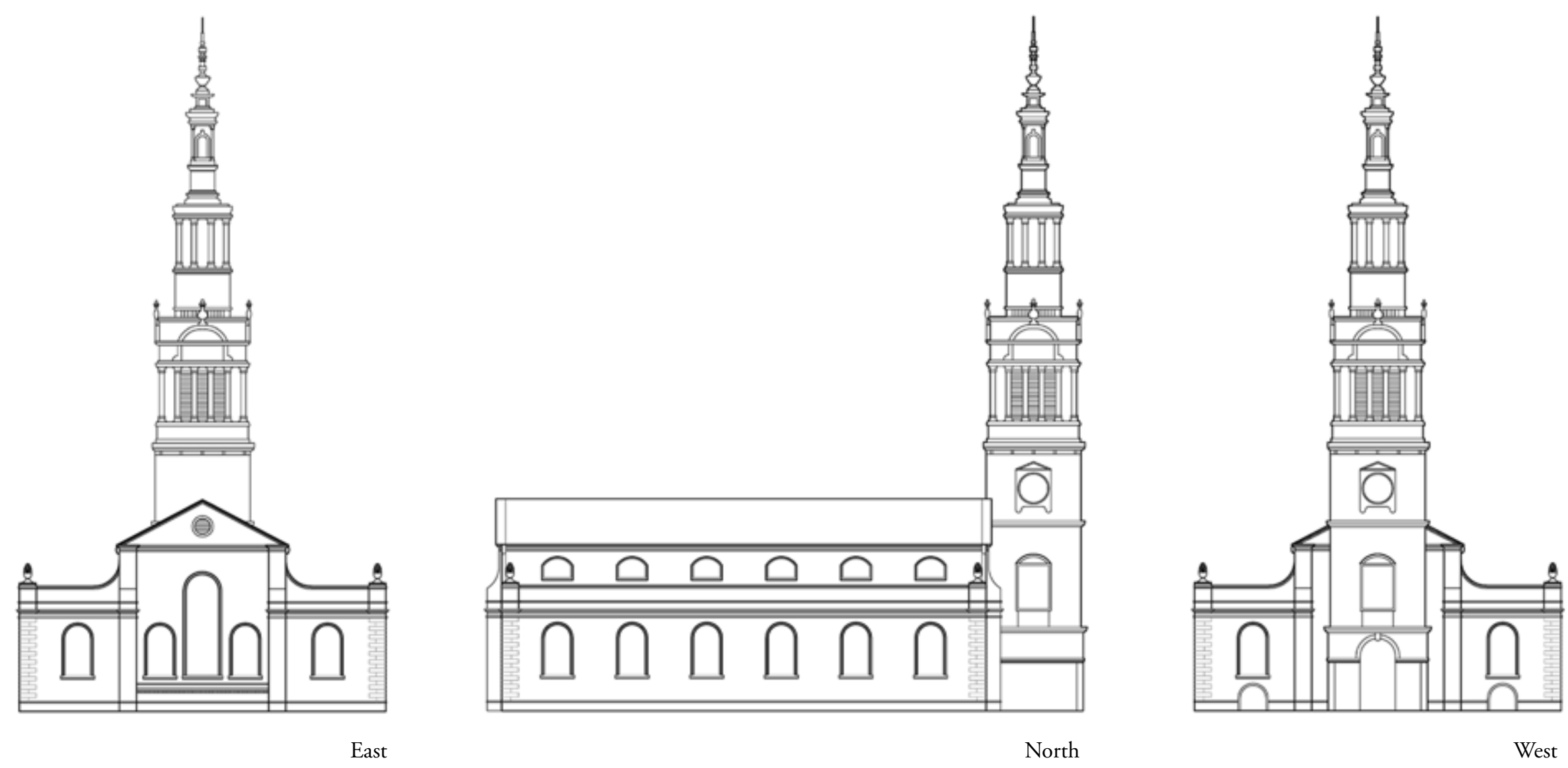

Figure 7.23 - 1704 Elevations 1:500 


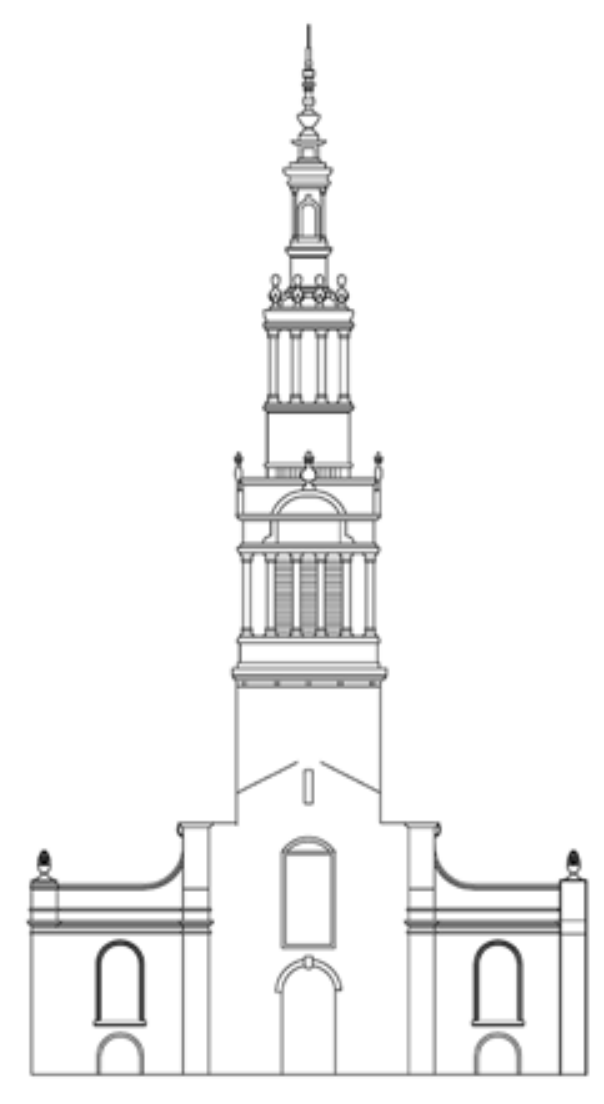

East
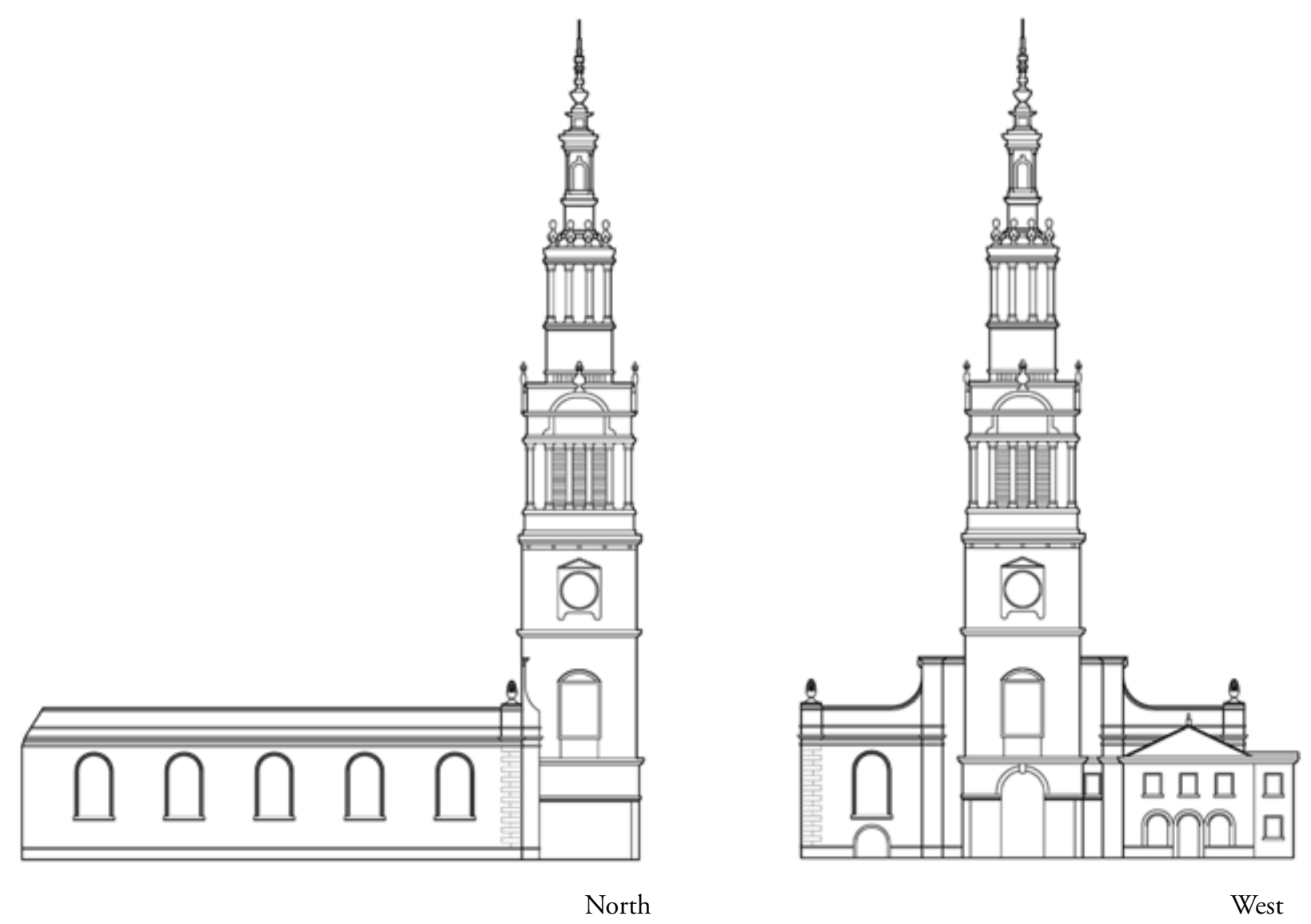

Figure 7.24-2010 Elevations

1:500 

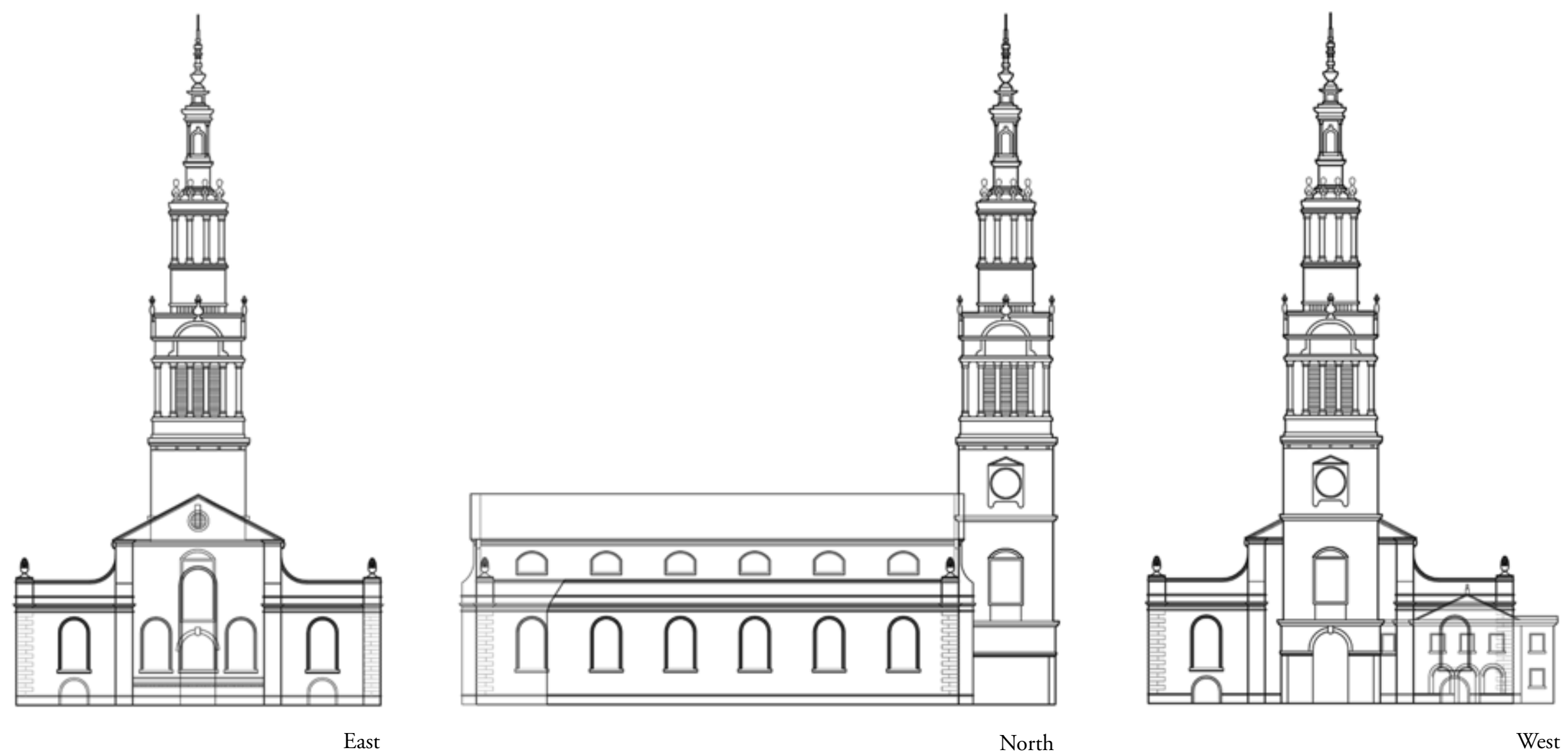

Figure 7.25 - Elevation Overlay 1:500 


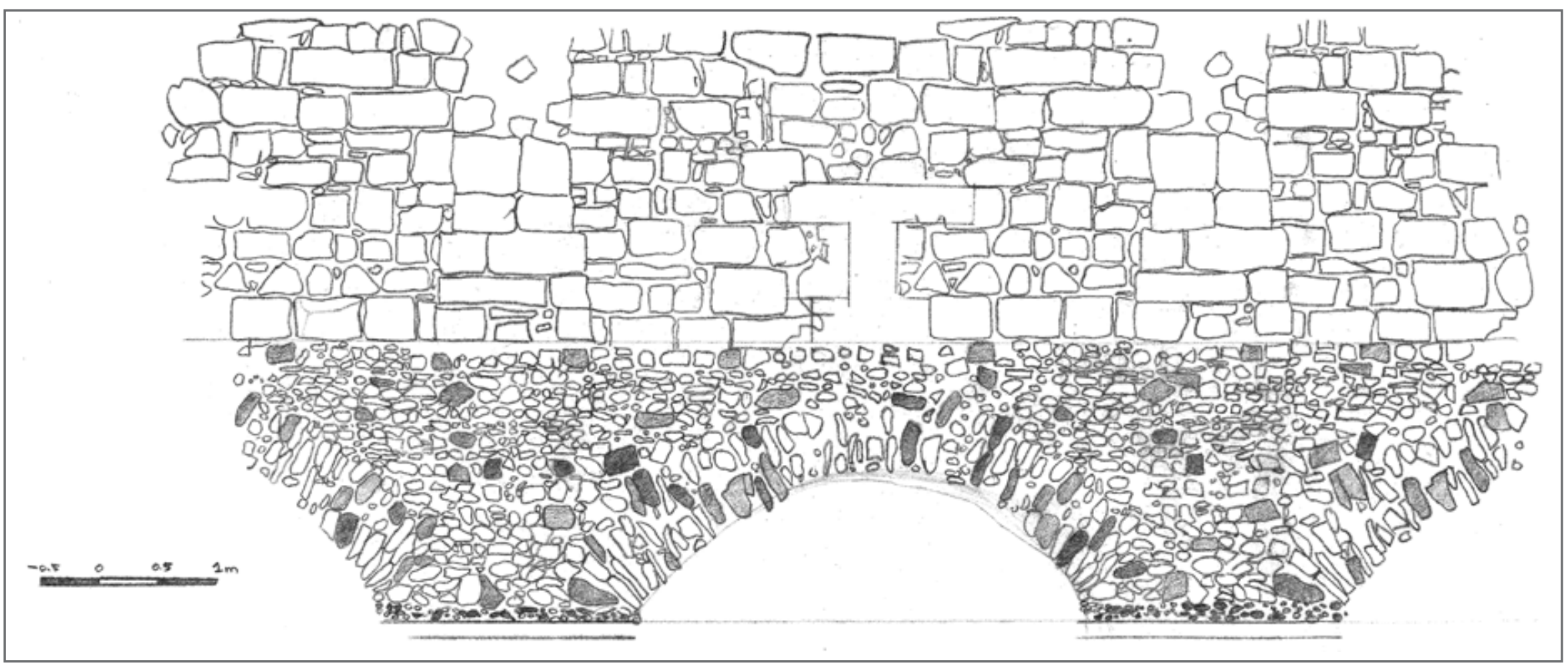

\section{Figure 7.26 - Franciscan and Wren Foundation Elevation}

Reproduced from source: Paul Herbert, "Excavations at Christ Church Greyfriars, 1976," London Archaeologist 3-12 (1979): 329. 


\section{Acoustic Analysis and Wall Design}

Noise is a serious landscape issue. ${ }^{182}$ For this design scheme to be successful it was imperative that it act as a physical place of silence. To attain this goal an in-depth look into the ways the park could be shielded from noise of the road adjacent was explored. It was decided from the outset that walls were needed to protect the site both visually and acoustically. Following this decision the context was put into the computer program Ecotect to devise ways the park could create openings that would keep noise to a minimum (Figure 7.27). Through this experimentation it was deemed that with significant overlap the walls could have large openings and still be effective in reducing unwanted sound. In conjunction with the Ecotect analysis, the environmental barrier principle that acoustic reduction is achieved easiest if placed as close to the road as possible helped dictate wall placement around the site. ${ }^{183}$ Using height parameters attained through the elevation study of Wren's church, the wall represents a reflection of the historical church while acting as a modern-day barrier. By angling one wall it effectively opens the interior space while emphasising the tightness and movement of the city on the other, creating an accentuated corridor.

The next study involved materiality and texture. For an effective noise barrier it is best to use absorptive materials. However, through the maquette process it was asserted that a hard material such as the plaster used was most appropriate in creating an environment of Stille. This material was then translated into clay bricks attained from excavations into the site (which soil comprises of clay, silt and sand, as shown in Figure 7.28). The warm tones of the clay are a subtle contrast to the greys and whites of the ruin and exude a connection to nature through the notion of wabisabi. Due to this decision a look at how texture alignment diffracts sound within the retreat itself became important. As demonstrated in Figures 7.29-7.30 the pattern of the tiles of the historical church and tower (Pattern 2) were copied and angled. Through a series of scale explorations this was further developed. The result is a hard and naturally rough surface that stops sound from penetrating and disperses noise back towards the source.

182- Colin English and Benz Kotzen, Environmental Noise Barriers: A Guide to their Acoustic and Visual Design (London: E \& FN SPON, in imprint of Routledge, 1999) 5.

183- Colin English and Benz Kotzen, Environmental Noise Barriers: A Guide to their Acoustic and Visual Design (London: E \& FN SPON, in imprint of Routledge, 1999) 39. 


\begin{tabular}{|c|c|}
\hline \multirow[t]{2}{*}{ Level } & \\
\hline & Direct \\
\hline & Useful \\
\hline & Border \\
\hline & Echo \\
\hline & Reverb \\
\hline & Masked \\
\hline
\end{tabular}
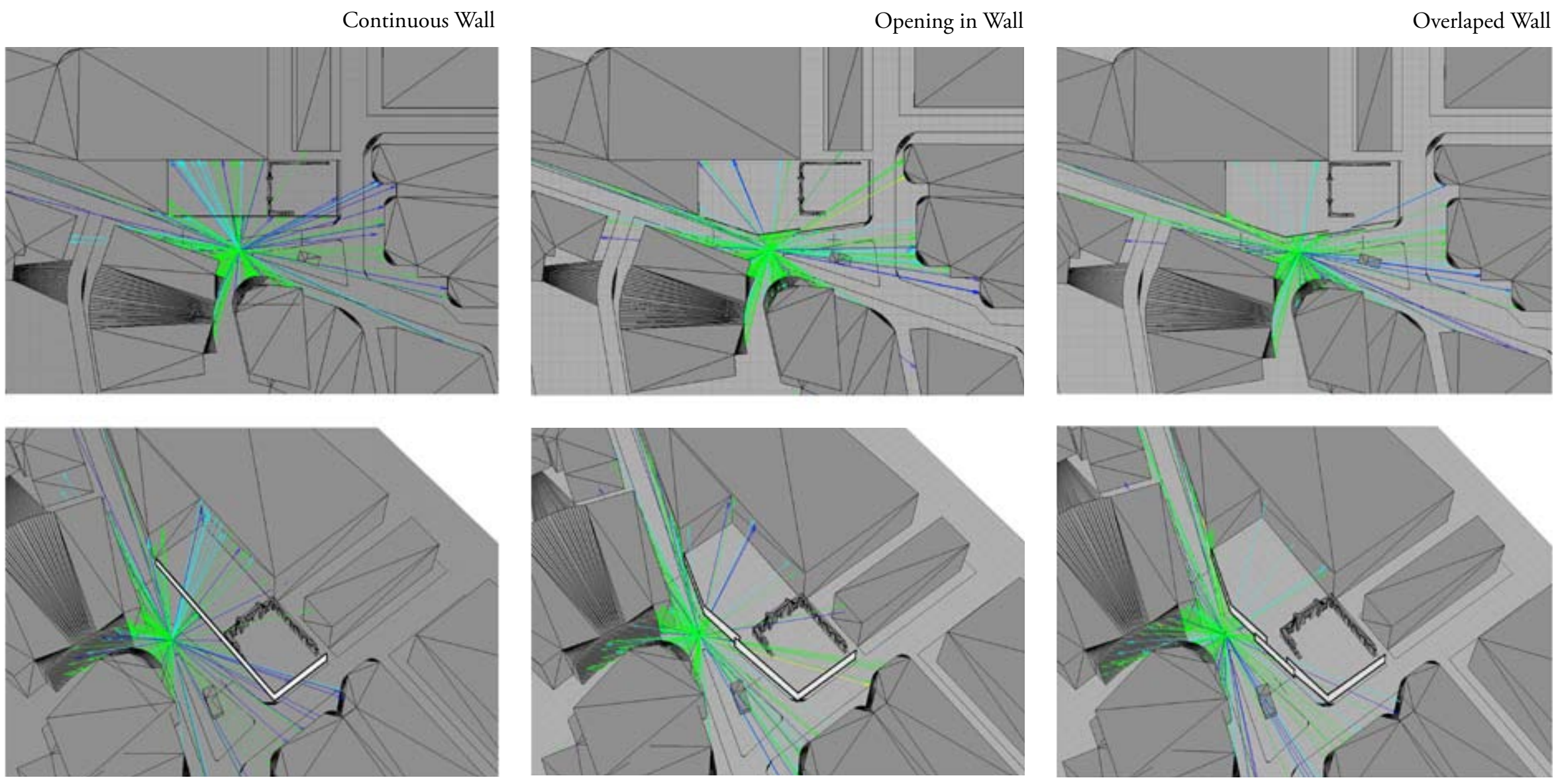

Figure 7.27 - Ecotect Acoustic Analysis 
Superficial: Hackney Gravel Member: Sand and Gravel Bedrock: London Clay Formation: Clay, Silt and Sand

Superficial: Lynch Hill Gravel Member: Sand and Gravel Bedrock: London Clay Formation: Clay, Silt and Sand

Superficial: Langley Silt Member: Clay, Silt and Sand Bedrock: London Clay Formation: Clay, Silt and Sand

Superficial: Alluvium: Silty Peaty Sandy Clay

Bedrock: London Clay Formation: Clay, Silt and Sand

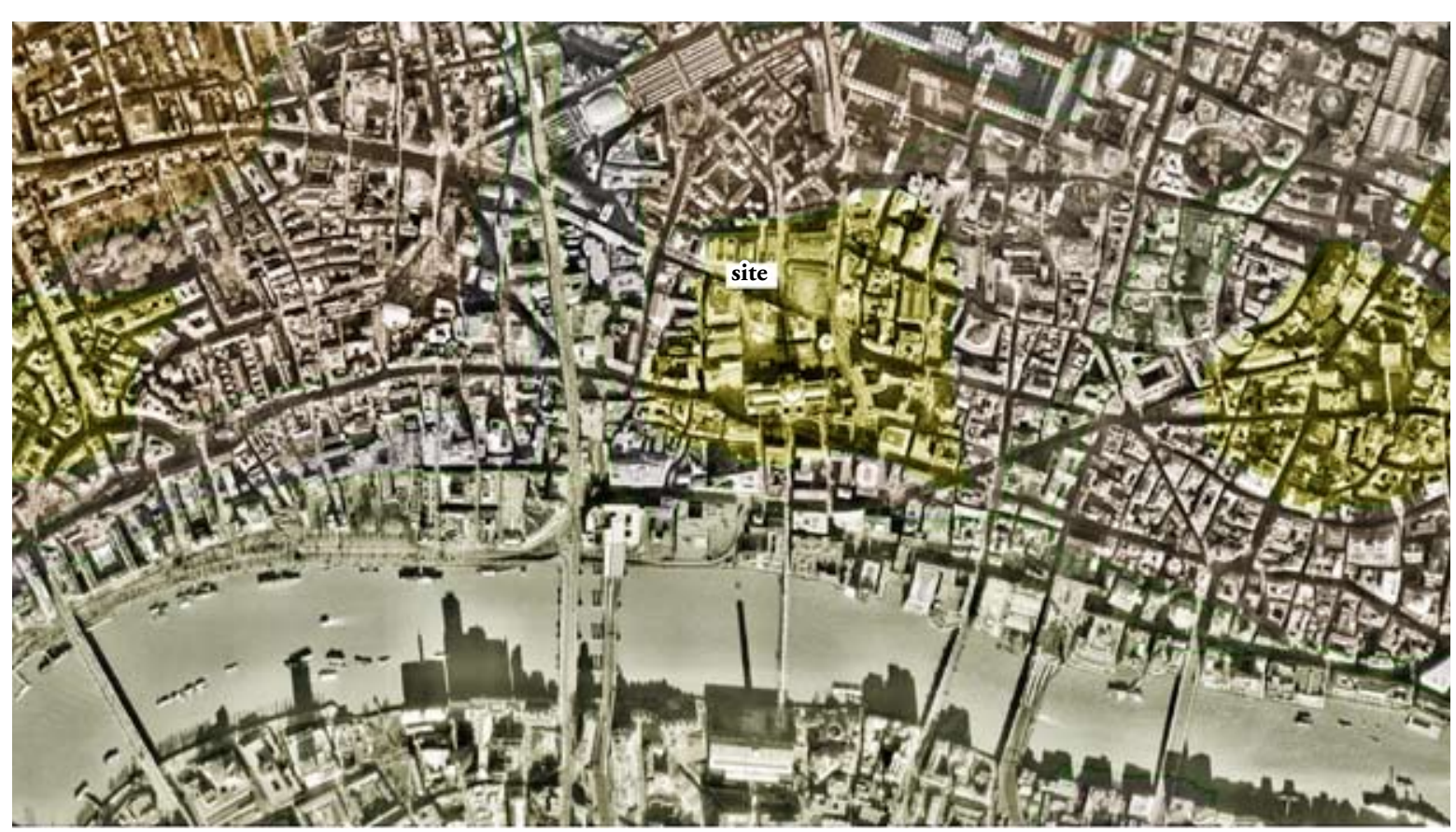

Figure 7.28 - Geology of London City

Reproduced from source: "Geology of Britain Viewer," British

Geological Survey, 8 September 2010, <http://www.bgs.ac.uk/

opengeoscience/?Accordion $1=1$ \#maps $>$. 
Acoustic Diffraction Diagram
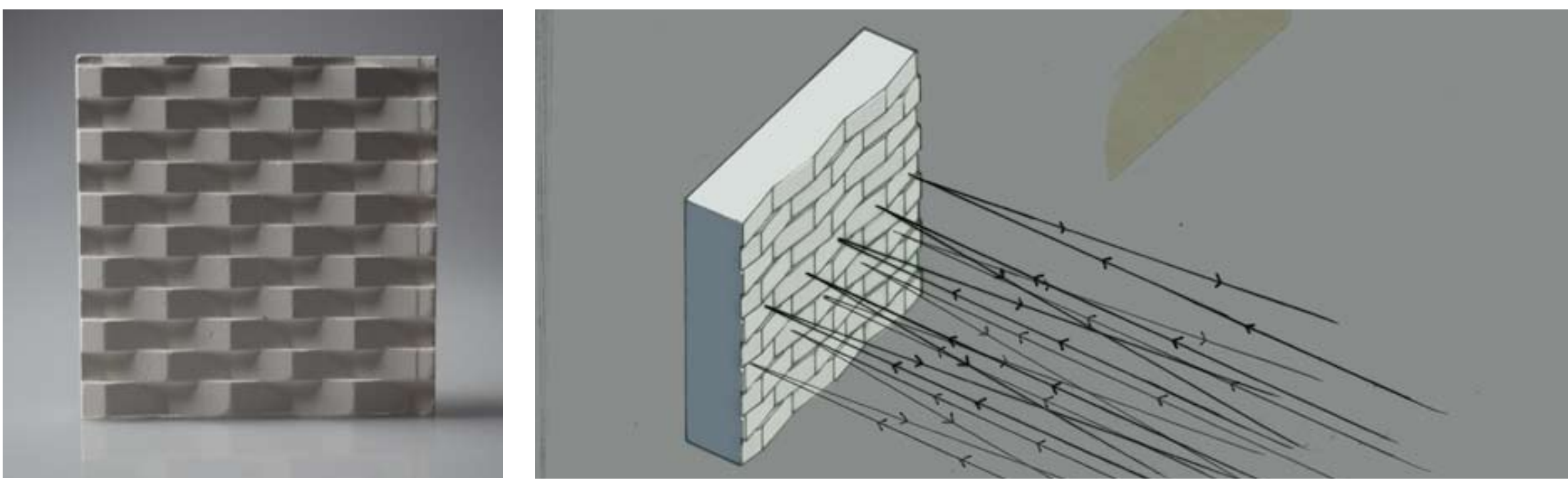

Pattern 1
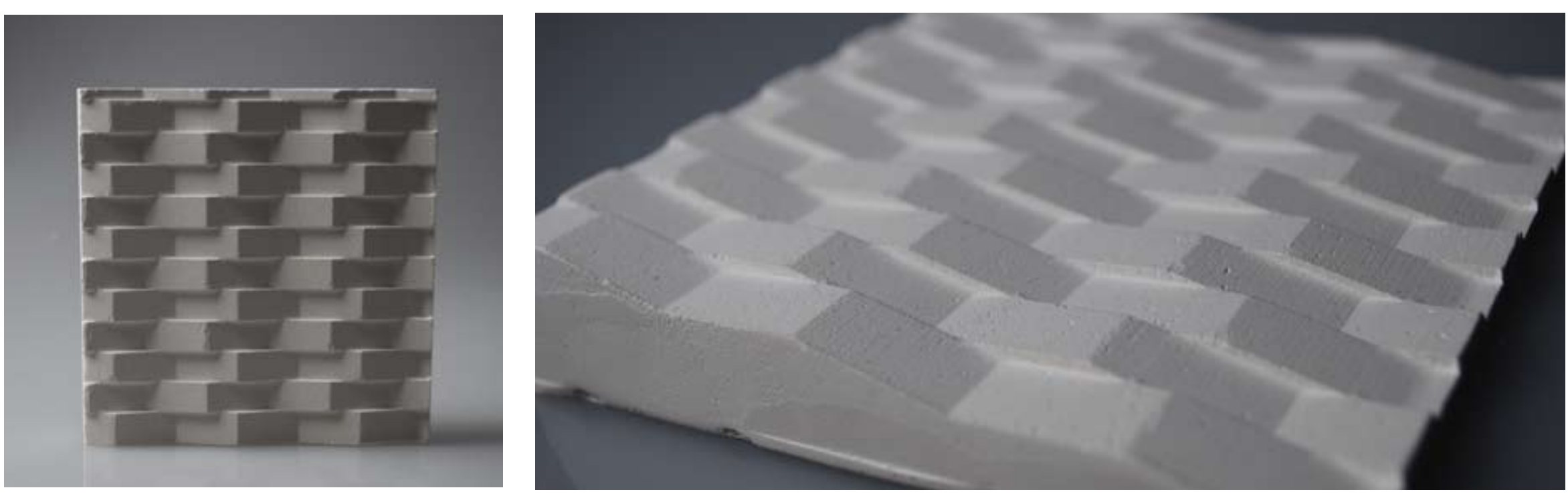

Figure 7.29 - Wall Pattern Study

Pattern 2 


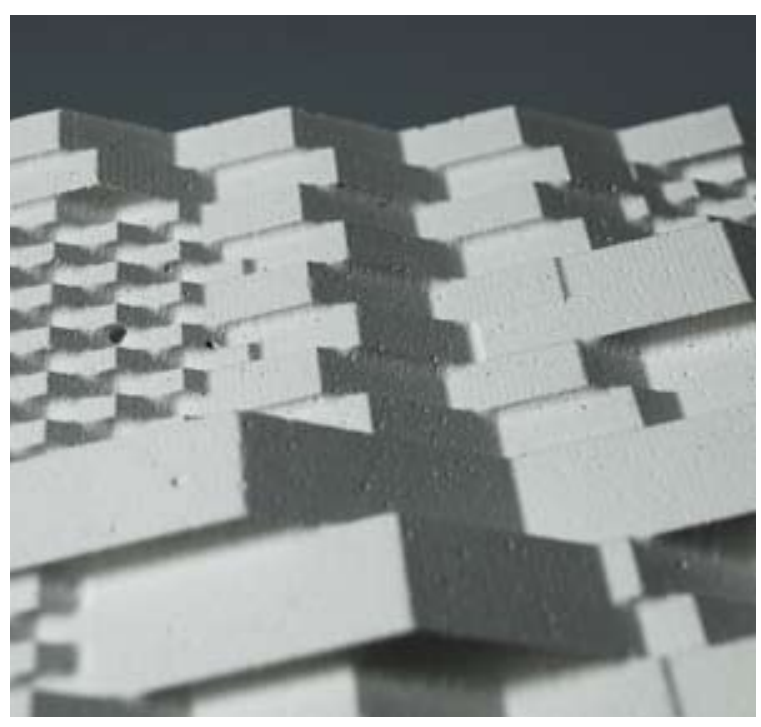

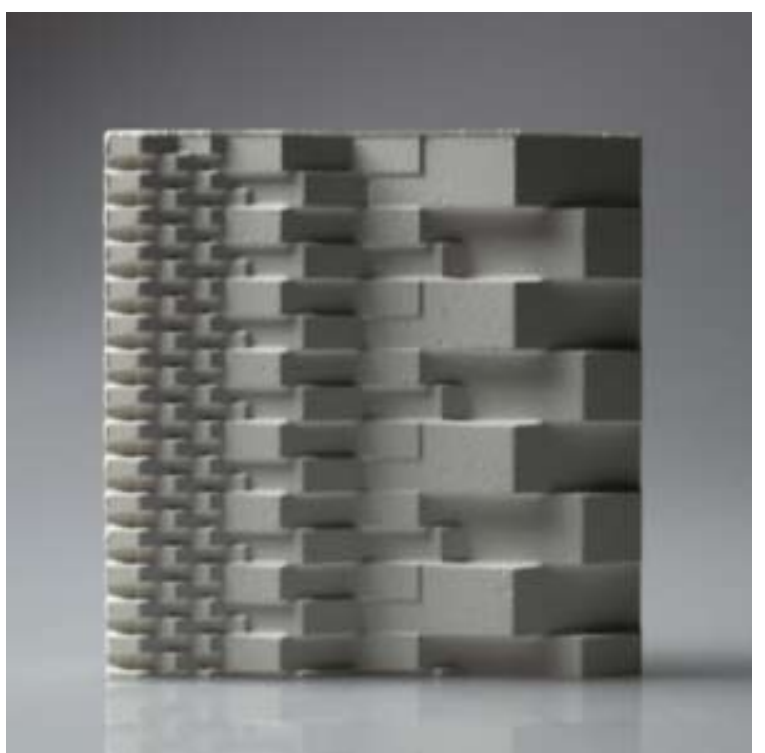

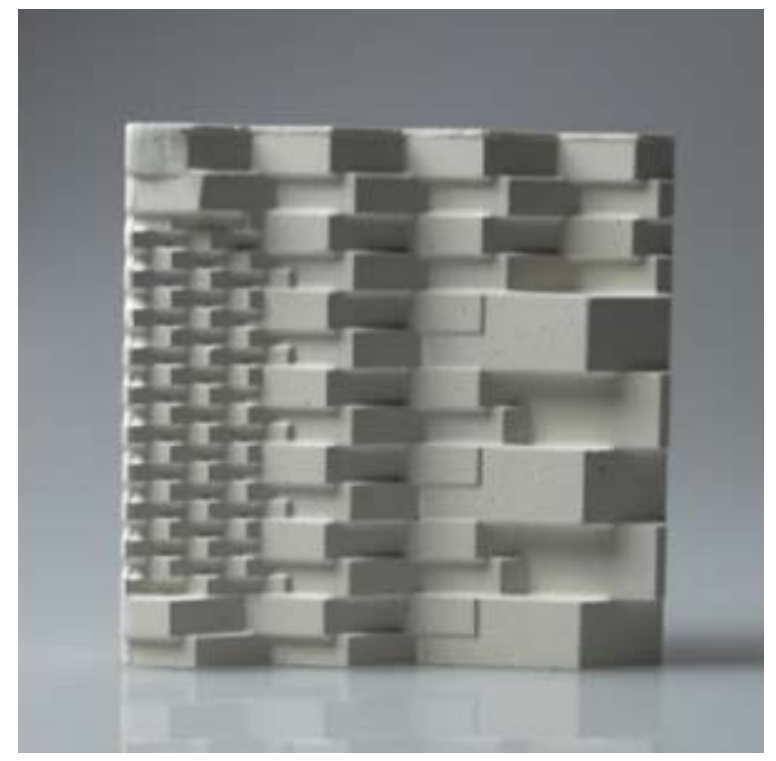

Figure 7.30 - Wall Pattern Scale Study

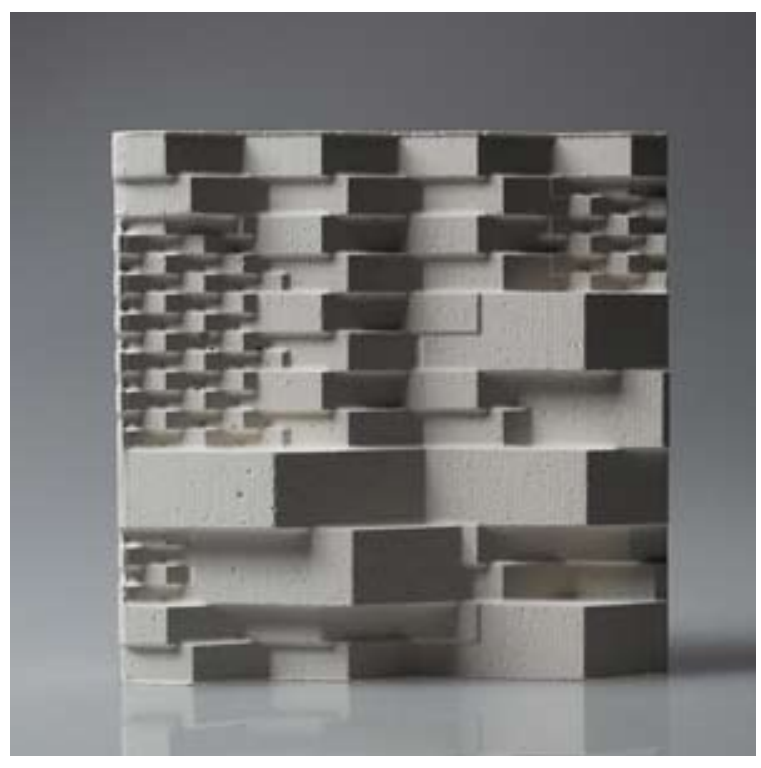

Pattern 2 Continued 
Other factors included addressing safety issues pertaining to a public space. This was where the program of screening and excluding the external environment began to cause compromises within public design guidelines. CPTED (Crime Prevention Through Environmental Design) states that surveillance is an important aspect that increases safety. ${ }^{184}$ To increase surveillance within the acoustic walls, perforations were investigated for their affect on visibility (Figure 7.31). While people are significantly more visible in the first examples from Figure 7.31, the subsequent articulation began to hint towards activity beyond, making the foreground space more elusive. This notion was further developed to create the prototype displayed in Figures 7.32 and 7.33. The wall segment prototype shows how it acts as a mediator and filter of the external environment. With fewer apertures in the back wall the space beyond is rendered increasingly private from the external city condition, while still aiding visibility and therefore safety. The wall is subsequently employed throughout the design in specific moments where increased filtering is desired, specifically where moments of full retreat and silence are to be accessed. ${ }^{185}$

184_ Paul Michael Cozens, David Hillier and Greg Saville, "Crime prevention through environmental design (CPTED): a review and modern bibliography,” April 2005, European Designing Out Crime Network, Emerald Group Publishing Limited, 5 October $2010<$ www.e-doca.eu> 330 .

185- A critique of this disclosed process of detailing the wall could be that it has over stimulated the design, detracting from an aesthetic of silence. While it is true that the finished design differs in this respect to the initial maquettes produced, the

subtle complexities also add intrigue at a close inspection, while blending into the context at an urban scale. The clay bricks are only $200 \times 100 \mathrm{~mm}$ for the majority. By using repetition the design manipulates aspects of religious architecture, but through a modern interpretation of it, aims to create a new and profound experience. 

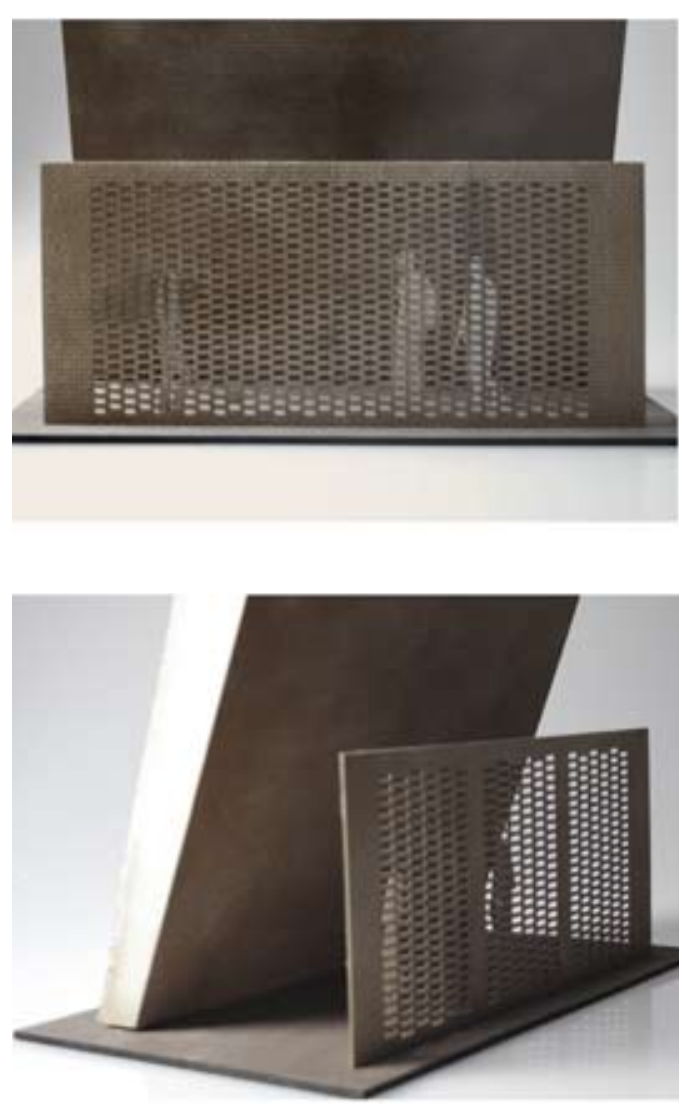

Figure 7.31 - Wall Perforation Study built at 1:20
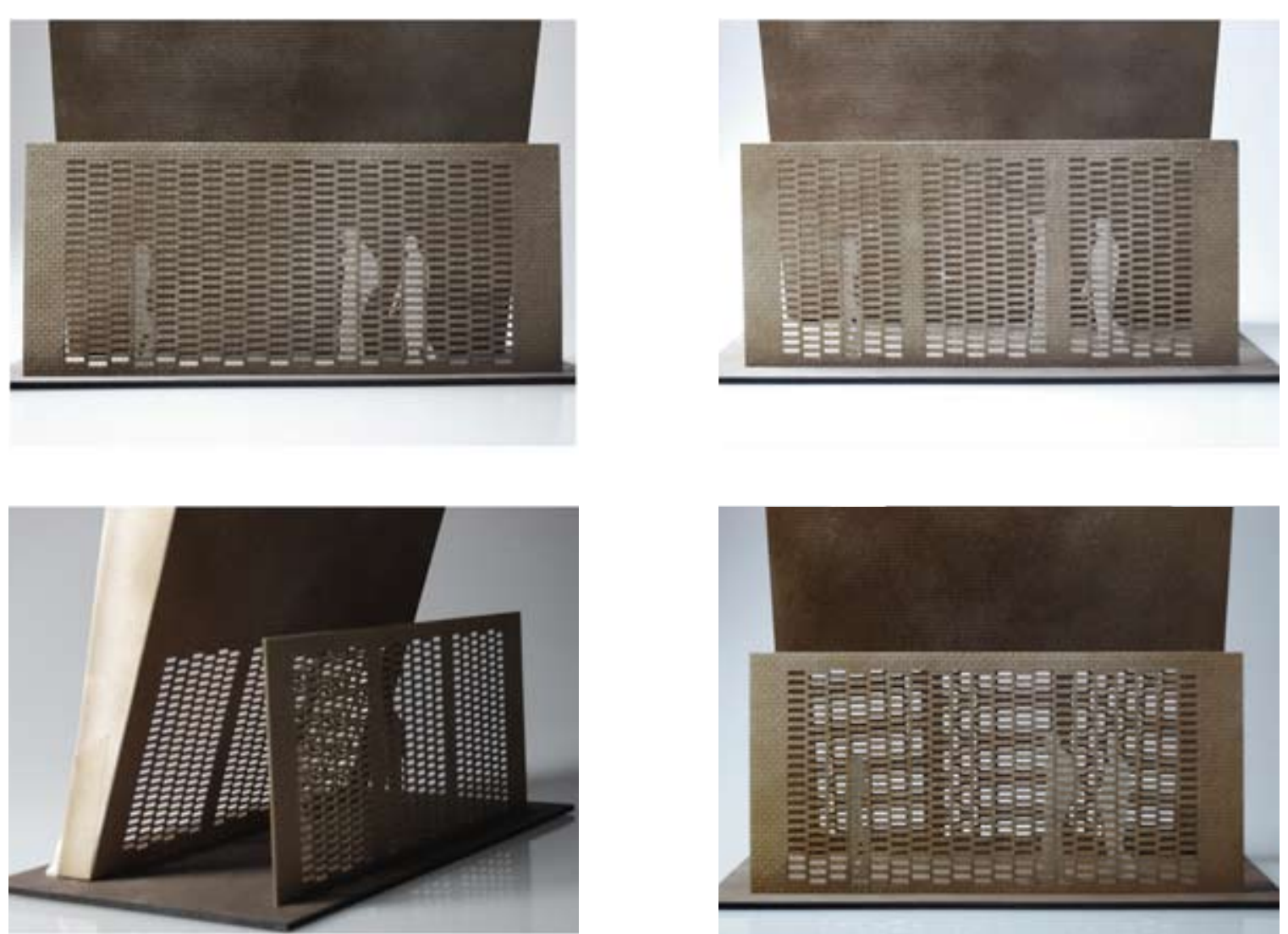

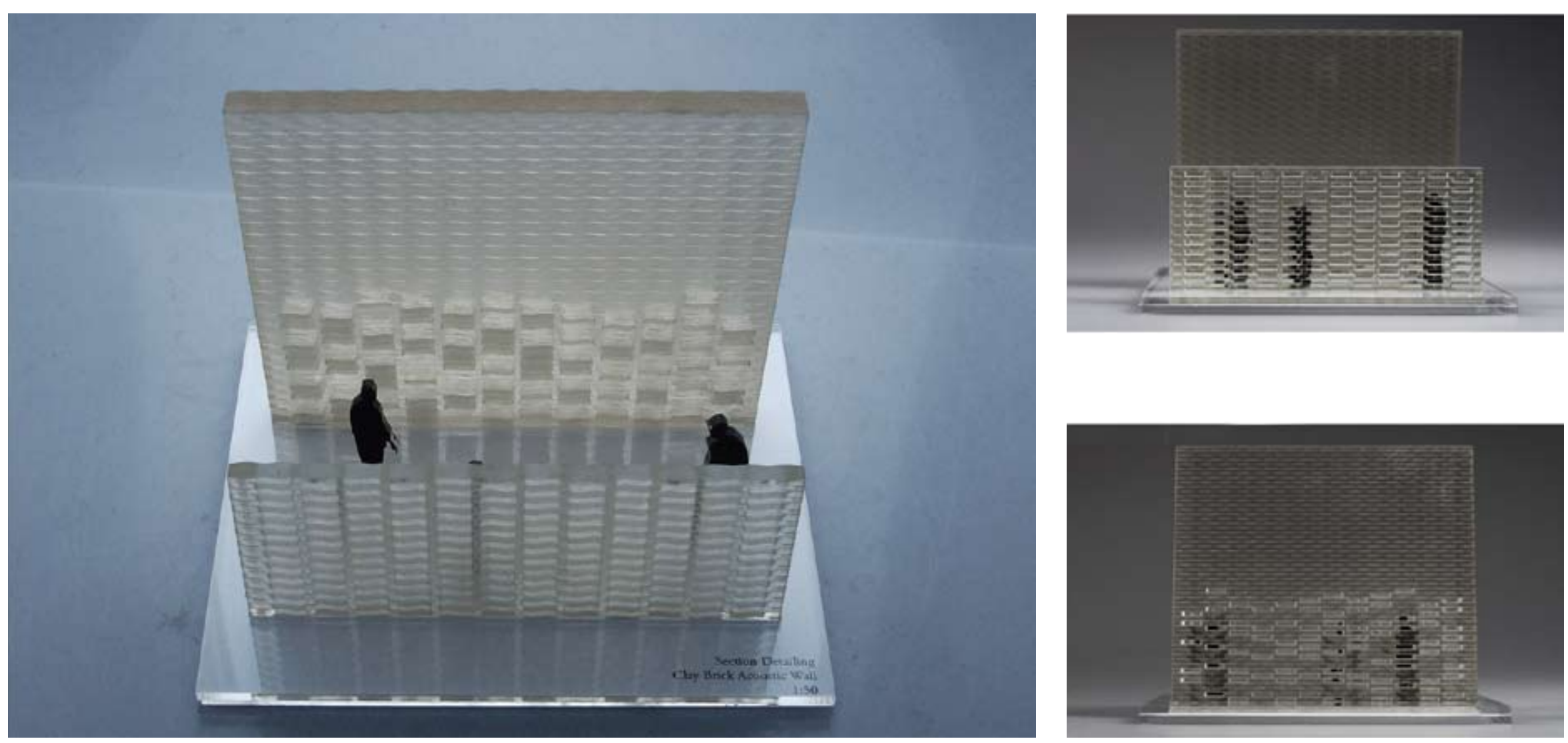

Figure 7.32 - Acoustic Clay Wall Prototype

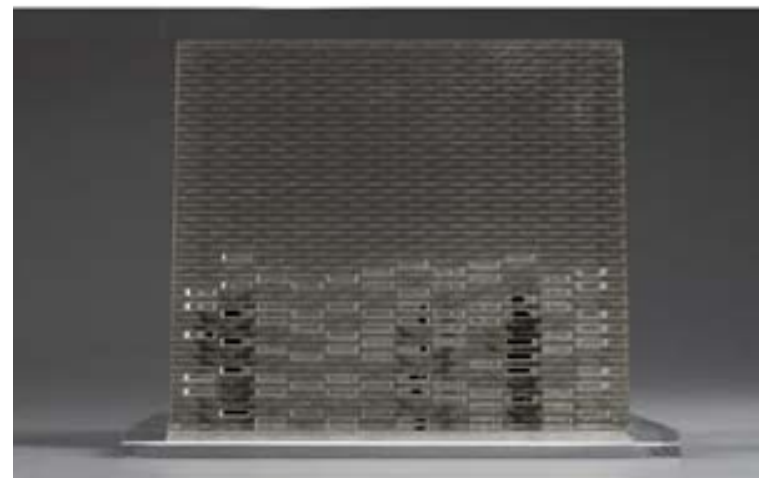



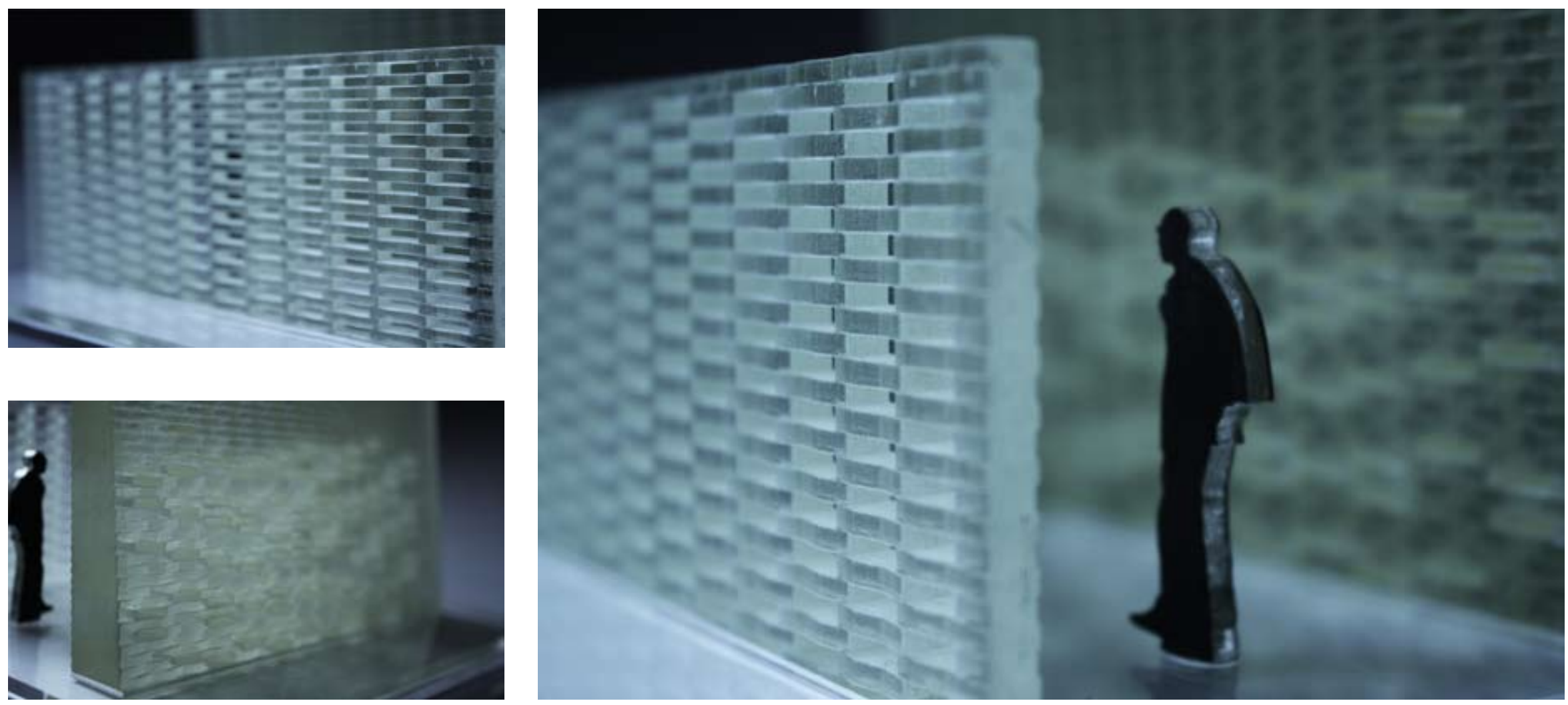

Figure 7.33 - Acoustic Clay Wall Prototype \#2

built at 1:50 

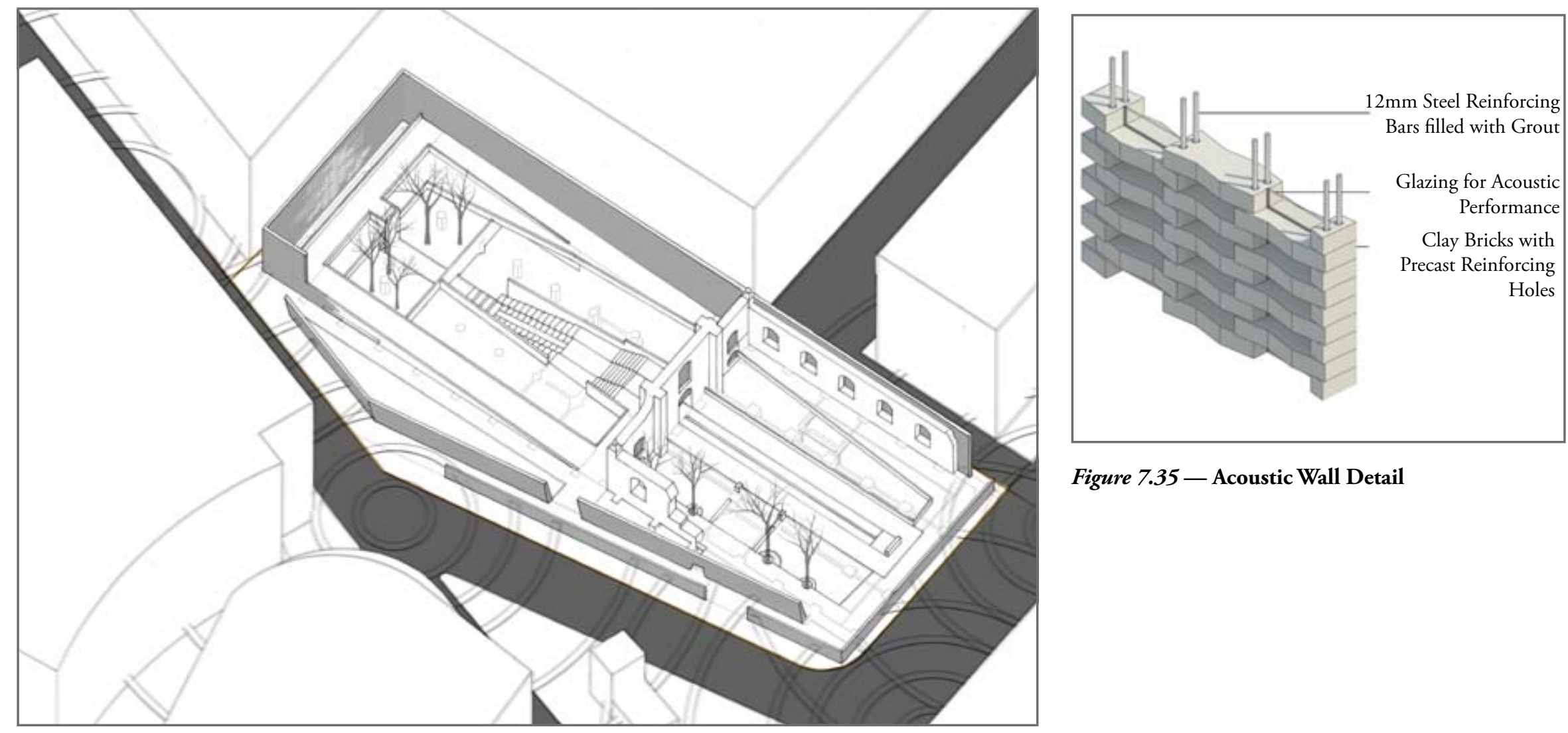

Figure 7.35 - Acoustic Wall Detail

Figure 7.34 - Traffic Noise Diagram 


\section{Circulation and Experiencing Greyfriars Silent-Scape}

The circulation around and through Greyfriars Silent-Scape is a significant element that aids the filtering process. The clay tiled pathways enable the pedestrian to create their own ritual down into the silent spaces below. By offering variety the space appears vast, ${ }^{186}$ and allows a feeling of soft descent similar to meandering through a forest. The multiple ways to access the underground spaces enables the user to exit by a different means than their entrance, therefore completing the journey. Similar to the way monks use repetitive tasks to assimilate silence (as discussed in Chapter 4), the act of continuous walking can generate a stillness which is heightened through specific moments where movement stops and complete silence can take place. ${ }^{187}$

Circulation is derived from evoking the rituals of the past and distorting them for modern day use, creating a shift in their importance. The central pathway is where this is most significantly displayed. This central axis is derived from Maquette 7 (Figure 7.7) and emphasises movement through a perspective view towards the Inaccessible Tree Courtyard. Although pivotal in the role of this silent-scape, it does not lead to any of the climactic points within the design without the person undergoing a series of strict right angled turns. These climactic spaces are located throughout the underground level and will be discussed in relation to silence shortly. As through complete removal into the quiet of the underground comes the ability to hear again.

The design uses levels as a way of creating separation from the city (refer to section in Figure 7.41). Highlighting this is the Ground Level where the majority of the pathways are located, continuing the movement from the city into the architecture. The Intermediate Green space is the next step down towards complete retreat. Still open, the green space is multifunctional but distinctly removed from the movement of the city. Lastly there is the Underground Level. This space is less rigidly defined, with pavers suggesting pathways in the open area (Figure 7.40). There are moments within this space that have been designed for increased stillness

186 - Rachel Kaplan and Kaplan Stephen, The Experience of Nature: A Psychological Perspective (Cambridge: University Press, 1989) 152.

187- The lack of a definitive ritual into the underground space can be a cause of critique. One could argue that by designing for exaggerated movement the park becomes 'loud' and without one specific path powerful notions of ritual have been lost.

However, through research into samu as discussed in Chapter 4 it is clear that a meditative and silent state can be reached

through labour in a tranquil environment. Strictly controlling movement is often a difference between landscape architecture and architecture. By allowing for multiple uses of the space it is my hope that it becomes versatile for the public to enjoy, rather than weakening the journey to the underground. 
through opportunities for meditation/contemplation. One of these spaces is located behind the Inaccessible Tree Courtyard (Figure 7.47). Focused on Tadao Ando's belief in a pure connection with the sky, this clay tiled space is a still moment surrounded by movement. ${ }^{188}$ A seat of rough clay with embedded timber stretches along the space that highlights the texture of the ruin, and observes the changing in scale of the clay brick wall. The wall pattern merging at this point brings into prominence the method of repetition applied throughout the scheme to aid contemplation. As architect Christopher Day elaborates in his book Places of the Soul, "unified materials... have a quietening influence." 189 This collective space employs a person to sit quietly, eat their lunch, and let their gaze wander as they observe silence.

A space of intimate silence within this design is under the Ground Level grass and seating area (Figure 7.48 and 7.49). Technically an indoor space, this underground area comprises of a waterfall and four London Plane trees (relocated from elsewhere in the site). The tree trunks are treated with seating independently to create a specific connection with different elements, rendering each unique. These elements are; nature, shadows and the passing of time, the external weather (with rain trickling down an imbedded gutter system), and illumination of the historical ruin (Figure 7.39). These spaces suggest solitude but are open to each other, instilling a sense of safety and connectivity. Artificial lighting is used sparingly in this example to enhance a subdued and contemplative atmosphere.

Water is used throughout to augment the atmosphere of Stille within the scheme. Beginning at the East and West ends, water quickly trickles down to the Underground Level. This disappearance from Ground Level is used to de-stabilise the journey and reinforce the Underground as the secure and sombre element in this silent-scape. The continuation of the water's imprint in the Ground Level's central pathway creates a dialogue of presence and absence. The absence evokes a silence; as does the ruin on the site evoke a similar sense of absence and silence. Ripples from the two waterfalls meet at the centre, in-between the foundation of Wren's tower. This moment is able to be viewed through a fragment of the tower itself, and is one of the highlights of the underground space (Figure 7.52).

188_ Marc Treib, "Silence may be the most Significant Gift an Architect can give a Noisy Society," Metropolis 10.6 (1991):

189- Christopher Day, Places of the Soul: Second Edition (Oxford: Architectural Press, 2004) 210. 
The most prominent materialisation of nature in the design is the Inaccessible Tree Courtyard. This space takes the place of an altar, acting what on surface level is seen as the destination of the central axis, but is soon realised to be an element of circulation and filtering. Similar to the mature forest at Bibliothéque Nationale de France, you may enter into a contemplative state as you circle the trees and bush without having access to it (see plans in Figures 7.37, 7.38 and 7.39). The wild nature of the trees contrast the otherwise highly controlled park, referencing Zen gardens. As an artefact in a gallery is shroud in glass, this nature is simultaneously protected from the profanity and noise of the city, and celebrated as something pure and beautiful through its containment.

A functional aspect of the design was the integration of gates to block off the underground areas at night. This was required due to CPTED guidelines. By limiting access and incorporating lighting, the park that is experienced during the day becomes an artifact to view at night (Figure 7.36).

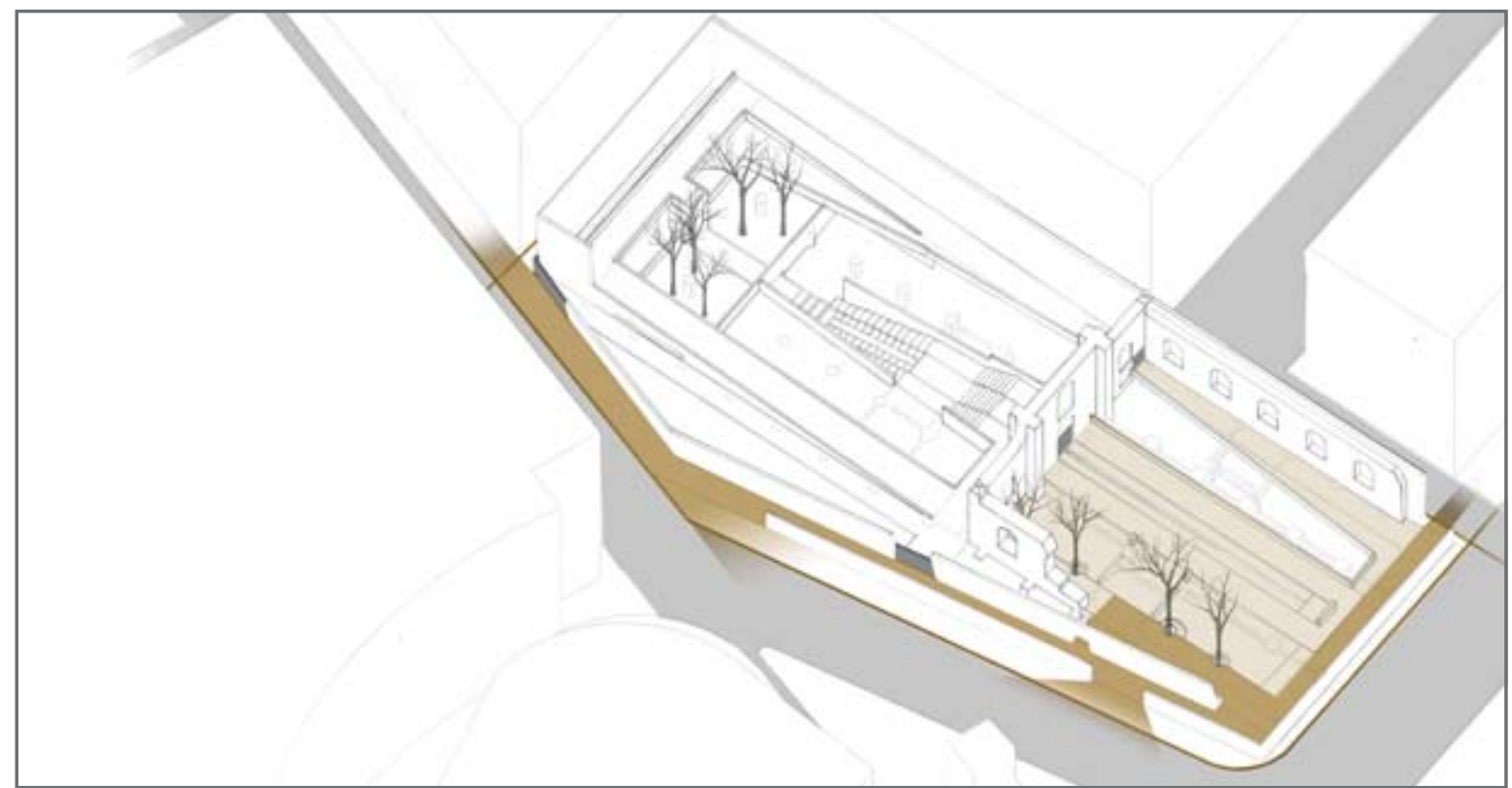

Figure 7.36 — Night Gate Diagram 


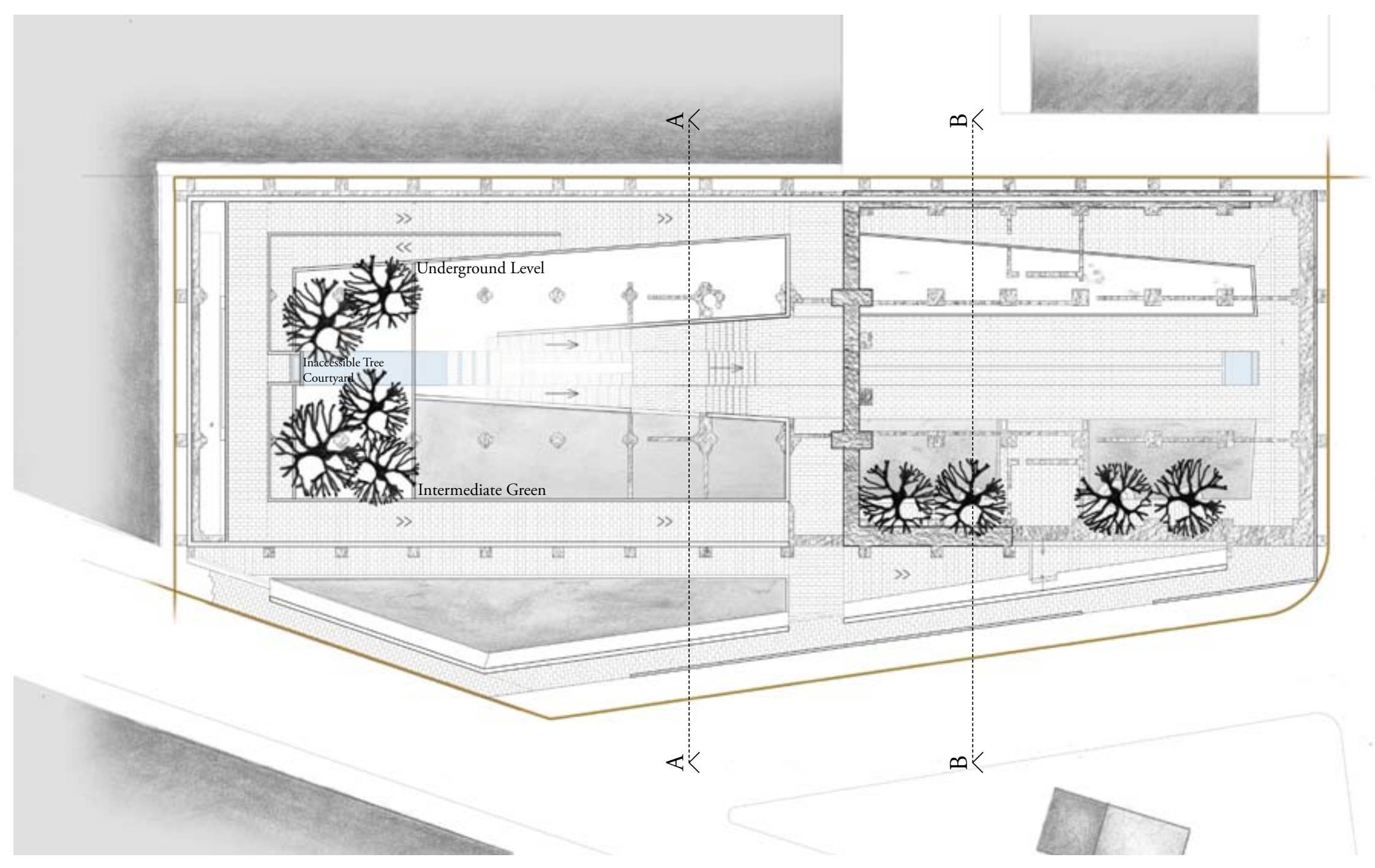




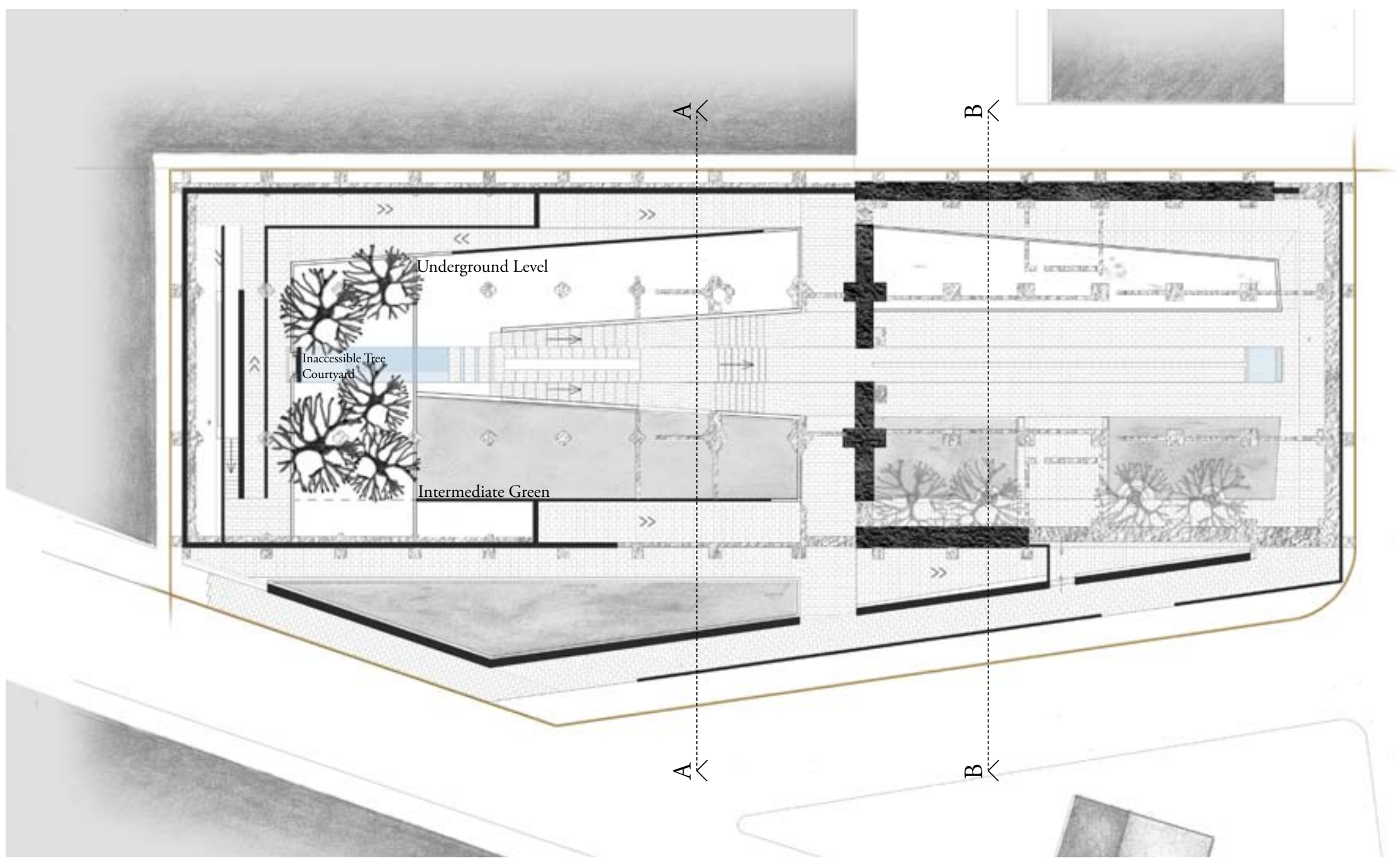




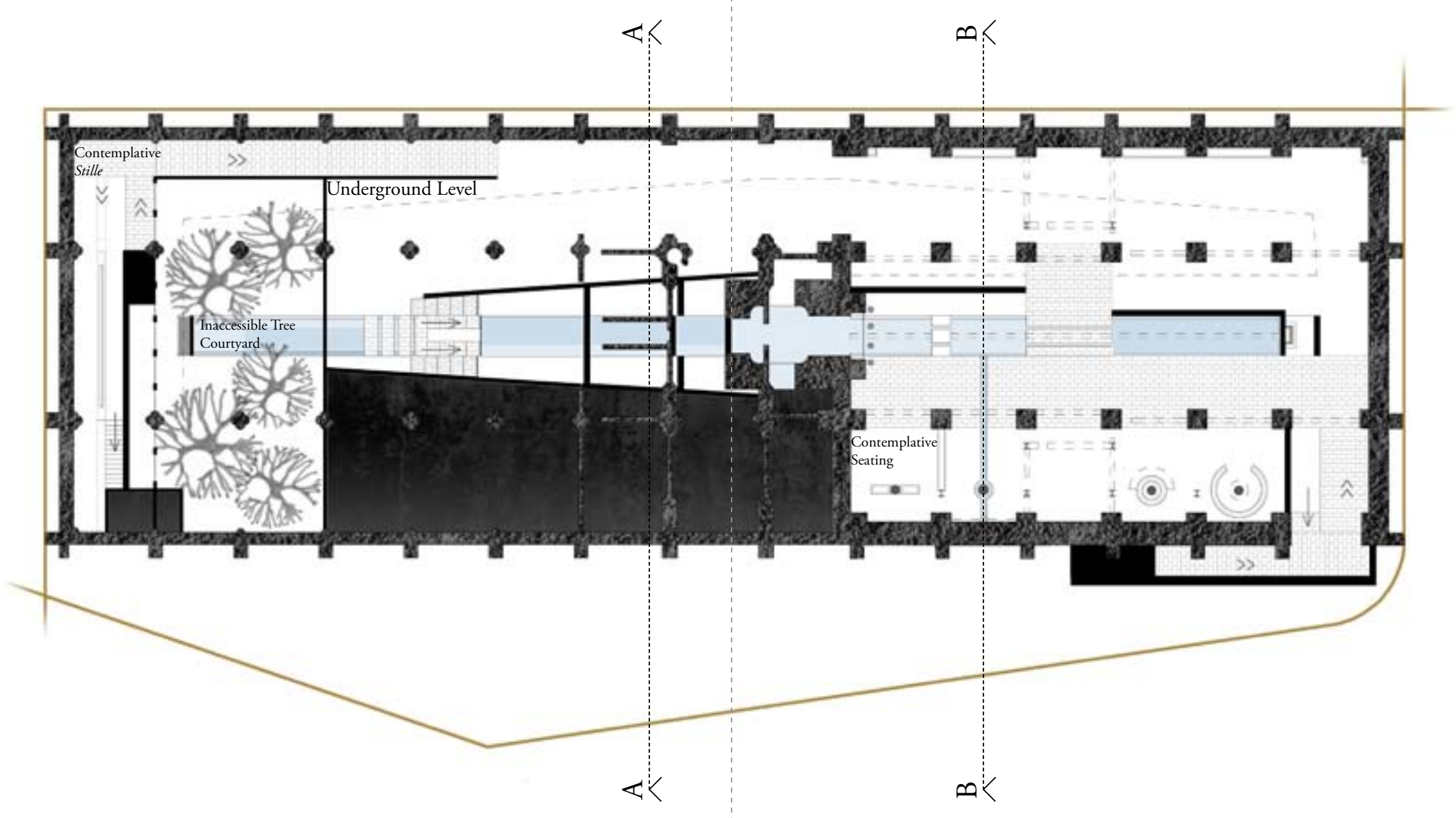




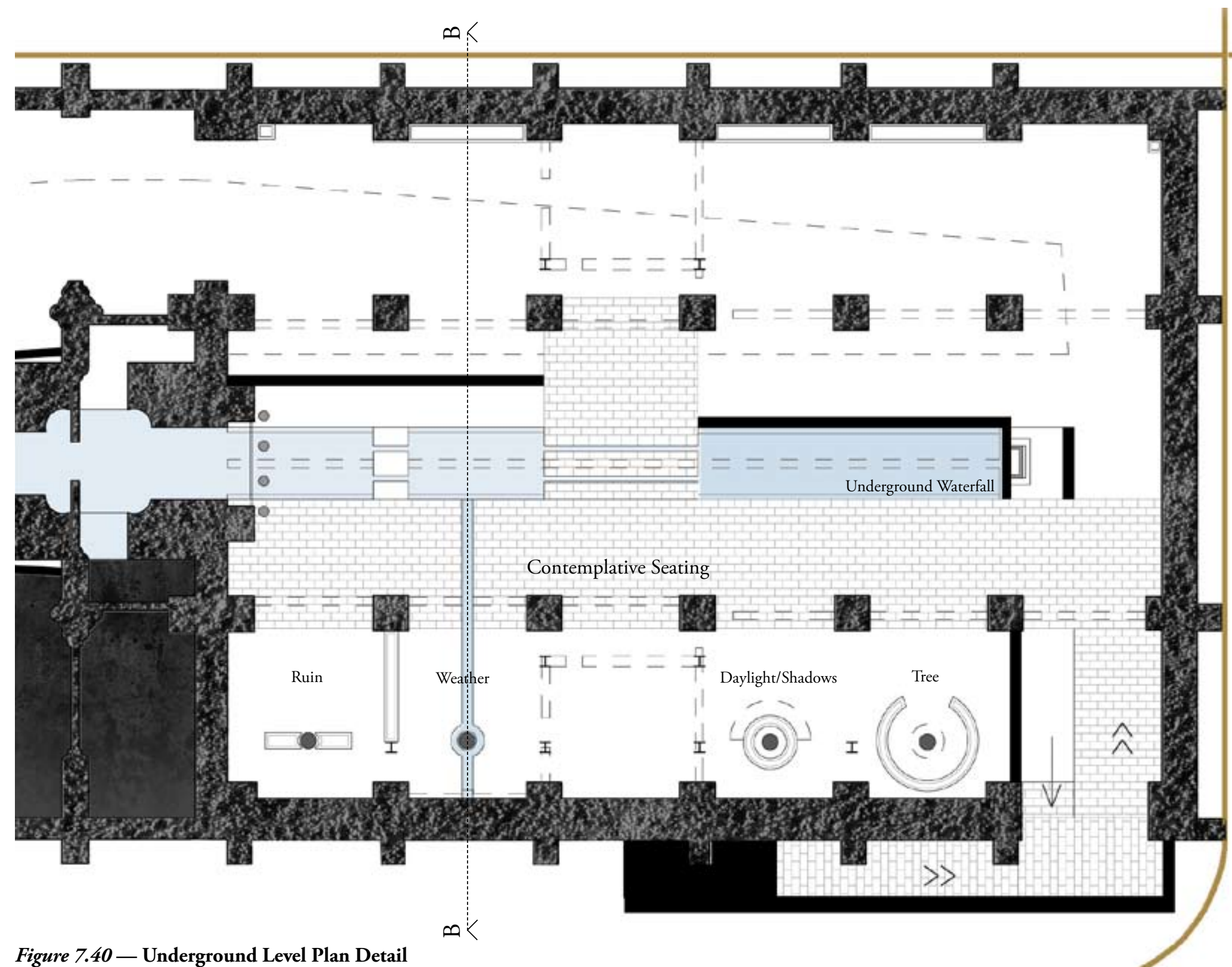




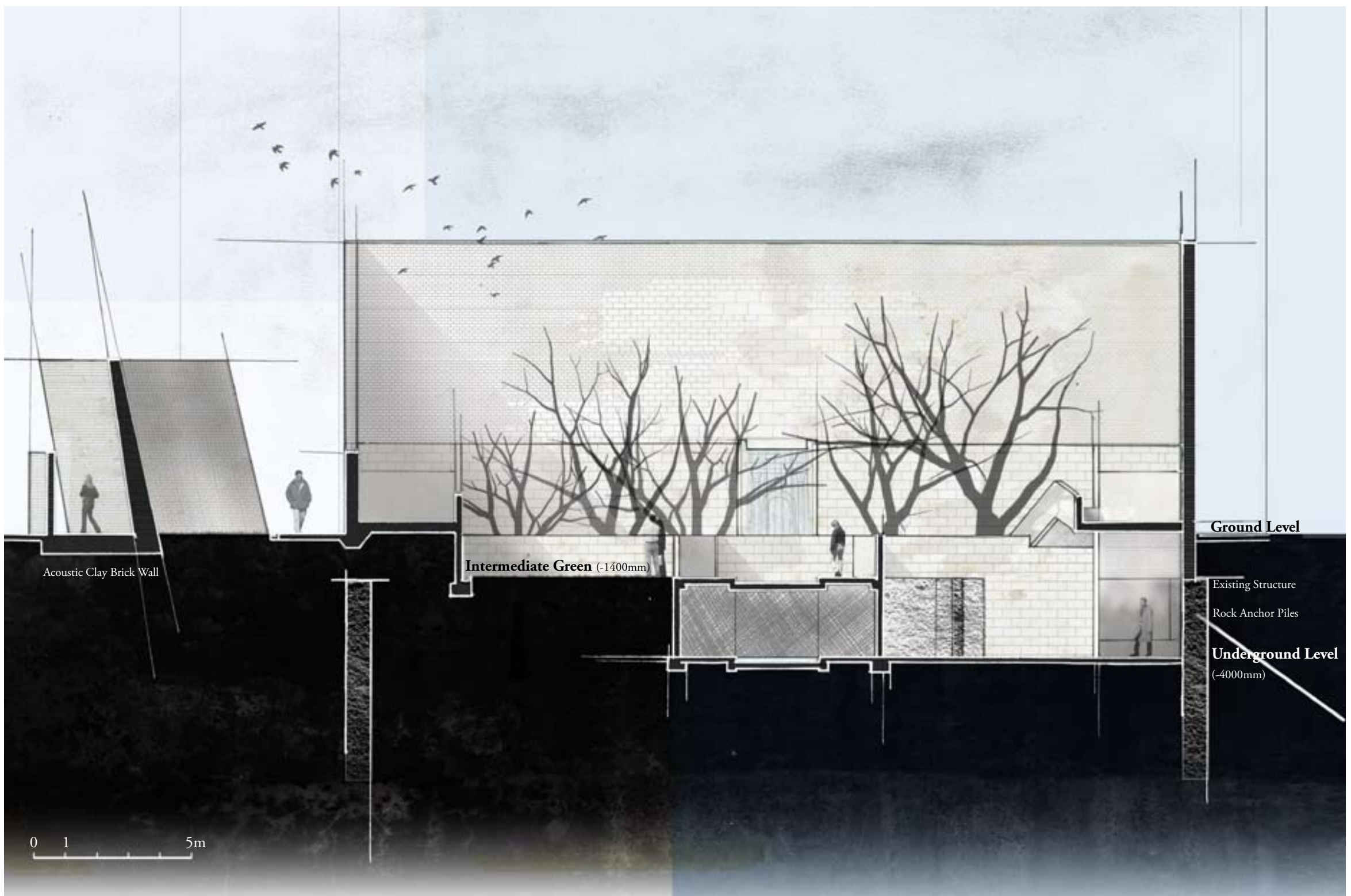




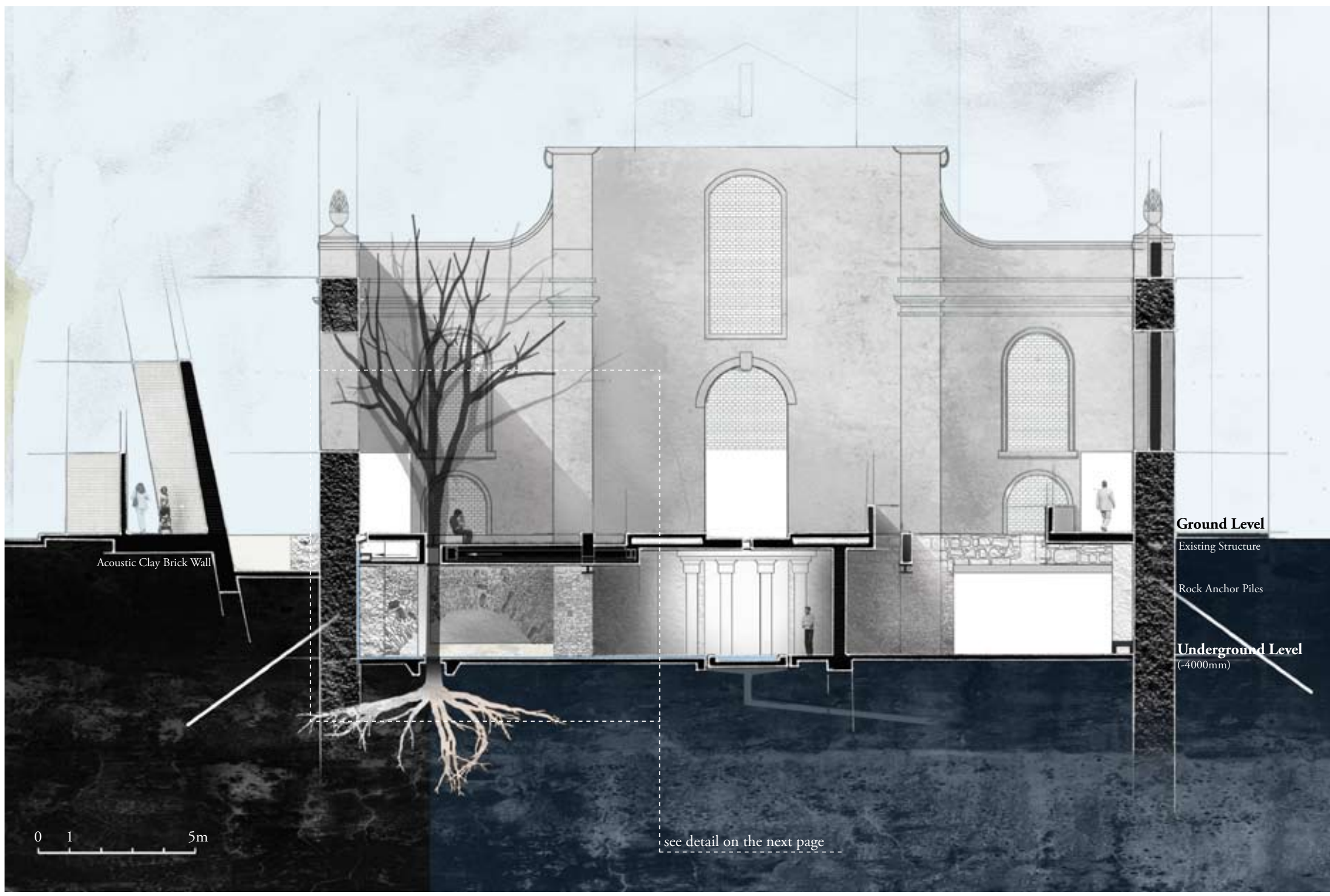

Figure 7.42 - Cross-Section BB 


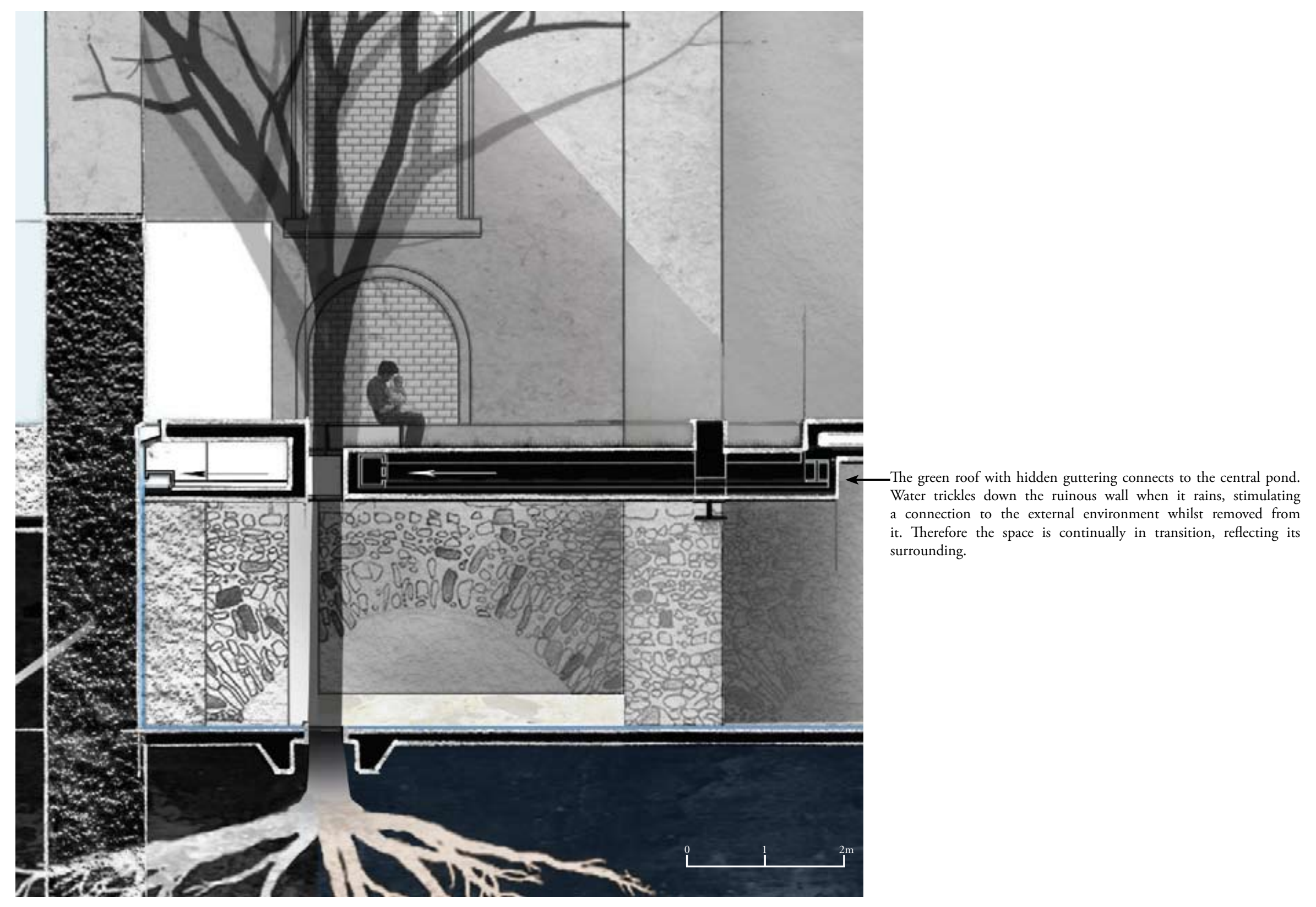




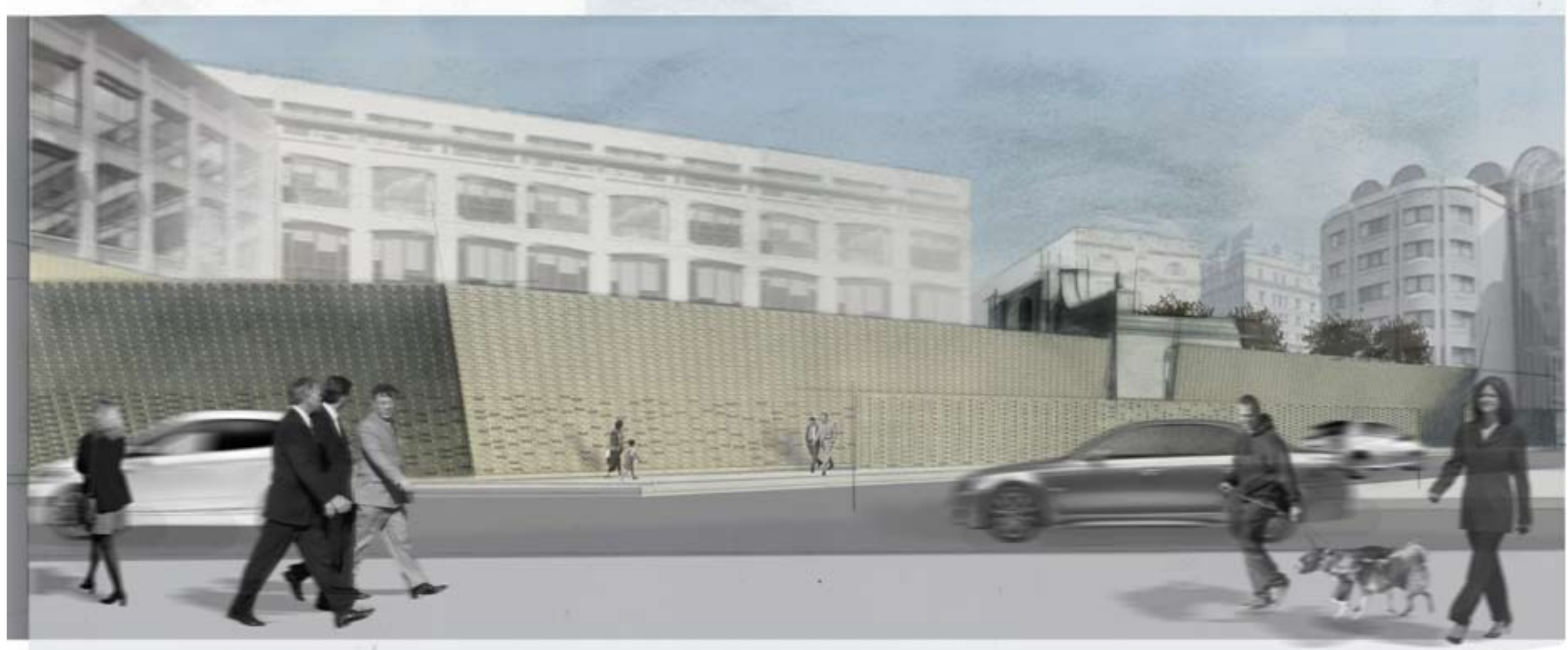




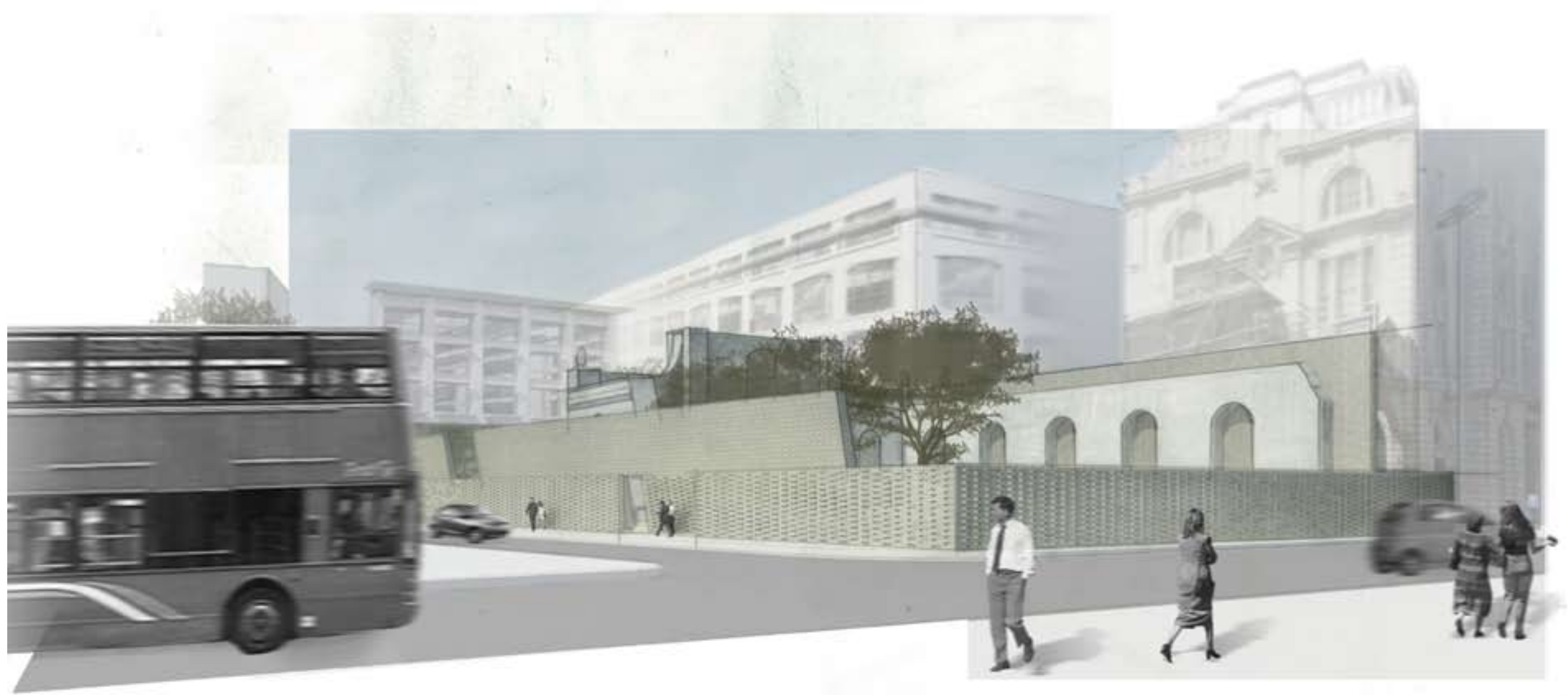




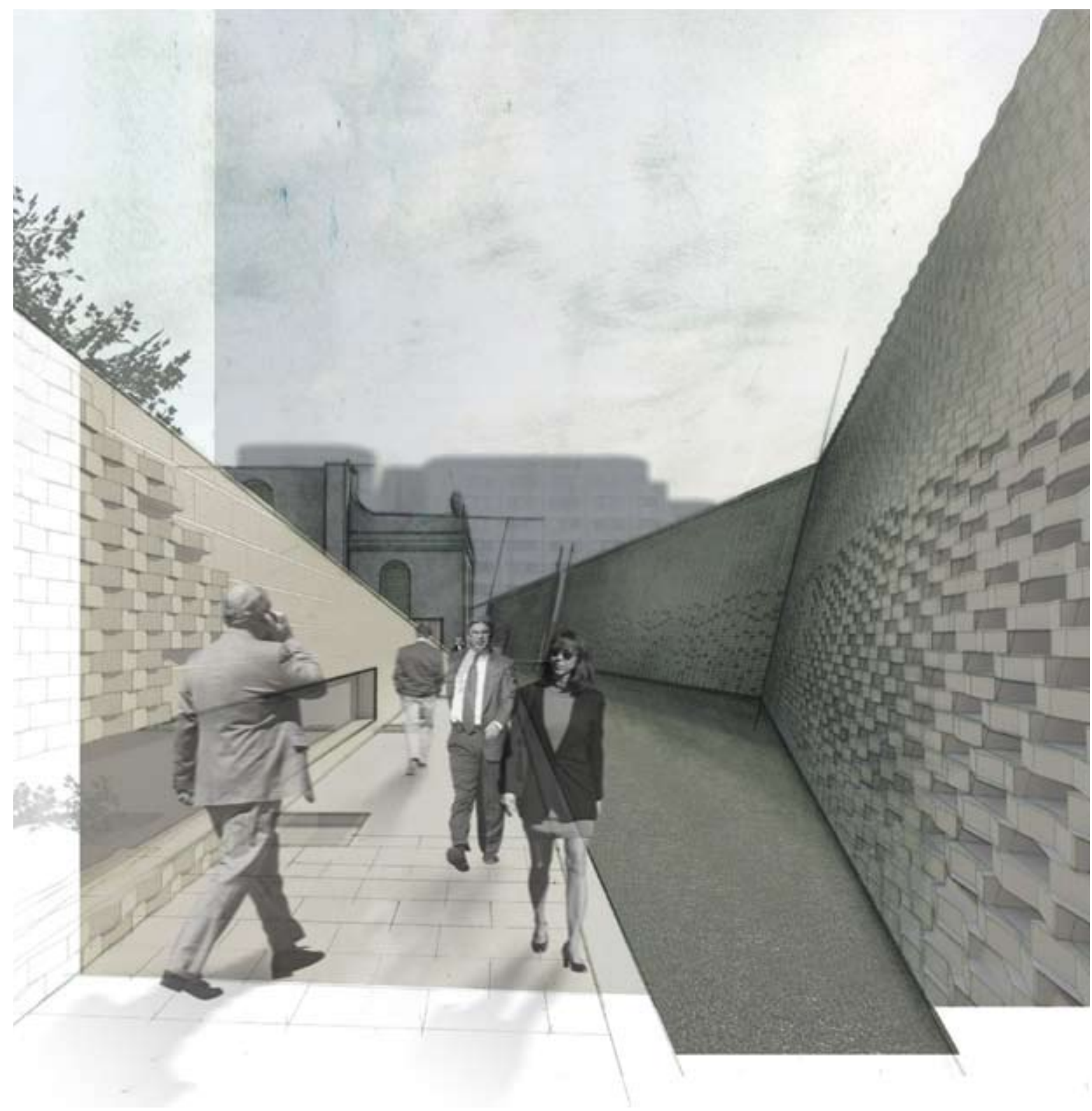

Figure 7.46 - Filtering the External Environment 


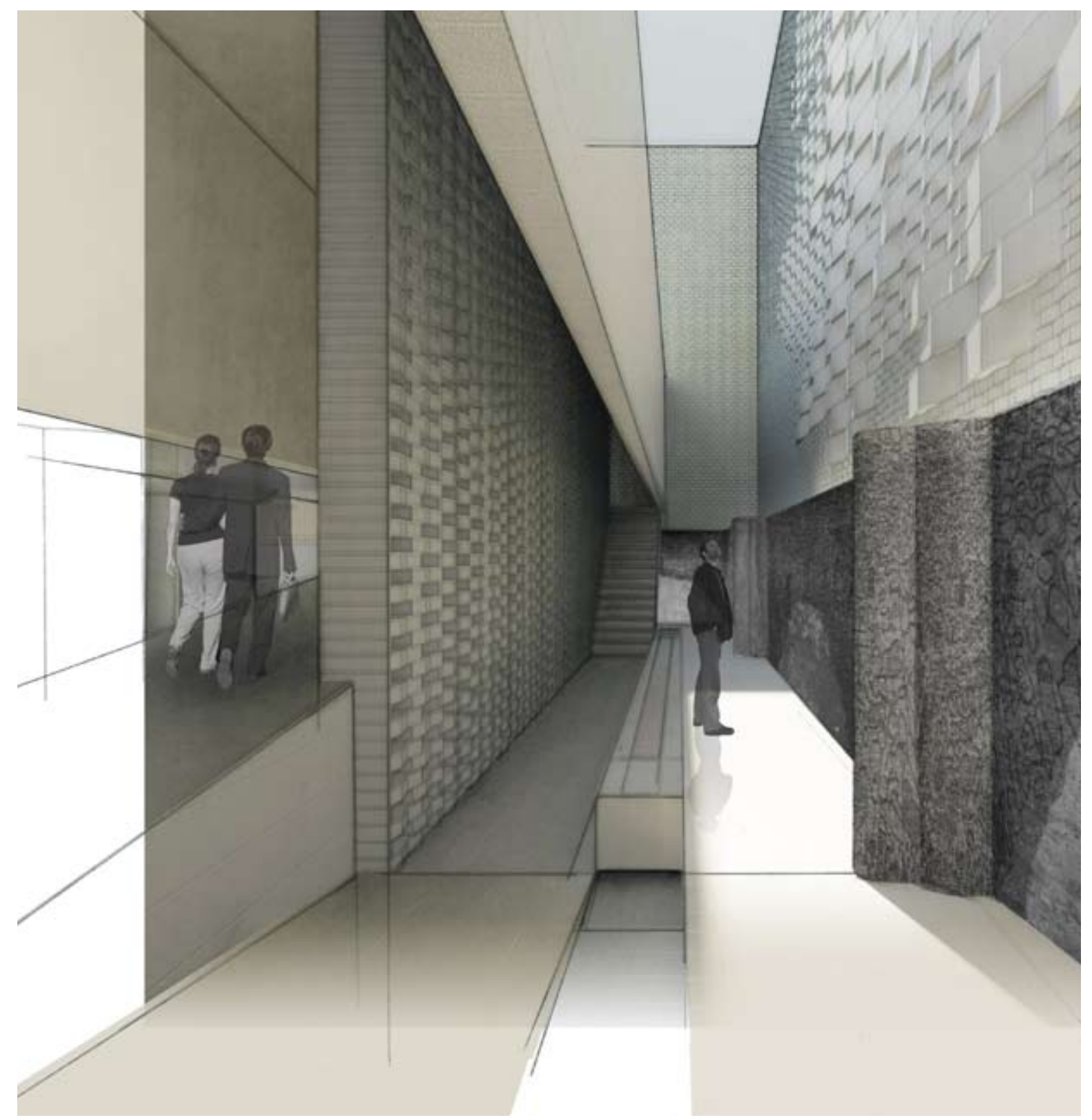




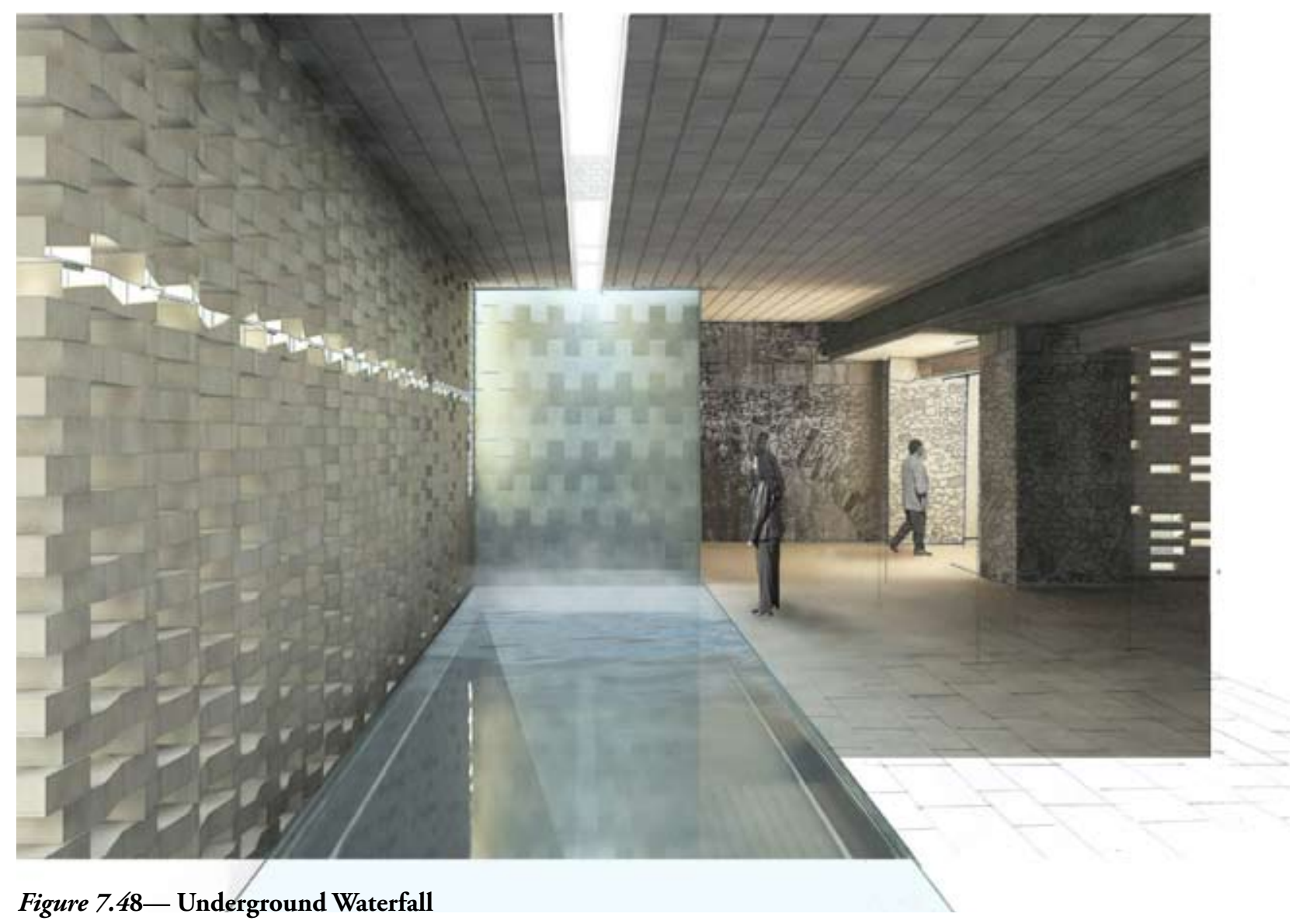




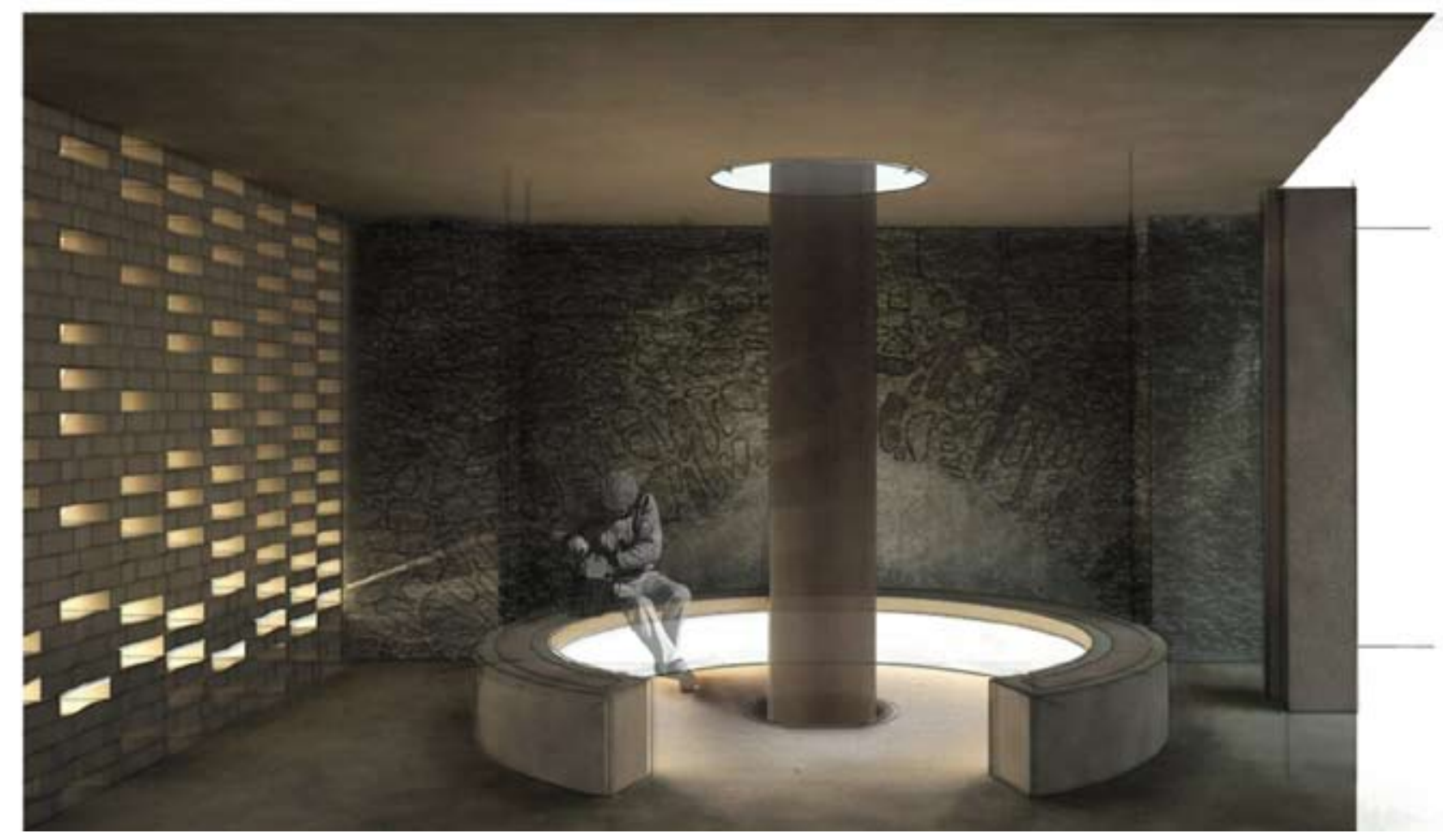

Figure 7.49 - Contemplative Seat 


\section{Tower Manipulation}

Another factor in this design was the strategy employed for dealing with the remaining Wren tower. The strategy was a method of fragmentation and may be viewed as controversial but is the most appropriate strategy for this particular scheme. By fragmenting the tower and subverting it in the design through its material use as a central pathway, the tower becomes a part of the ritual of removal from the city, and once again a part in the sequence towards attaining silence. This fragmentation is similar to how it was previously fragmented following the WWII blitz. ${ }^{190}$ In addition some would argue that since the restoration of the tower has focussed only on the exterior, while completely transforming the interior, it has lost an important part of its architectural heritage. Such facadism is common amongst restoration projects. ${ }^{191}$ By re-using the materials from the tower its external envelope is present in the scheme, only much subtler and landscape design orientated (Figures 7.50, 7.51 and 7.52). 


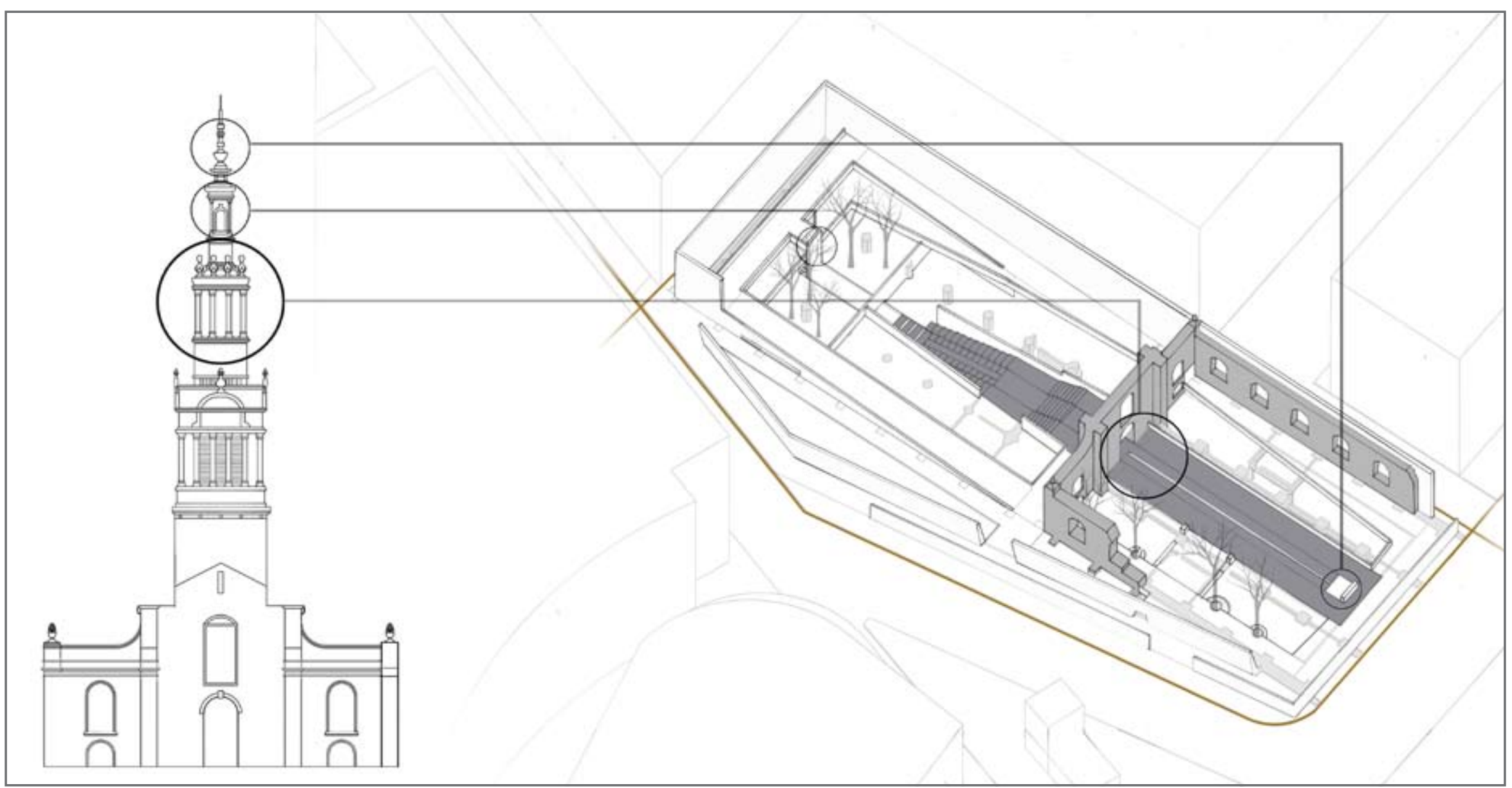




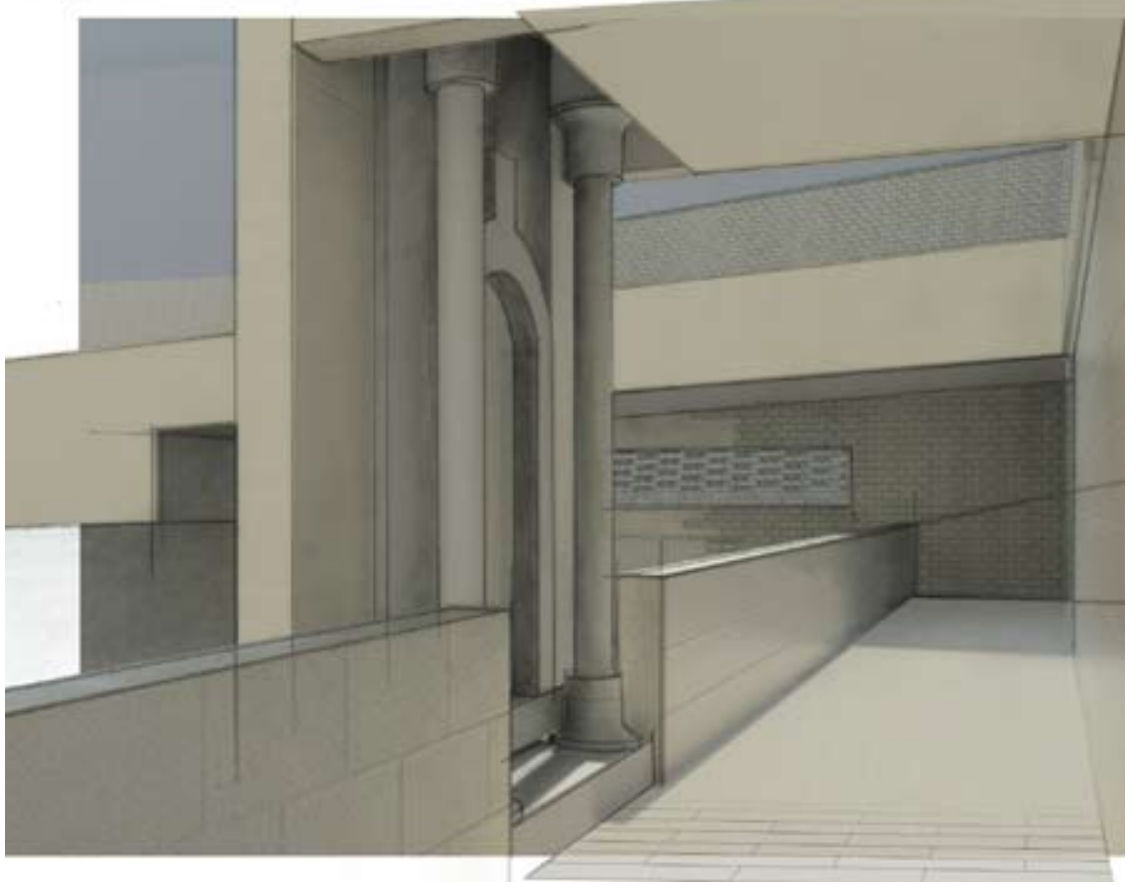

Figure 7.51 - Fragment Behind Waterfall

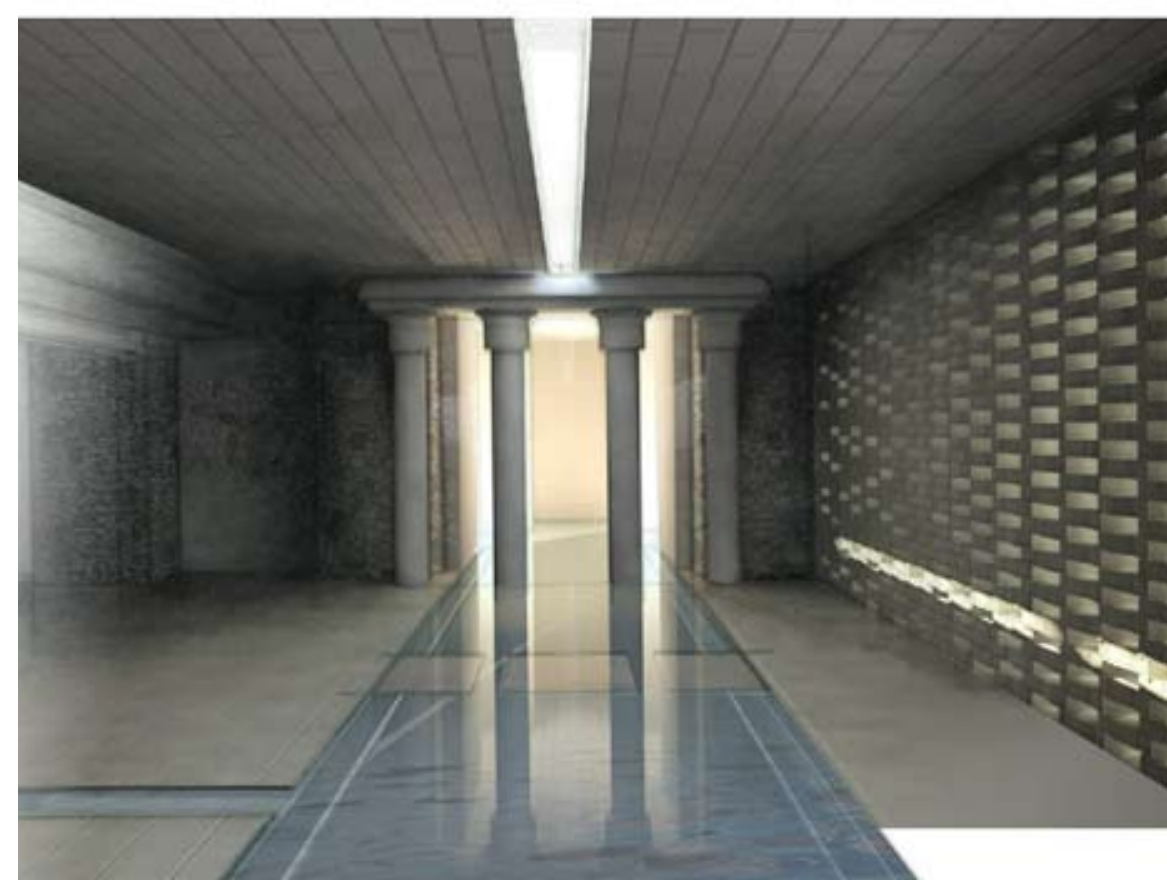

Figure 7.52 - Fragment Underground 


\section{Conclusion}

Greyfriars Silent-Scape uses many techniques to create an atmosphere of Stille. The tightly controlled landscape bars unwanted noise whilst ensuring that the fast pace of the city is calmed. By contrasting movement with stillness, and control with wild, the park offers multiple experiences for the user. It challenges the role of religion in society through its re-appropriation of the religious site for a modern use. At the same time it's respectful of the past and utilises the ruinous foundations to inspire a mode of contemplation through commemoration. This design is a bold statement towards the importance of collective silence within the confines of the city. It demonstrates the richness that can be achieved through an intense investigation into the conditions of site and the embracing of nature in an urban setting.
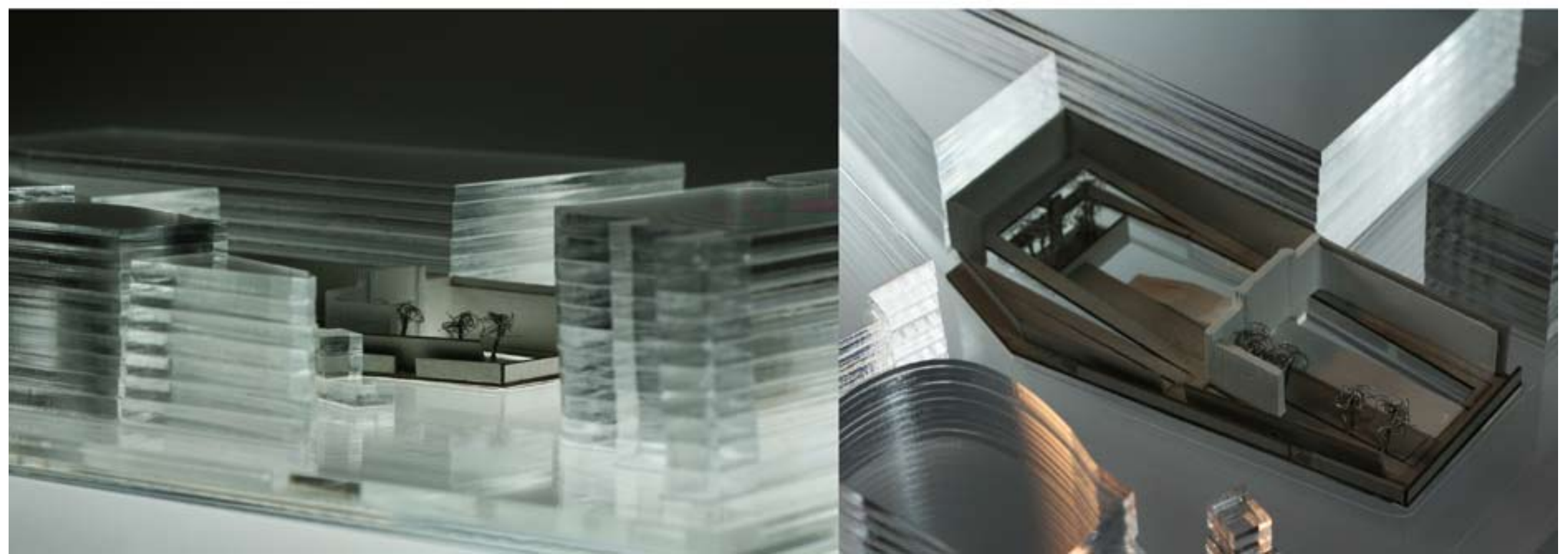

Figure 7.53 - Site Model: Greyfriars Silent-Scape built at 1:500 


\section{Conclusion}


This thesis investigated the ways in which the city can be a stressful and noisy place to live in. It has demonstrated the importance of accessing silence in an urban dweller's life and has outlined ways silence can be manifested. Ultimately this research has lead to the design of an architectural silent-scape. The following are the significant conclusions attained from each chapter and how they affected the resulting design.

Chapter 1 highlighted the city as vibrant, busy, but also stressful. Lack of control over urban stress was identified as the true detriment to peaceful city living. Urban noise and visual overload established the need to experience retreat to contrast the hectic rush of the urban hive. As it's the perceived lack of control over the stimulus that is the true detriment, providing moments of retreat in the city was recognised as one way to re-establish that sense of control. The next chapter introduced the notion of silence. Research into its presence in different cultures identified the existence of two understandings of the word in the German language. One translation, Stille, means silence but suggests an experience such as a beautiful and calm landscape. This definition was thereby used throughout the thesis when discussing silence as a moment in time.

The writing of Max Picard and Juhani Pallasmaa highlighted the need for silence in society and architecture. A summary of Picard proved that his belief in the loss of silence coincides with the lessening of religion in society. Pallasmaa, on the other hand, defined it as architecture's duty to "maintain and defend silence." ${ }^{192}$ His belief is that the role of silence has now come upon the architect for its successful integration into society.

Secularisation was identified in as an element that lessens interpersonal relationships and access to silence. As secularisation is a continuing trend in the West it opens the community to new spiritual experiences (sectarianism). This research suggests that silence can be spiritual to the secular person. To identify the stillness that is lessening from western society, an investigation into Christianity demonstrated how it is manifested. Dominant architectural characteristics in Christianity that inspire silence are ritual, repetition, perspective, and infinity. All of these were manipulated into the resulting secular design. Buddhism was also discussed as a religion that is becoming increasingly influential in the West. An investigation into Buddhist Zen gardens 
demonstrated a strong connection to nature and a natural aesthetic. It is through nature that Buddhism inspires Stille.

Cities already provide for secular retreats into silence within galleries, libraries and museums. An exploration into Das Kunstmuseum Kolumba and the Jewish Museum in Berlin helped establish that the most potent moments of silence in these schemes are located outside of the program of each. These spaces (the Commemorative Space and The Void) were designed for purely contemplation and are more powerful as a result. Further research into the manifestation of secular silence found it most prominent in nature. Theory from Guéguen, Darwin and Thoreau demonstrated the qualities of natural silence, which highlighted how it is as provocative as the silence found in religion. This in turn led to a discussion of city parks and how small-scale integration of nature into the city is currently unsuccessful in creating Stille. Too often they rely on the appearance of nature to create mental release from the city, rather than physically facilitating it. This is an area of critique that was further explored in the design process.

Analyses of case studies were significant in understanding the role of ritual in retreat. Researching past examples of architectural silence helped gain knowledge of how to proceed in this modern context. The design program and outcome reflect the case studies that were selected to illustrate the research. Examples included, the subtle use of materiality and incorporation of Buddhist ideals in the Church of the Light and the articulation of nature inspiring contemplation at the Bibliothéque Nationale de France. Similarly the Woodland Cemetery and its use of strongly controlled nature combined with ritualistic movement provided impetus for design.

After completing these analyses I saw an opportunity in creating a small-scale landscape that could incorporate significant features of silence. As buildings are strong elements in attaining silence in the city it was deemed that a hybrid design between landscape architecture and architecture would be devised — otherwise termed a silent-scape.

The process of maquettes was pivotal towards the success of the design. By physically producing a visual summary of each chapter I was able to understand important aspects, and through singling those out I could analyse them for their integration or exclusion in the final product. Likewise the in-depth study of the site conditions of Christ Church Greyfriars, both today and historically, 
gave rich context to manipulate. These two aspects gave my research grounding and proved the intricacies involved in manipulating silence. It's important to note that this design is not the only solution for the issue of visual and aural urban noise, but for the precise context of Greyfriars in the City of London it is the most appropriate. It demonstrates how green space can be further articulated to provide a community retreat, and how qualities of silence can be used diversely to enhance a retreat experience. Through filtering the cityscape with perforated walls and utilising levels to further the separation process, I endeavoured to remove the beholder slowly from noise and chaos, down to silence and calm.

A difficulty encountered was mixing the program with the phenomenon of Stille. The desire for a public landscape resulted in limitations on the design to preserve safety. I adhered to these limitations through subtle manipulations (as in the example of the acoustic wall process) so that both desires could be met. Unfortunately, this meant that night-time access had to be limited and no space could be entirely cut off from the view of other people, lessening the degree one could create moments of solitude or removal. This is an example of how a building program would have been easier to manipulate than a landscape.

As urban conditions that stimulate stress and alienation continue to rise, I suggest future research and design will focus more heavily on providing public retreat through silence. Retreat into a connection with nature is the ideal method of stimulating this silence in a community setting. Not only could this help diversify the urban experience, but it would establish a realistic opportunity for the urban environment to provide moments of Stille. 


\section{Bibliography}


Bachelard, Gaston. The Poetics of Space. Trans. Maria Jolas. Boston: Beacon Press, 1969.

Barrie, Thomas. Spiritual Path, Sacred Place: Myth, Ritual and Meaning in Architecture. Boston: Shambhala Publications, Inc, 1996.

Baum, Andrew. Jerome E Singer and Stuart Valins. Advances in Environmental Psychology: Volume 1, The Urban Environment. New Jersey: Lawrence Erlbaum Associates, 1978.

Bell, Daniel. "The Return of the Sacred? The Argument on the Future of Religion." The British Journal of Sociology 28.4 (1977): 419-449.

Berthier, Francios. Reading Zen in the Rocks: The Japanese Dry Landscape Garden. Trans. Graham Parkes. Chicago: University Press, 2000.

Birch, J. H. "The Franciscan Monastery of the Greyfriars, Newgate." Newbery House Magazine 10 or 11 (1894): 207-219.

Blaser, Werner. Tadao Ando: Architektur der Stille: Architecture of Silence. Trans. Elizabeth Schwaiger. Basel: Birkhäuser - Publishers for Architecture, 2001.

Borrie, Roderick and Thomas H Fine. "Flotation REST in Applied Psychophysiology." Easy Float Systems. 3 June $2010<$ http://www.easyfloatsystems.com>.

Bring, Mitchell and Josse Wayembergh. Japanese Gardens: Design and Meaning. New York: Von Hoffman Press, Inc, 1981.

Broner-Bauer, Kaisa. "Aarno Ruusuvuori and the Continuity of Finnish Modernism.” The Culture of Silence: Architecture's Fifth Dimension. Ed. Malcolm Quantrill and Bruce Webb. Texas: A\&M University Press, College Station, 1998. 195-212.

Bruce, Steve. God is Dead: Secularization in the West. Oxford: Blackwell Publishers, 2002.

Certeau, Michel de. The Practice of Everyday Life. Trans. Steven Rendall. Berkeley : University of California Press, 1984. 
Cohen, Seldon, David C Glass and Jerome E Singer. "Apartment Noise, Auditory Discrimination, and Reading Ability in Children." Journal of Experimental Social Psychology (1973): 407-422.

Connah, Roger. "Sometimes and Always, with Mixed Feelings: Untimely Notes on a Culture of Silence." The Culture of Silence: Architecture's Fifth Dimension. Ed. Malcolm Quantrill and Bruce Webb. Texas: A\&M University Press, College Station, 1998. 3-48.

Conradson, David. "The Experiential Economy of Stillness: Places of Retreat in Contemporary Britain.” Williams, Allison. Therapeutic Landscapes. Aldershot: Ashgate Publishing, 2007. 3348.

Constant, Caroline. The Woodland Cemetery; Towards a Spiritual Landscape. Stockholm: Byggforlaget, 1994.

Cozens, Paul Michael, David Hillier and Greg Saville. "Crime prevention through environmental design (CPTED): a review and modern bibliography." April 2005. European Designing Out Crime Network. Emerald Group Publishing Limited. 5 October 2010 <www.edoca.eu>.

Day, Christopher. Places of the Soul: Second Edition. Oxford: Architectural Press, 2004.

Darwin, Charles. The Voyage of the Beagle. New York: Cosimo, Inc, 2008.

Dierendonck, Dirk Van and Jan Te Nijenhuis. "Flotation Restricted Environmental Stimulation Therapy (REST) as a Stress-Management Tool: a meta-analysis." Psychology and Health June 2005: 405-412.

Drew, Philip. Church on the Water, Church of the Light. London: Phaidon Press Limited, 1996.

Eide, Fernette and Eide Brock. "Visual Overload and Visual Crowding - When More Means Less." 7 September 2009. Eide Neurolearning Blog. 4 June $2010<$ http://eideneurolearningblog. blogspot.com>. 
English, Colin and Benz Kotzen. Environmental Noise Barriers: A Guide to their Acoustic and Visual Design. London: E \& FN SPON, in imprint of Routledge, 1999.

European Environment Agency. Transport at a Crossroads: Term 2008: Indicators Tracking Transport and Environment in the European Union. EEA Report. Copenhagen, 2009.

Evans, Gary W. Environmental Stress. Cambridge: University Press, 1982.

Franklin, Adrian. Tourism: an Introduction. London: SAGE Publications Inc, 2003.

Freund, Julien. The Sociology of Max Weber. Trans. Mary Ilford. New York: Random House, 1968.

Fried, Michael. Absorption and Theatricality. California: University Press, 1980.

Gallagher, Winifred. The Power of Place: How our Surroundings Shape our Thoughts, Emotions, and Actions. New York: HarperPerennial, 1994.

Gifford, Robert. Environmental Psychology: Principles and Practice 2ed. Boston: Allyn and Bacon, 1997.

Glass, David C and Jerome E Singer. Urban Stress: Experiments on Noise and Social Stressors. New York: Academic Press, 1972.

Harding, Vanessa. The Dead and the Living in Paris and London, 1500-1670. Cambridge: University Press, 2002.

Heimstra, Norman W and Leslie H McFarling. Environmental Psychology. Ed. Edward L Walker. California: Brooks/Cole Publishing Company, 1974.

Henze, Anton. La Tourette: The Le Corbusier Monastery. Trans. Janet Seligman. London: Percy Lund, Humphries \& Co. Ltd, 1966. 
Herbert, Paul. "Excavations at Christ Church Greyfriars, 1976." London Archaeologist 3-12 (1979): 327-332.

Hermann, Heinrich. "On the Transcendent in Landscapes of Contemplation.” Contemporary Landscapes of Contemplation. Ed. Rebecca Krinke. New York: Routledge, 2005. 36-72.

Hirano, Akiko and Tim Wong. Wabi Sabi-Learning to see the Invisible. September 2007. 29 June $2010<$ http://www.touchingstone.com/Wabi_Sabi.html>.

Hoving, Thomas P. F. “Think Big about Small Parks.” 10 April 1966. The New York Times. 4 June $2010<$ http://www.nytimes.com>.

Into Great Silence (Die Große Stille). Dir. Philip Gröning. Carthusian Monastery. PhilipGröning-Filmproduktion. 2005.

Jackson, Kenneth T. "Preface." Central Park, An American Masterpiece. Sara Cedar Miller. New York: Harry N. Abrams, Inc, 2003. 7-7.

Jeffery, Paul. The City Churches of Sir Christopher Wren. London: The Hambledon Press, 1996.

Johnson, Glen. “Getting Overloaded.” 1998. Traumatic Brain Injury Survival Guide. 1 June $2010<$ http://www.tbiguide.com/index.html>.

Jones, Karen R and John Wills. The Invention of the Park: From the Garden of Eden to Disney's Magic Kingdom. Cambridge: Polity Press, 2005.

Juniper, Andrew. Wabi Sabi: The Japanese Art of Impermanence. Boston: Tuttle Publishing, 2003.

Kang, Jian. Urban Sound Environment. Oxon: Taylor and Francis, 2007.

Kaplan, Rachel and Stephen Kaplan. The Experience of Nature: A Psychological Perspective. Cambridge: University Press, 1989.

Kapleau, Philip. The Three Pillars of Zen. New York: Anchor Books, 1980. 
Keating, Thomas. Intimacy with God. New York: Crossroad Publishing Company, 1996.

Kinder, Terryl N. Architecture of Silence: Cistercian Abbeys of France. New York: Harry N. Abrams, Inc, 2000.

Koren, Leonard. Wabi-Sabi for Artists, Designers, Poets and Philosophers. California: Stone Bridge Press, 1994.

Krinke, Rebecca. "Contemplative Landscapes, Restorative Landscapes.” Contemporary

Landscapes of Contemplation. Ed. Rebecca Krinke. New York: Routledge, 2005. 107-138.

Krupat, Edward. People in Cities: The Urban Environment and its Effects. Cambridge: University Press, 1985.

Lawrence, Robyn Griggs. The Wabi-Sabi House. New York: Clarkson Potter/Publishers, 2004.

Levy-Leboyer, Claude. Psychology and Environment. Trans. David Canter and Ian Griffiths.

California: Sage Publications, Inc, 1982.

Lilly, John C. The Deep Self. New York: Simon \& Schuster, 1977.

Mason, Lesa, Teresa Norton and David C. Overholt. "At St Kolumba: The Drowned and the Saved: Transmitting the Spirit of Place-Interpretation/Meaning." 28 May 2010

$<$ http://74.125.155.132/scholar?q=cache:z-0PdbKGS2oJ:scholar.google.com/+st+kolumba+pet er+zumthor\&hl=en\&lr=lang_en\&as_sdt=2000>.

Milgram, Stanley. “The Experience of Living in Cities.” Science 167 (1970): 1461-1468.

Miller, Sara Cedar. Central Park, An American Masterpiece. New York: Harry N. Abrams, Inc, 2003.

"More than 90 per cent of the population use parks and green spaces: more green flag awards given this year." 2010. rudi.net. 12 October 2010 <http://www.rudi.net/node/22142>. 
Mumford, Lewis. "The Philosophy of Urban Open Space." Whitney North Seymor, Small Urban Spaces: The Philosophy, Design, Sociology and Politics of Vest-Pocket Parks and other Small Urban Spaces. Ed. Whitney North Seymor. New York: University Press, 1969. 13-22

Neckar, Lance. "Berlin: Topology of Contemplation." Contemporary Landscapes of Contemplation. Ed. Rebecca Krinke. New York: Routledge, 2005. 139-173.

Ong, Walter J. Orality and Literacy: The Technologizing of the World. New York: Methuen \& Co Ltd, 1982.

Oxford University Press Inc. Shorter Oxford English Dictionary, On Historical Principles: Sixth Edition. Vol. 2. New York: Oxford University Press, 2007.

Pallasmaa, Juhani. "An Architecture of the Seven Senses." Questions of Perception: Phenomenology of Architecture. Ed. S. Holl, J. Pallasmaa, \& A. Pérez-Gómez. San Francisco: William Stout Publishers: 2006. 27-38.

—. The Eyes of the Skin: Architecture and the Senses. London: Academy Editions, 1996.

-. The Thinking Hand: Existential and Embodied Wisdom in Architecture. Chichester: Wiley, 2009.

Perera, Janaka. "Buddhism fastest growing religion in West." 7 April 2008. Asian Tribune. 20 March $2010<$ http://www.asiantribune.com/?q=node/10418>.

Perrault, Dominique. Bibliotheque nationale de France, 1989-1995. Ed. Michel Jaques and Gaëlle Lauriot. Artemis, 1995.

-. Dominique Perrault, Projects and Architecture: with an essay by Laurent Stalder. Trans. Christopher Evans. Milano: Electa Architecture, c2002.

Picard, Max. The World of Silence. Trans. Stanley Godman. London: Harvill Press, 1964. 
Population Reference Bureau. Human Population: Urbanization. 2010. 10 June $2010<\mathrm{http}$ // www.prb.org/Educators/TeachersGuides/HumanPopulation/Urbanization.aspx>.

Prochnik, George. In Pursuit of Silence: Listening for Meaning in a World of Noise. New York: Random House, 2010.

Puknat, Siegfried B. “Max Picard.” Books Abroad 25.4 (1951): 340-343.

Quantrill, Malcolm and Bruce Webb, Ed. The Culture of Silence: Architecture's Fifth Dimension. Texas: A\&M University Press, College Station, 1998.

Richards, Jonathan. Facadism. London: Routledge, 1994.

Saini, Balwant. Fengshui Seminars with Roger Green. May 2000. 2 May $2010<$ http://www. fengshuiseminars.com/articles/healingarchmusic.html>.

Smart, Ninian. Background to the Long Search. London: British Broadcasting Corporation, 1977.

Stalder, Laurent. "Architecture, Projection of the Mind and Projection of the Body." Perrault, Dominique. Dominique Perrault, Projects and Architecture. Trans. Christopher Evans. Milano: Electa Architecture, c2002. 7-25.

Suzuki, Daisetz. Zen and Japanese Buddhism. Tokyo: Japan Travel Bureau, 1970.

Taylor, Charles. "Forward." The disenchantment of the world: a political history of religion. Marcel Gauchet. trans. Oscar Burge. New Jersey: Princeton University Press, 1997. ix-xv.

Tate, Alan. Great City Parks. London: Spon Press, 2001.

The Floatation Sanctuary. 2008. 12 May 2010 <http://www.floatationtank.co.nz/Home.html>.

"The Libeskind Building: The Voids." Jewish Museum of Berlin. 17 July $2010<$ http://www. jmberlin.de/main/EN/04-About-The-Museum/01-Architecture/01-libeskind-Building.php>. 
Thoreau, Henry David. Walden: or, Life in the Woods. London: David Campbell Publishers Ltd, 1992.

Treib, Marc. "Silence may be the most Significant Gift an Architect can give a Noisy Society." Metropolis 10.6 (1991): 56-67.

United Nations Human Settlements Programme. State of the World's Cities 2008/2009.

London: Earthscan, 2008.

van der Horst, Pieter W. "Silent Prayer in Antiquity." Numen 41 (1994): 1-25.

Williams, Celeste. "Recent Austrian Architecture: A Dynamic Silence." The Culture of Silence: Architectures Fifth Dimension. Ed. Malcolm Quantrill and Bruce Webb. Texas: A\&M University Press, College Station, 1998. 173-194.

Wilson, Bryan. Contemporary Transformations of Religion. Oxford: University Press, 1976.

Wirth, Louis. "Urbanism as a Way of Life." The American Journal of Sociology 44 (1938): 1-24.

Woodman, Ellis. “Zumthor's Cologne modern art museum is beyond time.” 21 September 2007. bd.online.co.uk. 2 July $2010<$ http://www.bdonline.co.uk/buildings/ zumthor\%E2\%80\%99s-cologne-modern-art-museum-is-beyond-time/3095607.article>.

Wrede, Stuart. “The Work of Erik Gunnar Asplund.” Perspecta 20 (1983): 195-214.

Zumthor, Peter. Thinking Architecture: Second Expanded Version. Trans. Maureen Oberli-Turner and Catherine Schelbert. Basel: Birkhäuser: Publishers for Architecture, 2006. 


\section{Appendices}




\section{Appendix A - Adaption to Urban Stress}

“... yet observation of urban life cannot but lead to the conclusion that despite the unpleasantness of stressful conditions life goes on. Families are raised, jobs are accomplished and even social graces and amenities are preserved in some quarters. Either the stressors are not as potent as popularly believed or else man has the capacity to adapt and even shrug off the stress." 193

David C Glass and Jerome E Singer

People may adapt to the urban environment but what psychological price do they pay? ${ }^{194}$ Psychologist Hans Selye theorised a basic model of behaviour process called the General Adaption Syndrome, (GAS). ${ }^{195}$ This model is based on the belief that urban stress is detrimental and human adaption involves a physical response from the body. Selye's three stages of stress are:

1. Alarm Reaction: Mobilises the body's reaction in preparation for resistance.

2. Resistance: Various methods for coping (adaption) are deployed. This stage continues until the stress is dealt with or all energy is used up.

3. Exhaustion: Resulting in illness (physiopathology). Long term effects of unsuccessful or extended coping can also be linked to developments of psycho or sociopathologies. ${ }^{196}$

A systemic response to stress does not always occur. Research findings demonstrate that cognitive adaptation is deployed more often than physical adaptation. Glass and Singer refer to the phenomenon of resource depletion due to adaption as the "psychic cost of stress." 197 This is the observation that while a person may be coping with day-to-day activities of a constant stress level, they are less able to deal with unknown frustrations that come their way. An added negative effect of adaption is that it tends to happen in isolation from other people and events. The result being that while the method employed is adopted so as to suit the individual momentarily, it can have destructive effects at a societal level. ${ }^{198}$

193 - David C Glass and Jerome E Singer, Urban Stress: Experiments on Noise and Social Stressors (New York: Academic Press, 1972) 6.

194- David C Glass and Jerome E Singer, 


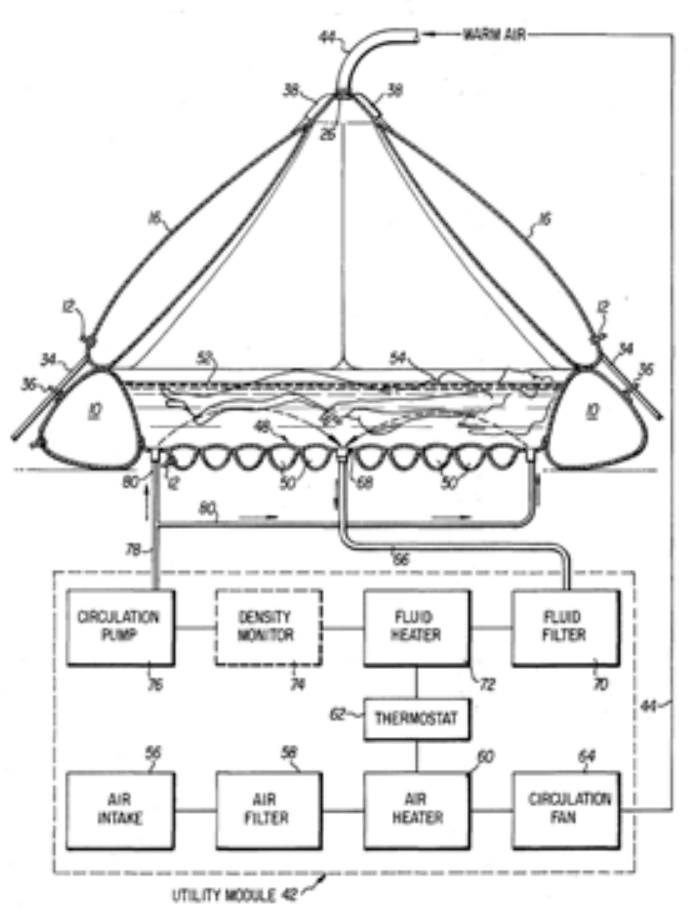

FIG.3

Figure B.1 - Section of an early patent for an

\section{'Isolation Module', 1977}

Source: Francis J Busco, "United States Patent: Isolation Module," 4 January 1977, Google Scholar, 20 May 2010 <http://www.google.co.nz/patents?hl=en\&lr=\& vid=USPAT4000749\&id=AQQsAAAAEBAJ \&o $=\mathrm{fn}$ $\mathrm{d} \& \mathrm{dq}=$ United + States+Patent:+Isolation+Module $\& \mathrm{pr}$ intsec $=$ abstract $\# \mathrm{v}=$ onepage $\& \mathrm{q}=$ United $\% 20$ States $\% 20$ Patent $\% 3 A \% 20$ Isolation $\% 20$ Module $\& \mathrm{f}=$ false>

\section{Appendix B - Floatation REST (Isolation Tanks)}

Floatation REST is an example of the rising in the commercialism of silence. REST is a development that began in the 1950's with John C. Lilly M.D. Used as part of sensory deprivation experiments, the technique was gradually refined in the 1960's to include a person held in a light free and sound reduced chamber, submerged in water at a constant temperature of $94.5 \mathrm{~F}(34.7$ C) with an Epson salt solution. ${ }^{199}$ This has provided the framework for what is now a widely available therapeutic solution for stressed individuals.

Through studying hormonal effects during and post floatation sessions it has been clinically proven that time spent in the floatation tank does reduce stress. Hormones directly related to stress levels, cortisol, ACTH and epinephrine, showed a decrease during sessions. In addition, blood pressure levels have been noted to drop post session, with a sustained increase related to the amount of sessions one has attended. ${ }^{200}$ Through creating a relaxing environment isolation floatation tanks are one way which the consumer market has countered the stressful way which we inhabit cities. It is the ultimate artificial form of escapism. Through limited auditory and almost no visual stimulation one has nothing more to do than 'simply be'.
199- John C Lilly, The Deep Self(New York: Simon \& Schuster, 1977) 118.

200 - Roderick Borrie and Thomas H Fine, "Flotation REST in Applied Psychophysiology," Easy Float Systems, 3 June 2010 $<$ http://www.easyfloatsystems.com> 2 . 


\section{Appendix C - Meditation}

There are many definitions and traditions of meditation. According to Ninian Smart, unlike prayer, meditation (specifically Theravadin) is not a communion with God. It is more internally focussed than outwardly seeking. This does not make meditation less of a sacred activity than prayer. ${ }^{201}$ In Buddhism the divine is seen as the individual and therefore holds spiritual significance by coming into contact with the essence of your being, thus beginning the process of transcendence.

Although based on peace and serenity, meditation can be an arduous task to obtain. It takes practice to silence external and internal noise. There are 'general guidelines' in how to reach a meditative state, but these are only broad as meditation is a deeply personal experience. However, a common element is for the person to be seated in a comfortable position in a quiet place. Following this a device (or 'meditative aid') is selected for that person to concentrate on, thereby slowly silencing all sensations and thoughts as they focus on the object. There are three stages through which you can ascend; the last and most involved stage is reached when the individual is totally awake, yet impervious to any distinctions that the mind may make. This is known as the stage of neither perception nor non-perception. ${ }^{202}$

Chanting is another way of attaining a meditative state. Similar to the way which Monks in Christian monasteries use the repetition of sacred reading (lectio divina) absorb silence, ${ }^{203}$ so too does intoning sutras invoke a deep internal silence within Buddhism. Used traditionally to absorb religious sermons, the meaning of most chanting has been lost through ritual. However, this has not lessened its significance. Practiced sitting, standing or while moving, by chantingsutras the mind is pointed towards the emptiness behind the repetitive words. ${ }^{204}$

\footnotetext{
201 - Ninian Smart, Background to the Long Search (London: British Broadcasting Corporation, 1977) 63-64.

202- Ninian Smart, Background to the Long Search (London: British Broadcasting Corporation, 1977) 64.

203 - Reading is an essential part of monastery life that perpetuates the stillness they observe. Originally monks were the only literates in society, and therefore both wrote and read as part of their duty to God. Today, in the instance of Cistercian monks, sacred reading (lectio divina) is an important part of their devotion. There are designated times to take part in individual sacred reading throughout the day. Each monk is given a book at the start of the year, and this is to last him until the next. Once reading time has finished the precious books are locked away and tasks are resumed. The reading acts as a method for obtaining silence that sets the tone for the entire day. The calming influence of reading is carried onto subsequent tasks, enabling contemplation to take place as the monk absorbs the message. Reference: Terryl N Kinder, Architecture of Silence: Cistercian Abbeys of France (New York: Harry N. Abrams, Inc, 2000) 19-20.

204 - Philip Kapleau, The Three Pillars of Zen (New York: Anchor Books, 1980) 20.
} 